\title{
DEVELOPMENT COOPERATION WITHIN THE FRAMEWORK OF THE WORLD TRADE ORGANIZATION
}

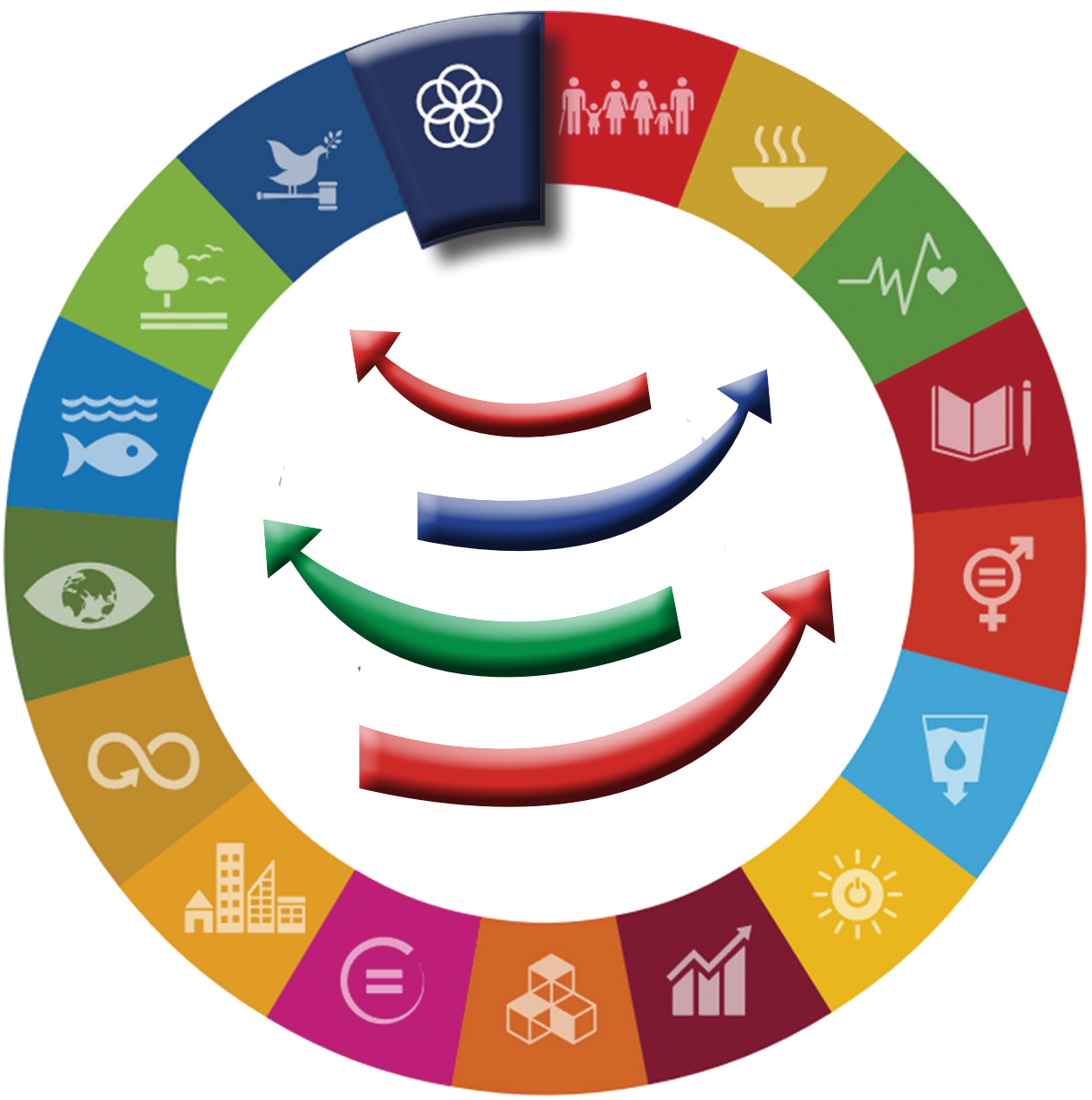




\section{DEVELOPMENT COOPERATION \\ WITHIN THE FRAMEWORK \\ OF THE WORLD TRADE ORGANIZATION}


MAŁGORZATA ZAJACZKOWSKI

DEVELOPMENT COOPERATION WITHIN THE FRAMEWORK

OF THE WORLD TRADE

ORGANIZATION 


\section{Reviewers}

Ida Musiałkowska

Krystyna Żołądkiewicz

\section{Editor and proofreader}

Katarzyna Skiert-Andrzejuk

(C) Copyright by Małgorzata Zajaczkowski \& SGH Warsaw School of Economics, Warsaw 2021

All rights reserved. Any copying, reprinting or distribution of a part or the whole of this publication without the prior permission of the publisher is forbidden.

First Edition

ISBN 978-83-8030-456-7

SGH Publishing House

162 Niepodległości Ave., 02-554 Warsaw, Poland

www.wydawnictwo.sgh.waw.pl

e-mail: wydawnictwo@sgh.waw.pl

\section{Cover design}

Ad Depositum

DTP

DM Quadro

\section{Print and binding}

volumina.pl Daniel Krzanowski

ul. Ks. Witolda 7-9

71-063 Szczecin

tel. 918120908

e-mail:druk@volumina.pl 


\section{TABLE OF CONTENTS}

Chapter 1

FROM FOREIGN AID TO DEVELOPMENT COOPERATION:

THE EVOLUTION OF THE INTERNATIONAL AID SYSTEM ...................... 21

1.1. The Scope and Definitions of Development Cooperation ............................. 22

1.2. Classification of Development Aid ............................................... 28

1.3. Development Aid Effectiveness ............................................... 31

1.4. Development Aid as a Permanent Element of International Relations ................ 36

1.5. Official Development Assistance (ODA) ................................................. 41

1.6. Program Basics of Development Cooperation ........................................ 53

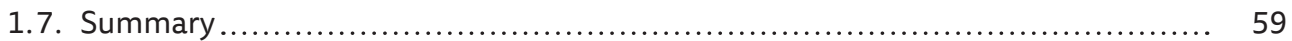

Chapter 2

MULTILATERAL AID ............................................................... 63

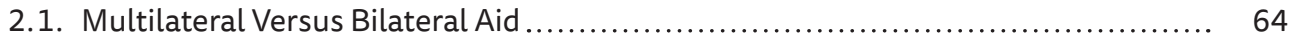

2.2. Multilateral Aid System .................................................. 72

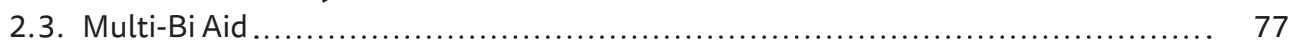

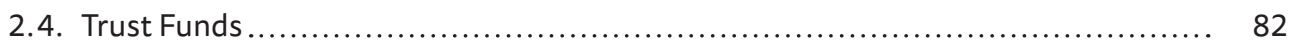

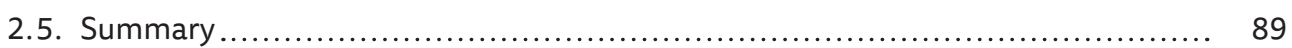

Chapter 3

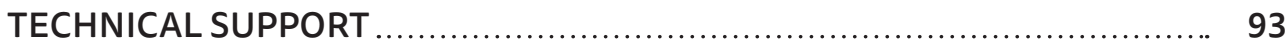

3.1. WTO Training and Courses .................................................... 94

3.2. Planning and Management of Technical Assistance ............................. 100

3.3. Financing of Technical Assistance .............................................. 103

3.4. Evaluation of WTO Activities in the Field of Technical Assistance .................... 109

3.5. Summary ................................................................ 112 


\section{TABLE OF CONTENTS}

Chapter 4

AID FOR TRADE .................................................................. 115

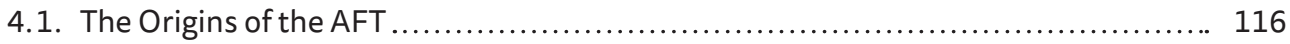

4.2. Aims and Assumptions of the AFT ............................................. 119

4.3. Scope and Categories of the AFT .............................................. 121

4.4. Coordination and Monitoring of the AFT ...................................... 123

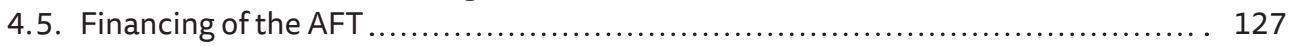

4.6. Achievements and Limitations of the AFT ..................................... 134

4.7. Summary .................................................................. 138

Chapter 5

PREFERENTIAL TREATMENT FOR DEVELOPING COUNTRIES ................. 141

5.1. Evolution of SDT Provisions ..................................................... 142

5.2. Fundamentals of the SDT System ............................................ 148

5.3. Effects of Using SDT ........................................................... 153

5.4. Evaluation of the Operation of SDT .............................................. 156

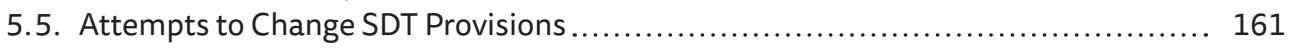

5.6. Summary ................................................................... 165

Chapter 6

THE WTO AS A DEVELOPMENT INSTITUTION ...................................... 167

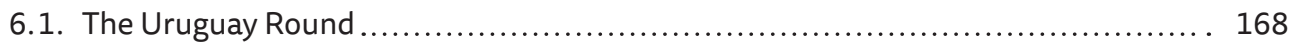

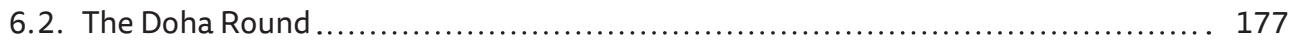

6.3. Trade Facilitation Agreement (TFA) ........................................... 192

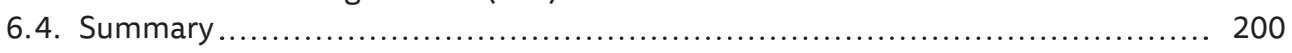

SUMMARY AND CONCLUSIONS ….................................................... 203

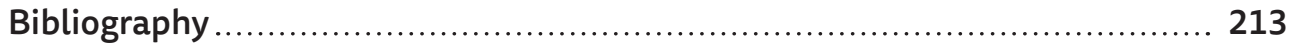

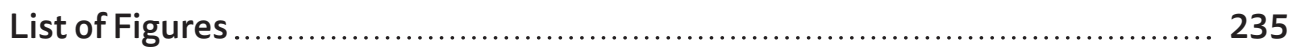

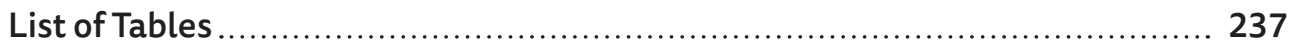




\section{Abbreviations and Acronyms}

AA - Agreement on Agriculture

ACP-EU Partnership Agreement - Africa, the Caribbean and the Pacific - European Union AfDB - African Development Bank

AFT - Aid for Trade

AGOA - African Growth and Opportunity Act

AIIB - Asian Infrastructure Investment Bank

AIL - Agreement on Import Licensing

AIP - Accession Internship Program

APEC - Asia-Pacific Economic Cooperation

APS Agreement - Agreement on the Application of Sanitary and Phytosanitary Measures AsDB - Asian Development Bank

ASP - Academic Support Program

ATC - Agreement on Textile and Clothing

ATPC - Advanced Trade Policy Course

BMGF - Bill \& Melinda Gates Foundation

BRICS - Brazil, Russia, India, China, South Africa

CBERA - Caribbean Basin Economic Recovery Act

CBFA - Committee on Budget, Finance and Administration

CIFF - Children's Investment Fund Foundation

CRS - Creditor Reporting System

CTD-Committee on Trade and Development

CTD-SS - Committee on Trade and Development Special Session

$\mathrm{CV}$ - Agreement on Customs Valuation

DAC-Development Assistance Committee

DAG - Development Assistance Group

DDA - Doha Development Agenda

DDAGTF - Doha Development Agenda Global Trust Fund

DFQF - Duty-Free and Quota-Free

DSU - Dispute Settlement Understanding

DNPL-Dutch National Postcode Lottery

EBA - Everything but Arms

ECOSOC - The Economic and Social Council 
EDF - European Development Fund

EIF - Enhanced Integrated Framework

EU - European Union

EPA - Economic Partnership Agreement

FAO - Food and Agriculture Organization of the United Nations

FDI - Foreign Direct Investments

FIMIP - French \& Irish Mission Internship Program

GATS - General Agreement on Trade in Services

GATT - General Agreement on Tariffs and Trade

GPEDC - Global Partnership for Effective Development Cooperation

GPA - Agreement on Government Procurement

GSP - Generalized System of Preferences

GSTP - Global System of Trade Preferences

HIPC - Heavily Indebted Poor Countries

HLF OECD - High-Level Forum

IADB - Inter-American Development Bank

ICAO - International Civil Aviation Organization

ICC-International Chamber of Commerce

IDA - International Development Association

IDO - International Development Organization

IFC-International Finance Corporation

IFTRTA; IF - Integrated Framework for Trade-Related Technical Assistance; Integrated Framework

IMF - International Monetary Fund

IMO - International Maritime Organization

IPR - Intellectual Property Rights

ITC-International Trade Centre

ITTC-Institute for Training and Technical Cooperation

JITAPA - Joint Integrated Technical Assistance Program for Africa

JITAP - Joint Integrated Trade Assistance Program

LDCs - Least Developed Countries

MDTF - Multi-Donor Trust Fund

MDG - Millennium Development Goals

MFA - Multifiber Agreement

MFN - Most Favored Nation

NAMA - Non-Agricultural Market Access

NDB - New Development Bank

NFIDC - Net Food-Importing Developing Countries

NGOs - Non-Governmental Organizations

NTP - Netherlands Trainee Program

OIE - World Organization for Animal Health 
ODA - Official Development Assistance

OECD - Organization for Economic Co-operation and Development

OEEC - Organization for European Economic Cooperation

PAT - Principal - Agent Theory

PLS - Progressive Learning Strategy

PTE - Program for Trade Expansion

RBM - Results-Based Management

RCI - Regional Coordinator Internship Program

RTPC - Regional Trade Policy Course

SCM - Agreement on Subsidies and Countervailing Measures

SDGs - Sustainable Development Goals

SDT - special and differential treatment

SDTF - Single-Donor Trust Fund

SPS - Sanitary and Phytosanitary Measures

STBF - Susan Thompson Buffett Foundation

STDF on SPS - The Standards and Trade Development Facility on Sanitary and Phytosanitary

TBT - Agreement on Technical Barriers to Trade

TCBDB - Trade Capacity Building Database

TCLAP - China LDCs \& Accessions Program

TEVAL - WTO dedicated trust fund

TFA - Trade Facilitation Agreement

TFAF - Trade Facilitation Agreement Facility

TIMM1 - French \& Irish Mission Internship Program

TiSA - Trade in Services Agreement

TNL05 - Netherlands Trainee Program

TPC - Trade Policy Courses, TPC

TPRM - Trade Policy Review Mechanism

TRIMs - Agreement on Trade-Related Investment Measures

TRIPS - Trade Related Intellectual Property Rights

TRTA - Trade-Related Technical Assistance

UN - United Nations

UNCTAD - United Nations Conference on Trade and Development

UNDP - United Nations Development Program

UNIDO - United Nations Industrial Development Organization

UNOPS - United Nations Office for Project Services

VER - Voluntary Export Restraint

WB - World Bank

WCO - World Customs Organization

WFP - World Food Program

WHO - World Health Organization

WTO - World Trade Organization 

Development cooperation is based on collaboration between aid donors and recipients, which include both state and non-state entities. This approach applies to all activities in the field of development aid, but also to the state of mutual relations between highly developed and developing countries. It covers both the traditionally understood development aid as well as regulations aimed at economic development and improvement of welfare of less developed countries. The development cooperation formula combines at least four elements:

- transfer of financial, material, technical resources to developing countries that fall into the category of Official Development Assistance (ODA);

- preferential trade regulations, i.e., the Generalized System of Preferences (GSP) and the WTO's Special and Differential Treatment (SDT);

- creation of international regulations favoring the economic development of less developed countries;

- activities aimed at promoting knowledge and awareness of development problems of less developed countries.

The approach based on development cooperation is an attempt to introduce changes to the international aid system in order to increase its effectiveness. An action is considered effective when net benefits, i.e. after deduction of costs, are positive and as large as possible. The predominance of benefits over costs makes the action considered effective. Accordingly, an appropriate objective of development cooperation is to increase the effectiveness in achieving development goals, which include economic growth and poverty reduction. In this regard trade plays an essential role. Therefore, the task facing the WTO is to provide developing countries with technical assistance and other forms of support to implement rules of international trade more effectively and assume greater obligations in terms of their trade liberalization. However, most WTO members are unable to carry out the process on their own, even if it was to bring tangible benefits. The reason lies in high implementation costs. Therefore, additional and more effective assistance is needed to implement the relevant changes and undertake economic reforms.

I am aware that the support offered by the WTO to developing countries is not the main area of its operation. The most important tasks of the WTO include the creation of international trade rules and the supervision of their compliance by the member states. This is due to the WTO's primary regulatory function, which is to "facilitate the implementation, administration and operation, and further the objectives, of the multilateral trade agreements" (Article III of the Agreement Establishing the WTO). For developing countries, this commitment took the form of trade-related technical assistance aimed at enabling less developed countries to exercise their rights and obligations of WTO membership and to benefit from 
trade. This means that technical assistance in the field of trade policy and trade law to developing countries is the basic instrument of WTO's development support.

The main thesis of the study is that the WTO activities towards developing countries are part of development cooperation. Actions are carried out within the WTO's statutory functions, and on the basis of multilateral agreements and daily practice, which enable developing countries move closer to achieving their development goals, especially in the field of trade. In order to prove the adopted thesis, six complementary hypotheses were formulated:

- Hypothesis 1: changes that are taking place within the international aid system indicate the need for a new approach to development assistance and greater involvement of the WTO;

- Hypothesis 2: the WTO's technical cooperation activities are complementary to those carried out under the broader structure, i.e. ODA;

- Hypothesis 3: modification of SDT regulations offers an opportunity to increase the effectiveness of operation of the WTO;

- Hypothesis 4: the WTO requires reforms, and thus adaptation to new international circumstances, which means increasing its role in the area of development assistance;

- Hypothesis 5: greater WTO support for developing member countries entails their more active engagement in trade liberalization on terms adjusted to individual economic needs;

- Hypothesis 6: adoption of a new formula for implementing WTO regulations, applied in the Trade Facilitation Agreement (TFA) and based on a flexible approach, shall increase the degree of adoption and application of WTO rules by developing countries.

Due to the interdisciplinary nature of the study, several research methods were used. The critical analysis of the research subject focused on:

- evolution of development aid mechanisms and instruments, including in particular changes within the multilateral aid system;

- principles and rules of trade policy, which were of particular importance for developing countries in the process of overcoming economic difficulties;

- GATT and WTO multilateral negotiations addressing development issues and support for developing countries;

- relations between the WTO and developing countries.

There was made a cross-sectional analysis of economic, political and institutional phenomena. It was shown that the interaction and interpenetration of the discussed issues result from the complex subject of research in the field of development cooperation. The inductive reasoning allowed general conclusions to be drawn on 
the basis of detailed and individual facts. It was a means of verifying specific issues, which included WTO technical assistance, the involvement in Aid for Trade, and the application of SDT regulations by developing countries. Thanks to the deductive reasoning, it was possible to present the rationale behind the need to introduce changes to the international aid system, in particular the reform of Official Development Assistance (ODA). Based on the analysis of selected theoretical issues related to aid effectiveness and the results of empirical research on the international aid system there was formulated a statement about the need of increasing the effectiveness of international aid system through greater inclusion and more active involvement of the WTO. Therefore, it allowed to draw conclusions and formulate opinion on the changing role of the WTO in the sphere of development cooperation. Consequently, it was possible to define the role and indicate the importance of the organization for the development of multilateral aid system. An attempt was also made to assess the actions taken by the WTO and to determine the direction of its evolution. For this purpose, I have highlighted the problem of WTO reform in the context of relations between the organization and developing countries.

Considerations on the role and importance of the WTO in the area of development cooperation constitute a new approach in research on the WTO. The starting point is the concept of international cooperation and the premises that make it possible within the perspective of international political economy. In this context, the role of organization is fundamental as it represents the most developed form of international cooperation, through which states strive to pursue their interests (Levy, Keohane, Haas, 1993; Keohane, 1984, 1989; Young, 1986; B.V. Yarbough, R.M. Yarbough, 1987; Popiuk-Rysińska, 2001; Łoś-Nowak, 2004). In line with the above assumption, the level of institutional development determines the dynamics and quality of international cooperation. The development of international institutions, which include international organizations, as well as international regimes and certain forms of repeated behavior, is the evidence of deepening interdependencies in the economic, political, and social spheres (Keohane, 1984, 1989; Keohane, Nye, 2001). Moreover, as a result of globalization, many competencies have been shifted from national to supranational level, and as the authority of governments has eroded, the significance of non-governmental actors in the decision-making process has increased (Strange, 1996). Accordingly, the mandate of international organizations, which gained the possibility to operate in areas beyond their previous statutory framework, was strengthened or even extended.

The new approach adopted in the book is the recognition of the international development aid system as an international regime, which has been given the formula of development cooperation in order to more effectively implement the assumed 
goals, i.e., economic growth and reducing poverty. The basis of this approach are the definitions of D. Krasner ${ }^{1}$, O.R. Young ${ }^{2}$, D.J. Puchali, R.F. Hopkins ${ }^{3}$, as well as R.O. Keohane, and J.S. Nye. ${ }^{4}$ They are all the pioneers in studies on international cooperation and international institutions, where international regimes are seen as specific types of institutions. Their uniqueness lies in the fact that they are treated as an institutionalized structure somewhere between obligatory and binding norms and rules of international law and the right to independence and freedom of action in international environment (Łoś-Nowak, 2004, p. 19).

The point of reference for the contemporary formula of the international aid system is the concept of a regime complex. It is a phenomenon defined as a set of various, sometimes narrowly focused regulatory systems, the elements of which are "linked more or less closely to one another, sometimes conflicting, sometimes mutually reinforcing" (Keohane, Victor, 2010, p. 2). Such a set of regimes, aimed at regulating the behavior of participants in a specific field, is becoming more and more common in world politics, especially in the situation of the occurrence of a phenomenon referred to as "institutional density" (Raustiala, Victor, 2004, p. 295). The international aid system can be regarded as a highly institutionalized structure within which various types of arrangements and contracts exist, but their implementation is not obligatory. The degree of achievement of the adopted goals depends on interests of entities participating in it. The formula of development cooperation is a concept that combines various elements that make up the development aid regime possible to operate.

In both cases - the international regime and development cooperation - behavior is expected to be adequate to the situation, consistent with the adopted principles, norms, and procedures. As part of development cooperation, these are the arrangements contained in the program documents - the Monterrey Consensus on Financing for Development (2002), the Paris Declaration (2005), the Accra Agenda for Action on increasing the effectiveness of development aid (2008), and the Busan Partnership (2011). Therefore, the international regime in the field of development cooperation

1 D. Krasner defined the international regime as "a set of implicit or formal principles, norms, rules and decision-making procedures around which the expectations of actors in a given field of international relations converge" (Krasner, 1983, p. 337).

2 After O.R. Young, the international regime can be treated as a set of multilateral agreements between states aimed at regulating domestic activities within a given area, in this case of assistance to developing countries (Young, 1982, p. 20).

3 According to the study of D.J. Puchali and R.F. Hopkins, the international regime functions in every field of international relations in which there is a certain regularity of certain behaviors (Puchala, Hopkins, 1982, pp. 61-92).

4 R.O. Keohane and J.S. Nye define international regimes as "sets of governing arrangements" which embrace "networks of rules, norms, and procedures that regularize behavior and control its effects" (Keohane, Nye, 2001, p. 17). 
is treated, firstly, as an institutionalized structure for exchanging commitments between donors and recipients of aid, and, secondly, as a code of conduct for states as well as non-state actors to take expected actions to achieve common goals.

International organizations, in this case the WTO, can be incorporated into the structure of an international regime, which is a much broader type of institution than an organization. They usually serve as a forum for meetings and negotiations and are a catalyst for reaching agreements (Keohane, 1984, p. 163). The WTO serves not only as a forum for communication among its members, but also for mutual exchange of commitments to liberalize international trade based on certain principles of standards, rules and decision-making procedures. Negotiation is the main means to reduce trade barriers and agree on joint decisions. Given the involvement of the WTO in development cooperation, the organization's activities go beyond its regulatory function. Expanding competencies is accompanied by increased responsibility for undertaken activity. Therefore, expectations are rising towards international organizations related to increasing its operational efficiency and achieving assumed goals.

The literature on the subject lacks studies that would include a comprehensive analysis of WTO activities in the field of support for developing countries. The vast majority of research on the WTO and developing countries focuses on individual problems and economic sectors where developing countries have had difficulties in meeting their commitments. The studies mainly concern the participation of developing countries in GATT and WTO multilateral negotiations and their influence on the degree of trade liberalization. In previous studies, the factor related to WTOled development aid was treated in a general way or ignored. This volume aims to fill this gap by providing insight into the role and importance of the WTO in development cooperation. The book is also a voice in the debate on the contemporary condition of the WTO and the organization's search for its place in the global economy.

The work consists of six chapters. Chapter I, under the title of From Foreign Aid to Development Cooperation: The Evolution of the International Aid System, attempts to present the reasons for modifying the international aid system and the need for creating development cooperation. Various approaches to clarify the issue and definitions of development aid have been identified. The ongoing discussion on the issue of development aid effectiveness was recalled. The starting point for considerations is Official Development Assistance (ODA). The proposed changes in the ODA concept have contributed to the expansion of development cooperation, based on the assumption that support should be provided in such a way as to meet development needs of recipient countries. This means a departure, at least in the declarative sphere, from aid in line with the priorities of foreign policy and economic interests of donor countries. 
Therefore, the key to achieving better results is to put emphasis on increasing the effectiveness of development cooperation, which means mainly the implementation of the objectives set in the form of the Millennium Development Goals (MDGs) and replaced in 2015 by the Sustainable Development Goals (SDGs).

In Chapter II, Multilateral Aid, the focus was on the evolution of international aid system. An attempt was made to identify potential benefits and threats resulting from the emergence of new entities (donors and recipients), instruments and funding mechanisms. Two basic problems related to the effectiveness of aid delivery and the achievement of development goals were observed. The first concerns an increasing number of entities participating in multilateral aid system, which leads to its fragmentation and difficulties in harmonizing activities. This number is increased, in addition to governmental and non-governmental organizations, by an expanding group of trust funds and other financial institutions. The second issue is the phenomenon of "bilateralization" of multilateral aid, which means the increasing control of bilateral donors over the activities of multilateral institutions. This process is a direct consequence of the inflow of funds defined as earmarked or multi-bi), the allocation of which is most often decided by donors. The WTO is subject to this type of change, although its dynamics is slower than in the case of other institutions specialized in providing aid (UN, WB). This chapter attempts to diagnose the impact of this sort of changes within the multilateral aid system on the functioning of the WTO. This is primarily about changes in the sources of financing development aid and the increasing control of bilateral donors over multilateral aid.

Chapter III is devoted to clarifying and organizing the issue of technical assistance through which the WTO carries out its ODA-related tasks. Benefiting from trade and more active participation in trade negotiations by developing countries require increasing their financial and material resources as well as expertise. Therefore, the provision of technical assistance by the WTO in the form of courses and training on trade policy and trade law allows to increase trade capacity of developing countries, and thus their institutional, legal, and administrative potential. Unlike specialized aid institution, the WTO does not directly provide funding to developing countries but gives support in the form of courses, trainings, and know-how. Although the tasks performed by the WTO within the framework of technical assistance are not able to meet immense needs of developing countries, they nevertheless constitute a significant supplement to activities undertaken within the framework of development cooperation. The chapter attempts to present the principles of operation of WTO's technical assistance and the main rationale behind the expansion of its coverage.

In Chapter IV, I analyze the initiative of Aid for Trade, a development aid program that focuses on supporting low-income countries in building trade capacity, enhancing 
their infrastructure and overcoming the barriers that constrain their ability to benefit from trade. Established by the WTO and multilateral development institutions (including the IMF, WB, UNDP, UNCTAD, ITC, and the OECD), the program was spread across different sectors and involves complex relationships among recipient country governments, bilateral donors, multilateral and regional agencies, private sector and other non-governmental organizations. The Aid for Trade is an expression of the pursuit of the objectives underlying development cooperation. Activities eligible for the AFT are part of ODA. The AFT covers a wide range of activities that fall into three categories: economic infrastructure development, productive capacity building, and trade policy and regulation. The chapter examines the role of the WTO in the AFT and identifies areas where the organization has taken specific action.

In Chapter V, under the title of Preferential Treatment for Developing Countries, I present the evolution and evaluation of the operation of special trade rules applied in the GATT and WTO. Their purpose was to enable the integration of developing countries into the international trading system on preferential terms. There are three basic forms of preferential treatment under the SDT provisions. The first is greater access to the markets of developed countries than under the MFN clause, the second is the possibility of obtaining a longer transition period for the implementation of WTO agreements, and the third is a temporary exemption from the application of regulations contained in the WTO agreements. This chapter examines the effects of SDTs, and thus their impact on the participation of developing countries in multilateral negotiations and on the international trading system. The SDT set of rules has been treated as a special form of support to developing countries when they are obliged to implement WTO multilateral trade agreements. Admittedly, it is not development aid in the sense of ODA, but a regulatory mechanism that was to enable developing countries to benefit from trade on preferential terms. However, with the establishment of the WTO, the impact of SDT rules on developing countries and the organization itself changed. The main theme in the chapter is the question of the continued application of SDT to a wide and diverse group of developing countries. Therefore, the proposals for modification as well as the lifting of the provisions were discussed.

Chapter VI, under the title of The WTO as a Development Institution, is a synthesis of efforts to integrate development into the mainstream of WTO trade negotiations. In 2001, with the commencement of a series of negotiations known as the Doha Development Agenda (DDA), there was a chance to adopt solutions that would, to a greater extent than in the GATT, foster the realization of trade interests of developing countries. The chapter explores the importance of development and aid issues of the Doha Development Agenda. The aim was to examine in which areas of negotiations the commitment to pursuing developing countries' trade interests was 
fulfilled. This largely concerned market access with regard to agricultural products and industrial goods, but also those areas that determine the growth of a state capacity, i.e., intellectual property and services. A separate section is devoted to the Trade Facilitation Agreement (TFA). It is the only multilateral agreement that has been adopted in the Doha Round. Its aim is to streamline and simplify customs and administrative procedures for cross border trade and to provide both technical and financial support for the implementation of appropriate regulations by less developed countries.

The research period adopted in the study covers the years 1995-2017. It allowed for the analysis and evaluation of the WTO's activity in the field of development cooperation, from the first attempts to introduce changes to international aid system, to negotiations of the Doha Round, and efforts to adopt regulations favoring trade liberalization in developing countries. The starting date was the year in which the WTO was established, the commitments made during the Uruguay Round (1986-1994) began to be implemented. It was especially important for developing countries, which during the GATT period were practically excluded from active participation in the international trading system. The creation of the organization and the introduction of new agreements gave impetus to their greater involvement in international trade. In addition, the Millennium Development Goals and the Sustainable Development Goals in force since 2015 were the main drivers for introducing changes within the international aid system. Thanks to them, the concept of development cooperation was worked out and the international community made efforts to increase the effectiveness of development aid. I refer to the period of GATT operation wherever it is justified from the point of view of the discussed problem. The reference to the historical context turned out to be necessary, first of all, in the case of the evolution of the international aid system and the analysis of special and differential treatment (SDT).

The publication uses rich literature on the subject on the GATT, WTO, and development aid. Primary sources were analyzed on the basis of statistical data contained in the databases of the World Trade Organization (WTO), the OECD Development Assistance Committee (OECD-DAC), and the United Nations Conference on Trade and Development (UNCTAD). Efforts were made to present the latest available data covering 2017, but in some cases, e.g., for the analysis of the multilateral aid scheme, data from earlier years were used. The scientific achievements of Polish researchers were an important source of information on issues related to development aid. From the point of view of the expansion of a new concept of development cooperation, these were studies by P. Bagiński, K. Czaplicka, J. Szczyciński, P. Deszczyński, E. Latoszek, D. Kopiński, as well as researches from earlier years, 
i.e., M. Gulcz, P. Samecki, and A. Nowak. In the context of considering the WTO and developing countries, the starting point for the research undertaken were the studies of B.M. Hoekman, C. Michalopoulos, A. Mattoo, J.J. Hallaert, W. Hynes, P. Holden, W. Martin, L.A. Winters, T.N. Srinivasan, and J.S. Wilson. The research approach used by A.H. Qureshi, who analyzed the WTO as a quasi-development institution from the perspective of international trade law, as well as S. Ostry, who based on the development paradigm, raised the issue of WTO's involvement in overcoming the North-South divide in the international trading system - were especially inspiring. A challenge was to investigate the economic, institutional, and political premises that could prove the growing importance of the WTO in the field of development assistance.

I would like to thank the reviewers - Professor Krystyna Żołądkiewicz and Professor Ida Musiałkowska - for valuable comments and remarks. 


\section{Chapter 1}

\section{FROM FOREIGN AID TO DEVELOPMENT COOPERATION: THE EVOLUTION OF THE INTERNATIONAL AID SYSTEM}

In normative terms, development cooperation means that relations of all parties - states and multilateral institutions that provide support, as well as countries receiving such aid - are of a cooperative nature or there is an attempt to achieve equal relations between them (Deszczyński, 2001; Bagiński, Czaplicka, Szczyciński, 2009). Building this type of approach is to improve the effectiveness of development aid delivery, first of all in the context of achieving its goals, which include primarily economic growth and poverty reduction.

The pursuit of introducing the principles of development cooperation into international practice is a challenge currently faced by entities interested in providing and receiving aid. On the donor side, these are states and multilateral international organizations, non-governmental organizations, as well as private philanthropic institutions and business representatives. The tendency to change is a result of the worldwide criticism of the outcomes of aid provided so far. Dissatisfaction is expressed both by the scientific and expert communities, as well as by societies and governments of developing countries. The main accusations concern: the lack of a clear improvement in economic growth and prosperity in developing countries, negative impact on the recipients' domestic policy, increasing spending on lowreturn and military purposes, directing aid to the elite and omitting those most in need (Burnell, 1997; Bagiński, 2009; Alesina, Dollar, 1998; Burnside, Dollar, 2000; Lancaster, 1999; Riddell, 1999). Such accusations undermine the legitimacy of development aid and its provision in the current formula. 
The need to introduce fundamental changes to the international aid system concerns especially the sphere of management, coordination, and implementation of aid. The postulates are directed mainly at Official Development Assistance (ODA), which is a universal and systemic indicator of activities undertaken by traditional donors. The source of the proposed changes is also a global strategy for the implementation of the basic development goals (MDGs and currently SDGs), extending the possibilities of financing development aid, e.g., with trust funds, as well as the growing importance of developing countries in the global economy and their pursuit of co-deciding on the shape of the international development assistance. This is reflected in the growing participation in the delivery of development aid by developing countries outside the OECD Development Assistance Committee (DAC).

The chapter analyzes the concept of development cooperation - its evolution and main objectives. The main problem turned out to be the lack of a coherent definition of the notion and variety of theoretical approaches related to development aid. In addition, the ongoing debate on its effectiveness was recalled. The WTO is one of many links in the evolving system of development cooperation, therefore the problems that accompany this process also concern the WTO (Qureshi, 2009). The most important ones include: the expanding group of aid donors, increasing the discipline related to ODA expenditure, and the mobilization of new sources of financing for development.

\subsection{The Scope and Definitions of Development Cooperation}

Development aid may be defined very broadly, and thus cover all market flows, including money transfers or foreign direct investment. In a narrower sense, the commonly accepted definition is the one relating to Official Development Assistance, prepared by the OECD Development Assistance Committee. As defined, ODA includes donations and loans made by governmental institutions or international organizations to support economic development and prosperity in developing countries. Loans are considered ODA if they contain a donation of $25 \%$ of the total amount. In addition, the condition for classifying financial aid as ODA is that the partner country for which support is provided is on the DAC List of ODA Recipients. ${ }^{5}$ The register of recipients is supplemented by a list of international organizations, including mainly intergovernmental institutions and NGOs, whose participation

The list of ODA recipients is updated by the OECD-DAC every three years. The list includes countries eligible for development aid, for which included are countries with low and middle gross national income per capita as defined by the World Bank, as well as least developed countries to which the UN classification applies. 
in development assistance may be partially or fully recognized as ODA (DAC List of ODA-eligible international organizations) (OECD, 2017a).

The definition itself and dilemmas related to the interpretation of the concept of development aid are important not only from the point of view of the methodology of approaching the topic, but also have a direct impact on aid effectiveness. Therefore, the starting point and the main definition of development aid used in this book is the definition that takes into account the effectiveness in achieving aid objectives and refers to the concept of ODA. Considering the criticism of the international development aid, the right approach seems to be to search for new forms and mechanisms of development aid or to modify the existing ones. The solution seems to be the formula of development cooperation.

Development cooperation assumes joint decision-making by all stakeholders and increased accountability of both donors and recipients. Donor activities should be carried out on the basis of supporting and complementing the efforts of developing countries to guarantee universal rights and social standards for their citizens, greater economic growth, and improved welfare (Alonso, Glennie, 2015). Therefore, aid should not be granted arbitrarily, disregarding the needs and interests of developing countries, which was a commonly accepted practice in traditional development aid, operating especially during the Cold War. On the other hand, aid recipients need to take greater responsibility for the use of development assistance. This means that its tangible effect should be social and economic reforms in developing countries, leading to poverty reduction and improvement of economic growth.

A distinctive feature of the international aid system that was taking shape at the turn of the millennium was going beyond the narrow formula of ODA. The term used to describe various types of aid activities to developing countries was the international aid architecture, meaning a loose and dispersed system of institutions and rules for managing aid to developing countries in terms of mobilizing and deploying resources. This structure comprised both bilateral and institutional donors, as well as aid recipients. Unlike ODA, it was extremely fragmented (UN, 2010). ODA is a criteria and rules-based mechanism, and so far, the only comprehensive instrument of its kind for tracing and assessing financial flows for development aid purposes. The aid architecture is made up of the ODA system, but also all kinds of other aid activities carried out by a wide group of participants. This means that in addition to bilateral and multilateral donors who are the members of the OECD-DAC, it includes new donors from developing countries (emerging economies), international NGOs, private foundations, and philanthropic associations, entrepreneurs, think-tanks or local and self-government communities (Bosh, 2011; Kaberuka, 2007). 
In the context of development aid, many similar terms are used, such as foreign aid, international aid, development cooperation, as well as economic or financial aid, and even partnership. Although they are not the same, they are often used as synonyms to describe a similar course of action by states, international organizations or private entities. The problem of aid is complex, therefore the basis for the analysis of development cooperation is to explain the premises and goals behind the traditional aid system (Tomasevski, 1993, p. 52). The starting point is various definitions of development aid, as well as the problem of increasing its effectiveness. It is a factor necessary to achieve the objectives underlying the provision of aid and the motives for its further providing.

Several approaches have developed in the international political economy in which the concept of aid is analyzed in order to explain the motivations of donor states. For example, under the concept of economic determinism, aid depends on the economic interests of influential groups within the donor country. Economic policy, including relations with developing countries, is conducted in such a way that the consequences for the country's economy are taken into account when making decisions (Mueller, 1997). In turn, supporters of the rational choice theory explain bilateral and multilateral aid as an undertaking aimed at maximizing benefits for the donor states, which is influenced by conditions and their role in the international system. The state is a unit with specific interests resulting from its position and role in world politics. The frame of reference is the preferences of the decision-making donor state. Rational action is judged by the criterion of profit maximization and loss minimization. Decisions are made under the conditions of full access to information and real assessment of the situation, not assumptions (Ostrom, 1999, pp. 35-71). In contrast, in social constructivism, aid is the result of continuous negotiations between individuals in which at least several parties participate - aid donors, multilateral aid agencies, and representatives of governments receiving aid (Hopkins, 2000, p. 348). This is a situation that comes about through a tender, where donors and recipients of foreign aid set the terms.

The international political economy perspective treats aid as a donor's political activity that can be explained and justified by political and economic goals (Hopkins, 2000, p. 347). From this point of view, the end of the Cold War removed the strategic rationale for aid, which was support for states sharing the same political and economic goals. This, in turn, weakened aid supporters in the national donor circles and lowered commitment to aid. The beginning of the 1990s was a period of decline in the importance of development aid in policies of donor countries. This meant that aid was a result of political premises and strategic calculations, and not economic needs of the recipients (Alesina, Dollar, 1998, pp. 1, 12, 13). This was 
because donors used to consider primarily political factors, such as colonial past, alliances, strategic interests, and not the recipients' needs.

A variety of theoretical approaches results in the lack of a uniform definition of development aid. This is due to the ongoing changes in the sphere of development aid and difficulties in delimiting the area of economic cooperation from aid to developing countries. Therefore, at least two approaches to defining development aid have been elaborated. The first is related to the overall flow of development means, i.e., capital, goods, services, labor force, technology from the donor country to the country with a low level of development, which means that the aid covers not only benefits provided under special conditions, but also under market rules (Nowak, 1997, pp. 16-17; Bagiński, Kowalska, 2010, p. 88). This approach is in line with the interpretation adopted by the United Nations Conference on Trade and Development (UNCTAD), which did not specify the criteria for the transfer of resources to developing countries, but only recommended that industrialized countries donate $1 \%$ of their annual output - gross national income (GNI), ${ }^{6}$ to less developed countries, including funds from private sector. ${ }^{7}$

On the other hand, the second approach, narrower than the previous one, assumes that development aid includes only "measures whose flow takes place under special conditions and which are not directly used for military purposes" (Nowak, 1997, p. 17). This position is shared by the majority of donor states and international organizations, as reflected in the commonly used definition of ODA, developed by the OECD-DAC. However, the introduction of a clear division between the two abovementioned approaches is a great simplification, as it is difficult to avoid the flow of market measures as part of the provision of aid, because their presence is an inevitable element of resources imported from abroad for the implementation of development tasks. Aid and market development measures according to A. Nowak (1997, p. 17) complement each other, and the border between them is difficult to define.

Consequently, in the literature on the subject, there are many definitions related to development aid, its goals and tasks. The evolution of the concept and changes in its scope testify to the dynamic development of this sphere, especially since the beginning of the 21st century. There is a general division between the definition of development aid treated in terms of charity (Malek, 1991, p. 1; Zinkin, 1978, p. 272) and the one perceived from the perspective of efficiency. ${ }^{8}$ The predominant approach

The basic measure of the amount of development assistance is the percentage of GNI devoted to ODA.

The initiative appeared at the second session of UNCTAD in 1968, at which the secretary general R. Prebisch proposed adopting a minimum level of $0.7 \%$ of GNI for official aid. Some highly developed countries declared a level of $1 \%$ of GNI of their total flows (History of..., 2002).

8 M.H. Malek said that altruism was the main motivation behind aid. This point of view was shared by M. Zinkin, who defined aid as a charitable activity that cannot lead to the satisfaction of the donor's interests, as it ceases to be help. 
reflects actual conditions under which the aid is provided, as well as the effects that the parties involved expect to obtain. Due to the fact that the overriding party in providing aid since the 1950s, was a donor state, the definitions of aid were made from the donor's point of view. For instance, P. Burell $(1997$, p. 3) defines aid as the transfer of resources between societies, which is primarily to satisfy the needs and interests of the recipient. C. Lancaster (2007, pp. 9-10) defines it as the voluntary transfer of public funds from a government to another independent government, non-governmental organization, or international organizations (such as the World Bank or the United Nations) with at least $25 \%$ of subsidies, one of the aims of which is to improve the living conditions of the population in the recipient country. This definition is similar, with some exceptions, to the ODA standards adopted by the OECD. In turn, R.C. Riddell (2007, p. 21) treats aid very broadly, applying it to various sources and forms, unless there was a need to narrow it down to a specific form, such as ODA. An equally wide approach to aid was taken by C.C. Adelman, J. Norris, and J. Weicher (2005), who included into foreign aid remittances of labor migrants, individual philanthropic and corporate activities. Other definitions of aid were included in the studies of, among others, F. Tarp, P. Hjertholm (2000), or J. Tendler (1997).

A set of concepts relating to development aid was introduced to Polish literature by M. Gulcz (1988), J. Winiecki (1975), A. Nowak (1997), and P. Samecki (1997). The subject of their research was foreign economic aid, which they treated as a transfer of funds from the donor country or an international organization to the recipient state on preferential terms, therefore more convenient than market conditions. According to A. Nowak (1997, p. 14), development aid is the basic instrument of state policy. It is a form of preferential flow of development resources (material, financial, services, technical, and others) from economically developed countries to states at a low level of development. Development policy is at the same time a form of external influence of the state on developing countries and it occupies an intermediate place between general foreign policy and foreign economic policy. Since 2000, research on development aid in Polish subject literature has been conducted by P. Deszczyński (2011), E. Latoszek (2010), M. Proczek (2013), P. Bagiński, K. Czaplicka, J. Szczycinski (2009), D. Kopiński (2011), and J. Szymoniczek (2016). The definitions of development aid or development cooperation used refer mainly to activities classified as ODA.

Various ways of understanding and implementing development goals are clearly visible in the development policy of states and international organizations. At the declarative level, development aid is an activity aimed at overcoming poverty and solving economic and social problems of developing countries. On the other hand, 
in practice it is a form of realizing political and economic interests of donors (Severino, 2009, p. 6). This means that developed countries are willing to use such means of capital, goods, and services movement which, apart from transferring funds to less developed countries, bring them economic gains. From this perspective, development aid plays a secondary, and thus stimulating, role in relation to economic turnover based on market conditions (Deszczyński, 2011, pp. 87-89).

In the case of an international organization, development aid is a result of collective actions of members of the organization implementing goals and tasks on the basis of jointly made decisions. The function of coordinating and harmonizing jointly agreed activities is performed by international multilateral organizations. These are usually institutions specialized in a strictly defined area, such as health, education, human rights, and trade. In this regard, development assistance is characterized by a relatively high level of institutionalization, which is manifested in the creation of numerous international organizations, associations, banks, funds, contracts, and agreements. Therefore, international development aid system can be regarded as an international regime under which its various participants strive to achieve the expected goals, in this case concerning the development needs of less developed countries. A helpful element are commonly adopted principles, norms, rules, or decision-making procedures, although their observance is usually voluntary (cf. Krasner, 1984; Keohane, 1989; Young, 1997; Keohane, Victor, 2010).

Regardless of the profile of activity, an international organization performs the function of a negotiating assembly for agreeing priorities and action strategies by making joint decisions, as well as exchanging information on policies pursued by members of the organization. In the area of development aid, the goal of a multilateral organization is to implement programs and projects financed by members of a given institution. Therefore, the organization plays the role of an administrator and coordinator of development aid and is also involved in the preparation of analytical and research facilities to create aid strategies (Baginski, Czaplicka, Szczyciński, 2009, p. 98).

An organization like the WTO is based on mutually agreed and accepted agreements which set the principles, rules, and standards of operation in the international trading system. The WTO's development goals include activities aimed at greater integration of developing countries into the international trading system. This means taking into account the interests and development needs of these countries to a much greater extent by adopting new or modified trade rules (WTO, 2001a). The WTO is on the list of institutional donors and is authorized to provide assistance in the form of ODA. On the other hand, it undertakes, in line with its functions, other activities aimed at achieving the development goals of its members that are 
not eligible for ODA. These include, inter alia, obtaining by developing countries extraordinary trade benefits due to easier access to the market of highly developed countries, provided for in the Generalized System of Preferences (GSP) and Special and Differential Treatment (SDT) regulations.

\subsection{Classification of Development Aid}

Depending on the criteria adopted, development aid may be provided in many ways and in various forms. Nowadays, the boundaries between individual forms of aid are increasingly blurred (Riddell, 2007, p. 77). One of the most universal and comprehensive classifications of development aid in the Polish literature on the subject is the one adopted by P. Deszczyński and based on the version introduced by M. Gulcz (1988, pp. 66-80). P. Deszczyński distinguishes five criteria: flow channels, ways of providing aid by a donor, method of using aid by a donor, burdening the payment of a recipient, procedures for the disposal of aid by the beneficiary (Deszczyński, 2011, pp. 98-100) (Table 1).

Table 1. Classification of Forms of Development Aid

\begin{tabular}{|c|c|c|}
\hline & Criterion & Forms of aid \\
\hline \multirow[t]{3}{*}{$\begin{array}{l}\text { M. Gulcz (1988) } \\
\text { Foreign economic aid }\end{array}$} & Flow channels & $\begin{array}{l}\text { - Bilateral } \\
\text { - Multilateral }\end{array}$ \\
\hline & Payment burden & $\begin{array}{l}\text { - Refundable } \\
\text { - Non-refundable }\end{array}$ \\
\hline & $\begin{array}{l}\text { Ways of using the aid by } \\
\text { a recipient }\end{array}$ & $\begin{array}{l}\text { - Project aid } \\
\text { - Non-project aid } \\
\text { - Tied aid } \\
\text { - Untied aid }\end{array}$ \\
\hline \multirow[t]{5}{*}{$\begin{array}{l}\text { P. Samecki (1997) } \\
\text { Foreign economic aid }\end{array}$} & Source of origin & $\begin{array}{l}\text { - Government bilateral aid } \\
\text { - Multilateral aid } \\
\text { - NGOs assistance }\end{array}$ \\
\hline & Form of providing aid & $\begin{array}{l}\text { - Financial } \\
\text { - Material } \\
\text { - Technical }\end{array}$ \\
\hline & $\begin{array}{l}\text { Degree of freedom in using } \\
\text { the aid }\end{array}$ & $\begin{array}{l}\text { - Tied } \\
\text { - Untied }\end{array}$ \\
\hline & Purpose of aid & $\begin{array}{l}\text { - Project } \\
\text { - Program }\end{array}$ \\
\hline & Financing method & $\begin{array}{l}\text { - Non-repayable loans } \\
\text { - Sale for the recipient's local currency } \\
\text { - Preferential loans }\end{array}$ \\
\hline
\end{tabular}




\begin{tabular}{|c|c|c|}
\hline & Criterion & Forms of aid \\
\hline $\begin{array}{l}\text { T. Kamińska-Blichowska } \\
\text { (2007) } \\
\text { Economic aid }\end{array}$ & Types & $\begin{array}{l}\text { - Financial } \\
\text { - Donations } \\
\text { - Stadf training } \\
\text { - Transfer of licenses, technology, and know-how } \\
\text { - Military assistance } \\
\text { - Organizational and legal assistance }\end{array}$ \\
\hline K. Czaplicka (2009) & Functional criterion & $\begin{array}{l}\text { - Financial } \\
\text { - Material } \\
\text { - Technical }\end{array}$ \\
\hline \multirow[t]{2}{*}{ K. Andrzejczak (2010) } & Functional criterion & $\begin{array}{l}\text { - Financial } \\
\text { - Material } \\
\text { - Technical }\end{array}$ \\
\hline & Material criterion & $\begin{array}{l}\text { - Financial } \\
\text { - Commodity aid } \\
\text { - Service aid }\end{array}$ \\
\hline \multirow[t]{5}{*}{ P. Deszczyński (2011) } & Flow channels & $\begin{array}{l}\text { - Bilateral } \\
\text { - Multilateral }\end{array}$ \\
\hline & $\begin{array}{l}\text { Ways of providing aid by } \\
\text { a donor }\end{array}$ & $\begin{array}{l}\text { - Financial } \\
\text { - Technical } \\
\text { - Humanitarian } \\
\text { - Food aid }\end{array}$ \\
\hline & $\begin{array}{l}\text { Method of using aid by } \\
\text { a donor }\end{array}$ & $\begin{array}{l}\text { - Project } \\
\text { - Program }\end{array}$ \\
\hline & $\begin{array}{l}\text { Burdening the payment of } \\
\text { a recipient }\end{array}$ & $\begin{array}{l}\text { - Refundable } \\
\text { - Non-refundable }\end{array}$ \\
\hline & $\begin{array}{l}\text { Procedures for the disposal of } \\
\text { aid by a recipient }\end{array}$ & $\begin{array}{l}\text { - Tied } \\
\text { - Untied }\end{array}$ \\
\hline \multirow[t]{5}{*}{ D. Kopiński (2011) } & Source of origin & $\begin{array}{l}\text { - Bilateral } \\
\text { - Multilateral }\end{array}$ \\
\hline & Forms of providing aid & $\begin{array}{l}\text { - Financial } \\
\text { - Material } \\
\text { - Technical }\end{array}$ \\
\hline & $\begin{array}{l}\text { Degree of freedom in using } \\
\text { the aid }\end{array}$ & $\begin{array}{l}\text { - Tied } \\
\text { - Untied }\end{array}$ \\
\hline & Purpose of aid & $\begin{array}{l}\text { - Project } \\
\text { - Program }\end{array}$ \\
\hline & Other types & $\begin{array}{l}\text { - Private } \\
\text { - Humanitarian } \\
\text { - Sector-wide approach }\end{array}$ \\
\hline
\end{tabular}

Source: own study.

Another important position in the Polish literature is the classification of economic aid by P. Samecki, (1997, pp. 25-29) slightly modified by D. Kopiński (2011, pp. 19-25). The authors included in their set of criteria: the source of origin, forms of providing aid, degree of freedom in using the aid and its purpose. Moreover, D. Kopiński distinguished the following categories: private aid, humanitarian aid, and a sector-wide approach. Noteworthy is also a more detailed breakdown of the forms 
of aid provided by multilateral institutions, proposed by T. Kamińska-Blichowska (2007, pp. 323-324). The literature also features a functional criterion according to which aid is divided into four forms: project aid, program aid, technical assistance, and humanitarian aid (Andrzejczak, 2010, pp. 22-23) (Table 1).

In practice and as a result of changes in the international aid system, the clear line between individual forms of aid is blurred. A commonly used division is, for example, the choice of repayable or non-repayable assistance. The first includes an element of donation and is granted on non-market terms, the second is related to the recipient meeting certain conditions as regards its use and usually takes the form of donations or subsidies (loans). In the event of tied aid, the recipient is obliged to implement a strictly defined form of aid in close economic cooperation with the donor. This means, inter alia, obligation to make purchasing certain goods and services in the donor country. However, this form is being abandoned in favor of untied aid.

On the other hand, program aid is a support provided within a specific sector. Its purpose is to solve broader problems of a macroeconomic nature, e.g., in the case of difficulties with the balance of payments, the purchase of certain goods or debt reduction. The opposite of program aid is project aid directed to a specific goal, such as construction or modernization of infrastructure or training. This assistance is most appropriate when the recipient has limited own resources, or its preferences differ from those of the donor. Program aid was most often used in the case of corrupt countries or countries with poorly developed infrastructure. Unlike project aid, it is easier to control by the aid donor. In the previous decades of the 20th century, it was the dominant form of aid. Nowadays, it is believed that project aid is the main reason for the ineffectiveness of development aid, and its extensive use by donors is the phenomenon of aid proliferation, duplicating aid efforts, and high transaction costs (Kopiński, 2011, p. 23). In connection with the desire to increase the effectiveness of aid, project aid is gradually being abandoned in favor of program aid, which covers a broader catalog of development needs (Sobotka, 2008, p. 165). Contrary to the project, program aid must, as a rule, be implemented in cooperation with representatives of the recipient state, it is not related to a single undertaking and usually serves longterm support for economic policy reforms.

Particular forms of assistance may coexist in different configurations. For instance, multilateral aid, as in the case of the WTO, can be non-repayable and technical. Within the material criterion, financial, product, and service assistance are distinguished. In this regard, financial aid most often consists of remittances and may take the form of sectoral programs or strategies, but also projects, if the fund is managed by the recipient state (Andrzejczak, 2010, p. 22). Financial assistance is most often implemented in the form of debt reduction of a recipient country. On the other hand, assistance as a service 
provided by a donor usually takes the form of projects and technical assistance, but material aid is the donor's transfer of certain basic goods (e.g., humanitarian aid) or goods for long-term development of a given sector (e.g., machinery).

Aid classifications are not a finite structure and are subject to change in line with the development of various forms of aid. For instance, due to the way in which the donor transfers aid, it is possible to join the existing group of activities that are commonly used by WTO members, namely the extraordinary commercial advantage of granting a market access concession for goods from developing countries, mainly LDCs. The legal basis for this type of activity are the regulations contained in Part IV of the GATT $1994 .^{9}$ On the other hand, the main criterion for the division of development aid is the method of distribution, on the basis of which bilateral and multilateral aid are distinguished.

\subsection{Development Aid Effectiveness}

The problem of aid effectiveness relates to the development dimension of support, i.e., the impact of aid on the achievement of development goals, which generally include the reduction of poverty and boosting economic growth. Finding an answer to the question about the legitimacy of granting aid has been the subject of numerous research studies. The intention was to investigate the effectiveness of aid understood as the degree of achievement of the assumed goals (Samecki, 1997, p. 79). Due to fundamental differences in study results, the researchers can be divided into two groups - those who claimed the aid was effective and those who asserted the opposite. The group in which the authors shared the view on the positive correlation between aid and economic growth included: R. Cassen (1994), H. Hansen, F. Tarp (2000), L. Beynon (2003), J. Hudson (2004), C.J. Delgaard (2004), P. Collier, D. Dollar (2001, pp. 1787-1802; 2002, pp. 1470-1500), T. Addison, G. Mavrotas, and M. McGillivray (2005). ${ }^{10}$ For instance, H. Hansen and F. Tarp, after analyzing 131 scientific papers based on econometric models, concluded that only a few cases showed no positive effect of aid on growth, and only in one case (Mosley, 1986) it was clearly negative. Researchers who did not find positive correlations between aid and economic performance in the recipient country were of a different opinion. These

9 In 1965, GATT Articles XXXVI, XXXVII, and XXXVIII were added to the GATT General Agreement, which dealt with the issue of preferential treatment of trade interests for developing countries, including in particular the least developed countries (LDCs).

10 These are researchers included in the "third generation" who have been publishing their works since the beginning of the 1990s. This period is significant due to changes in the international aid system caused by the end of the Cold War (Hansen, Tarp, 2000). 
included, apart from the mentioned P. Mosley (1987), P. Boone (1996), H. White (1992b), D. Moyo (2009), R. Rajan, and A. Subramanian (2005, pp. 11, 18-33).

It is assumed, following R. Cassen, that most of the aid works, and thus contributes to the achievement of development goals in recipient countries (Cassen, 1994, pp. 6-7). However, a review of research on both the positive and negative relationship between aid and economic growth leads to the conclusion that there is no clear position on interaction of both factors and, consequently, no proven method of improving the effectiveness of development aid. The reason lies in the complexity of the research subject, and thus numerous economic, political, or ethical factors influencing the results of relationship between aid and economic growth and development (cf. Samecki, 1997, pp. 87-88). An additional difficulty is the variety of types of assistance, which have a different impact on the recipient countries. Some types of aid, such as shortterm aid, have no impact on economic growth, while other types of support, such as in the field of infrastructure or capacity building, tend to have a positive effect.

Due to changes in the international economic environment and different economic conditions, it is difficult to understand the interplay between development aid, macroeconomic policy, and political economy, and finding positive correlations between the aforementioned factors - aid and economic growth - is complicated. Therefore, the most important issue is not to clearly state whether aid works, since it is known that the assessment of aid effectiveness is difficult to carry out, but rather it is about determining when and what kind of instruments and measures should be applied depending on the situation in the recipient countries. Moreover, the relationship between economic growth and aid depends on many additional factors, including the launch of reforms in trade and other related areas (e.g., investment) (Easterly, 2001, pp. 285-287, 290-291; Cali, te Velde, 2010, pp. 725-740). Aid is not a direct solution to accelerating economic growth and reducing poverty. However, it can stimulate changes in economic policy sectors, such as trade, that result in economic growth and social change.

The aid effectiveness criterion can be presented after P. Samecki's definition as the following formula, where $D_{b}$ means the recipients' welfare, $P$ means the total transfer of aid, and $a$ - other factors determining the recipients' welfare:

therefore

$$
\begin{gathered}
D_{b}=f(P, a) \\
P+D_{b}<D_{b}+\Delta D_{b}(P),
\end{gathered}
$$

$$
\begin{aligned}
& P<\Delta D_{b}(P) \\
& \frac{\Delta D_{b}(P)}{P}>1 .
\end{aligned}
$$


Treating aid effectiveness as a development efficiency means that it is understood relatively narrowly, because it is only limited to the economic sphere. It is a necessary procedure from the point of view of the methodology of measuring aid effectiveness. Therefore, other areas of development, i.e., social and cultural, remain beyond the possibility of being examined based on the adopted formula (D). According to it, the purpose of aid is to maximize that part of global income that is generated thanks to the transfer of aid in the recipient countries. The main task is therefore to examine under what conditions the aid contributes to the achievement of the maximum development effect in the recipient countries. In other words, it is about explaining how and whether aid has a positive effect on economic results, including, in particular, economic growth.

A breakthrough study on the relationship between foreign aid, economic policy, and economic growth in recipient countries was the work by $C$. Burnside and D. Dollar $(1997$, p. 33) published three years later by the World Bank. The authors concluded that development aid positively influences growth in a context of wellconducted fiscal, monetary, and trade policies, but produces little results when policies are inadequate and state institutions are weak. Both researchers advocated selectivity in the allocation of aid. They argued that aid should be systematically granted to countries with a good or appropriate policy, where the effectiveness of the aid depends directly on the quality of economic policy. Thus, aid has a positive effect on economic growth in the environment of a well-formulated policy (Hansen, Tarp, 2000, p. 387).

The Burnside and Dollar's (1997) study was an important contribution to international debate on aid effectiveness. It was all the more significant as it coincided with preparations for the international UN Conference in Monterrey in March 2002 on Financing for Development. Conclusions from the study constituted a significant argument for increasing the amount of development aid. It was a clear signal for donors who, because they believed it was ineffective, tried to reduce the financial resources. For instance, in the late 1990s there was a record decline in the volume of ODA relative to the gross national income (GNI) of non-OECD-DAC countries. There was a decline from $0.54 \%$ of GNI in 1961 to $0.22 \%$ in the late 1990 s. It was caused by the phenomenon known as aid fatigue, which intensified after the end of the Cold War and the geopolitical changes in world politics (Bauhr, Charron, Nasiritousi, 2013; UN, 2010, p. 50).

In the course of further research, P. Collier and C. Burnside proposed extending their hypothesis on the positive impact of aid on economic growth to include criteria for allocating aid in order to eliminate poverty more effectively. It involved selecting countries with high poverty rates and well-conducted economic policies (Collier, Dollar, 
2001, 2002; Hudson, 2004). The authors argued that directing aid in the way they proposed could significantly improve the provision of aid and contribute to reducing poverty in countries with sound economic policies (Aid Effectiveness..., 2002). This was in line with the assumptions contained in the Washington Consensus, created by John Williamson and supported by the International Monetary Fund and the World Bank. In this context, adopting a policy of stable and sustainable economic growth and development meant increasing the effectiveness of development aid (Hansen, Tarp, 2000, p. 393).

Evaluation of the Burnside and Dollar (1997) model, carried out by other researchers, did not provide a clear answer about the relationship between aid and other variables (Easterly, 2003, p. 24). It turned out that the interaction between the policy pursued in the recipient country and the aid was impossible to verify (Roodman, David, 2007). Thus, this statement undermined the conclusions regarding the stability of economic policy and the effectiveness of development aid (Beynon, 2003, pp. 7, 17; McGillivray, 2003, pp. 8-10; Munro, 2005). On this basis, F. Tarp and H. Hansen (2000, p. 394; 2001) recognized that although aid can be effective, its results do not depend solely on economic policy. Therefore, they proposed a solution for the best possible use of various development aid instruments depending on individual conditions in the recipient states. They argued that the impact of aid on growth and poverty reduction differs depending on countries, regions, governing systems and political situations. Similar conclusions were reached by W. Easterly, R. Levine, D. Roodman $(2000,2004)$ and J.E. Antipin and G. Mavrotas (2006). Such an approach supports the claim that aid should be tailored to the individual needs of the recipient country. Providing assistance on the basis of a one-size-fits-all model does not lead to effective solutions, as evidenced by the above-mentioned studies.

The type of 'good policy' implemented by the state in the case of using variables such as institution quality and social capital has an even smaller impact on aid effectiveness. A research by M. Baliamoune-Lutz and G. Mavrotas (2009) showed that both elements - institutions and social capital - are important when trying to increase aid effectiveness. Once the role of social capital and institutions is taken into account, the impact of policies tends to disappear. Once again it has been proven that the conclusions from the research by C. Burnside and D. Dollar (1997) do not fully come true. This means that granting aid on the basis of 'good policies' criterion does not lead to optimal allocation of aid. This is because countries with a high level of social capital and efficiently operating institutions can fully benefit from development aid, regardless of policy quality.

One of the research trends indicating the possibility of confirming the positive impact of aid on growth is the concept of complementary policies. According to its 
basic assertion, development aid serves to improve trade capacities of developing countries in the process of trade liberalization, which leads to increased benefits from trade. Empirical research on complementary policies, where trade is the basic tool for achieving growth and poverty reduction, was of fundamental importance for the establishment of the Aid for Trade initiative (Hallaert, Munro, 2009, pp. 26-27). This means that undertaking reforms in related areas of the economy increases the positive impact of trade on economic development. Its dynamics, according to J.J. Hallaert (2010, p. 28), depend on complementary policies and transmission channels, which mainly include production efficiency and investment (Berg, Krueger, 2003). Trade itself does not directly affect economic growth, but through transmission channels it is one of the key aspects of this process. According to A. Berg and A. Krueger (2003), trade has an important and positive impact on various spheres of the economy, which means that trade liberalization should be the first step in various reforms undertaken by a developing country.

Trade should play a central role within a set of complementary policies. This is confirmed by the research of R. Chang, L. Kaltani, N. Loayz (2005, pp. 26-27), and also K. Kołodziejczyk (2010, p. 117). The authors showed that the positive impact of trade on economic growth is greater when it is accompanied by higher levels of education, better infrastructure, flexible labor market, stable inflation, and development of the financial sector. Consequently, better results in terms of productivity and growth are achieved when complementary reforms in non-trade areas are introduced with the lifting of trade barriers. An increase in benefits of trade liberalization, according to B. Bolaky and C. Freund (2006, pp. 5-6, 24-25), is also brought by institutional and regulatory reforms, although an unduly extensive and restrictive regulatory system does not have a positive effect on trade.

The effectiveness of trade reforms, as claimed by J.J. Hallaert (2010, p. 17) depends on the implementation of the broader reform package of which trade is an integral part. As a result, overlapping changes in various areas of the economy stimulate each other and guarantee the continuation of reforms in the area of trade. L.A. Winters, N. McCulloch, and A. McKay reached a similar conclusion in their research (2004, p. 92), according to which trade liberalization reduces poverty, and this effect is all the more durable the more closely it is connected with changes introduced in other areas (including investment, productive capacity, institution building, and regulations).

In-depth reforms in the area of trade, combined with reforms in other spheres of the economy, according to B. Hoekman (2007, pp. 225-226), have a much greater impact on poverty reduction than the effects of limited trade liberalization at the global level. Therefore, in order to improve economic growth and reduce poverty, it 
is considered appropriate to start multilateral negotiations on trade liberalization in conjunction with special development aid programs (Prowse, 2005, pp. 241-242; Hoekman, Prowse, 2005, p. 21). In the first case, it is a series of negotiating rounds within the WTO and regulations favoring the development of trade in developing countries, and in the second, the maintenance or even extension of development assistance mainly to LDCs. Due to the different internal conditions and different levels of development of the recipient countries, the one-size-fits-all rule under the international aid system was rejected. It was necessary to develop an approach that would take into account, on the one hand, the development needs of the recipient states, and, on the other, guarantee donors to maintain control over the funds transferred. The concept of complementary policies contributed to the justification of this approach.

\subsection{Development Aid as a Permanent Element of International Relations}

International conditions play an important role in shaping the concept and implementation of development aid programs. The scope and scale of provided development aid are closely related to the state of the world economy and the economic and social situation of individual regions of the world. The decisive factor is the degree of mutual economic and political interdependencies as well as the readiness for joint action of aid donors to achieve development goals.

The literature on the subject highlights several breakthrough events that initiated the process of building an international development aid system and influenced the inclusion of this issue in the policies of states and international organizations. At least five such events can be distinguished chronologically:

1) building the international order after the end of World War II,

2) decolonization,

3) political and military rivalry of the Cold War period,

4) institutionalization of development aid,

5) millennium Development Goals.

The period of building a new international order lasted from the end of World War II to the beginning of the 1960s. Development aid, as a new form of international relations, had entered world politics a decade earlier. The prototype of aid was the plan for the reconstruction of Europe, known as the Marshall Plan, by means of which the United States initiated the process of economic recovery of Europe after the devastation of war. The United States was the first country to introduce 
development aid as a permanent element of its foreign policy. The institutional and doctrinal foundations of this move were included in the speech of President $\mathrm{H}$. Truman of January 20, 1949. On the fourth point (The Point Four Program) the president declared the launch of permanent technical support for less developed countries. ${ }^{11}$ In this way, one of the basic instruments of the policy of stopping the expansion of the Soviet Union and other communist states emerged. It is worth mentioning that the policy of containment was directed not only against the Eastern Bloc countries, but also the People's Republic of China.

Being guided by strategic and ideological considerations was the main premise when creating assistance programs for both Western and Eastern bloc countries. To subordinate the goals of development aid to the interests of the donor states was an approach represented by both capitalist and socialist states. This resulted from the pressure to achieve political and strategic benefits for donors, and as a consequence, limited the possibilities of achieving real development goals, such as poverty reduction.

A turning point in the construction of international aid system was the process of decolonization, which reached its peak in the 1960s. In Africa alone, more than 35 independent states were established at that time. These events were announced by the United Nations as the 1st Decade of Development, and its main goal was to achieve economic growth in developing countries at the level of 5\% of GNP annually by 1970 and to increase development aid from the northern countries (Bagiński, Czaplicka, Szczyciński, 2009, p. 59). In highly developed countries, a recommendation was adopted to allocate $1 \%$ of GNP for development purposes in both preferential and market forms.

Due to the development disparities between the newly established countries of the South (referred to as Third World countries) and former metropolises, their mutual relations focused mainly on development aid. Ex-colonial states demanded financial compensations and economic concessions from their former metropolises, and the main addressees of their postulates became the institutions of the United Nations. Developing countries, more and more organized and aware of their needs, demanded from the more developed countries to implement their economic demands and to increase their influence on world politics. One of the examples of such a situation was the debate on the GATT forum at the turn of the 1950s and 1960s, which led to the adoption of changes to the General Agreement.

11 The concept of aid to developing countries was announced in the document presented by President Harry Truman on January 20,1949, in The Fourth Point Program. This is where the official name of this declaration comes from, which turned out to be part of a wider program of technical assistance to developing countries (Grant, 1979, p. 3). 
However, before the provisions on preferential treatment for developing countries were included in the GATT regulatory order, a number of initiatives were taken. The 1958 Haberler Report proved to be helpful, as it stated that international trade regulations were unfavorable to the export of basic products from developing countries (Zangh, 2018, p. 56). In the same year, the GATT launched a Program for Trade Expansion (PTE) in developing countries and a Committee III was established to examine trade measures restricting developing countries' exports. Developing nations launched an initiative called the Action Program, in which they made specific demands for changes to the General Agreement to be more conducive to their commercial interests. During the Kennedy Round in 1963, a governing committee was established. Work in this area was completed in 1965 and resulted in the decision to introduce a new, IV chapter, under the title of Trade and Development, to the GATT. These regulations, known as special and differential treatment, concerned the obligation to treat developing countries in a special way and not to apply to them the principle of reciprocity, concessions, and trade benefits between GATT contracting parties.

The conditions of the Cold War period determined international relations, both in the sphere of politics and in relations between state and non-state actors. The former colonial states became the arena of a struggle for political influence by rival political and military blocs. In such an arrangement, development aid was to a large extent subordinated to the realization of the interests of competing powers and it became an instrument in the external policy of states through which interested entities, such as the United States and the Soviet Union, pursued their political and economic interests in the Third World. ${ }^{12}$ The goals of the states from both political and military blocs resulted from the general principles of foreign policy and the prevailing social and political systems, but also from the economic and trade policy in force at the time (Deszczyński, 2001, p. 73). This led to the instrumentalization of development aid, and thus taking into account by the donors primarily their own goals and political and economic benefits. The instrumentalization of development aid meant that donor countries subordinated the granting of aid to specific economic goals, e.g., promoting exports and creating conditions for investment, finding new markets, creating new jobs and ensuring supplies of energy resources to donor countries (Knorr, 1975, pp. 135-138, 169; Deszczyński, 2001, p. 74).

12 The term "Third World" was used interchangeably with the concept of developing countries during the Cold War, which was due to the division into rival political and military blocs. The terms "First World," meaning rich western states, and "Second World," referring to socialist states, were generally not used. Due to the evaluative nature of the term "Third World," it is also not used today. On the other hand, rich countries are called the "Global North" because they are mostly north of poorer countries, called developing countries or "Global South". 
The end of the Cold War paradoxically caused stagnation and consternation as to the direction and volume of development aid. The largest donors of aid, i.e., the United States, the UK, and France, recorded a significant decrease in their ODA expenditure for seven consecutive years since 1990 (from USD 16.2 billion in 1990 to USD 8.4 billion in 1997) (OECD, 2006). This meant that development aid during the Cold War was in practice subordinated to ideological, military, and individual commercial interests.

With the disappearance of the bipolar system, the goals of development policy were weakened. There was a period of stagnation and a search for a new aid formula, as evidenced by several factors. Firstly, as a result of changes in international politics, a new group of countries undergoing transformation gained the opportunity to receive aid funds, which increased competition between the existing aid recipients and the new candidates (Bagiński, Czaplicka, Szczyciński 2009, pp. 65-66). Secondly, interest in development aid declined among traditional donors as a result of their involvement in their own domestic affairs, as well as strong criticism of the ineffectiveness of development aid. Thirdly, there were demands to revise the existing support concepts towards the empowerment of developing countries. The idea was to create assistance programs based on partnership and development concepts, adjusted to the needs and internal conditions of the recipients. In contrast, donors set certain requirements for developing countries, on the fulfillment of which they conducted the continuation of aid. Such an arrangement led to contradictions and tensions, which in turn had an impact on the quality and effectiveness of aid.

The institutionalization of development aid was the effect of economic ties deepening since the 1960s, which led to economic and political interdependencies. It was accompanied by the conceptualization of aid and the creation of rules for its provision. As a result of this process, new phenomena and trends in domestic and international politics appeared that changed international relations and influenced international aid system (Nowak, 1997, p. 30).

The main pillars of the international aid system that was taking shape at the beginning of the 1960s were the UN, World Bank, and the OECD. Within the UN, the leading institutions responsible for development issues include the United Nations Conference on Trade and Development (UNC-TAD) established in 1964, the United Nations Development Program (UNDP) established in 1965, and the World Food Program (WFP) launched in 1964. The role of the World Bank in the area of development aid increased as a result of the establishment of two institutions - the International Development Association (IDA) in 1960 and the International Finance Corporation (IFC) in 1956. On the other hand, within the Organization for European Economic Cooperation (OEEC), the predecessor of the OECD, the Development 
Assistance Group (DAG) was established, the name of which was changed to the currently functioning Development Assistance Committee (DAC).

Activities on the forum of development aid organizations were mutually intertwining. The impulse to change the general framework of international development assistance in the 1980s and 1990s was a series of conferences organized under the auspices of the United Nations and the accompanying debate on aid effectiveness within the OECD. Many of the later Millennium Development Goals were originally formulated at UN conferences on development issues. ${ }^{13}$ An important stage was the 1994 Agenda for Development by UN Secretary General Boutros Boutros-Ghali, which emphasized the special need to deal with development issues as a determinant of peace and security.

In the debate on the effectiveness of development aid, arguments concerning the change of the aid concept prevailed. The idea was to conduct aid activities according to political and economic priorities of the recipient countries, not of the donor countries. Within the framework of the DAC, a list of headline targets was established to assess progress in different areas of development aid. Designating them on the basis of decisions taken at UN summits allowed the DAC to take a leading role in creating a new form of development aid based on cooperation, partnership, and responsibility. In 1996, the DAC made a conceptual framework with seven headline goals, which were then repeated under the United Nations Millennium Declaration. An OECD Strategic Document Shaping the 21st Century: The Contribution of Development Cooperation became the basis for the designation of the MDGs. The document included the following goals to be achieved by 2015: a reduction by one-half in the proportion of people living in extreme poverty, ensuring universal education, promoting gender equality and accessing women to education, reducing the mortality rate of children up to 5 years of age by two thirds and maternal mortality by threequarters, providing access to primary health care for all, including family planning methods, and the implementation of national sustainable development strategies and the use of methods to inhibit environmental degradation (OECD, 1996, p. 2).

The Millennium Declaration, endorsed by 189 member states of the United Nations in 2000, was recognized as a turning point in the history of development aid, setting new standards of conduct in this area. The set of eight Millennium Development Goals with indicators enabling the assessment of the implementation of aid activities is the commitment of the international community to engage

13 The leading topics of the UN conference were: education (Jomtien, 1990), the situation of children (New York, 1990), the environment (Rio de Janeiro, 1992), human rights (Vienna, 1993), population (Cairo, 1994), social development (Copenhagen, 1995), women's rights (Beijing, 1995), food production (Rome, 1996). 
in solving key problems of the 21st century. ${ }^{14}$ The donor-recipient partnership and the approach based on direct dialogue and mutual responsibility for development issues were accepted (Waage, 2010). It was a symbolic breakthrough, which meant a slow departure, at least at the declarative level, from the instrumentalization of aid objectives towards greater involvement in the implementation of the needs and objectives of recipient states.

As a result of the Millennium Declaration, there has been a convergence of positions on the goals of development aid between representatives of donors and recipients. The focus was on the most salient issues on which there was general agreement, both at the government and public level. Some activities were adjusted, for instance, it was announced to depart from project-based assistance, characterized by the implementation of individual projects, and to provide program-based assistance, including comprehensive and coordinated activities (Sobotka, 2008, p. 165). Even if these commitments remained in the realm of promises, as evidenced by the failure to meet the 2015 deadline for implementation of most MDGs, the change turned out to be significant due to joint international efforts. An expression of the international community's sustained will to continue this approach was the replacement of the MDGs goals with the Sustainable Development Goals in 2015.

\subsection{Official Development Assistance (ODA)}

The basis of international practice in the field of development aid and the rules for providing it is Official Development Assistance mechanism established in 1969 by the OECD-DAC. ${ }^{15}$

Aid provided in the form of ODA must meet four basic conditions:

- the partner country or multilateral institution to which the support is directed must be on the list of development aid recipients established by the OECD-DAC (the list of countries is reviewed every three years, and the list of international organizations every year);

- donations and loans are made by the donor country's government, including local governments or international organizations;

- the main objective of the aid is to support economic development and prosperity in developing countries;

14 The Millennium Development Goals consisted of 8 headline goals, 18 additional goals, and 48 indicators.

15 The definition of ODA was specified in 1972. 
- loans and grants should include a donation element of at least $25 \%$ of the total amount (calculated at a discount rate of 10\%) (OECD ODA).

The concept of ODA entered international practice relatively quickly. It appeared for the first time in the Pearson Commission Report, which called for $0.7 \%$ of GNI to be transferred by developed countries to ODA. This goal was approved by the UN General Assembly in 1970 and included in the International Development Strategy for the 2nd UN Development Decade.

The target of $0.7 \%$ of GNI became the benchmark for assessing the size of ODA and it was expected that the donor countries would achieve it in the 1970s. In practice, the implementation of the detailed guidelines included in ODA turned out to be difficult. On the one hand, the definition narrows down the subject of development aid to specific activities, and on the other hand, it leaves some criteria so imprecise that it leads to any interpretation in terms of various types of activities. The problem is that ODA does not take into account those elements that are important from the point of view of aid effectiveness, i.e., the relationship between the amount of ODA expenditure and the final results. The entire ODA has been subordinated to the method of reporting on the expenditure and the amount of aid, and the effects of this aid have not been focused on. Due to the criticism, the ministerial body of the DAC referred to the issue of changes in the definition of ODA at the turn of the 1980s and 1990s, as well as in 2012. It was proposed to supplement ODA with an element of Official Concessional Assistance (OCA) in order to perform tasks related to, inter alia, humanitarian aid, and environmental protection. Another proposal concerned the classification of funds that are not directly transferred to developing countries in the form of additional concessional contributions (Hynes, Scott, 2013, pp. 11-12). Ultimately, however, at the OECD-DAC High-Level Forum in December 2014, it was decided to leave the existing ODA without introducing significant modifications (OECD, 2014).

Criticism of the definition and principles of providing assistance in the form of ODA moved to the forum of non-governmental institutions and academic debate. One of the most radical assessments of ODA was made by J.M. Severino and O.Ray. They found that profound changes related to the functioning of ODA, concerning goals, participants, and instruments of development aid, contributed to its obsolescence (Severino, Ray, 2009, p. 17). Their proposal is to replace ODA with an instrument called Global Policy Finance. Its aim would be to finance three main components of the concept of sustainable development, i.e., reducing development disparities between the economies of the North and South countries, better access to basic services on a global scale and securing the use of and from global public goods, i.e., environmental and health protection. C.C. Adelman (2011) was also in favor of changing ODA, 
calling for its extension by focusing on the total net expenditure of all development aid efforts, including private flows. A new tool for measuring development aid efforts was proposed by W. Hynes and S. Scott under the name of Official Development Effort. This mechanism would consist of a development grant and a licensed loan component (i.e., additional government guarantees) established when signing a loan agreement (Hynes, Scott, 2013, p. 16). The novelty of this proposal was that ODA would exclude any subsidies for national development programs, including the maintenance of refugees, education of students from developing countries and the promotion of knowledge about development problems.

Generally speaking, the proposed changes under ODA concerned three main areas:

1) increasing financial commitment for development;

2) expanding the group of participants in the development aid system;

3) introducing more discipline in ODA expenditures.

Ad. 1. The failure to meet the goal of increasing the annual level of ODA to $0.7 \%$ of GNI by 1975 and, at the latest, by 1980, is cited as the main reason for raising ODA expenditures (Pearson Commission) (Report..., 1969, p. 18, History of ..., 2000, pp. 3-11; Roodman, 2014, pp. 3-4). Although, since the launch of the ODA, aid expenditure has been systematically growing in absolute terms, but the amount of expenditure calculated as a percentage of the GNI of the donor countries has decreased, which in fact has shown the diminishing scale of their involvement in development aid. Not counting the first years after World War II, when aid expenditure exceeded $1 \%$ of GNI, since the 1970 s this indicator was less than $0.4 \%$, while in the 1990 s it fell below $0.3 \%$ of GNI (Figure 1 ).

Figure 1. DAC Members' ODA as per cent of GNI, 1960-2017

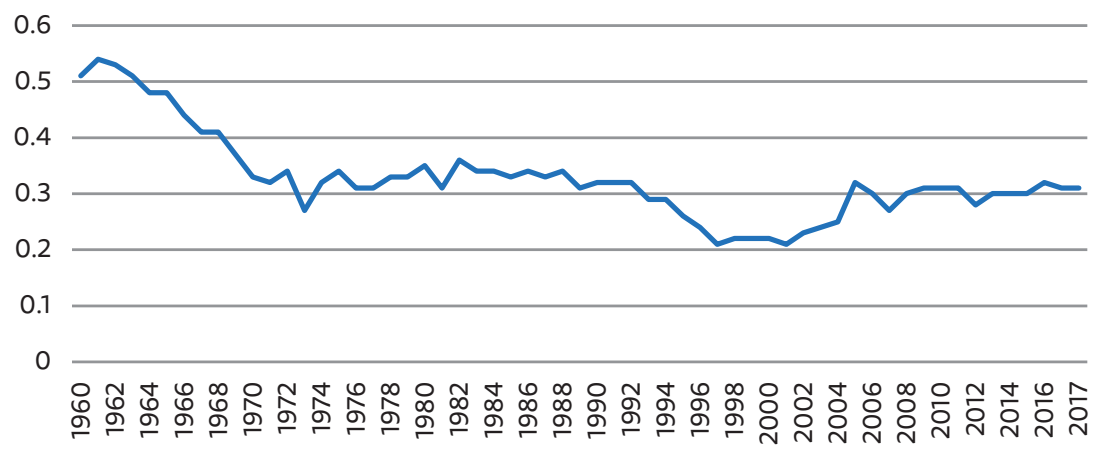

Source: OECD, 2018e.

The real value of development aid grew from the 1960s to 1992, when it reached the highest level. However, since 1992, the volume was systematically falling, which 
meant that in real terms (taking into account inflation and fluctuations courses) in 1997, it was $23.7 \%$ lower than in 1992. The reason for the collapse was the end of the Cold War and new problems in domestic politics and international relations faced by donors from the OECD-DAC. The importance of ODA as an instrument for the flow of funds to developing countries declined significantly. Improvement occurred after 2000 - measured in real terms, after adjusting for inflation and currency fluctuations, ODA doubled in 2016 and 2017 (an increase of over 102\%).

\section{Figure 2. ODA Volumes of the DAC Members, 1960-2017} (USD billion, 2016 Constant Prices)

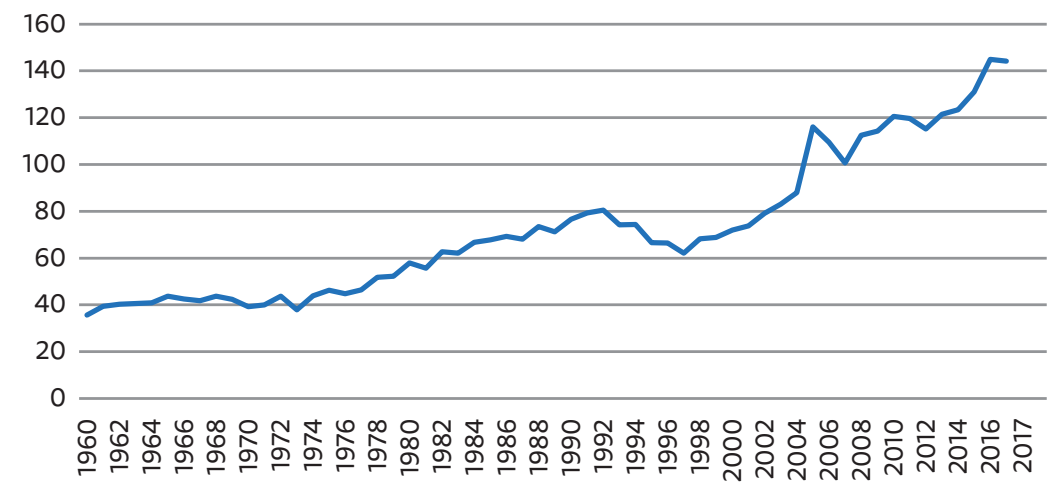

Source: OECD, 2018e.

In 2017, ODA amounted to USD 144179 billion, a slight decrease of $0.6 \%$ after adjusting for inflation and exchange rate fluctuations compared to the previous year. This means that in 2016 ODA reached the level of USD 144965 billion and it was an increase by $8.9 \%$ compared to 2015 , when the volume was nearly USD 131 billion (Figure 2). The reason for the hesitations was the refugee crisis in the countries of the European Union. Although the increase in aid to refugees in countries, donors increased the total amount of aid, but even without taking these costs into account, the total ODA in 2016 increased by 7.1\% (OECD, 2018c). The level of transfers to LDCs has also changed. In 2016, bilateral aid to LDCs decreased in real terms by $3.9 \%$ compared to 2015, but already in 2017 it increased by 3\% (OECD, 2018c). In 2017, the average aid volume rate for all DAC members was $0.31 \%$ of GNI (Figure 3 ).

The majority of members do not meet the $0.7 \%$ GNI, which has been recognized as the official target of achieving the optimal level of aid to developing countries. In 2017, this requirement was met only by Sweden (1.01\%), Luxembourg (1\%), Norway (0.99\%), Denmark (0.72\%), and the UK (0.7\%) (Figure 3). Although the $0.7 \%$ GNI target is controversial and there are conflicting opinions, it remains the 
binding purpose for increasing development aid (Clemens, Moss, 2005; Kopiński, 2011). The United States, Germany, the UK, Japan, and France traditionally provide the largest amounts of ODA resources in terms of value. However, in this group of countries, in 2017 only the United Kingdom reached the threshold of $0.7 \%$ of GNI. A year earlier, this criterion was also met by Germany (OECD, 2018e).

Figure 3. ODA Grant Equivalent as Percent of GNI, DAC Member Countries, 2017

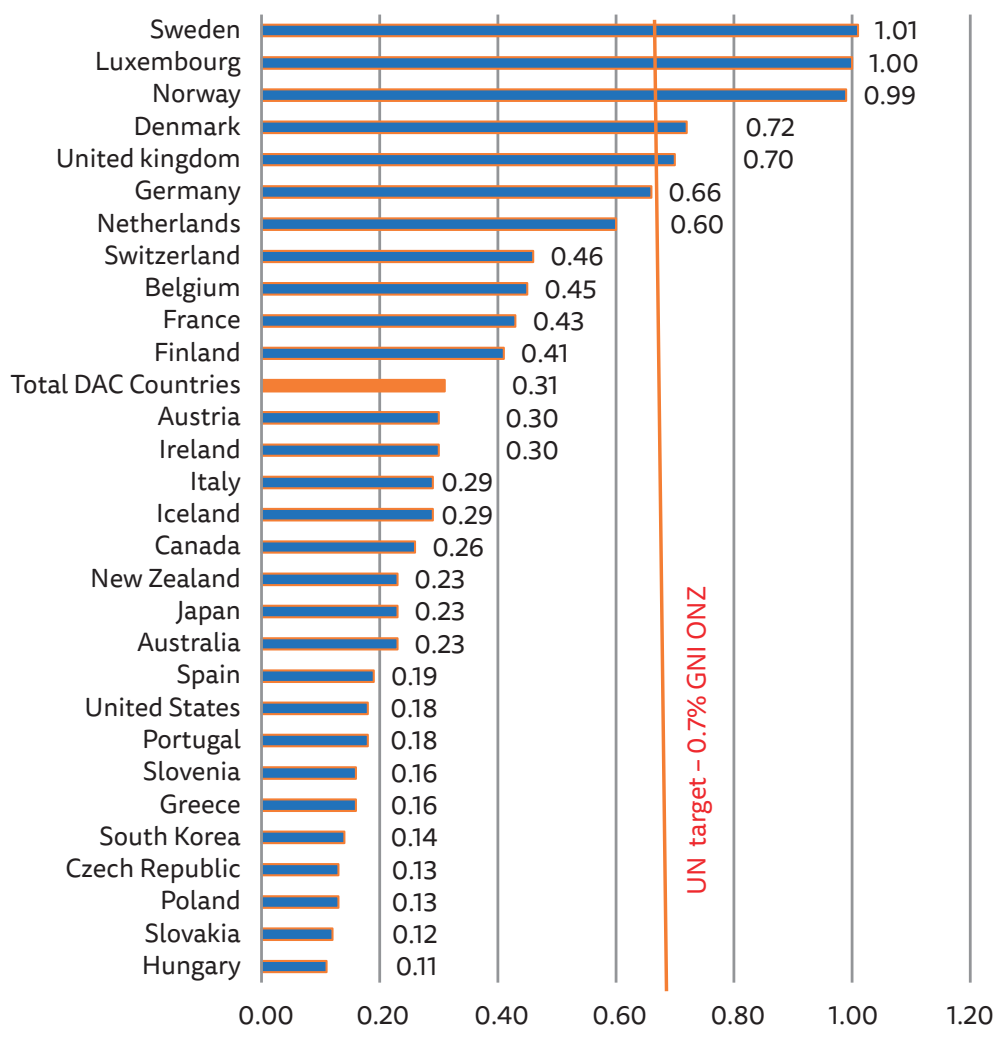

Source: OECD, 2018e.

Ad. 2. States or institutions on the official OECD-DAC lists are not always able to effectively carry out the tasks assigned to them. Hence the need to expand the group of official aid donors and recognize the importance of entities in the development aid system, such as NGOs, representatives of the private sector, countries that are not members of the OECD-DAC, as well as recipients of development aid. In line with the ODA objectives, the donor may be a governmental institution of the donor country (including local government), as well as an international governmental organization. In practice, this term ceased to refer only to traditional aid donors, 
concentrated in the DAC, and began to include other countries and institutions that voluntarily reported the amount of their aid flows to the OECD-DAC. Among them, 20 non-DAC countries submit reports on their aid activities, including 10 providing the Committee with their own statistical statements, which are used by the OECD to generate expenditure forecasts. The developing countries, and thus the existing recipients of aid, also became aid-donors. This applies primarily to China, Brazil, India, Russia, Turkey, Mexico, but also Saudi Arabia, Kuwait, and the United Arab Emirates, whose importance in development aid is systematically growing. ${ }^{16}$ This issue complicates the hitherto arrangement of the aid system under the auspices of the OECD-DAC. The ODA index, which includes only the expenditures of the donors concentrated in the DAC, does not reflect the current state and dynamics of development in terms of real development aid. It is about transfers allocated for development purposes by China or the Persian Gulf states to African states. This means that their financial messages in this area are difficult to capture, hence they are most often presented in estimates (Table 2).

Table 2. Estimated Financial Flows of OECD-DAC Members and Selected Non-DAC Countries, 2012-2016 (Net Disbursements, Current Prices, USD billion)

\begin{tabular}{|l|c|c|c|c|c|c|}
\cline { 2 - 7 } \multicolumn{1}{l|}{} & 2012 & 2013 & 2014 & 2015 & 2016 & 2016 (\% of total) \\
\hline $\begin{array}{l}\text { ODA from 29 DAC member } \\
\text { countries }\end{array}$ & 127 & 134 & 37.5 & 31.6 & 144.9 & 86.9 \\
\hline $\begin{array}{l}\text { ODA from 20 reporting } \\
\text { countries, beyond the DAC }\end{array}$ & 6.1 & 16.3 & 4.6 & 17.5 & 14.5 & 8.7 \\
\hline $\begin{array}{l}\text { Estimated flows from } \\
\text { 10 non-reporting countries, } \\
\text { beyond the DAC }\end{array}$ & 5.6 & 6.8 & 7.0 & 6.9 & 7.5 & 4.4 \\
\hline $\begin{array}{l}\text { Subtotal flows from non-DAC } \\
\text { countries }\end{array}$ & 11.8 & 23.2 & 1.7 & 4.6 & 21.9 & 13.1 \\
\hline Estimated total value & 138.7 & 157.9 & 69.1 & 56.0 & 166.8 & 100.0 \\
\hline
\end{tabular}

Source: OECD, 2017b.

Among the non-DAC donor countries that report their aid flows to the OECD database, the United Arab Emirates recorded the highest ODA/GNI ratio in 2015, amounting to $1.12 \%$. The next place was taken by Saudi Arabia. For comparison, Sweden had the highest share of ODA/GNI among DAC members in the same year

16 Reports on state aid flows are regularly sent to the OECD-DAC by the following countries: Azerbaijan, Bulgaria, Croatia, Cyprus, Estonia, Israel, Kazakhstan, Kuwait, Latvia, Lichtenstein, Lithuania, Malta, Romania, Russia, Saudi Arabia, Thailand, Timor East, Turkey, United Arab Emirates. Due to the lack of precise data, estimates of development aid are prepared by the OECD for: Brazil, Chile, China, Colombia, Costa Rica, India, Indonesia, Mexico, Qatar, and South Africa (OECD, 2017b). 
- it amounted to $1.41 \%$ of GNI (Figure 4). The 2015 data is due to the relatively long period required for the OECD-DAC to collect information from donors outside the Committee.

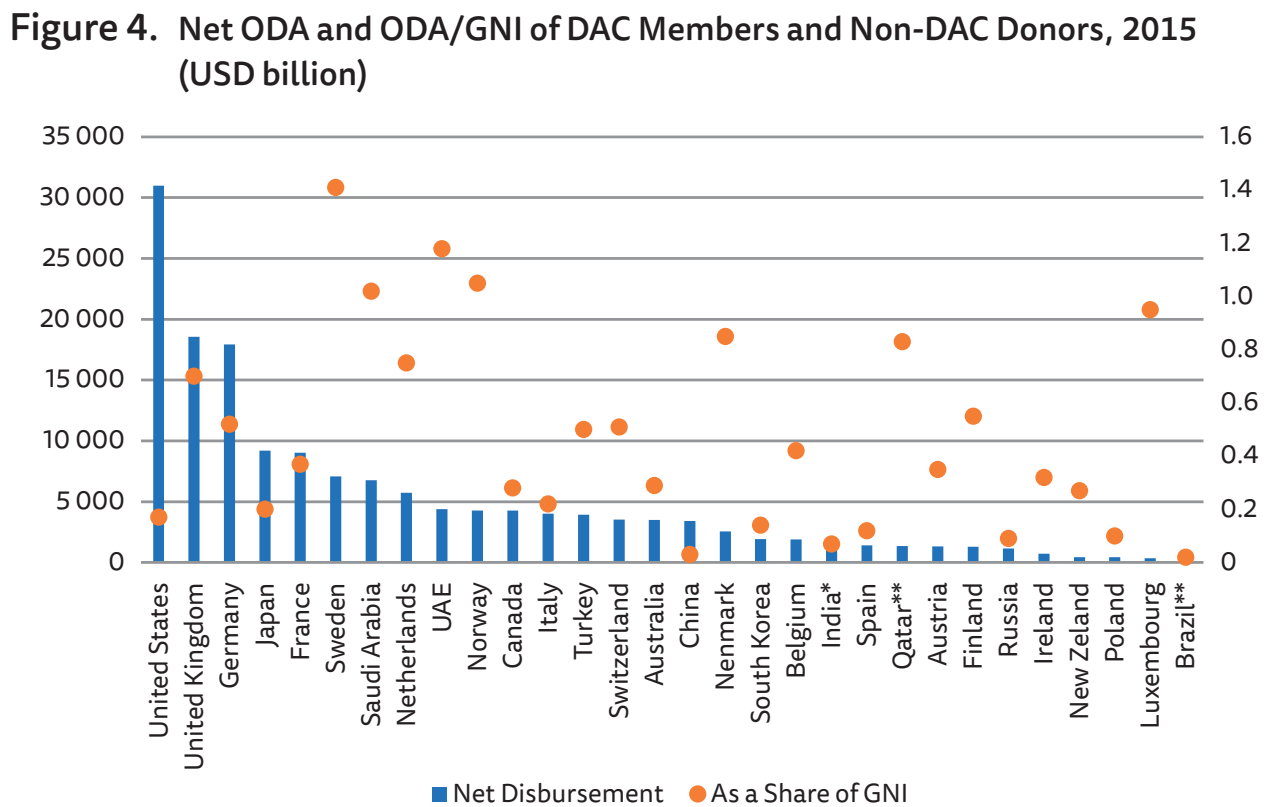

Source: OECD, 2017b.

One of the most dynamic factors changing the international aid system is the growing position of private philanthropic organizations and NGOs. This means that the state monopoly in the field of development aid has ended, and the NGO sector and private institutions have recorded an unprecedented development of their activities, both in terms of an increase in financial contributions, as well as new initiatives and forms of cooperation (Kharas, 2007a, pp. 2-3). Development NGOs, such as Oxfam, Care, Save the Children, have become one of the most important institutions deciding on the shape and directions of aid. Like private philanthropic organizations, multinationals, family businesses and other institutions, they have achieved an unprecedented position as equal partners to states and NGOs. Their importance and role in debates and practice of development cooperation is evidenced by the adoption at the OECD High-Level Forum (HLF-4) in Busan in 2011 of the global initiative to increase the effectiveness of development cooperation (Global Partnership for Effective Development Cooperation).

The total value of aid grants provided by private entities (corporations, family businesses, philanthropic institutions, and other non-profit) and NGOs from DAC 
countries has been increasing since 2000. In 2017, their contribution to development assistance amounted to over USD 40.4 billion. This meant a fourfold growth compared to 2000. The data submitted to the OECD were classified as grants which were defined as transfers made by private voluntary agencies and NGOs in cash, goods or services for which no payment was required (Figure 5).

\section{Figure 5. Development Aid Grants by Private Sector and NGOs in DAC Countries, 2000-2017 (million USD)}

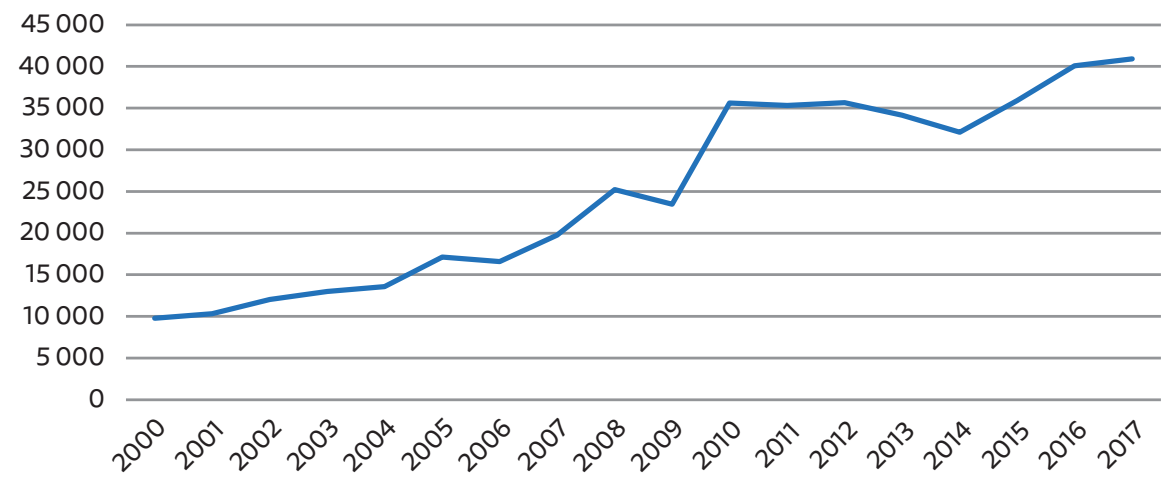

Source: OECD Data 2018.

Private sector financing for development is gaining importance. This is especially true of private philanthropic foundations, which play an increasing role in finding innovative ways to promote it. ${ }^{17}$ Most philanthropic foundations come from the United States and Canada (77\%), the rest from Europe (18\%) and other regions of the world (5\%). ${ }^{18}$ The most generous in 2013-2015 were philanthropic foundations: Bill \& Melinda Gates Foundation, Children's Investment Fund Foundation, Susan Thompson Buffett Foundation, and the Dutch National Postcode Lottery. Their share in financing development is shown in Figure 6.

In 2013-2015, private philanthropic institutions contributed over USD 23.4 billion in total to development cooperation (OECD, 2017c). Nearly half of this sum came from the Bill \& Melinda Gates Foundation, which provided a total of over USD 11.6 billion in that period. The largest foundations, most of which are American entities, spend

\footnotetext{
17 Philanthropic foundations are defined as non-profit organizations with non-profit ownership and their own funds, e.g., from donations, investments, dividends, lotteries, crowdfunding, and promoting social, educational, charitable or other activities (OECD, 2017c).

18 The first poll on private philanthropy was conducted by the OECD in 2003. In 2017, the survey was expanded, and the data came from 130 private philanthropic institutions. Most entities were registered in North America, the rest in the UK, the Netherlands, Switzerland, Germany and in India, Brazil, Mexico, Panama, China, the United Arab Emirates, and Africa (OECD, 2017c).
} 
over USD 3 billion annually on development aid (OECD, 2003a). The next places are occupied by representatives of the private sector and NGOs from Canada, Germany, and Switzerland (Figure 6).

Figure 6. The Largest Philanthropic Foundations per Region, 2013-2015 (USD million)

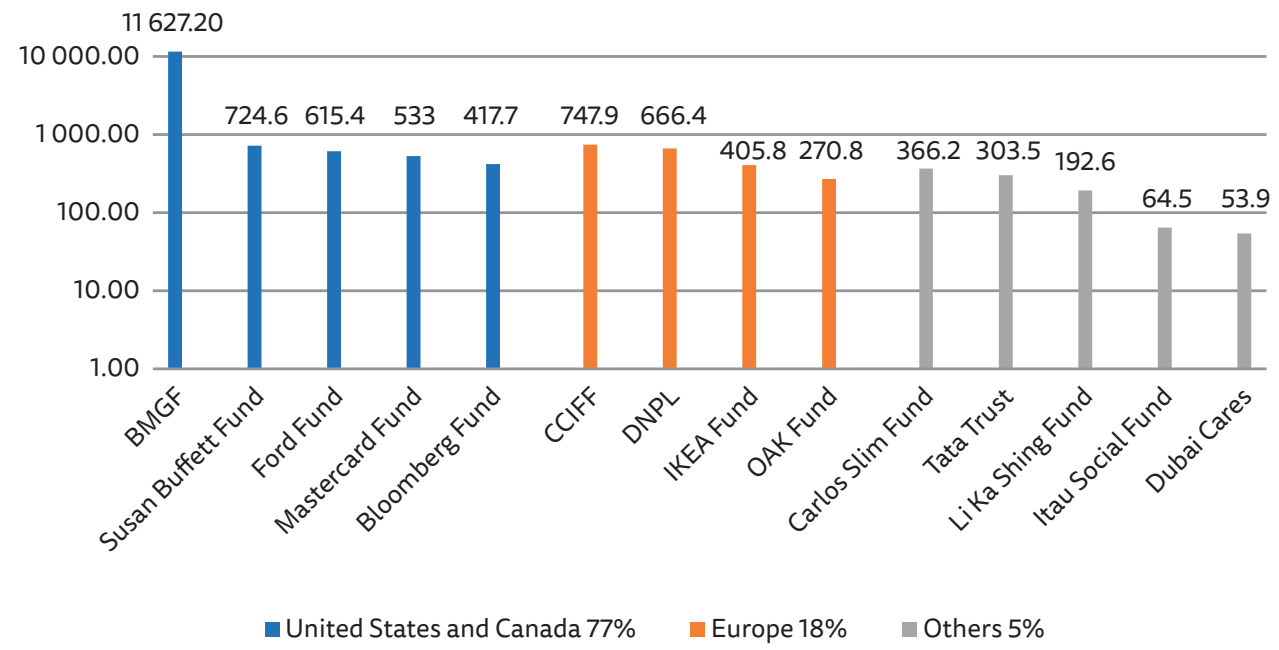

Source: OECD, 2017c.

Ad. 3. One of the most important ways to increase the effectiveness of aid is to introduce greater discipline related to ODA spending categories. Some categories of ODA raise doubts about the development motivations behind the decision to include them. These are costs that do not constitute real aid to the countries in need, as they do not have to result directly from the development policy pursued by a given country, and therefore may lead to abuses due to excessive spending of the donor state. Therefore, the real expenditure on development aid may be overestimated, which significantly affects the total amount of ODA (Kopiński, 2011, p. 46).

The extension of ODA to additional expenditure took place in the 1970s and 1980s. Among the main donors associated with the DAC, the winning option was to include as many types of transfers as possible to developing countries. As a result, such items were classified as development aid which were not direct aid, but constituted part of the expenses related to its service. 
Figure 7. Components of DAC Countries' Net ODA, 2000-2017 (USD million, 2016 Constant Prices)

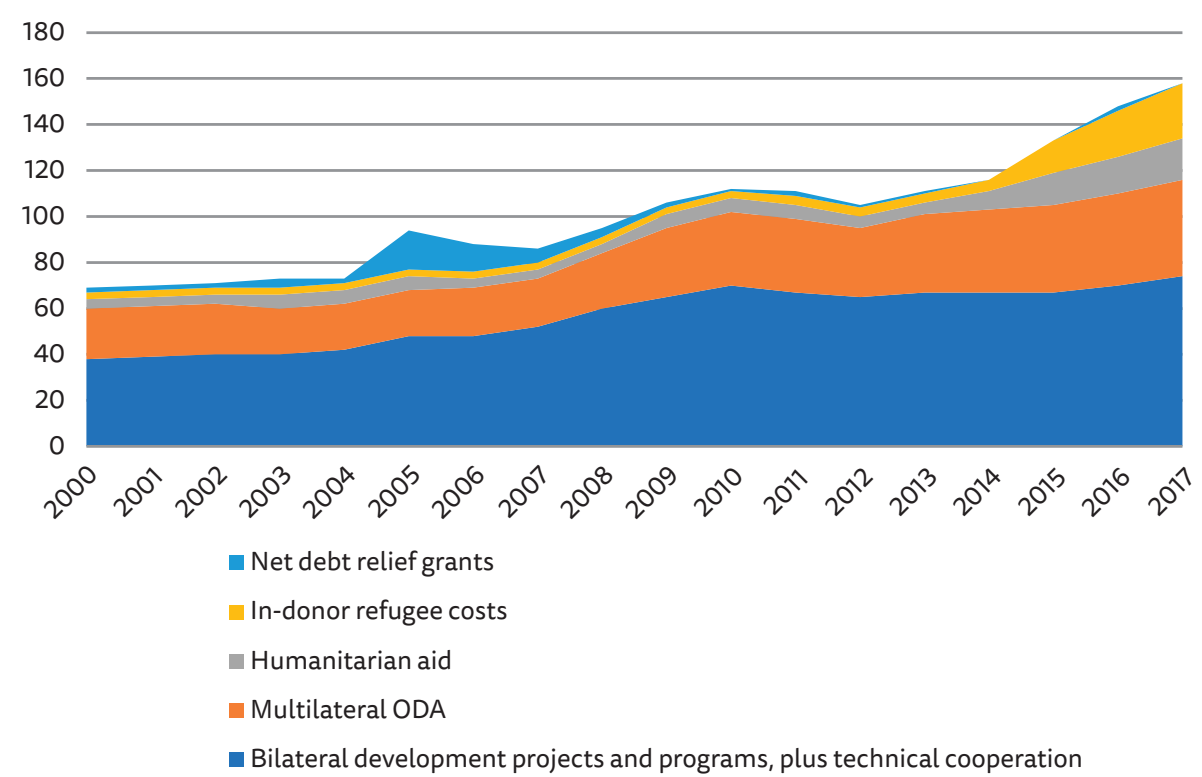

Source: OECD, 2018c.

ODA currently includes the following categories of aid.

1. Administrative costs - the category has been operating under ODA since 1979. It includes the charges related to the provision of assistance, which include, inter alia costs of operating program aid, staff salaries or expenses related to the maintenance of aid organizations (including the administrative budget). Due to the different practices and accounting (depending on the method of aid management), these expenses are difficult to compare between individual DAC members, not to mention other donors (Hynes, Scott, 2013, p. 8). In 2014 and 2015, the administrative costs of all DAC members exceeded USD 8.5 billion, which accounted for over $6.5 \%$ of the total ODA (OECD DAC). According to the critics of the ODA, this situation leads to the expansion of the bureaucratic apparatus and the need to constantly increase expenditure on development (Kgaras, 2007a, p. 10; Roodman, 2015, p. 4).

2. Expenditure on scholarships for students from developing countries - this category was included in ODA in 1984. It contains funds that normally remain in the donor country, making their contribution to improving social and economic conditions in developing countries not obvious, especially when recipients remain in the donor country. Expenditures for educational purposes of students 
from developing countries are justified only when these people return to their home countries and take up employment in them (Hynes, Scott, 2013, p. 9). Otherwise, such action does not necessarily contribute to development in the countries of the South.

3. Costs of maintaining refugee camps up to 12 months after arrival - this category was classified as ODA in 1988, even though it is hardly be considered a direct contribution to development and welfare in a developing country. The increase in the inflow of refugees to EU countries between 2014 and 2016 contributed to the increase in total ODA (Figure 7). The expenses related to the stay of refugees in DAC countries in 2017 amounted to USD 14.2 billion, which accounted for $9.7 \%$ of total ODA. It was a decrease by $13.6 \%$ compared to 2016 , when the share amounted to $11 \%$ of the total ODA. ${ }^{19}$ The problem of the influx of refugees has affected the increase in ODA expenditure, primarily in EU Member States, although 13 of them indicated that spending on refugee-related purposes came from sources other than the budget allocated to ODA (OECD, 2016b, p. 152).

4. Technical assistance or technical cooperation - this is a category of expenditure on development aid, which is defined differently depending on the institution. In the terminology of the WTO and the World Bank, the terms technical assistance and technical cooperatio ${ }^{20}$ are used interchangeably. The $\mathrm{OECD}^{21}$ and the $\mathrm{EU}^{22}$ define it differently. Between 1999 and 2000, the average volume of DAC members' total technical cooperation expenditure amounted to less than USD 13 billion. In 2016 the total amount of support for bilateral projects, programs, and technical cooperation increased by $3 \%$, hence their total share in net ODA decreased from 58\% for the period 2010-2012 to 49\% in 2016 (Figure 7). In 2017, total support for bilateral programs, projects and technical cooperation increased in real terms by $4 \%$ and accounted for $51 \%$ of total ODA (OECD, 2018c). Although this category consumes a large portion of ODA spending, it

19 In 2014, before the refugee crisis, in the European Union the share of costs in total ODA was 4.8\% (OECD, 2018c).

20 According to the definition of the World Bank, technical assistance is understood as the transfer or adaptation of concepts, knowledge, practices, technologies or skills conducive to economic development. The objectives of the WB technical assistance are classified as follows: a) policy development, b) institution building, c) capacity building, and d) support for projects or programs (Managing Technical..., 1997; Arndt, 2000, p. 141).

21 Technical cooperation can be carried out in at least two ways: by grants targeted at citizens of the countries receiving development aid in the form of educational and training activities, and by funding consultants, advisers, teachers, and administrative staff serving in developing countries. This also applies to financing the purchase of equipment and devices (OECD, 2001).

22 The European Commission made a similar distinction between the two terms. It treats cooperation as a much broader term, encompassing all activities aimed at increasing human and institutional capacity through the transfer, adaptation and use of knowledge, skills, and technology. Technical assistance is a narrower term and concerns the implementation of specific tasks. It refers to the activities of personnel involved in the implementation and management of technical cooperation (European Commission, 2008, p. 7). 
appears to be one of the more legitimate and necessary items. In case of the WTO, which will be analyzed later, it is of fundamental importance in the context of its engagement in development cooperation.

5. Debt relief - this category includes the cancellation of financial liabilities that are not ODA loans, i.e. liabilities under HIPC and export credits and loans, including for military purposes. Since 2000, there has been a dynamic increase in the debt relief of developing countries, which has resulted in a significant increase in net ODA spending for some donor countries, even though it did not entail any financial transfers (Roodman, 2014, pp. 5-6; Severino, Ray, 2009, p. 18). In 2005 and 2006, a high level of debt relief was recorded, constituting over $20 \%$ of the total net ODA (Figure 7). This was mainly due to the mobilization of emergency measures to reduce the debt of Iraq and Nigeria (OECD, 2016a). For comparison, in 2015 , spending on debt relief amounted to $0.2 \%$ of the total net ODA, and in 2017 - approximately $0.34 \% .^{23}$

6. Research related to the problems of developing countries and aimed at increasing the awareness and knowledge of development issues concerning less developed countries - the category was included in ODA in 1979. These are national expenditures that are used to popularize development issues in order to gain public support for increasing expenditures for development purposes. The effects of these activities, which can be financed at the same time from sources other than ODA, are difficult to assess and verify (Roodman, 2014, pp. 5-6).

7. Humanitarian and food aid - the definition of ODA implies that funds should be used for purposes related to the long-term economic and social development of recipient countries. On the other hand, this expenditure is justified from a humanitarian point of view and is an indispensable element of support for LDCs and countries struggling with natural disasters. In 2017, humanitarian aid amounted to over USD 15.5 billion, which accounted for nearly $10.6 \%$ of total ODA. It was an increase of over 6\% compared to 2016.

Due to different practices in the donor countries, it is difficult to precisely define and distinguish between the various expenditures incurred for development aid purposes. It is about the transfer of funds to developing countries and the costs that are generated in the country - donors, e.g., scholarships for foreigners or maintenance of refugee camps. The line between these expenses is fluid. Military spending remains the most problematic. Despite the formal ban on including them in ODA, they were often treated in this way by some donors (e.g., debt cancellation or export credits

23 In 2016, they were higher by approx. $1.7 \%$ of the total ODA due to the cancellation of Cuba's debts (OECD, 2018c). 
for military purposes) (OECD, 1993). According to the definition, ODA should not include expenses related to military aid, conducting military operations, costs related to peacekeeping operations, and conducting research on nuclear energy. ${ }^{24}$

\subsection{Program Basics of Development Cooperation}

A turning point in the approach to development aid was the UN Millennium Summit and the adoption of the MDGs. Both donors and recipients recognized the need to adopt new aid delivery rules in order to improve its effectiveness and achieve development goals. The new approach was expressed in the formula of development cooperation, understood as greater activity and responsibility for assistance on the part of donors and recipients. New institutional solutions in this area were gradually developed at international conferences devoted to the issues of improving the effectiveness of aid delivery. The first, on financing for development, was held in Monterrey in 2002 under the auspices of the United Nations. Subsequent meetings with the participation of various stakeholders, state and non-state, were organized under the patronage of the OECD as part of the High-Level Forum (HLF). The first of the series of meetings took place in Rome in 2002 (HLF-1), next in Paris in 2005 (HLF-2), in Accra in 2008 (HLF-3), and in Busan in 2011 (HLF-4).

The purpose of the adopted provisions was to create a new form of development assistance based on cooperation and mutual recognition of the rights and obligations of all participants. According to the objectives, development cooperation should be characterized by the following features.

24 By means of multilateral agreements, it was decided that the following items should not be included in ODA: a) military aid expenditure (military equipment and services, military debt cancellation, anti-terrorist operations). The exceptions are costs related to the use of the armed forces of the donor country to protect and deliver humanitarian aid and the provision of relief services); (b) military costs related to peacekeeping operations. The exceptions are selected categories of costs related to peacekeeping operations approved and administered by the United Nations. This includes operations to protect human rights, observation of elections, assistance to demobilized soldiers, training of administrative personnel, including customs and police officials, economic stabilization consultancy, and carrying out weapons and mine clearance operations. Similar aid operations, but outside the UN, may also qualify as ODA, but do not qualify as peacekeeping operations; (c) expenditure related to nuclear energy as well as non-proliferation activities for military purposes. The exception is the use of nuclear energy for peaceful (civil) purposes. These may include expenditure on the construction of power plants, security systems, and medical use of radioisotopes; d) costs related to the organization of social and cultural programs, including those aimed at promoting the image of the donor state. The only exception are activities aimed at building the recipient's cultural potential, the criteria of which are specified in detail in the documents (OECD-ODA, Official...). 


\section{An effective development financing system}

In 2002, at the United Nations International Conference on Financing for Development in Monterrey, a document was adopted (Monterrey Consensus), in which the following actions were committed:

- mobilization of domestic resources in developing countries,

- mobilization of international resources, i.e., foreign direct investment (FDI) and other private capital flows,

- development of international trade,

- intensification of international financial and technical cooperation,

- reduction of external debt,

- solutions to systemic issues, i.e., increasing the coherence and consistency of international monetary, financial, and trade systems (Monterrey Consensus..., 2002).

The main problem raised in the debate was not so much the increase in additional funds for development aid, but the mobilization of existing national and international resources. The aim was to attract private capital to developing countries and create the right investment climate. It was about the development of credit and investment market, limiting the negative impact of short-term transfers and tied aid (Sobotka, 2008 , p. 5). As a result of transformation of international aid system, ODA ceased to be the dominant indicator of assessing financial flows to developing countries. It was largely overtaken by the growing volume of FDI, private funds, and workers' remittances. The estimated distribution of flows to developing countries is shown in Figure 8, where ODA includes both bilateral and multilateral transfers, and the "non-ODA" category means other official remittances as well as state loans, export, FDI, including grants on market conditions.

One of the more widely developed themes of the Monterrey Consensus is the area of international trade. Therefore, the WTO has an important role to play (Monterrey Consensus..., 2002). The close interdependence between international trade and economic development and poverty reduction, underlined in the adopted document, makes the integration of developing countries into the international trading system a priority task. Therefore, the Monterrey Consensus committed to modify the regulatory regimes affecting international trade in such a way as to allow developing countries to integrate more fully into trade. It was emphasized that trade liberalization may be an element of the sustainable development strategy in these countries, provided that it is conducted taking into account their economic situation. The biggest obstacles to reaping the benefits of liberalization are trade barriers, subsidies and other trade-distorting measures, especially in sectors with 
a high share of exports from developing countries, such as agriculture and textiles (Monterrey Consensus..., 2002, par. 28).

Figure 8. ODA and Other Financial Resources Directed to Developing Countries, 2000-2016 (USD million, 2016 Constant Prices)

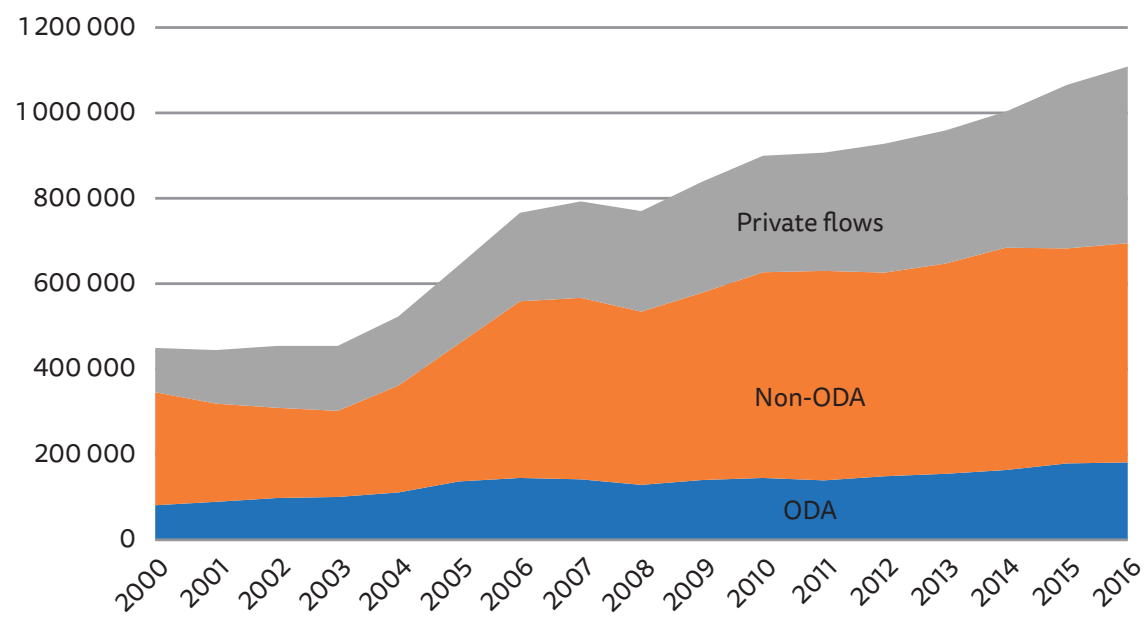

Source: OECD, $2018 f$.

\section{Dialogue and information exchange}

Mutual contacts between donors and recipients of aid should be based not on unilateral messages from donor states and multilateral organizations but on the active participation of all concerned. At the HLF in Rome in 2003, aid donors for the first time formally recognized the need to take into account the development needs of recipient countries. The Rome Declaration established the principle that each developing country defines its development priorities and goals so that aid programs are best suited to their needs (Rome Declaration..., 2003). In the newly emerging form of aid, the starting point for the size, type, and directions of support was to be the analysis of the needs of the recipient country. Narrowly understood development aid meant a constant, asymmetric system between the donor and the recipient, where the other party was usually passive and subordinated to the decisions of the former. In the new approach, the role and importance of the recipient state, which to a large extent depended on the amount, direction, and type of aid, was increased.

The basis of the new approach was the ownership concept, which is translated as the effective exercise of power by partners over their development programs, also when these programs are implemented in whole or in part with external financial 
resources. The implementation of this principle in practice requires agreement between donors and recipients of aid to define the roles and responsibilities of each party (OECD, 2005). Developing countries have been responsible for conducting their own development policy and actively creating development strategies, and donors have been obliged to support developing countries in implementing the principle of ownership, and thus respecting their development policies and strategies. In Rome, a discussion began on the harmonization and simplification of requirements for recipients, especially at the local level. Moreover, the recipients should focus on planning and implementing their own development strategies, and not on meeting complex requirements set by donors (Atwood, 2012, p. 5).

\section{Adapting the rules and regulations related to the provision of aid to the growing interdependence between highly developed and developing countries}

The goal of both recipient and donor countries was to achieve the best possible level of economic development, reduce poverty, and solve problems related to backwardness and underdevelopment (Bagiński, Czaplicka, Szczyciński, 2009, pp. 13-14). The idea was to create effective economic cooperation, based not on a charity structure, but on mutual interests, such as opening markets and counteracting protectionism (UNDP, 1994). In this system, developing as well as highly developed countries were equally interested in providing development assistance. It was about achieving long-term goals such as security, stability, and sustainable development. The implementation of these tasks was reflected in the adoption of the Paris Declaration in 2005 (Paris Declaration..., 2005). The most important from the point of view of increasing the effectiveness of aid were:

- the principle of ownership, which means that developing countries themselves determine their development strategies;

- the principle of alignment of aid to recipient development strategies, which means that aid donors support development strategies devised by developing countries and implement support through local institutions;

- the principle of donor harmonization, which implies that aid donors coordinate their activities and procedures and share information to avoid duplication of activities;

- the principle of managing for results, where donors and recipients of aid are responsible for the results of their activities, which is to lead to better management of funds and improvement of the decision-making procedure aimed at the implementation of planned activities; 
- the principle of mutual accountability, which consists in the fact that both donors and recipients are responsible for the implementation of aid activities, thanks to which both parties would identify themselves more with the programs undertaken and gain social support.

Detailed proposals of measures included in the Paris Declaration were to contribute to the improvement of aid effectiveness. All commitments (56 in total) were to be implemented at the national level and take effect from 2010. Additionally, 12 indicators were included to control and evaluate progress in areas important from the point of view of providing assistance, including such as the predictability of aid transfers, the use of the recipient countries' administrative and financial systems in the first place, or the activation of actions at the local level in the recipient countries. ${ }^{25}$

\section{Streamlining the channels and methods of providing and implementing development aid}

For this purpose, a set of measures was adopted concerning the harmonization and coordination of aid programs between donors, as well as reduction of operating costs, decrease of tied aid, better use of aid by recipient country and improvement of evaluation systems. Relevant provisions were included in the Accra Agenda for Action adopted in 2008, which also developed some provisions of the Paris Declaration (Accra Agenda..., 2008). For instance, changes in relationship between donors and recipients of aid were to be made thanks to the inclusion of certain common operating practices. The most important ones included: using the distribution channels and systems of the partner country in the first place, applying the principle of predictability and transparency of behavior in order to help recipients plan and implement development strategies, defining conditions for providing aid together with recipients based on their own development plans, moving away from tied aid, avoiding aid fragmentation by introducing the principle of division of labor between donors (Accra Agenda ..., 2008, points 6-26).

25 The Paris Declaration adopted 12 indicators that were supposed to contribute to improving the effectiveness of aid. The implementation date was set for 2010. The indicators were to be used at a national level and monitored by external institutions. The set includes the following elements: indicator No. 1 - partners have operational development strategies (ownership), indicator No. 2 - responsible country system (alignment), indicator No. 3 - aid flows are aligned on national priorities (alignment), indicator No. 4 - strengthen capacity by coordinated support (alignment), indicator No. 5a - use of country public financial management systems (alignment), indicator No. 5b - use of the country procurement system (alignment), indicator No. 6 - strengthen capacity by avoiding parallel implementation structures (alignment), indicator No. 7 - aid is more predictable (alignment), indicator No. 8 - aid is untied (alignment), indicator No. 9 use of common arrangements and procedures (harmonization), indicator No. 10 - encourage shared analysis (harmonization), indicator No. 11 - results-oriented frameworks (managing for results), indicator No. 12 - mutual accountability (mutual accountability) (Paris Declaration..., 2005; Accra Agenda..., 2008, pp. 910). 


\section{Recognition of non-governmental organizations and the private sector as equal and independent partners in development policy}

The importance and role played by these participants in the international aid system was confirmed at the Fourth High-Level Forum (HLF-4) in Busan (South Korea) in 2011. The introduction of permanent changes to the international aid system was confirmed in the initiative on the Global Partnership for Effective Development Cooperation, adopted at that time. The Global Partnership concept is based on the Paris Declaration and on the common global rules for monitoring progress (OECD, 2012c). The partnership formula referred not only to the relationship between donors and recipients, but also to building cooperation between traditional donors (DACs) and participants from NGOs and the private sector. The aim was to create a new type of coalition of all governmental and non-governmental entities to jointly finance development. ${ }^{26} \mathrm{~A}$ total of 160 countries and around 50 governmental organizations and NGOs have signed the partnership agreement.

Progress in implementing the commitments has been very slow. Most of the goals and tasks have not been achieved. The main reason was the lack of political will on the part of traditional aid donors concentrated in the DAC and insufficient involvement of developing countries (OECD, 2012a). On the other hand, account should be taken of the wide material scope of the changes and the relatively short period since the Monterrey (2002) and Paris (2005) documents were adopted.

In the OECD review study Aid Effectiveness 2005-2010: Progress in Implementing the Paris Declaration, it was found that only one of the 12 goals to be fulfilled by 2010 was achieved (OECD, 2011a). It was an improvement in the level of coordination of technical cooperation between donors, and thus an increase in the compliance of aid programs with the national development strategies of the recipient countries (indicator 4) (OECD, 2011a). Despite some progress in the implementation of the ownership principle, serious problems of developing countries with "translating national development strategies into sectoral strategies and operational programs" were identified (Bagiński, Kowalska, 2010, p. 121). There has also been little success in reducing tied aid (indicator 8 ) and in harmonizing aid, especially in carrying out a verification of the measures taken (indicator 10) (UNDP, 2011).

26 For these activities, a steering committee of 18 representatives from all participating parties was established. The committee was chaired by three co-chairs from the group representing traditional donor countries, recipient donors and recipient governments. Civil society organizations, parliamentarians, and the private sector obtained their representatives (First High-Level..., 2014). 
Along with the debate on program changes regarding development aid, including the goals and principles of the support provided, there is a discussion on how to increase the effectiveness of financing development tasks. In line with decisions made at three UN conferences on financing development (Monterrey in 2002, Doha in 2008 and Addis Ababa in 2015), a commitment was made to intensify activities in order to increase resources for the achievement of the Sustainable Development Goals. Therefore, it was recommended to mobilize public resources domestically, stimulate the resources of the private sector at the national and international level, as well as intensify activities under international development cooperation between various multilateral institutions (Addis..., 2015).

\subsection{Summary}

The process of working out a new formula of development aid, which began in the late 1990s, resulted from the worldwide criticism of the then forms, methods, and quality of providing aid. The previous formula of aid was not conducive to the coordination of development policy between donors and was detached from other state policies, such as trade, agriculture, or industry. The new approach to aid was about adopting solutions that would benefit developing countries in order to integrate them into the world economy by taking more responsibility for creating their own development strategies.

As a result of the global debate and arrangements between development aid stakeholders, a concept based largely on a comprehensive approach to development emerged. The focus of the debate has shifted from the question of the amount of aid to the question of development. The new approach, expressed in the Global Partnership agreement (Busan, 2011), assumed a move from the issue of aid effectiveness to the issue of development effectiveness. This entailed the coordination of economic policy areas that affect the design and implementation of development aid, i.e., trade, finance, social policy, and the expansion of the group of aid donors to include new participants. In this case, it was primarily the non-governmental and private sector as well as developing countries belonging to the group of emerging economies, i.e., China, Brazil, and India. The aid element that appeared in cooperation between the countries of the South (South-South cooperation) influenced the global system of development aid, changing its previous framework shaped by the OECD-DAC.

Conceptual changes in the approach to development aid made it necessary to modify ODA. However, making permanent changes is not a simple task. ODA remains the basic indicator for tracking and assessing the amount of funds allocated 
to development aid. Nonetheless, other financial flows to developing countries managed to outstrip the volume of ODA transfers. These include increasing FDI flows and private debt and remittances of economic migrants. However, the change in international conditions and the approach of traditional donors led to the modification of some elements of ODA, in particular to a reduction in the amount of expenditure that did not constitute real aid, and therefore was not transferred directly to the recipient country. Consequently, in order to reduce this type of investment, resources have been concentrated or controlled in the donor countries. This mainly concerned technical assistance and administrative expenses.

The new approach in the formula of development cooperation was based on the belief that the key to achieving better results is to focus on increasing the effectiveness of development aid. This is evidenced by empirical research on the impact of aid on economic growth and poverty reduction (Addison, Morrisey, Tarp, 2017, p. 988). The hypothesis of C. Burnside and D. Dollar (1997) assumed that the effectiveness of aid depends directly on the quality of economic policy, so aid has a positive impact on economic growth in the environment of a well-conducted economic policy (Hansen, Tarp, 2000, p. 387). Although the claim was questioned, it had significant implications for attempts to introduce changes to the international aid system. Information on the research was widely commented on by the media and eagerly quoted in reports of international institutions advocating increasing funding for development programs (Easterly, 2003, pp. 24-26). This was due to the international community's need for strong evidence that the aid is bringing the expected benefits (How to make..., 1999). The most adequate statement in the context of the research on aid effectiveness is that of P. Samecki that the impact of the effects of aid on economic results differs depending on country and sector (Samecki, 1997, p. 98).

One of the research streams pointing to the possibility of confirming the positive impact of aid on economic growth was the concept of complementary policies. According to its objective, trade, and more specifically trade liberalization, was to play a decisive role in the process of changes leading to the improvement of macroeconomic indicators in the recipient countries. The idea was that the importance of trade grew and so had an impact on economic growth and poverty reduction with the introduction of economic reform package. Therefore, the research focused on the analysis of the channels of influence on trade, such as the promotion of investments, productive capacity, institutions, and regulations.

The result of the debate on the shape of development cooperation and how to increase its effectiveness are the following conclusions:

- firstly, there are no clear guidelines on how to increase the effectiveness of development aid; this is confirmed by empirical studies on the impact of aid on 
growth and poverty reduction; the solution is neither the mechanical application of aid allocation rules nor a single case study to guide decision makers;

- secondly, development aid is an ambiguous concept, it is based on various assumptions and criteria, which result to a large extent from the priorities of the donors' development policy; with the introduction of the principles of the Paris Declaration and the provisions of the Busan HLF, this approach is changing to pay more attention to the interests and needs of the recipient states;

- third, ODA is the dominant, but not only, criterion for assessing development aid; therefore, efforts were made to modify its formula in line with the decisions on increasing aid effectiveness and the international debate on the implementation of the Sustainable Development Goals;

- fourthly, the effectiveness of aid depends on many factors that have different impacts and strengths depending on the country, region, social capital, institutions, and economic potential; the direction of changes is set out in the goals of increasing the effectiveness of development aid adopted in the Paris Declaration and in practice implemented under the Aid for Trade program;

- fifth, aid should be provided in such a way as to meet development needs of recipient countries; therefore, the approach in the development cooperation formula was based on the belief that the key to achieving better results is to increase the effectiveness of development cooperation, and not only the effectiveness of aid delivery; in line with the provisions of the Busan HLF, the main objective is to strengthen the role of aid as a complement to other sources of development financing (from aid effectiveness to effective development cooperation) (OECD, 2012c); aid by itself cannot break the poverty cycle, and development cooperation should therefore act as a catalyst to mobilize resources to achieve development goals.

Poor results in implementation of specific indicators included in the documents from Paris and Accra do not completely invalidate the achievements related to the transformation of international aid system. The most important factors showing the direction of the evolution of international development cooperation include the growing role of aid in the development of South-South economic cooperation and the significant increase in the importance of non-state entities in the process of introducing changes to the aid system, mainly NGOs and the private sector. 



\section{Chapter 2}

\section{MULTILATERAL AID}

The multilateral aid system is becoming more and more complex. The circle of entities offering and receiving aid is expanding, and the number of ways and channels of its transmission is growing. According to the OECD, the multilateral aid system consists of around 263 international organizations and funds (OECD, 2017a). Institutions on the official OECD-DAC list of institutional donors are eligible to provide ODA. Apart from it, there is a large group of other multilateral entities that form the system of multilateral development cooperation. The WTO is a specialized multilateral organization linked to the UN, although it maintains farreaching separateness. It participates on an ad hoc basis in the work on financing and development of the UN General Assembly and the Economic and Social Council (ECOSOC). In matters relating to development and aid issues, the WTO actively cooperates with multilateral organizations, especially those with an economic profile (primarily the World Bank and the IMF). This is due to its statutory functions defined in the Agreement establishing the WTO as well as joint development aid initiatives such as the AFT, the EIF or the TFAF.

The WTO is one of the elements of the multilateral aid system and is subject to ongoing changes in it. The chapter tries to identify the types of these changes, the main trends and their impact on increasing the effectiveness of aid. An attempt was made to analyze and evaluate the most important components of the process, which include multi-bi measures, the phenomenon of bilateralization of multilateral aid, and the growing importance of funding channels such as trust funds.

The main manifestation of changes in the multilateral aid system is the departure from funding channels based on a simple division of aid into bilateral and multilateral forms. Traditional forms of development aid have lost their importance, while the earmarked or multi-bi resources sent to or through multilateral institutions are playing an increasing role. The dynamic surge in the inflow of multi-bi funds resulted 
in the emergence of a new category of aid known as multi-bi aid. Contrary to funds directed to the main budget of the institution (core), this type of formula allows donors to allocate voluntary contributions for specific purposes relating to countries, regions, sectors, development issues, and thus, increases their impact on the allocation of aid. It is a relatively new means of financing aid, beneficial above all from the donor's point of view, as it makes the aid more visible to the citizens of the donor countries and allows the funds to be kept under control. The situation with regard to the impact of multi-bi financing on the operation of multilateral institutions is different. Their influence is ambiguous, which leads to the phenomenon known as bilateralization of multilateral aid.

Along with the increase in the number of entities involved in the provision of aid, the possibilities of creating instruments and mechanisms for financing programs and initiatives have broadened. Additional mutual funds have been mobilized to service the new multi-bi funding sources. These entities did not replace the existing ones but enlarged the group of participants in multilateral aid. As a result, the risk of duplication of the same projects, initiatives, and programs has increased, as well as the loss of the already damaged coherence of operation within international aid system. The aim of this chapter is to investigate and evaluate the operation of trust funds and the growing importance of multi-bi funding, as well as their impact on the degree of meeting development needs of less developed countries. Such funds, on the one hand, contribute to the organization's financial resources and allow it to carry out additional tasks, but, on the other hand, they may constrain the statutory activities of the organization.

\subsection{Multilateral Versus Bilateral Aid}

The theoretical analysis suggests that multilateral aid is superior and more preferable to bilateral aid. The choice of a multilateral institution is more conducive to achieving development goals than bilateral aid that is subordinated to foreign policy objectives (Alesina, Dollar, 2000, p. 33). This approach was inspired by research on multilateralism and institutions conducted by J.G. Ruggie and D. Rodrik (1993, pp. 6-14). Multilateralism entails coordination of behavior and reciprocity on the basis of generally accepted rules, which does not exclude the occurrence of some dispersed forms. The advantage of multilateralism over bilateral actions results from at least two factors, which include the informational function and the nature of the interaction between a multilateral institution and aid recipients (Rodrik, 1995, pp. 8-9). This means that first of all, institutions provide information treated as 
a public good, better than individual donors, especially when it comes to monitoring aid recipients. Second, the relationship between the multilateral organization and the aid recipient is less politicized and therefore more oriented towards the achievement of actual development goals. The more autonomy an organization has towards its members, the more effectively it can provide assistance, and thus make it independent of changes in the policy of the recipient country (Rodrik, 1995, pp. 13-15).

Multilateral aid is better received by public opinion in both the donor and recipient countries than bilateral aid. This is due to the principal-agent theory (PAT), which explains the motives behind the decision to choose a multilateral form. A multilateral institution limits the influence of national interests on aid-related activities (Milner, Tingley, 2011, pp. 6-7). In this model, the individual donor (principal) and the multilateral agent have different approaches regarding loss of control of funds and burden-sharing. The extent to which the preferences of a multilateral organization match the preferences of a single donor depends on the extent to which the loss of control over funds is a problem for the donor (Milner, Tingley, 2011, pp. 10-11). Considering the transaction costs that an organization has to incur in servicing individual donors, it remains unclear whether the increase in benefits for the donor may be greater than the loss of effectiveness at the level of a multilateral organization. While donor country governments may be inclined to use foreign aid to pursue their political interests, donor society may be more interested in meeting the needs of the recipient countries. Hence, multilateral institutions enjoy more trust than their own governments, which are more difficult to monitor. Multilateral institutions are accountable to their member states, and not to individual governments (Keohane, Macedo, Moravcsik, 2009, pp. 14-15). On the other hand, when the public is less favorable to foreign aid, governments allocate the greater part of their aid resources through multilateral channels (Milner, 2004, pp. 13-15).

In accordance with the terminology adopted by the OECD-DAC, aid provided to developing countries qualifies as multilateral ODA only if it meets two basic conditions. First, aid is directed to an international organization whose members are states represented by their governments, and some or all of the activities of a member state are subordinated to the achievement of development goals. Second, the contributions from the member states form a common budget from which development projects or programs are financed according to the organization's statute. These funds, paid to the organization, lose their national character, and decisions about their use are made by all interested members. Any other forms of ODA that do not meet these criteria are classified as bilateral aid (OECD, 2015, p. 24).

The bilateral form is the dominant way of providing assistance. It accounts for $72 \%$ of total ODA flows (OECD, 2015). Within the framework of bilateral aid, 
the choice of countries or regions covered by the assistance of a single donor state results from internal preferences of different nature (historical, cultural, economic, political, religious), which may be subject to fluctuations. This factor may be a serious limitation for third countries, as their inclusion in the aid system of a given state is conditioned by a change in its aid policy. In turn, for countries with close political and economic ties to a donor country, such a situation may guarantee the continuation of assistance. In such an arrangement, the donor can, in return, count on special treatment in the recipient's country, e.g., during tender decisions. As part of bilateral aid, the most frequently selected countries and regions are those with which the donor has had special historical or cultural ties, e.g., former colonies and dependent territories. Other factors that play a decisive role in choosing the recipient state are economic, trade, and religious considerations (Deszczyński, 2011, pp. 102-103).

Moreover, supporters of the bilateral option indicate that direct aid is more effective due to the fact that the donor knows the specifics of a country that is culturally and historically closer to it. There is a belief that bilateral aid is more accessible and easier to manage. This means that the conditions to be met by a potential beneficiary are less complicated than in the case of multilateral aid, and the operation of a project or program is less expensive and easier to carry out (OECD. What we know..., p. 5). The bureaucratic apparatus of an international institution consumes a greater administrative cost, which in turn leads to a reduction in the actual amount of aid directed to the recipient. On the other hand, some researchers indicate that bilateral aid is more fragmented than multilateral aid, i.e., it is characterized by a higher degree of dispersion of aid sources directed to the recipient, which increases bureaucracy, transaction costs, and may lead to corruption (Gulrajani, 2016, pp. 6-14). In the case of the bilateral form, there are various channels for the distribution of funds. They include the public sector, non-governmental sector, public-private partnership, and other entities (e.g., private agencies, consultancy). While two-way flows can be made through various channels, most bilateral transactions take place through public networks (Table 3). In contrast, multilateral flows, as defined by the OECD, can only be transferred through multilateral channels.

The overwhelming prevalence of bilateral aid in terms of funds provided over multilateral aid in global ODA indicates that donors continue to prefer this form of support to developing countries. This is mainly due to the widely held belief that bilateral aid is much more beneficial for a donor country because of its own political and economic interests. However, taking into account preference surveys in donor countries, satisfaction is greater with multilateral aid than with bilateral aid, even though it may contain more restrictive conditions (EC, 2010). Multilateral institutions 
are seen as more flexible, possessing valuable technical skills and knowledge in the field of development policy (OECD, 2011b).

Table 3. Types of Aid Distribution Channels

\begin{tabular}{|c|c|c|}
\hline Aid channel & First-level implementing partners & Examples \\
\hline \multicolumn{3}{|c|}{ Bilateral } \\
\hline Public sector & $\begin{array}{l}\text { - Donor governments (central, state, and } \\
\text { local institutions) } \\
\text { - Aid recipients (central, state, and local } \\
\text { institutions) }\end{array}$ & $\begin{array}{l}\text { - Development Ministry } \\
\text { - Ministry of Finance } \\
\text { - Ministry of Foreign Affairs }\end{array}$ \\
\hline Non-governmental & - Non-profit entities & $\begin{array}{l}\text { - Foundations } \\
\text { - Associations } \\
\text { - Cooperatives }\end{array}$ \\
\hline $\begin{array}{l}\text { Public-private } \\
\text { partnership }\end{array}$ & $\begin{array}{l}\text { - Private actors } \\
\text { - Bilateral and multilateral agencies }\end{array}$ & $\begin{array}{l}\text { - Development finance institutions } \\
\text { - Funds }\end{array}$ \\
\hline Other & - For-profit entities & $\begin{array}{l}\text { - Consultancies } \\
\text { - Think-tanks }\end{array}$ \\
\hline \multicolumn{3}{|c|}{ Multilateral } \\
\hline Multilateral & - Inter-governmental institutions & $\begin{array}{l}\text { - World Bank } \\
\text { - EU } \\
\text { - UN } \\
\text { - WTO }\end{array}$ \\
\hline
\end{tabular}

Source: own study based on Gulrajani, 2016.

In both cases - bilateral and multilateral aid - there are strengths and weaknesses. The effectiveness of the aid is determined both by factors related to the functioning of public and non-governmental institutions, as well as the training and qualifications of the administrative staff/ experts involved. Moreover, the type of aid depends on the purpose and recipient to which it is directed. For instance, in the case of natural and humanitarian disasters, when immediate action is needed, bilateral aid, i.e. aid targeted directly at the recipient is more effective. Decisions on its launching and transferring to the appropriate addressees are made faster and do not require a long procedure, which is often required in multilateral organizations. In the case of long-term aid activities, spread over the years, multilateral aid is better suited. Although its effects are hardly visible in the short term, the changes and reforms that may occur thanks to the multilateral support are systemic in nature and are more permanent.

The literature on the subject is dominated by an approach that favors multilateral institutions. In research on the effectiveness and allocation of aid, the most common claim is that multilateral entities are more altruistic than bilateral ones and that they pursue development goals more effectively (Maizels, Nissanke, 1984; Powell, Bobba, 2006; Headey, 2008; Easterly, Pfutze, 2008; Birdsall, Kharas, 2010, pp. 24, 32, 47). 
The multilateral form of aid is a better safeguard for the continuity of aid flows to recipient countries, although not necessarily the most preferred type for donors. The following arguments speak in favor of the expansion the scale of multilateral aid:

- relatively more representative share of states and greater resources; participation in a multilateral institution causes states to encourage each other to contribute funds; image and position of the state in international politics are important here;

- less dependence on the political and strategic interests of the donor states, which means more effective implementation of development needs of the recipient countries;

- long-term nature; the risk related to financing is lower, so theoretically the chance of achieving long-term goals increases, which gives certainty of financing and implementation of development strategies in recipient states;

- the ability to pool resources; development aid decisions are the result of agreement between members of the organization, which in turn result from a jointly planned budget; by pooling resources within an organization, donors share the effort of assistance, using their own experiences and knowledge; it allows for the expansion of aid both geographically (inclusion of countries that have not had aid programs so far) and in terms of problems (aid directed to new sectors of the economy);

- common response to global problems; directing funds to multilateral organizations allows donors to focus their attention on major global challenges and threats, as reflected in the Sustainable Development Goals (formerly MDGs) (OECD, 2010, p. 34);

- financing of global public goods; this is an example of the advantage of multilateral channels of aid over bilateral ones (Kharas, 2010, p. 59); international multilateral organizations increasingly recognize their respective role in the management and coordination of global public goods;

- implementation of large programs and projects; as part of multilateral activities, the chances of implementing multi-dimensional and costly aid programs that exceed the financial, administrative, and organizational capacity of an individual donor are growing; in the case of a joint initiative, the costs, as well as the responsibility for completing the task, are spread over a larger number of participants; in turn, oversight of the project by the entire organization gives a greater chance of its implementation;

- lower risk to the donor; due to the persistent difficulties with the implementation of aid programs or projects in developing countries, multilateral aid is more beneficial from the point of view of an individual donor; it tries to avoid costly and risky programs that an international organization might undertake; 
- greater benefits to LDCs; empirical studies show that LDCs perceive aid from multilateral sources as more stable due to the longer financing period (OECD, 2015, p. 156; Kharas, 2007b, pp. 10-11); for multilateral organizations, allocating funds to LDCs is a priority, but not always for bilateral donors; in 2011, DAC donors made a commitment to reach $0.15-0.20 \%$ of their GNI as part of ODA directed exclusively to LDCs (the initiative called Istanbul Program of Action for LDCs); in 2013, LDCs received nearly 41.9\% (approximately USD 17 billion) of multilateral ODA directed to developing countries; for comparison, in the case of bilateral ODA, the amount of funds for LDCs amounted to USD 30.2 billion in 2013, which accounted for $32.7 \%$ of the total bilateral development aid (UN, 2016a);

- less fragmented and divided as in the case of bilateral aid; aid channeled through multilateral organizations is avoidable duplication of programs and projects implemented for the same aid recipients and targeted at the same sectors (OECD, 2015, pp. 151-152).

As already mentioned, aid recipients overwhelmingly prefer multilateral donors. This tendency has continued since the Cold War, when development aid, especially in the bilateral form, was an instrument of ideological, economic, and political competition. In line with the research carried out in 2015 by two groups of researchers (R. Davies, J. Pickering and S. Custer, Z. Rice and others), ${ }^{27}$ respondents representing the recipient countries were much more satisfied with multilateral aid than with bilateral one, both in the case of DAC members as well as countries from outside this group. The distinguishing features of multilateral aid, which were identified in the first study, were the reduced conditionality of programs or projects, flexibility, the ability to respond to needs of the recipient countries, including the use of national systems, as well as professional knowledge, and technical skills (Davies, Pickering, 2015, pp. 46-48). On the other hand, in the second study, multilateral donors were recognized for their ability to handle large, long-term international programs and were perceived as a dominant and stable source of funding (Custer, Rice, Masake, Latourell, Parks, 2015, pp. 47-48). Respondents also pointed to the shortcomings of multilateral institutions. The criticism concerned mainly the duplication of national human resources of the recipient and the ineffective system of decision making and management. Moreover, the problem was the lack of transparency related to the running of the program or project, insufficient information, and poor communication between the donor and recipient. Difficulties also resulted from extensive bureaucracy (EC, 2016, pp. 196-198). These included centralization in donor decision-making and

27 In the first of the cited studies, respondents (administrators, practitioners) came from 40 beneficiary countries, and in the second from 126 countries. More: Davies, Pickering, 2015; Custer, Rice, Masaki, Latourell, Parks, 2015, p. 47; Andreopoulos, Campanelli Andreopoulos, Panayides, 2011. 
insufficient support for development of national human resources of the recipients. Moreover, in the case of DAC donors, there was a discrepancy between declarations within the framework of the national debate on aid effectiveness and the actual implementation of programs (Davies, Pickering, 2015, p. 33). In the case of donors who are not members of the DAC, their strength, according to the assessment of the recipients, was a limited degree of conditionality, and their weakness - the lack of transparency of procedures (Custer et al., 2015, pp. 47-48). As regards the issue of granting aid under certain conditions, the requirements of bilateral donors are often comparable or even greater in the case of aid provided by multilateral institutions (e.g., WB, IMF, EU). In turn, the transparency of operating procedures within the organization's international relations can be lowered thanks to increased bureaucracy. Therefore, due to the complex organizational structure, decision-making procedures or financing principles, the provision of assistance may be delayed and may not reach the people in need directly (Table 4).

Table 4. Multilateral Aid - Arguments For and Against

\begin{tabular}{|c|c|}
\hline \multicolumn{2}{|c|}{ Multilateral Aid } \\
\hline For & Against \\
\hline $\begin{array}{l}\text { - Economies of scale (lower aid costs by spreading } \\
\text { fixed costs among members of a multilateral } \\
\text { institution) } \\
\text { - Political neutrality and legitimacy } \\
\text { - Large scale of capital and knowledge resources } \\
\text { (know-how) } \\
\text { - Lower unit costs } \\
\text { - Provision of public goods }\end{array}$ & $\begin{array}{l}\text { - Complex institutional structure (bureaucracy) } \\
\text { - Lack of transparency } \\
\text { - Higher absolute costs and salaries } \\
\text { - Lack of accountability } \\
\text { - Lower efficiency associated with an extensive } \\
\text { organizational structure, lengthy decision-making } \\
\text { procedures and lack of operational transparency }\end{array}$ \\
\hline
\end{tabular}

Source: own study based on OECD, 2010.

There is no clear criterion for the division into supporters of the bilateral and multilateral form. Aid donors who show a similar course of action in foreign policy may prefer different forms of aid distribution. For instance, bilateral aid is the dominant form in France and the United States. The main premise for choosing such an option is probably the willingness to play a decisive role in international relations and the readiness to implement individual actions (Riddel, 2007, p. 55). On the other hand, the UK, Japan, the Netherlands, Germany, and Italy are states that show a strong commitment to multilateral aid. Poland is also one of them.

All members of the DAC (30 countries and the EU) emphasize their commitment to multilateral aid system and to the principles of development cooperation (OECD, 2015, p. 72). Some Committee members point out in detail the steps taken in this direction, while others only explain in general terms the importance of development 
cooperation through multilateral channels. The first group includes 11 countries (Belgium, Canada, Denmark, Finland, Switzerland, Austria, Germany, Portugal, Spain, Sweden, and the Czech Republic), which have a separate multilateral aid strategy in addition to the parallel general development policy agenda. The second includes countries (Greece, South Korea, Poland, Slovakia, and Slovenia), which do not have special strategies for multilateral actions (broken down into thematic and sectoral objectives), but assign them to general guidelines under development cooperation (OECD, 2015, p. 73). Regardless of general tendencies, the choice depends on international and domestic factors, i.e., donor's internal financial condition, their political concepts and foreign policy strategies (Lancaster, 2007; Lundsgaarde, 2013).

In the last decade, both forms of aid have come closer to each other, mainly due to the way in which financial remittances are allocated, referred to as earmarked or mixed funds (multi-bi). Defining financial resources as multi-bi, and therefore partially multilateral and partially bilateral, is due to the fact that they are directed to a multilateral organization, but the donor retains control as to the purpose for which they are intended. Therefore, the following common features of bilateral and multilateral aid can be distinguished:

- both forms of assistance are targeted at similar or the same regions and sectors of the economy; this is evidenced by empirical studies conducted by B. Reinsberg, K. Michaelow, and V.Z. Eichenauer (2014; pp. 2324; Annen, Knack, 2015);

- aid may be offered at various levels of preference, ranging from the grant-based funding to market conditions; however, in the case of bilateral and multilateral ODA, the relevant ODA criteria should be respected (donation component of $25 \%$ of the total amount);

- the implementing units are mainly public institutions (i.e., international in the case of multilateral aid and national in the case of bilateral aid);

- both channels are used in countries with similar development conditions, and often their scope of involvement covers the same countries and sectors;

- bilateral and multilateral donors take part in the same policy debates on development cooperation, e.g., at the G-8, G-20, OECD High-Level Forum on Aid Effectiveness, or within the UN system (Guljarani, 2016, p. 7).

The acceleration of the globalization processes resulted in the emergence of postulates to increase the importance and share of multilateral aid in the overall benefits of ODA. The effectiveness of development aid depends on the adoption of comprehensive development programs and strategies, and therefore decisions made jointly by many institutional entities. The need to extend multilateral aid had already appeared in a report by the Independent Commission on International Development Issues in 1980. It argued about the inevitability of changing the system 
and the need to build an international aid structure on a global scale. The Brandt Commission report warned that the large number of international organizations providing aid would lead to a fragmentation of activity, overlapping responsibility and competition between organizations (The Report..., 1980). It was also emphasized that problems that should be dealt with in an integrated manner are constantly transferred from one forum to another, each institution tries to maintain its status, even if its original goals were achieved (The Report..., 1980). This proves, on the one hand, the need for further identification of development problems and create appropriate programs to address them, and on the other hand, the overlapping tasks and dispersed responsibilities that are permanent feature of multilateral aid.

\subsection{Multilateral Aid System}

The multilateral aid system is the entire flow of funds or other resources directed to and through an international institution, aimed at assisting developing countries. It includes both financial transfers sent as ODA (multilateral ODA) and preferential (concessional) aid from institutions outside the ODA framework. Organizations eligible for ODA are included in the official list prepared by the DAC (List of ODA - eligible international organizations), which is reviewed and verified every year.

Another term used in the context of the multilateral aid system is that of the international aid architecture. It is usually formed by the ODA system, but also by all kinds of multilateral institutions that are not on the official OECD DAC list of institutional donors. This group also includes aid donors from developing countries (emerging economies), numerous non-governmental organizations (NGOs), private foundations and associations. Due to the multiplicity of entities and different methods of providing aid, this structure is dispersed and fragmented, which makes data on financial flows differently classified and difficult to compare. This is notably the case with the new aid financing instruments, such as multi-bi aid, but also with the numerous trust funds established to operate them.

Under the multilateral ODA, funds transferred to multilateral institutions are divided into two parts:

- core contributions;

- earmarked or non-core contributions, also referred to as mixed multilateralbilateral funds (multi-bi) (OECD, 2012b, p. 14).

The basic contribution is the main source of financing development tasks by the institution in accordance with its statute and purpose. The second type of funds transferred to multilateral institutions are earmarked funds, the destination 
of which is decided or co-decided by the donor, and therefore retains some control over them. In practice, they are classified as bilateral ODA. They remain under the donor's control, despite the fact that they are directed to the institution and, through it, transferred to the recipients.

To be classified as a multilateral institution within the meaning of ODA, certain criteria must be met (OECD, 2012b, p. 7):

- conducts all or part of its activities in favor of development;

- act as an international agency, institution, or organization whose members are national governments or funds managed autonomously by such agency or organization;

- pools contributions that are at the disposal of a multilateral organization, although the directions and goals may be co-decided by the donor.

\section{Figure 9. Composition of Gross ODA Disbursements (Excluding Debt Relief) (USD billion, 2013 Constant Prices)}

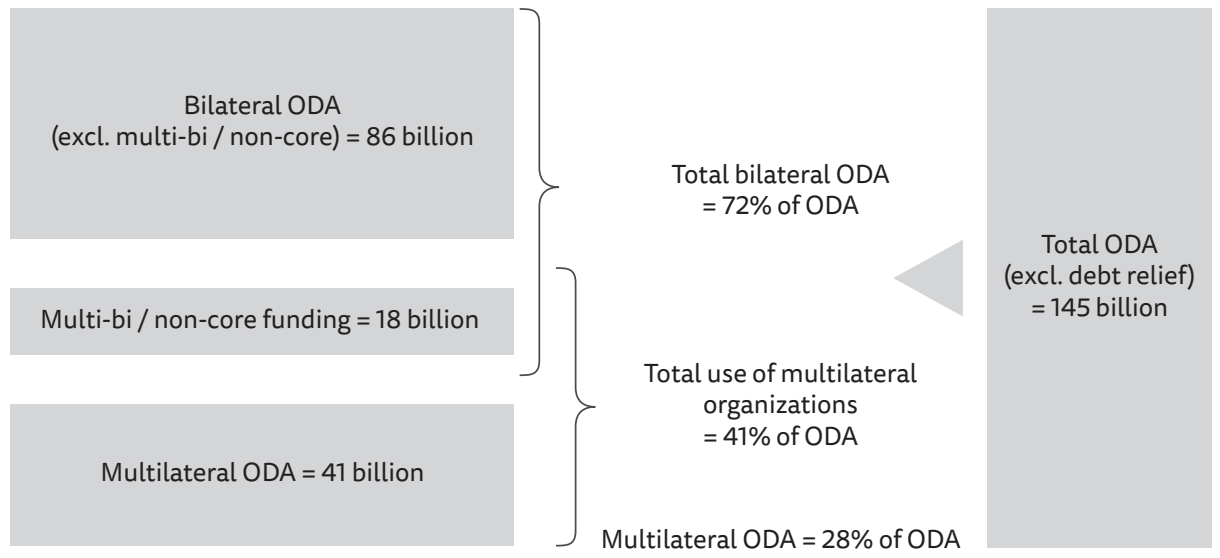

The share of multilateral aid in total ODA has remained at a relatively steady level of 30-40\% since the 1970s. A short-term breakdown in the provision of both multilateral and bilateral aid occurred in the 1990s, but at the beginning of the 21st century there was another dynamic growth of spending. Taking into account the core and non-core resources, the share of aid directed by multilateral institutions in the total gross ODA in 2013 was $41 \%$ (Figure 9). This means that the multilateral aid system (core + non-core) increased from 36\% to 41\% between 2007 and 2013. On the other hand, the resources qualified as the multilateral ODA in 2013 amounted to $28 \%$ of total ODA, which was a decrease from $32 \%$ in 2001 . In 2013 , the value 
of total aid provided by multilateral organizations exceeded USD 59 billion (OECD, 2015, p. 43). Funds eligible only under the multilateral dimension amounted to USD 41 billion, in line with the remaining USD 18.3 billion for non-core funding. Funds of this type became the main source of financing for development programs and accounted for $31 \%$ of all funds sent to multilateral organizations in 2011-2013 (OECD, 2015, p. 19).

Under the multilateral aid system, the following aid providers are distinguished:

- multilateral development banks, including the World Bank Group and its International Development Association (IDA);

- regional development banks - Asian Development Bank (AsDB), African Development Bank (Af DB);

- United Nations agencies, funds, and programs,

- The European Union - EU multilateral development aid covers the European Development Fund (EDF) and activities financed from the EU budget;

- other institutions of the UN system;

- other multilateral organizations, including the WTO. ${ }^{28}$

Among multilateral international organizations, the greatest assistance is provided by the $\mathrm{EU}^{29}$ the World Bank Group, and UN programs and funds. Over 63\% of all funds (both core and non-core) within the multilateral aid are channeled through this triad. In 2013, these institutions received, respectively, 21, 22, and 20\% of total core and non-core flows (Figure 10). Despite the fact that their share in the total amount of ODA remains relatively stable, the structure of finances and the way funds are transferred to and through each of these organizations differs significantly. In general, there is a tendency to slowly move away from core to non-core funding. This trend is particularly visible in the case of UN agencies (in 2009-2013), periodically within the WB funds and slightly within EU funds (in 2010-2012 the core funds decreased, but increased again in 2013). ${ }^{30}$ The increase in total funding under UN programs is primarily due to an increase in non-core funding. In 2013, they accounted for $76 \%$ of all UN funds and programs, compared to 58\% in 2007 (OECD, 2015, p. 5).

28 The WTO maintains strong ties with the United Nations, although it is not a specialized agency of the UN. Relations between the WTO and the United Nations are regulated by a special agreement - the Arrangements for Effective Cooperation with other Intergovernmental Organizations-Relations Between the WTO and the United Nations, signed on November 15, 1995.

29 The European Union has a special status under the multilateral aid system. Firstly, because 19 Member States belong to the DAC, and secondly, because the EU itself is a donor of development aid. Therefore, the EU is a member of the DAC along with the other 29 countries. Funds for this purpose are determined in the process of budgetary negotiations in accordance with the EU Treaty. For analytical and statistical purposes, the EU is treated as a multilateral organization under the development aid system, regardless of its nature and international legal status.

30 In the case of the EU, the highest level was recorded in 2009. 
Figure 10. Core and Non-Core Contributions from DAC Countries, 2013 (USD million, 2013 Current Prices)

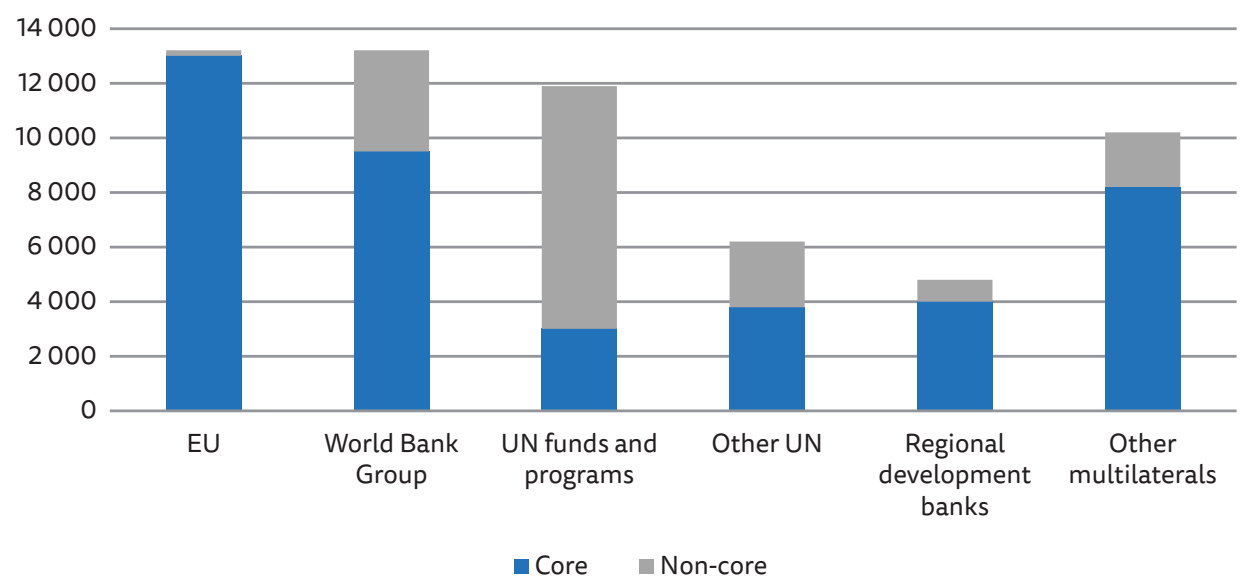

Source: OECD, 2015.

The largest donors of multilateral development aid are members of the OECDDAC (as of August 2017). However, there is a wide divergence in this group regarding commitment to the multilateral aid system. The differences are both in size and their structure, as well as in the evolution of aid policy, i.e., adaptation to changes related to the concept of development cooperation. In 2013, the largest increase in expenditure - including both core funding and multi-bi - as part of multilateral aid were recorded in the UK, Spain, Iceland, Switzerland, and Italy. In the same period, the largest decreases occurred in Australia and Canada. The United Kingdom became the largest multilateral aid donor in 2013, ahead of the United States. Next were Germany and France, whose main component of multilateral aid were funds from the core budget (Figure 11).

Excluding contributions to the EU budget, the UK was also the largest contributor to the multilateral ODA in 2013. Contributions to multilateral organizations accounted for $58 \%$ of its total ODA. It was followed by Italy (56\%), Canada (55\%), and Finland (52\%). Portugal had the smallest share (10\% of its total ODA). On the other hand, when including contributions to the EU, this order changes significantly. In relative terms, Poland was the largest donor of multilateral aid, accounting for $86 \%$ of total ODA, followed by Greece (82\%), Slovakia (82\%), and Italy (76\%). In turn, Japan recorded the lowest share of multilateral aid among all OECD-DAC member states, amounting to $25 \%$ (OECD, 2015, p. 30). In the case of Poland and other countries with relatively small budgets allocated to development aid, it is believed that contributions to an international organization may bring better opportunities to achieve economies of 
scale and aid effectiveness by pooling resources and extending the scope of aid by many countries. In such a situation, the transaction costs resulting from the necessity to support projects or aid programs are taken over by multilateral organizations with developed administrative apparatus and infrastructure prepared to operate in many regions receiving development assistance.

\section{Figure 11. Distribution of Core and Non-Core Resources Among DAC Members (USD million, 2013 Current Prices)}

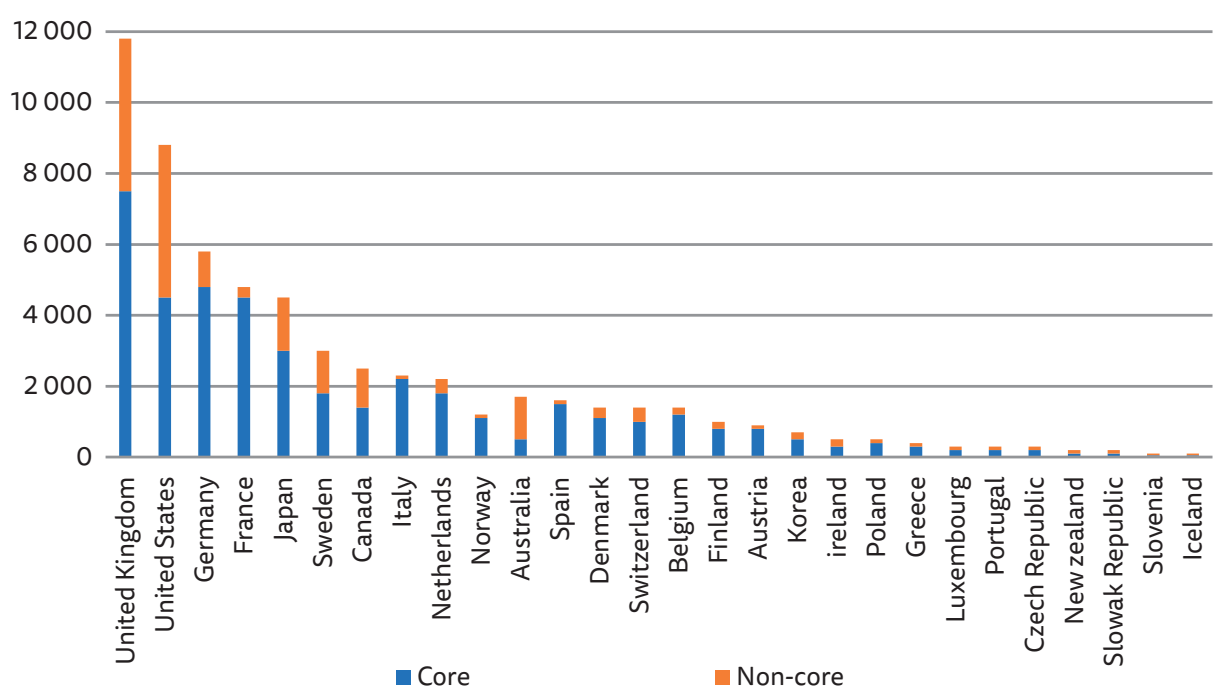

Source: OECD, 2015.

The multilateral aid system is also changing with the growing involvement of nonDAC donors, mainly Brazil, China, India, South Africa, Saudi Arabia, Turkey, and the United Arab Emirates. In 2009, the amount of funds transferred by these countries was estimated at USD 794 million, while in 2013 it amounted to USD 1.2 billion (see Figure 12). In total, in 2009-2013, these countries transferred over USD 5.2 billion for development aid through international organizations (core and non-core). This was particularly evident in the case of emergency aid (e.g., the Ebola crisis in Africa).

The participation of selected non-DAC countries in multilateral aid represents a small part of their overall development aid efforts. Compared to donors from the Committee, their involvement in the multilateral system is about 2\% (Figure 12). This means that the vast majority of them direct aid through other channels, including bilateral aid. In the case of five countries, i.e., China, India, Turkey, the United Arab Emirates, and Saudi Arabia, the aid provided in a multilateral form is below 7\% of their total development aid (OECD, 2015, p. 164). These countries are particularly 
interested in financial institutions that are involved in infrastructure development projects in Asia. An example is the New Development Bank (NDB) or the Asian Infrastructure Investment Bank (AIIB).

Figure 12. Multilateral Funding of Non-DAC Countries, 2009-2013

(USD million, 2013 Current Prices)

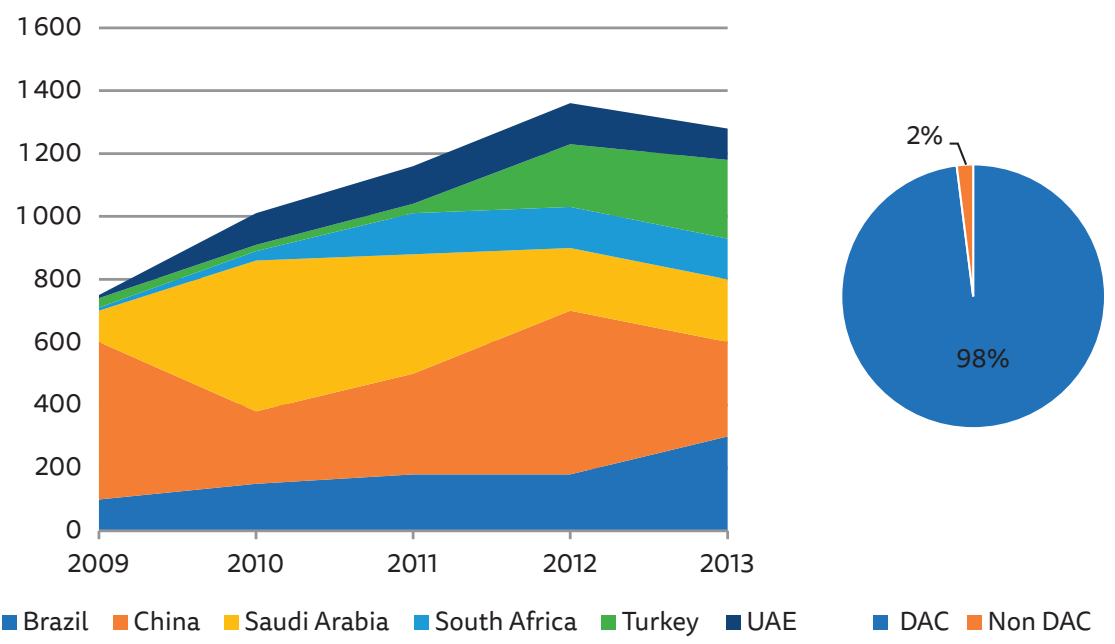

Source: OECD, 2015.

Most of funds at the disposal of multilateral organizations go to LDCs. In 2013, these countries received $45 \%$ of all outflows of multilateral institutions. ${ }^{31}$ This level decreased in comparison to 2007, when the share of transfers directed to LDCs amounted to $54 \%$ of all aid expenditure at the disposal of multilateral organizations (OECD, 2015, p. 47). This decline is mainly due to a shift in priorities in overall aid allocations in OECD DAC countries. For example, in 2014. ODA to LDCs accounted for $0.09 \%$ of the total GNI of OECD DAC countries, well below the UN target that countries should provide at least $0.15 \%$ of their GNI as ODA to LDCs (OECD, 2016d).

\subsection{Multi-Bi Aid}

Multi-bi aid is where multilateral organizations that qualify for ODA receive financial resources over which the donor retains control. These kinds of financial resources, known as earmarked, mixed (multi-bi) or non-core, are allocated to

31 These data relate to 28 multilateral organizations on the OECD DAC list. 
a specific country, region, sector, or even project after prior agreement between the donor and the multilateral organization. These are bilateral funds channeled through a multilateral institution, which are classified as bilateral aid for formal reasons (OECD, 2015, p. 44). They can be managed through trust funds that operate within or on behalf of multilateral institutions (Reinsberg, Michaelowa, Knack, 2015, p. 2). They were separated from the total expenditure of multilateral institutions in 2004. DAC member states are required to report the amount of multi-bi funds transferred to the OECD database. ${ }^{32}$ These resources are among the fastest growing funds directed to multilateral institutions. They are flexible and subject to frequent fluctuations, as in the case of bilateral aid, which means that they can be increased or decreased in a very short time at the discretion of the donor government (Tortora, Steensen, 2014, p. 25; Reinsberg, Michaelowa, Eichenauer, 2015, p. 544).

Multi-bi aid has become the dominant form of financial flow for many multilateral institutions. As a result, the multilateral aid system has fundamentally changed, and its traditional structure based on funding from the organization's core resources has been questioned. The multi-bi category confirms the validity of the claim made in the Principal-Agent Model. It shows that the donor (principal) maintains control over the funds paid in and uses the developed institutional procedures and knowledge that the organization (agent) has acquired in the field of development aid. The organization, in turn, receives additional funds from which its statutory tasks or new goals are financed. In a situation of shrinking financial resources of an organization, it uses additional sources of financing its activities.

Multi-bi funds have become the fastest growing portion of financial resources at the disposal of multilateral organizations. In the years 2007-2013 they increased by $93 \%$, while at the same time core funding rose by $24 \%$ (OECD, 2015, p. 96). In 2013 , on an aggregate basis, earmarked funds accounted for $31 \%$ of DAC members' total contribution to multilateral aid organizations, or $13 \%$ of total gross ODA (Figure 13). However, some researchers point out that this data may be underestimated, and funds of this nature may exceed $20 \%$ of total ODA and almost $60 \%$ of all funds transferred to multilateral institutions (Eichenauer, Reinsberg, 2017; Reinsberg, 2015). One of the factors driving the growth of multi-bi aid is humanitarian spending. This area constitutes a significant part of multi-bi funds. In 2008, humanitarian emergency funding accounted for $38 \%$ of multi-bi funds, declined to $28 \%$ in subsequent years, and exceeded 36\% again in 2013.

32 More on the types of OECD-DAC databases in Chapter IV on the Aid for Trade Initiative. 
Figure 13. Volume and Share of Multi-Bi Funding in Total Multilateral Aid, 2007-2013 (USD billion, 2012 Constant Prices)

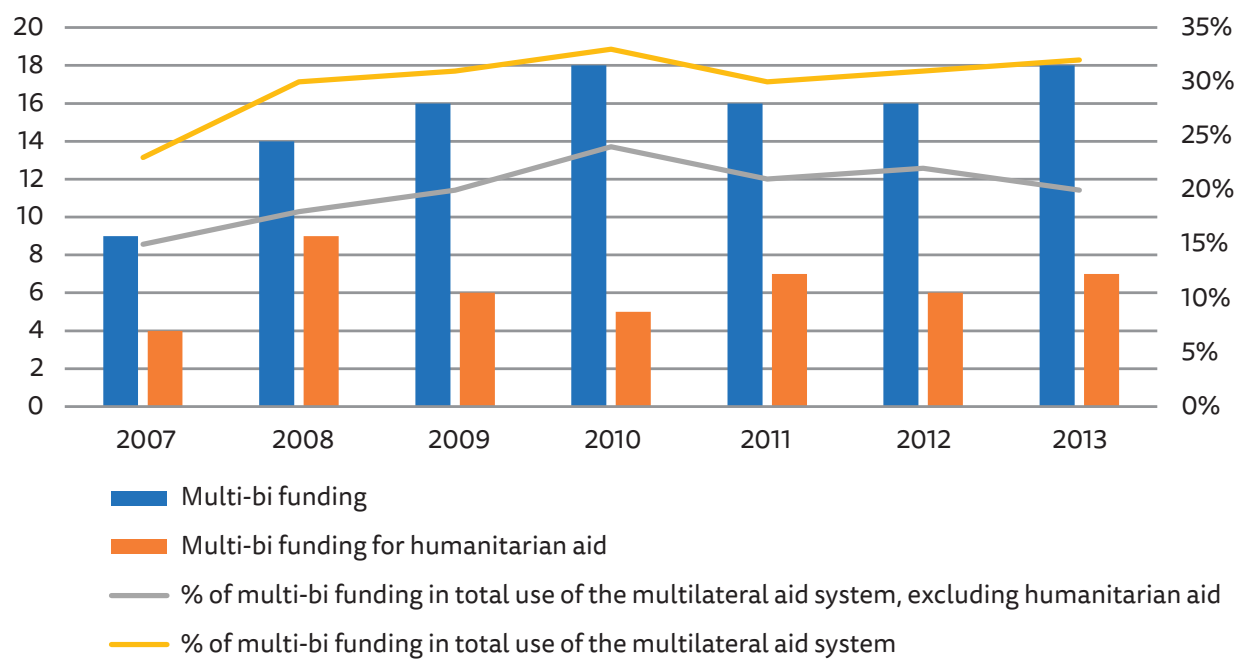

Source: OECD, 2015.

Different organizations base their budgets on multi-bi funds differently. The largest recipients of earmarked funds include UN programs and agencies and the World Bank Group. Their share in the total inflow of financial resources in 2013 amounted to $76 \%$ and $28 \%$, respectively (OECD, 2015, p. 13). On the other hand, the EU relies almost exclusively on financing from core contributions, which in 2013 amounted to nearly $98 \%$ of the total funds allocated to development aid (see Figure 10). The WTO, as a separate institution but associated with the UN system, is one of the entities that increasingly rely on non-core funding. Among the five largest multilateral institutions, UN funds and programs received nearly $50 \%$ of non-core resources in 2013, and organizations related to the UN, to which the WTO belongs, a total of $14 \%$ (see Figure 10). The share of multi-bi funds in the case of other institutions was as follows: The World Bank Group - 20\%, other multilateral institutions $11 \%$, regional banks - 4\%, and the EU - 1\% (OECD, 2015, p. 46). In the group that includes the WTO, organizations have seen an increasing reliance on multi-bi measures. In 2007, their share in relation to the total resources was $31 \%$, and in 2013 already over 41\% (OECD, 2015, p. 46).

Multi-bi funds are voluntary and can be allocated to a specific country, project, region, sector or program, as desired by the donor country. They fulfill their task best in the event of the need to launch humanitarian aid or in other emergencies that require quick and flexible action (humanitarian disasters, natural disasters). 
Moreover, these funds are transferred not only from donors who are members of the DAC, but also from donors such as private foundations, NGOs, transnational corporations, and other units involved in providing aid. The growing number of donors creates opportunities for increasing funding, but on the other hand, it leads to an increasingly complex situation within international aid system. Coordination and harmonization of activities becomes more and more difficult. This is because new entities are not subject to the same rules and principles as members of multilateral organizations. Therefore, it is difficult to make them comply with specific institutional procedures, such as in the case of the OECD-DAC.

The reasons for the increase in earmarked funds are the interests of the donor and the priorities of their foreign policy, but also the pursuit of the goal of increasing the effectiveness of aid within multilateral institutions. In the first case, the reason why countries choose to transfer funds in the form of multi-bi is to keep their influence over the funds they send. It is also a willingness to be seen as a giver of aid (Tortora, Steensen, 2014, p. 15; Reinsberg, 2015, p. 23; Milner, Tingley, 2013; Reinsberg, Michaelowa, Knack, 2015, p. 2). The sustained increase in multi-bi resources may lead to the selection of such geographic directions and sectors for allocating aid resources that correspond to the interests of the donor states, rather than a longterm program adopted by international institutions. Interest in this type of funds is often shown by highly developed countries, pushing for the implementation of their own priority programs within the organization. This leads to the phenomenon referred to as the bilateralization of multilateral institutions or multilateral aid (Tortora, Steensen, 2014, pp. 14-16), also described by the Trojan horse metaphor (Sridhar, Woods, 2013). As a consequence, allocating earmarked funds within the organization leads to an increasing influence of individual donors on the decisionmaking system within a multilateral organization, favoring the largest donors, limiting the independence of institutions in the creation, collection, and dissemination of information (Andreopoulos, Campanelli, Panayides, 2011).

The second reason for increasing the earmarked funding is the desire to improve the effectiveness of aid. According to the assumptions, multi-bi funds may be faster and easier to allocate in the countries and sectors of the economy of the recipients, as they are not subject to complicated procedures within multilateral institutions but depend on the direct decisions of the donors. Therefore, they prove themselves in crisis and emergency situations that require the activation of immediate aid. Research conducted in this matter indicates, however, that development aid financed from earmarked resources may bring about effects opposite to those planned. Nevertheless, it is difficult to unequivocally assess the impact of multi-bi funding on increasing the effectiveness of development cooperation and the implementation of 
the adopted principles. It depends on the understanding between donors, multilateral organizations and recipients of aid, as well as on daily practice.

The literature on the subject is dominated by a critical assessment of the increasing dependence of multilateral institutions on multi-bi funds and their impact on the multilateral aid system. This is evidenced by the following examples:

- additional funds, which are not foreseen in the project phase within a given multilateral organization, may lead to an imbalance in the stability of the organization's budget and its functions (OECD, 2015, p. 30); unpredictability and voluntariness in the provision of multi-bi funds can create problems related to the management and administration of programs and projects run by a multilateral organization (Tortora, Steensen, 2014);

- ad hoc contributions may lead to duplication of projects and programs led by different multilateral institutions; having a limited time to spend multi-bi funds, the organization tries to deploy them as quickly as possible in the recipient countries, which does not always turn out to be effective;

- the influence of donors on the size, direction, and type of funds increases bureaucracy and administrative costs of a multilateral institution (OECD, 2015, pp. 30, 109-113); this is because the organization is often required to conduct additional audits and reports for the donor states of multi-bi funds;

- greater donor tendency to contribute to the earmarked pool may mean that fewer of them go to the core, otherwise referred to as multilateral ODA (Tortora, Steense, 2014, pp. 19-20); this situation leads to the dependence of a multilateral organization on multi-bi resources and a reduction in its operational autonomy;

- the dependence of development assistance on multi-bi funding does not fully correspond to the concept of development cooperation and the strategy for increasing aid effectiveness included in the Paris Declaration (2005) and the Accra Agenda for Action (2008).

On the other hand, however, aid financed by multi-bi funds is a complex phenomenon and therefore various aspects are assessed. The same features that make multi-bi aid an attractive tool for increasing efficiency may otherwise limit its operation. These include:

- flexibility of multi-bi resources; they allow international organizations to perform tasks that would not be possible within the statutory functions of the organization with funds from the core budget; yet, it is not just a multilateral organization that decides how to spend them; moreover, these funds are most often transferred to the organization at the end of the calendar year, which means that the organization cannot predict when or if it will receive additional funding at all; 
- the possibility of financing programs in countries that could have difficulties obtaining any funding (e.g., fragile states or countries resulting from civil wars) (World Bank, 2011, pp. 8, 29); the choice depends on the individual decision of the donors who may block the transfer of funds for such purposes;

- quick collection and allocation - the factor is an incentive for some people to make decisions about granting aid, and for others it is an obstacle that weakens the decision-making structures of multilateral institutions; directions and goals are decided by the donor in consultation with a multilateral organization;

- ease of fund management; according to the assumption, earmarked funds should be better and more efficiently spent, because they are intended for specific goals, i.e., specific projects, sectors, countries, and regions; on the other hand, there is a serious risk of duplicating similar programs and funding the same goals;

- transaction costs; using the institution's resources, i.e., knowledge, procedures, and proven aid delivery channels, lowers costs related to service and management; however, there are additional costs resulting from the need to re-audit, submit reports, and operate new financial instruments;

- independence from organizational procedures; multi-bi funds are voluntary and independent of long-term international commitments and budget planning procedures within international organizations; this is advantageous for the donor, as it gives them greater flexibility; however, it does not necessarily serve the institution's long-term development strategy, nor does it support the aid recipients themselves due to the short-term planning time.

\subsection{Trust Funds}

The dynamic growth of multi-bi funding within multilateral institutions resulted in the need to appoint appropriate institutions to service them. Although they are not new financing instruments in the field of development assistance, they have become a rapidly growing part of multilateral system and a major tool for servicing development programs, including those managed and administered by the WTO. Trust funds in the field of development aid appeared in the early 1960s, when Western countries sought to expand the scope of UN activities, which, however, was opposed by the USSR. Consequently, this dispute led to the creation of several large UN development funds and programs, such as UNDP, which were largely financed by voluntary contributions. Both the new funds and programs and the existing specialized UN agencies (such as the World Health Organization or the International 
Labor Organization) soon depended on periodic and voluntary contributions, and therefore on individual financial decisions of donor countries (Graham, 2015).

In accordance with the objectives of the Monterrey Consensus (2002) and the Paris Declaration (2005), mechanisms of financing development aid should contribute to improving its effectiveness. In practice, contrary to the original objectives, there was a significant increase in the number of entities participating in international development cooperation, which made the coordination and harmonization of activities difficult (Reinsberg, Michaelowa, Eichenauer, 2015, p. 532). On the other hand, it increased the possibilities of obtaining additional funds.

According to the way resources are used, trust funds are divided into horizontal and vertical. Taking into account the criterion of the origin of resources, trust funds are single donor (SDTF) and multi-donor (MDTF). Horizontal trust funds are usually dedicated to a single country and are best suited for pooling resources and coordinating emergency assistance (after conflicts or natural disasters). They are designed to support short- and medium-term projects or a specific sector, e.g., public administration. On the other hand, vertical or global trust funds can finance aid to a greater number of recipient countries and are also used to implement projects related to global public goods, such as climate change, health and education, international security or international stability of the economic system. This means that they are characterized by a lack of competition and exclusivity at the global level. However, these areas do not coincide with the classification applied to development assistance, therefore their destination depends on the decisions of the fund members.

Most of the trust funds are entities based on contracts between a single donor and a multilateral institution. Therefore, the vast majority of multi-bi aid is channeled through single donor trust funds (Figure 14). The latter are more focused on humanitarian assistance, while the MDTF - on global problems (Reinsberg, Michaelowa, Eichenauer, 2015, p. 546). In both types, funds can be reinvested to increase income. They are usually led by a single administrative structure, for example a multilateral institution. The supervision of the spending of funds, partly or not at all, is not in the hands of a multilateral institution but depends on the fund's members. The decision must first and foremost be in line with the preferences of the fund's shareholders, which, apart from donors, may also include representatives of recipients, NGOs, the business sector and other private entities. Administrative support provided by a multilateral organization to a fund is not directly related to its impact on the manner and direction of allocating money. Financial transfers directed to aid through a multilateral institution often constitute an important part of its resources and thus make it possible to function within development aid system. This is especially important in the case of institutions related to the UN system. 


\section{Figure 14. The Use of Different Aid Financing Channels by Donor Countries,} 2006-2012 (in \%)

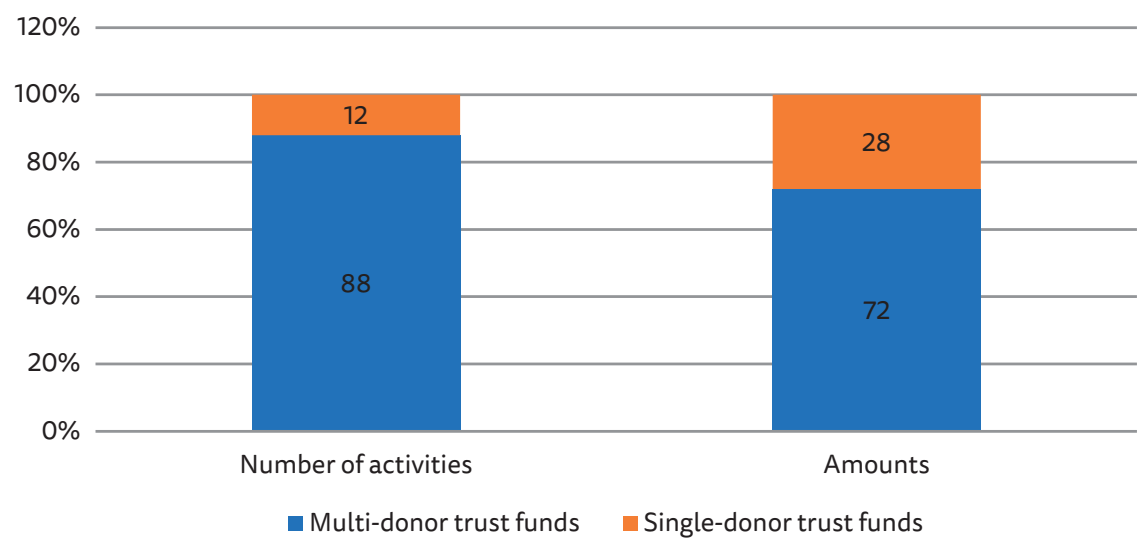

Source: Reinsberg, Michaelowa, Eichenauer, 2015.

The boom in trust funds in the 1990s was caused by disappointment with traditional financing mechanisms and criticism of development aid system. Faced with growing challenges in developing countries, donors recognized that previous international aid mechanisms were insufficient to address sustainable development issues and move closer to achieving the MDGs. Previous aid financing instruments have been criticized for being too fragmented, with low flexibility and subordinated to the pursuit of donors' interests. Taking into account the commitments and provisions of the Paris Declaration, the activity of trust funds is assessed in two ways.

First, trust funds are seen as a financing mechanism that addresses problems related to the effectiveness of development aid. By design, the trust fund is supposed to perform the function of coordinating and harmonizing decisions while financing specific goals and beneficiaries. Smaller and less experienced donors can be involved in the trust fund, as the financial risk is lower and public funds are used directly to achieve a specific goal. They can be established for a single donor, but also for a group of donors that jointly finance a common priority area.

In the case of MDTFs, their management structure allows them to include a wide range of stakeholders, such as NGOs, private philanthropic foundations, corporations, and recipients. The idea is that the decision-making process should reflect greater national representativeness and accountability. An additional advantage of the operation of multilateral funds is the distribution of risk and responsibility among many participants of such an undertaking. Therefore, the principle of ownership is at the center of the MDTF's interest, i.e., the partner country's supervision over its development program, as well as assistance in strengthening the institutional 
capacity of recipients. An important element of trust funds is that they allow donors to act quickly, which is important in emergency situations, without having to wait long for decisions.

The second approach is critical of the operation of funds. This is where the risk associated with the instability and unpredictability of multi-bi financing, as well as the loss of independence and operating autonomy of a multilateral institution is considered. The analyses highlight problems that may arise when a multilateral organization agrees to manage a trust fund over which it actually has no control (Barakat, 2009, p. 112). To some extent, the risk of instability becomes the inevitable opposite of the flexibility of multi-bi aid, a feature that is highly appreciated by the donor community (Tortora, Steensen, 2014, p. 25). Research by V.Z. Eichener and B. Reinsberg (2016, p. 27), however, did not confirm the concerns related to the instability of trust funds.

The emergence of numerous trust funds did not significantly improve the effectiveness of aid. The commitments made in the programming documents (the Paris Declaration, the Monterrey Consensus, the Accra Agenda for Action) regarding development cooperation have largely not been implemented. This is confirmed by empirical studies. Firstly, the issue of aid recipients' participation in the process of making joint decisions and the application of the principle of ownership of aid programs has not changed much (Barakat, Rzeszut, Martin, 2012, p. 33). Donors did not want to leave decisions and greater responsibility for managing resources to host governments. The condition for the recipients was to strengthen their institutional systems. For instance, in their study V.Z. Eichenauer and B. Reinsberg (2017) found evidence that some donors use earmarked aid to get around countries with weak governance structures. Second, there has been no significant improvement in terms of enhancing cooperation and harmonization of activities between donors. The new entities did not replace the previous ones but created an additional structure and deepened the fragmentation of the multilateral aid system (Kharas, Linn, 2008; Acharya, Fuzzo, 2006).

At the Fourth High-Level Forum in Busan in 2011, participants agreed to "improve coherence of our [their] policies on multilateral institutions, global funds and programs" The main goal was to "make effective use of existing multilateral channels, focusing on those that are performing well (...) work to reduce the proliferation of these channels" (Busan Partnership..., 2011, par. 25b). Despite declarations, the fragmentation of multilateral system has deepened, and donor coordination even weakened. This was shown by the results of the study conducted by P. Nunnenkamp, H. Öhler, and R. Thiele (2011, p. 12). Most of the trust funds are single donor entities (SDTF). Their decisive advantage over multilateral funds shows that states 
are not willing to undertake joint ventures to finance development (Reinsberg, Michaelowa, Eichenauer, 2015, p. 540). They show more interest in creating single funds than in coordinating activities with other donors (see Figure 14). Moreover, due to the growing number of trust funds, especially SDTF, transaction costs increased. More trust funds mean higher costs for a multilateral organization to handle them.

The literature on the subject indicates a lack of sufficient data that would allow for a comprehensive evaluation of the operation of trust funds, their impact on increasing the effectiveness of aid, and achieving development goals. Information on multi-bi trust funds addressed to multilateral organizations is often incomplete or inaccurate, which results from imprecise criteria used to identify individual financial flows. The OECD-DAC database to which information from individual donors and institutions is sent is not a complete source. Complicating the matter is that trust funds are often classified as multilateral institutions. Consequently, it may lead to double counting of the same funds. For this reason, OECD statistics may not be factual. An attempt to fill this gap was made by V.Z. Eichenauer and B. Reinsberg (2017), who added and updated the types of flows where they were missing, and the information collected was incorrect or imprecise. Their database covers all DAC donors from 1990 to 2012.

In the case of the WTO, there are several types of trust funds that finance aidrelated activities of the organization. The main criterion for the allocation is the degree of control over the trust fund. First, they are trust funds managed only by the WTO and which finance organization's statutory activities, such as technical assistance. They belong to the group of Doha Development Agenda Global Trust Fund, China LDCs \& Accessions Program, Netherlands Trainee Program, French \& Irish Mission Internship Program, and the Ministerial Conference Trust Funds (see Table 5). The second category includes units administered by the WTO, but these funds support programs that do not belong exclusively to the organization. In practice, administrative supervision over them is exercised by the WTO Secretariat, but spending decisions are made jointly by the WTO and other multilateral institutions, such as the IMF and WB. Examples are trust funds related to the following initiatives: STDF on SPS, EIF, and TFAF (WTO, 2017a, p. 8).

A similar division concerning trust funds and multilateral organizations that supervise them was proposed by V.Z. Eichenauer and B. Reinsberg (2016). The criterion was whether the multilateral institution was directly involved in the implementation of aid projects. In this setup the WTO can fulfill two functions, as an international development organization (IDO) that deals with the implementation of aid projects, and as an institution administering the fund, which only acts as an intermediary in the transit of funds and has no influence on the implementation of projects. In 
this arrangement, the distribution of WTO trust funds can be made according to the criterion relating to the degree of involvement of the organization. The first group includes trust funds strictly implementing WTO projects related to its statutory tasks, such as technical assistance. This is the DDAGTF. The second group includes entities over which the WTO exercises administrative supervision. An example is a trust fund related to STDF or EIF initiatives (see Table 5). In this situation, the WTO plays the role of a multilateral organization with a transit character. It is used to send funds for project implementation, but it has no direct influence over the use of multi-bi funds (cf. Reinsberg, Michaelowa, Eichenauer, 2015, p. 536).

Table 5. WTO-Related Trust Funds, 2017

\begin{tabular}{|c|c|c|}
\hline & Multi-donor trust funds & Single-donor trust funds \\
\hline $\begin{array}{l}\text { Non-earmarked } \\
\text { funding }\end{array}$ & Doha Development Agenda Global Trust Fund & \\
\hline \multirow{5}{*}{$\begin{array}{l}\text { Earmarked } \\
\text { funding/multi-bi }\end{array}$} & French \& Irish Mission Internship Program & China LDCs \& Accessions Program \\
\hline & $\begin{array}{l}\text { Ministerial Conferences } 2015 \\
\text { (Nairobi) \& } 2017 \text { (Buenos Aires) Trust Funds }\end{array}$ & Netherlands Trainee Program \\
\hline & Trade Facilitation Agreement Facility & \\
\hline & Standard and Trade Development Facility on SPS & \\
\hline & Enhanced Integrated Framework Trust Fund & \\
\hline
\end{tabular}

Source: own study based on WTO, 2017a.

\section{Figure 15. WTO Technical Assistance Resources, 2007-2017 (CHF million)}

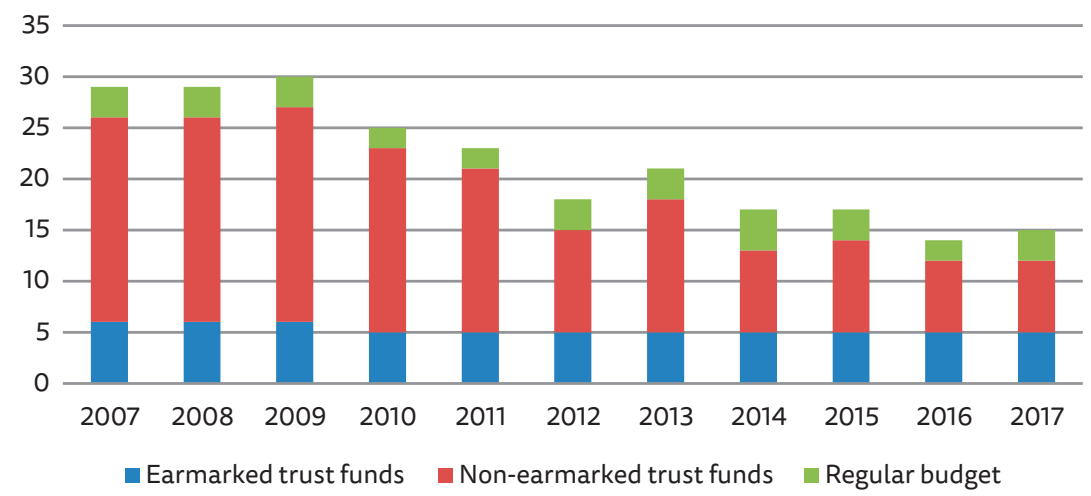

Source: own study based on WTO, 2017a.

In the case of the WTO, the division presented above does not reflect the actual state of relations between the WTO and the mutual funds cooperating with it. In fact, these contacts are mixed and cannot be divided unequivocally. On the other 
hand, the trend related to the development of financing resources under the WTO is similar to that of other multilateral organizations dealing with development assistance. The dynamics of the inflow of multi-bi funds under the WTO is, however, slightly lower and there are some exceptions in the form of the DDAGTF. On the one hand, the importance of trust funds in financing the organization's activities is relatively high, but on the other hand, the share of multi-bi the main component of funds - remains modest, amounting to around $12 \%$ of all voluntary contributions received by the WTO (2017a). This is due to the following factors:

- the DDAGTF is the main source of funding for the WTO's technical assistance activities, but funds sent through it do not qualify as earmarked or multi-bi, but are referred to as non-multi-bi (Figure 15); this means that, unlike standard funds, DDGTF resources can be spent on purposes in line with WTO priorities;

- the vast majority of WTO-related funds are MDTFs, prompting them to cooperate and coordinate more; however, apart from the DDGTF, the remaining multilateral funds do not engage directly in the implementation of WTO tasks; these are multilateral initiatives established by a consortium of multilateral organizations, where the WTO plays the role of the fund's supervisor and administrator; as a result, its impact on the implementation of specific projects is smaller and results from joint arrangements with other multilateral organizations, such as the World Bank, IMF, and the OECD.

Most of the WTO's aid-related tasks are financed from the DDAGTF. These are voluntary contributions, classified as non-earmarked. In recent years, significant drops in the inflow of this type of contributions have been recorded. Compared to 2015, these contributions decreased by 30\% (Figure 15 and 16). In 2017, they amounted to CHF 6.2 million, while in 2013 the level was close to CHF 14 million. The record year was 2009, when the funds accumulated by the DDAGTF reached almost CHF 20 million. In 2017, for the first time since the creation of the DDAGTF (2002), its contributions accounted for less than half (48\%) of the WTO's total resources for technical assistance. The remaining categories of financing sources remained at a similar level. The increase was in the case of multi-bi trust funds, which in 2017 were slightly higher than the year before, reaching the level from 2015. About one third of the resources came from the WTO core budget, which is held steady at CHF 4.5 million.

Taking into account the commitments made in the documents on increasing the effectiveness of aid, some multilateral institutions (UN, WB) have taken steps to reduce the number of trust funds. The aim was to stop further fragmentation of multilateral aid system and therefore reduce transaction costs related to the servicing of trust funds. It mainly concerned entities consisting of one donor and those funds that did not exceed the minimum level of own resources. It was also about adjusting 
them to the process of strategic planning, risk management, and budget planning, including core and non-core resources (Tortora, Steensen, 2014, p. 26). Bilateral donors, who did not want to limit their influence on international development institutions, opposed these plans. In a survey conducted by the DAC in 2013, 22 of its participants from member states did not hide that the main motivation for increasing multi-bi trust funds is the desire to maintain control over organizations and adjust their activities to their own priorities (OECD, 2013, p. 19). One of the examples concerning the willingness to maintain control over organizations is the extension of the activity of international organizations to new areas related to global public goods (Reinsberg, Michaelowa, Eichenauer, 2015, p. 550). Another reason is internal interests within a multilateral institution. Competition between different administrations and departments for additional funding and revenues is leading to a growing interest in multi-bi aid.

\section{Figure 16. Volume of Funding Received Through WTO-related Trust Funds, 2012-2017 (CHF million)}

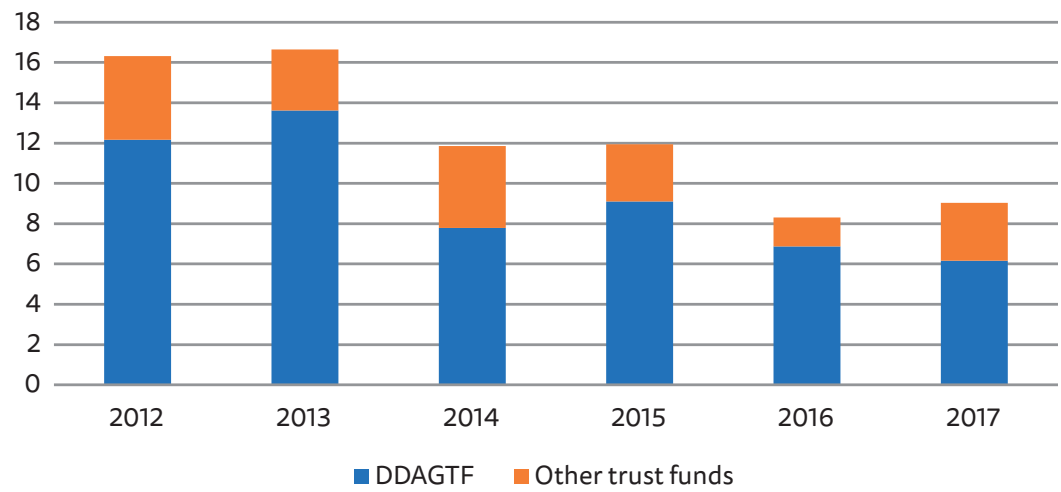

Source: WTO, 2018a.

\subsection{Summary}

It is assumed that multilateral aid provides opportunities for collective action and a common response to global challenges. It is the preferred form of aid as it is believed to be less affected by day-to-day political influence than bilateral aid and is also more predictable and implemented in line with the development needs of recipient countries. Consequently, multilateral aid is valued more by donor and recipient societies than bilateral aid. In turn, bilateral aid is subject to the donors' control, corresponds to their interests and is more visible in the short term. 
One of the hallmarks of multilateral aid system is the dynamic development of multi-bi resources. For this reason, aid financed from such resources have come to be referred to as multi-bi aid. In the subject literature the negative assessment of the growing pool of this type of funds prevails mainly due to the difficulty to predict effects on the multilateral aid system. The implementation of development aid goals through the multi-bi channel is not fully in line with the international commitments made in the Paris Declaration (2005), the Accra Agenda for Action (2008) or the Busan Partnership Agreement (2011). The prevailing view is that earmarked (multi-bi) funding undermines the ownership principle of recipient countries' development programs and reduce the predictability of financial flows. Such a situation may lead to the replacement of core contributions to multilateral institutions by multi-bi funds, complicate budget management of these organizations, and increase administrative costs and bureaucracy, as well as fragmentation and dispersion of funds.

The implementation of development goals requires more and more expenditure from public and private funds, therefore earmarked or multi-bi funding will play an increasingly important role. There are several reasons why countries increase the amount of multi-bi funds within multilateral organizations: firstly, it has an impact on planning the organization's budgets, secondly, they want to show citizens specific goals for which public funds are allocated, thirdly, they gain greater control over the funds spent from the international organizations' pool due to the prevailing opinion about the ineffectiveness of multilateral channels. Therefore, this tendency will lead to the bilateralization of multilateral aid, which means limiting the independence of institutions as regards the administration of funds for development purposes. Even if the far-reaching goal of such a process is to increase the effectiveness of aid delivery, especially when it is possible to bypass the bureaucratic system of decisionmaking, the donors themselves want to decide for what purposes, what amount and to whom to transfer funds.

The benefits of this new multi-bi funding are only partial. Indeed, these resources are largely channeled through single-donor trust funds, while the multi-donor form is sporadic. This means that states and other non-state actors show less interest in joint initiatives than in unilateral action, which leads to the fragmentation of multilateral aid system. In addition, the same features that distinguish multi-bi aid are deemed beneficial by some, and problematic by others. For instance, flexibility and volatility in funding may be seen by some as a positive element in enabling a rapid emergency response, and for others as an obstacle to the planning and management process of a multilateral organization. Donor control over multi-bi funds can be transferred to specific development goals, in line with the needs of recipient countries, e.g., 
in humanitarian crises. On the other hand, aid may be more subordinated to the interests of donors than to the needs of recipient countries.

In the case of the WTO, the situation is slightly different. Multi-bi aid has so far been an additional source of funding for technical assistance. The contributions sent via the DDAGTF were only at the disposal of the WTO. The organization controlled them and decided on their purpose in accordance with the statutory objectives. However, since 2013, a decrease in financial inflows from the DDAGTF has been observed. This could mean reducing interest in providing aid through multilateral channels and replacing them with multi-bi or bilateral aid.

In view of the increasing number of WTO-related trust funds, there is a distinction between those entities that are directly managed by the WTO and participate in the implementation of assistance tasks, and those that are solely administratively supervised. The WTO can play a twofold role in this arrangement. In the first case, it is the role of the institution implementing the objectives related to development aid, which means, first of all, technical and training assistance to the WTO. In the second case, the organization exercises administrative supervision over the fund, and thus is a multilateral organization of a transit nature. It is used to send funds for project implementation, but it does not directly decide on the use of multi-bi funds. It cannot be ruled out, however, that the WTO, in consultation with fund shareholders and other multilateral institutions, influences specific issues related to the disbursement of funds. 


\section{Chapter 3}

\section{TECHNICAL SUPPORT}

As the concept of development cooperation has evolved, the approach to technical assistance has changed as well. Within the WTO, the terms technical assistance and/ or technical cooperation are used interchangeably. In both cases, it serves to define the WTO's Trade-Related Technical Assistance (TRTA). In general, technical assistance means the transfer of knowledge and technology from a developed country to a developing country by sending specialists and experts to assist local authorities, state institutions, and private entities at various levels of activity. Specialist knowledge and know-how are transferred not only to public entities, but also to private institutions and entities in the economic, political, social, and organizational spheres. Technical assistance provides advisory and training services to entities from developing countries, both inside and outside the recipient country. Its aim is to raise the level of knowledge, qualifications, skills, or production capacity in developing countries (OECD, 2008, p. 149). Technical assistance is to contribute to the construction of human capital, and thus to raise qualifications of professionally active people (Arndt, 2000), as well as to improve management and implement reforms in the recipient country (Kopiński, 2001, p. 20; Andrzejczak, 2010, p. 23).

In the case of the WTO, the purpose of TRTA is to develop human and institutional capacity of developing countries. It is necessary for them to benefit from trade exchange and to participate more actively in trade negotiations and increase their financial and material resources as well as expertise in trade policy and commercial law. Even though the tasks carried out by the WTO within the framework of technical cooperation are not able to meet needs of developing countries in this area, they nevertheless constitute an important element of international development cooperation.

The evolution of multilateral aid system also forced the introduction of changes to the WTO technical assistance, both in the area of the type of activities and sources 
of financing (multi-bi funds). The chapter analyzes WTO technical cooperation, its scope, types, and forms. Technical assistance is the basic form of action of the WTO carried out in the ODA formula. Unlike other international organizations dealing with aid, the WTO does not provide funds directly to developing countries, but it does provide assistance in the form of courses, training, and know-how.

\subsection{WTO Training and Courses}

WTO technical assistance and training is provided in various forms and for various groups of recipients from developing countries, including, in particular, LDCs. This type of activity is coordinated by the Institute for Training and Technical Cooperation (ITTC), established in 2003 within the WTO Secretariat. It is responsible for the implementation of the two-year technical assistance plans approved by the WTO Trade and Development Committee, which is represented by all members of the organization.

The obligation to provide technical assistance to developing countries has been included in the following WTO agreements: The Agreement on the Application of Sanitary and Phytosanitary Measures (SPS Agreement), the TBT Agreement, the TradeRelated Aspects of Intellectual Property Rights (TRIPS Agreement), the Agreement on Customs Valuation (CV Agreement) or the Dispute Resolution Understanding (DSU) (Bossche, Zdouc, 2017, p. 110).

The WTO offers a wide range of different types of courses and trainings tailored to audience in different regions of the world and with different levels of knowledge about international trade rules and principles of organization. In order to increase the effectiveness of education, in 2010 Progressive Learning Strategy (PLS) was introduced at three levels of advancement. This made it possible to expand the course offer and the possibility of acquiring knowledge.

Courses and other activities are aimed primarily at government officials and other representatives from civil society, journalists, academia and the private sector in developing countries. Participation in them, especially in online courses, is open to all interested, however participants from LDCs have priority. The types and forms of activity, as well as the duration, change in a two-year cycle in accordance with the Biennial Technical Assistance and Training Plan. This is due to the need to adapt to the amount of available financial resources, needs reported by developing countries and decisions taken within the WTO.

The number and types of courses vary from year to year. It depends on the number of applicants, the need for a specific type of activity and the financial resources 
at the disposal of the WTO. The trainings are aimed at two groups of recipients: people with general knowledge and specialists in strictly defined fields. All types of courses are conducted in accordance with the Progressive Learning Strategy at three levels - Basic, Intermediate, and Advanced, in three official WTO languages: English, French, and Spanish. In 2017, 40\% of the total training was general, which was a decrease compared to 2016, when this share was $47 \%$. In terms of expertise courses, Sanitary and Phytosanitary Standards and Technical Barriers to Trade were the most popular. It was followed by courses on market access for goods, including the Trade Facilitation Agreement and TRIPS (Figure 17). In 2017 approximately 18500 participants took part in almost 350 technical assistance activities hosted by the WTO. A year earlier, this number remained almost unchanged (Figure 18).

\section{Figure 17. Subjects of WTO Technical Assistance Courses and Training (in \%)}

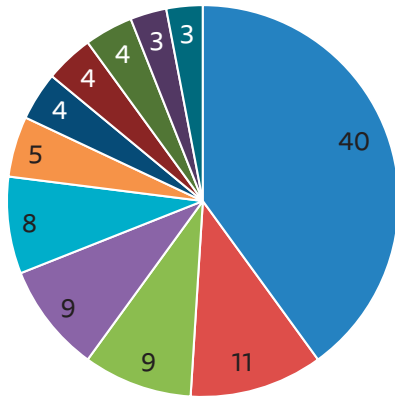

$\begin{array}{lll}\square \text { General } & \text { SPS } & \text { Market access for goods } \\ \square \text { TRIPS } & \text { Services } & \text { WTO accession } \\ \square \text { Rules } & \square \text { Gov. procurement } & \square \text { Agriculture } \\ \square \text { Dispute settlement } & \square \text { Environment } & \end{array}$

Source: WTO, 2018c.

In terms of the types of activities carried out by the WTO in the field of technical assistance, nearly 10 forms of action can be distinguished.

\section{E-learning courses for beginners and intermediates}

They are held on a continuous basis ( 24 hours a day, 7 days a week) on the http://ecampus.wto.org platform. It is the basic and most popular form of training in almost all areas of trade policy, both for general knowledge and for specialists. It allows a large number of people to be trained worldwide with a relatively small team from the WTO Secretariat. At a time when WTO resources are dwindling, e-learning 
plays a key role in maintaining the WTO's commitment to Trade-Related Technical Assistance. In 2015, a total of over 7500 participants from 145 countries (including aspiring countries) took part in the course, while in 2017 the number exceeded 10000 (Figure 18). More than half of all applicants of WTO training completed the on-line courses. ${ }^{33}$ They can be divided into three groups: ones that introduce the subject of the WTO at the basic level, the general and thematic ones at the intermediate level, and those that prepare one for the creation of their own e-learning courses.

\section{Figure 18. Number of Participants in WTO Technical Assistance Activities,} 2010-2017

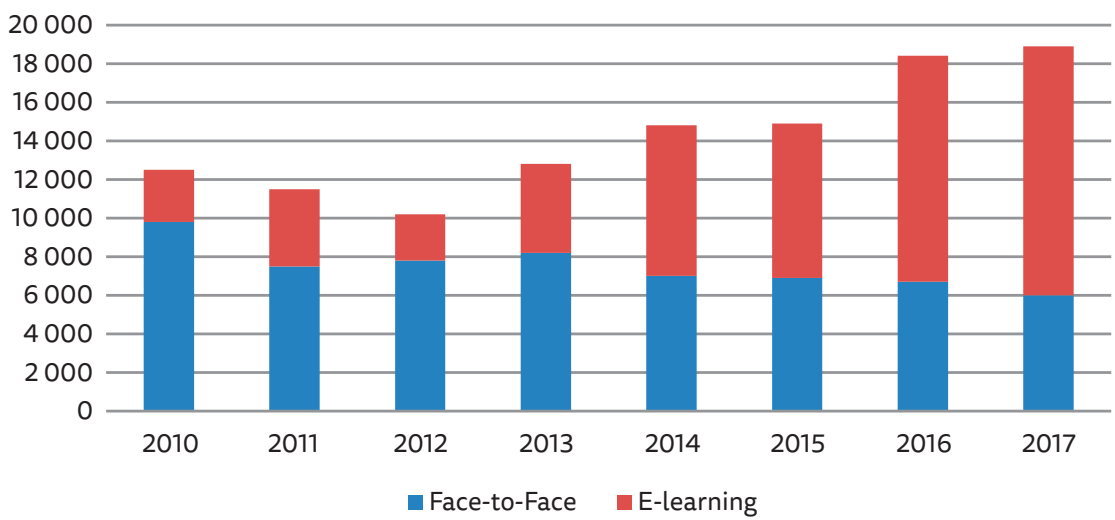

Source: WTO, 2018a.

\section{Intermediate Level - Regional Trade Policy Course (RTPC) and seminars}

This is usually an eight-week course on regional policy for both professionals and generalists. It is aimed at participants from seven regions: Africa (French and English), Asia and the Pacific, the Caribbean, Latin America, Arab and Middle Eastern countries, Central and Eastern Europe, and Central Asia. ${ }^{34}$

33 The share of individual regions in online courses is as follows: Africa - 38\% of all participants, Latin America - 20\%, Asia and the Pacific - 19\%, Central and Eastern Europe and Central Asia - 10\%, the Middle East and the Arab states - 9\%, the Caribbean and other regions - 5\% (WTO, 2016a, p. 134).

34 For example, training for specialists in 2015 included: English workshops in Kenya on sanitary and phytosanitary measures and technical barriers to trade, regional workshops in French, organized in Côte d'Ivoire, relating to intellectual property and public health; a seminar organized at the Institute in Vienna for the countries of Central, Eastern Europe, Central Asia and the Caucasus on government procurement; a seminar on agriculture organized in the UAE for Arab states and the Middle East (WTO, 2016a, p. 132). 


\section{Advanced Level - Regional Trade Policy Course and seminars}

For people with general knowledge, these are Advanced Trade Policy Courses (ATPC), and for specialists - training on a specific topic, as requested. They are usually held in Geneva-based training facilities or, less frequently, in a member state. Courses for specialists in the field of trade policy concern, among others, dispute resolution, intellectual property rights, regional trade agreements, sanitary and phytosanitary measures, trade in services, and trade policy analysis.

\section{Figure 19. Types of Courses and Training under the WTO Progressive} Learning Strategy

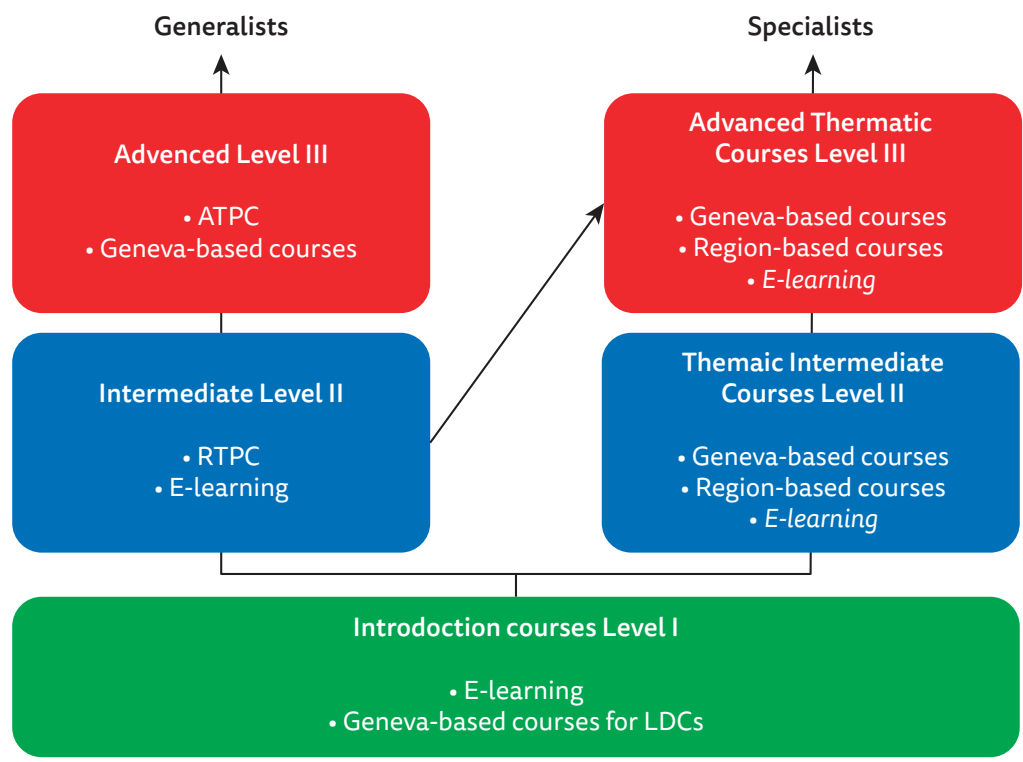

Source: WTO, 2011c.

\section{Technical support missions to certain developing countries - WTO members}

The missions are established at the request of a developing country and concern the necessity to fulfill obligations resulting from the WTO agreements and/ or to integrate trade into national economic development plans.

\section{WTO information centers in developing countries}

Over 65 such centers have been opened around the world. In 2015 alone, nine new ones were established: seven in Africa (in Chad, Lesotho, Cameroon, the Democratic 
Republic of Congo, Equatorial Guinea, Guinea, and Uganda), one in the Middle East (in Lebanon), and one in Central Asia (Kyrgyzstan) (WTO, 2016a, p. 134).

\section{Support related to teaching and conducting research on WTO and international trade}

This type of assistance is provided in two ways:

- using the WTO program (WTO Chairs Program) launched at universities in developing countries and LDCs,

- as part of an Academic Support Program.

The first is a program currently being implemented in 21 academic institutions in developing countries. Its second edition has been running since 2014. The second program provides support for those institutions from developing countries that are not included in the WTO Chairs Program.

\section{Weekly information training in Geneva (Geneva week)}

These are meetings addressed to senior state officials and are attended by representatives of developing countries - members of the WTO who do not have permanent representations to the WTO in Geneva. The aim is to provide information about the latest developments in the organization.

\section{Internship programs for government officials}

The WTO runs four long-term apprenticeship programs:

- The Accession Internship Program (AIP) funded by China,

- French \& Irish Mission Internship Program (FIMIP) funded by France and Ireland,

- Netherlands Trainee Program (NTP),

- Regional Coordinator Internship Program (RCI) financed by the DDAGTF (WTO, 2016a, p. 24).

All internship programs take place in Geneva, either at the headquarters of the mission where the trainees are temporarily employed, or at the WTO Secretariat. The first of four programs is for students from developing countries and LDCs, the remaining three are for middle-level officials. Their goal is to gain knowledge about the activities of the WTO by participating in training conducted by WTO employees and members of permanent missions. 


\section{Legal assistance related to the use of the WTO dispute settlement mechanism}

(Art. 27.2 Understanding on the Rules and Procedures Governing the Settlement of Disputes, DSU)

\section{WTO introductory course for LDCs in Geneva}

LDCs have privileged access to WTO training and courses as part of technical assistance. According to the 2012-2017 average, representatives of these countries account for one third of the total number of participants in training and meetings conducted by the WTO. This applies both to activities in the form of face-to-face meetings and in the e-learning formula (WTO, 2018a, p. 23).

Table 6. WTO Technical Assistance Activities by Region, 2016

\begin{tabular}{|l|r|r|r|r|r|r|r|r|r|r|}
\hline \multicolumn{1}{|c|}{ Region } & \multicolumn{2}{c|}{ National } & \multicolumn{2}{c|}{ Regional } & \multicolumn{2}{c|}{ Global } & \multicolumn{2}{c|}{ Other } & \multicolumn{2}{c|}{ Total } \\
\hline Africa & 40 & $36 \%$ & 14 & $24 \%$ & 0 & $0 \%$ & 10 & $27 \%$ & 64 & $20 \%$ \\
\hline Arab and Middle East & 7 & $6 \%$ & 6 & $10 \%$ & 0 & $0 \%$ & 1 & $3 \%$ & 14 & $4 \%$ \\
\hline Asia and the Pacific & 24 & $22 \%$ & 14 & $24 \%$ & 0 & $0 \%$ & 3 & $8 \%$ & 41 & $13 \%$ \\
\hline $\begin{array}{l}\text { Central and Eastern } \\
\text { Europe, Central Asia }\end{array}$ & 18 & $16 \%$ & 8 & $14 \%$ & 0 & $0 \%$ & 5 & $14 \%$ & 31 & $10 \%$ \\
\hline Caribbean & 3 & $3 \%$ & 5 & $8 \%$ & 0 & $0 \%$ & 0 & $0 \%$ & 8 & $3 \%$ \\
\hline Latin America & 18 & $16 \%$ & 7 & $12 \%$ & 0 & $0 \%$ & 5 & $14 \%$ & 30 & $10 \%$ \\
\hline Subtotal & 110 & $100 \%$ & 54 & $92 \%$ & 0 & $0 \%$ & 24 & $65 \%$ & 188 & $60 \%$ \\
\hline Global & 0 & $0 \%$ & 5 & $8 \%$ & 109 & $100 \%$ & 13 & $35 \%$ & 127 & $40 \%$ \\
\hline Total & 110 & $100 \%$ & 59 & $100 \%$ & 109 & $100 \%$ & 37 & $100 \%$ & 315 & $100 \%$ \\
\hline
\end{tabular}

Source: WTO, 2017b.

Taking into account the regional distribution, the majority of participants of WTO trainings and courses came from Africa (20\%), Asia and the Pacific (13\%) (Table 6). This was due to the privileged position of LDCs and easier access of people from these countries to WTO courses. It was about both the financial conditions and the pool of vacancies. It was followed by representatives from Latin America (10\%), Central and Eastern Europe, and Central Asia (10\%), the Middle East and Arab states (4\%) (WTO, 2017b, p. 135). The remaining 40\% of actions defined as global were targeted at all participants, regardless of the region. Geneva-based courses, e-learning, internship programs, and legal advice prevailed. 


\subsection{Planning and Management of Technical Assistance}

The WTO carries out technical assistance tasks in order to achieve four basic results (see Figure 20). The structure for planning, steering and evaluating WTO TA activities is based on a Results-Based Management (RBM) mechanism. Donors pledged to implement the RBM principles in the Millennium Declaration ${ }^{35}$. Since 2013, it has been the basic tool for the preparation, implementation and evaluation of technical assistance and in the WTO, it is used only to handle trade-related technical assistance activities (WTO, 2011b, p. 3). It was introduced to streamline the process of carrying out tasks related to the organization of courses and training, especially at the planning and decision-making stages, as well as to increase transparency and accountability for their performance. This approach is in line with the objectives of the Paris Declaration.

In line with the Biennial Technical Assistance and Training Plan for 2014-2015 and 2016-2017, the organization adopted a task performance goal based on four basic results (Figure 20):

- Result 1:WTO agreements are implemented and developing countries and LDCs fully exercise the rights and obligations of membership in the organization;

- Result 2: WTO candidate countries participate in accession negotiations in accordance with the WTO accession procedures;

- Result 3: members gain access to and use information on the WTO, leading to an improved knowledge of how the WTO works;

- Result 4: cooperation of the WTO with members of parliaments, journalists, and representatives of civil society. Support for students and academic centers dealing with issues of international trade and the WTO, which is to lead to an increase in research and training on this subject (WTO, 2015a, p. 18).

Slight modifications of the last two results appeared in the two-year plan for 2018-2019. In the case of Result 3, it was assumed that academic institutions and other stakeholders will conduct research related to the functioning of the WTO and pass it on to policymakers. In turn, in order to achieve Result 4, it was assumed that

35 The application of RBM to the MDGs was limited to Objective Eight and partly also Objective Seven. The Eighth Objective was to "realize a global partnership for development and encompasses four targets: (8a) develop further an open, rule-based, predictable, non-discriminatory trading and financial system, (8b) address the special needs of the least developed countries, (8c) address the special needs of landlocked developing countries and small island developing States and (8d) deal comprehensively with the debt problems of developing countries through national and international measures in order to make debt sustainable in the long term." The seventh goal concerned the application of sustainable methods of managing natural resources by taking into account the principles of sustainable development in national strategies and programs, the use of methods that inhibit the depletion of the natural environment (European Center..., 2014, p. 5). 
all interested non-governmental entities would obtain information and knowledge on the work and issues related to the WTO (WTO, 2017c, p. 20).

Figure 20. WTO Roadmap for Technical Assistance Activities

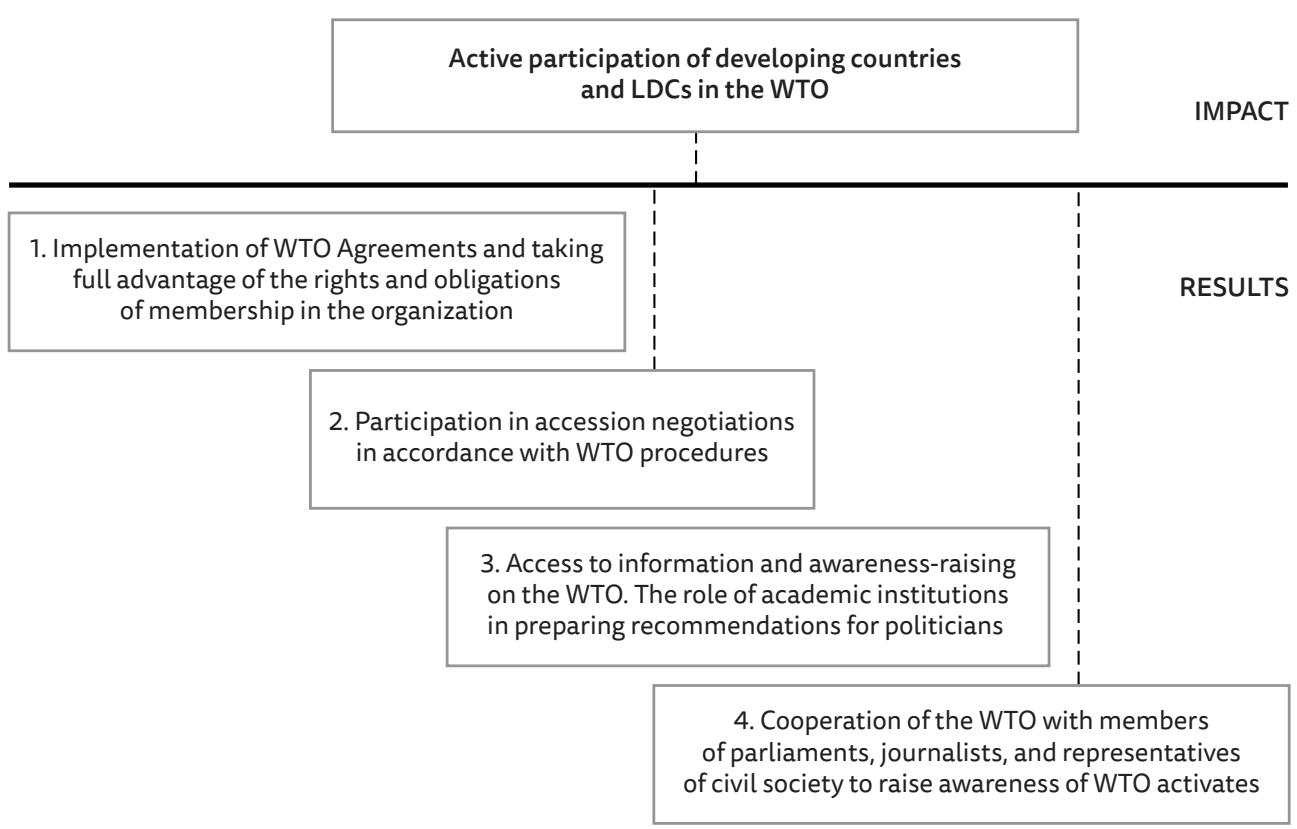

Source: own study based on WTO, 2015, 2015a, 2017c, 2018a.

The achievement of Result 1 on the implementation of agreements is of the greatest importance for the functioning of the WTO. This means that the basis for the organization's operation is the adoption and implementation of jointly agreed rules, however, additional preferences in the form of concessions and exemptions apply to developing countries and LDCs. ${ }^{36}$ The variety of activities offered regarding Result 1 is incomparably greater than the other three, i.e., participation in accession negotiations (Result 2), access to information and raising the level of knowledge about the WTO (Result 3) and cooperation of the WTO with members of parliaments, journalists, representatives of civil society (Result 4) Figure 20. Approximately $82 \%$ of the total amount for WTO technical assistance is allocated to the task of implementing WTO agreements (Result 1 ). For the remaining results 2,3 , and 4 , it is $5 \%, 2 \%$, and $12 \%$, respectively, of total WTO resources directed to technical

36 This problem is discussed in more detail in Chapter V. 
assistance purposes (WTO, 2018c. The other three forms of engagement can be considered as complementary to Result 1.

According to the Biennial Plan 2016-2017, the results of activities undertaken by the WTO in the framework of technical assistance were largely achieved (WTO, 2018a, p. 6). In total, the value of goals achieved in 2017 increased by $5 \%$ compared to 2016, which brought the result at the level of $62 \%$. The most successful was Result 2 concerning the participation of countries in accession talks, which was reached at the level of 75\% (50\% in 2016). This was followed by the result related to the implementation of WTO agreements, the implementation of which was $69 \%$ compared to $71 \%$ in 2016 . Result 4, relating to cooperation with representatives of civil society, parliamentarians, journalists and the support of academic centers, was completed with the result of $56 \%$ compared to $39 \%$ in 2016 . The least favorable was Result 3 related to access to information on the WTO and the use of related knowledge. In this case, it was 25\%, as in 2016 (WTO, 2018a, p. 6).

Figure 21. WTO Technical Assistance Activities by Impact Range, 2012-2017 (in \%)

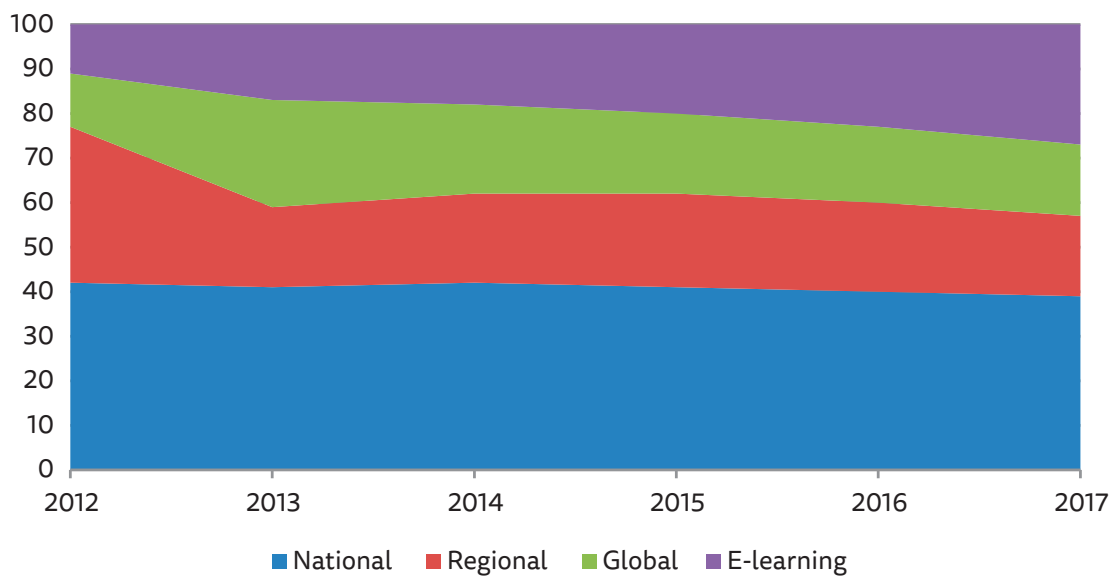

Source: WTO, 2018a.

Taking into account the criterion of the scope of activities undertaken under the WTO's technical assistance, four types of activity are distinguished: national, regional, global, and e-learning. The last type is a separate category due to the method of delivery. Figure 21 shows that, despite a slight, but persistent decline since 2014 , the number of activities on a national scale is still the dominant element of technical assistance. In 2017, this category reached $39 \%$ of total TA activity and has remained at a similar level for two years. Its great popularity results from the ease of their organization, which is emphasized by the WTO Secretariat. This applies to the 
flexibility of deadlines and high attendance. There is a clear upward trend in online courses. Their share in the total offer has been systematically increasing since 2012, which means that it is the second largest category of activities undertaken by the WTO. The share of other types of activity - regional and global - remains constant (Figure 21). Due to changing financial resources as well as the demand for certain types of activities, their participation may fluctuate further.

While improvements in the management of technical assistance have been observed, mainly with regard to the organization of training and its funding, it has been difficult to obtain reliable data on the impact of WTO's actions on trade policy of aid recipients. The WTO organizes several hundred independent activities on various topics every year (315 activities in 2016). In 2015, about 15000 people from over 130 different countries took part in them, while in 2017 the number of participants exceeded 18 000, and they came from 147 countries (WTO, 2017b, pp. 134, 136). Gathering reliable and representative data on the possible outcomes of actions taken is always a challenge with such a large sample.

\subsection{Financing of Technical Assistance}

The WTO does not provide financial aid in the form of grants and preferential loans, as well as in-kind aid, in line with the principles underlying the provision of ODA. However, financial contributions from WTO member countries for development purposes are directed to provide training and courses for representatives of developing countries or to support specific trade capacity building in recipient countries.

Technical assistance activities are financed from three sources: the WTO core budget for technical and training assistance, voluntary contributions from members of the organization, channeled through the DDAGTF, and other trust funds. On average, about $63 \%$ of financial resources allocated to technical assistance come from the DDAGTF, followed by contributions from the core budget (24\%) and transfers from other trust funds (13\%) (WTO, 2015a, p. 33).

Table 7. Planned WTO Budget for Technical Assistance, 2011-2017 (CHF million)

\begin{tabular}{|l|r|r|r|r|r|r|r|}
\cline { 2 - 7 } \multicolumn{1}{c|}{} & 2011 & 2012 & 2013 & 2014 & 2015 & 2016 & 2017 \\
\hline Core funding (regular budget) & 5.7 & 4.4 & 4.5 & 4.5 & 4.5 & 4.5 & 4.5 \\
\hline DDAGTF & 24.0 & 18.0 & 18.6 & 14.4 & 14.4 & 12.0 & 12.0 \\
\hline Other funds & 1.3 & 1.2 & 1.2 & 2.3 & 2.4 & 2.5 & 2.5 \\
\hline Total & 31.0 & 23.6 & 24.3 & 21.2 & 21.3 & 19.0 & 19.0 \\
\hline
\end{tabular}

Source: own study based on WTO, 2009a, 2012a, 2013a, 2015a. 
The size of the WTO core budget for technical assistance remains relatively constant, amounting to CHF 4.5 million (Table 7). Before 2012, due to changes within the organization, there were more funds available for technical assistance. However, at the turn of 2009-2011, they were reduced by about $20 \%$, which corresponded to nearly CHF 1.2 million (WTO, 2012c, p. 4). This was done because of the global financial crisis (2008+) and the resulting fiscal problems of major contributors to the WTO budget and the DDAGTF. The appreciation of the Swiss franc, in which WTO funds are invested, should also be considered as a cause. Therefore, it was decided to revise the two-year WTO technical assistance plan, thus lowering the forecasted budget for the years 2016-2017 to CHF 19 million (Table 7). Based on more realistic financial forecasts, the core budget for technical assistance was set at around CHF 4.5 million per year. The situation is different in the case of extra-budgetary funds channeled through the DDAGTF and other trust funds (WTO, 2012, p. 41). Contrary to the organization's core budget, contributions to the WTO trust funds are voluntary.

WTO funds that finance TA activities fall into three categories:

1) the Doha Development Agenda Global Trust Fund,

2) WTO trust funds,

3) funds administered by the WTO and co-created by other multilateral institutions.

Ad. 1 . The specificity of the DDAGTF is that it is the main source of funding for WTO technical and training assistance, and the resources at its disposal are not considered multi-bi. This means that, unlike other funds, WTO resources from the DDAGTF are extra-budgetary (non-core), but do not qualify as earmarked or multi-bi funds. The WTO retains full control over the purposes and the ways of their disbursement. The Global Trust Fund, led by the WTO, is a multilateral trust fund (MDTF) designed to finance assistance to a larger number of beneficiary countries and is used to implement projects in a specific sector or field. It was established by WTO member states in December 2001 at the Ministerial Conference inaugurating the Doha Round. In accordance with the obligation contained in the WTO Ministerial Declaration of Doha, the trust fund aims to finance technical assistance programs and training activities for developing countries and LDCs, as well as economies in transition (Doha Declaration, par. 40; WTO, 2001b). The DDAGTF is overseen by the bodies of the WTO, i.e., the Committee on Budget, Finance and Administration, and the Committee on Trade and Development.

Since 2013, there has been a downward trend in contributions and expenditure under the DDAGTF. In 2015, 13 members of the WTO undertook to transfer a total of CHF 9.1 million, while in the following year the amount of funds decreased to CHF 7 million, and in 2017 to CHF 6.3 million (Figure 22). Compared to 2011, when the contributions exceeded CHF 15 million, the interest of donors in this type of aid 
financing mechanism has clearly decreased (WTO, 2012, p. 42). The largest donors of funds are the EU, Germany, Sweden, France, Norway, the United States, Canada, and Japan (Table 8). However, the increase in the share of some donors was in fact due to the appreciation of the CHF against most other national currencies. As a consequence, this situation led, inter alia, to a gradual reduction in the contribution to the DDAGTF from the annual average in 2011-2013, exceeding CHF 13 million, to a level below CHF 8 million in 2014 and slightly over CHF 6 million in 2017 (see Table 8).

\section{Figure 22. Financial Resources from the DDAGTF, 2011-2017 (CHF million)}

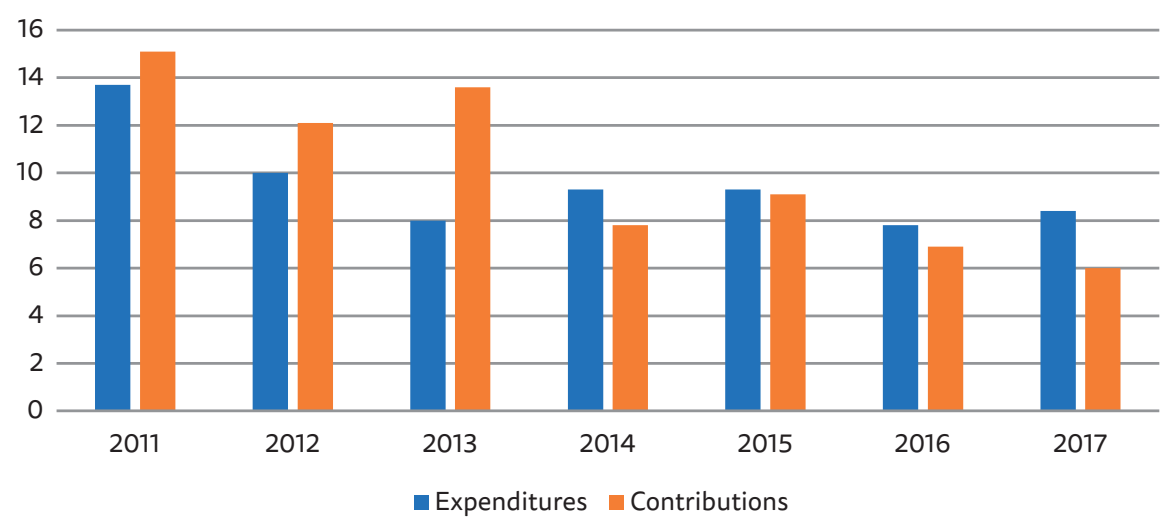

Source: WTO, 2017d.

The creation of the DDAGTF was the result of changes that took place within multilateral development aid system. They resulted from the necessity to adjust to the commitments contained in the Monterrey Consensus and the Paris Declaration. One of the objectives set at that time was to counteract the fragmentation of multilateral aid. The establishment of one consolidated fund was to ensure a stable funding basis and prevent the dispersion of funding sources, but in practice, the rules of operation did not guarantee the implementation of tasks at a predictable level. Typically, contributions to the fund are made in the last months of the calendar year, which makes the planning process difficult. For instance, the good outcome of DDAGTF for 2015, which amounted to CHF 9.1 million, resulted from the payment of a larger sum of funds in the last month of 2014. This is a different practice from the core budget planning rules of an international organization, which are done several years in advance.

Ad. 2. Financing of the WTO technical assistance from other funds account for approximately $12-13 \%$ of the organization's total resources allocated to TRTA. The number of funds operating for the purposes of implementing WTO tasks changed over 
the years and depended on the purpose for which the funds were to be collected. It should be noted that these are voluntary funds, resulting from an individual decision of the donor country. In 2015, total contributions under the WTO funds exceeded CHF 2.8 million. In the following year, the amount of funds decreased by half, but in 2017 it returned to the previous level of approximately CHF 2.9 million (Table 9).

Table 8. The DDAGTF in 2011-2017 (CHF million)

\begin{tabular}{|c|c|c|c|c|c|c|c|c|}
\hline $\begin{array}{l}\text { Contribution } \\
\text { and Pledges }\end{array}$ & 2011 & 2012 & 2013 & 2014 & 2015 & 2016 & 2017 & Total \\
\hline Australia & 1803600 & - & 2689900 & 61370 & 2162382 & - & - & 6717252 \\
\hline Austria & 258600 & 240200 & 243600 & 241400 & 104900 & 109000 & 215200 & 1412900 \\
\hline Canada & 944276 & 1362298 & - & - & - & - & - & 2306574 \\
\hline Czech Republic & 23746 & - & - & - & - & - & - & 23746 \\
\hline Denmark & 331230 & 321903 & 491063 & 482422 & 400028 & - & - & 2026646 \\
\hline Estonia & 26209 & 23199 & 24160 & 24640 & 24120 & 21800 & 21520 & 165648 \\
\hline European Union & 1187500 & 1024050 & 1232000 & 317592 & 1658552 & 1294800 & 218000 & 6932494 \\
\hline Finland & 1228000 & - & - & - & - & - & - & 1228000 \\
\hline France & 611000 & 600500 & 617000 & 608500 & 434400 & 433200 & 455600 & 3760200 \\
\hline Germany & 1237500 & 1198000 & 1233000 & 1203000 & 1060000 & 1083000 & 1139000 & 8153500 \\
\hline Japan & 395604 & 395604 & 368744 & 312019 & 267413 & 218643 & 233669 & 2191696 \\
\hline South Korea & 322350 & 334950 & 313600 & 336350 & 346500 & 347200 & 331100 & 2332050 \\
\hline Liechtenstein & 40000 & 40000 & 40000 & 40000 & 40000 & 40000 & 40000 & 280000 \\
\hline Netherland & 1472990 & - & - & 875000 & 495000 & 490000 & 490000 & 3822990 \\
\hline Norway & 1593626 & 2438905 & 2287108 & 2163722 & 1161373 & 1177302 & 722022 & 11544058 \\
\hline Spain & 400050 & - & - & - & - & - & - & 400050 \\
\hline Sweden & 2074322 & 2386905 & 2245600 & - & - & 1253700 & 1929722 & 9890249 \\
\hline Switzerland & - & 800000 & 800000 & - & - & - & - & 1600000 \\
\hline Taiwan & 184200 & - & 181400 & - & - & - & - & 365600 \\
\hline United States & 940580 & 940535 & 851885 & 1127392 & 950400 & 529036 & 571172 & 4896000 \\
\hline $\begin{array}{l}\text { Total } \\
\text { Contributions }\end{array}$ & 15075383 & 12107049 & 13619060 & 7793407 & 9104068 & 6997681 & 6367005 & 71063653 \\
\hline $\begin{array}{l}\text { Total Number of } \\
\text { Donors }\end{array}$ & 19 & 13 & 15 & 13 & 13 & 12 & 12 & - \\
\hline
\end{tabular}

Source: own study based on WTO, 2017d.

The group of trust funds financing training programs related to the WTO technical assistance includes three entities: a scholarship program financed by China and directed to LDCs in connection with their accession to the WTO (TCLAP), the French \& Irish Mission Internship Program (TIMM1) and the Netherlands Trainee Program (TNL05). Apart from them, the WTO also occasionally uses other funds, intended for specific purposes. For example, in 2014-2015 there was a fund for the evaluation of the functioning of the WTO funds (TEVAL). 
Table 9. WTO Technical Assistance Trust Fund Contributions (CHF million)

\begin{tabular}{|c|c|c|c|c|c|c|c|c|}
\hline Fund & 2011 & 2012 & 2013 & 2014 & 2015 & 2016 & 2017 & Total \\
\hline \multicolumn{9}{|c|}{ WTO TRUST FUNDS } \\
\hline $\begin{array}{l}\text { French - Irish } \\
\text { Internship } \\
\text { Programme } \\
\text { (TIMM1) }\end{array}$ & 1153805 & 1157782 & 801800 & 789400 & 808200 & 814050 & 847050 & 6372087 \\
\hline $\begin{array}{l}\text { China LDCs } \\
\text { \& Accessions } \\
\text { Programme } \\
\text { (TCLAP) }\end{array}$ & - & - & 362800 & - & 485000 & 485000 & 473000 & 1805800 \\
\hline $\begin{array}{l}\text { Netherlands } \\
\text { - Trainee } \\
\text { Programme } \\
\text { (TNL05) }\end{array}$ & 94701 & 1793909 & - & 1750000 & 875000 & - & 875000 & 5388610 \\
\hline $\begin{array}{l}\text { Evaluation } \\
\text { of WTO Trust } \\
\text { Funds Activities } \\
\text { (TEVAL) }\end{array}$ & - & - & - & 96240 & 215006 & - & - & 311246 \\
\hline $\begin{array}{l}\text { 10th/11th } \\
\text { Ministerial } \\
\text { Conference } \\
\text { (TMI10 TMI11) }\end{array}$ & - & - & - & - & 398288 & - & 728906 & 1127194 \\
\hline $\begin{array}{l}\text { Total } \\
\text { Contributions }\end{array}$ & 1248506 & 2951691 & 1164600 & 2635640 & 2781494 & 1299050 & 2923956 & 15004937 \\
\hline \multicolumn{9}{|c|}{ TRUST FUNDS RELATED TO WTO AND OTHER ORGANIZATIONS } \\
\hline $\begin{array}{l}\text { STDF on SPS } \\
\text { (TWB01) }\end{array}$ & 6520551 & 4528188 & 3605765 & 4344281 & 4558478 & 4045375 & 4678392 & 32281030 \\
\hline $\begin{array}{l}\text { Trade } \\
\text { Facilitation } \\
\text { Agreement } \\
\text { Facility (TFAF) }\end{array}$ & - & - & - & - & 4402355 & 2268892 & 1217200 & 7888447 \\
\hline $\begin{array}{l}\text { Total } \\
\text { Contributions }\end{array}$ & 7769057 & 7479879 & 4770365 & 6979921 & 11742327 & 7613317 & 8819548 & 55174414 \\
\hline
\end{tabular}

Source: own study based on WTO, 2017b, 2017d.

Some of the funds that remained from TEVAL were donated to the DDAGTF (WTO, 2017d). Moreover, in connection with the organization of the WTO Ministerial Conference, a special fund for the participation of LDCs is cyclically activated. In 2015, it was the 10th Ministerial Conference in Nairobi (TMI10), and in 2017 the 11th Ministerial Conference in Buenos Aires (TMI11).

Ad. 3. The third category of funding sources for technical assistance are funds from programs co-created and co-financed by the WTO and other multilateral organizations. These are trust funds supporting aid initiatives such as the STDF, TFAF, and the EIF (Table 9). At this point, the Standards and Trade Development Facility (STDF) and its fund (The Standards and Trade Development Facility on Sanitary and Phytosanitary (STDF on SPS) should be mentioned in more detail. The Facility was established in 2002 by international organizations, i.e., the World Bank, WTO, FAO, 
OIE, and the WHO. It is a mechanism for coordinating and financing the activities of developing countries in the field of capacity building to implement international sanitary and phytosanitary standards. Its aim is to improve the standards of human, animal, and plant health protection in developing countries, and therefore grant foreign markets better access to their goods and services.

The Trade Facilitation Agreement Facility can be placed in the same category as the STDF. In both cases, the WTO manages the secretariat of these programs and administers their trust funds. Both funds can benefit private and public entities from developing countries. Two types of grants are awarded: for project management and for their preparation (Calster, Prévost, 2013, p. 814). The STDF in the first three years of operation was financed from a fund belonging to the World Bank Development Grant Facility. In turn, the TFAF fund was created as a result of transformations related to the completion of the negotiation process on the Trade Facilitation Agreement. TFAF took over the tasks of two previous funds: Trade Facilitation National Needs Assessments and Trade Facilitation Negotiating Group.

Apart from these, there is another structure through which the WTO carries out its technical assistance tasks to assist LDCs - the EIF initiative and its trust fund. The WTO handles the EIF Secretariat, while the fund is managed by the UN Office for Project Services (UNOPS).

Due to the reduction of resources in the WTO core budget for technical assistance, the system of courses and training was reorganized. First of all, the number of faceto-face courses has been limited in favor of a greater offer of e-learning training. Before the changes that took place between 2009 and 2011, two types of activities were financed from the core budget: training conducted at the seat of the WTO in Geneva and national missions. The on-site training courses included three-month Trade Policy Courses for general knowledge participants, induction courses for LDCs, Geneva week meetings, selected thematic courses, and legal assistance related to the use of the dispute settlement mechanism. In turn, the WTO's national missions in the recipient countries were transformed over time into Academic Support Program (ASP) at universities. Their number has been reduced and funding has been limited, making them dependent on the proceeds from the trust funds.

Thanks to the use of the education system at various levels of advancement and for various groups of recipients, the pressure to organize costly stationary training has decreased at the seat of the WTO in Geneva. This applies to the basic course for participants from LDCs as well as Trade Policy Courses for participants with higher level of general knowledge. In the first case, the number of courses was limited, and in the second - their duration. In addition, the source of funding was changed. TPCs were to be financed not only from the core budget, but also 
from the DDAGTF. Moreover, a reduction in financing of the weekly information meetings of the Geneva week-type was announced. Changes were made to national missions and academic programs (ASP), which were to be entirely financed by voluntary contributions from members of the organization through funds. Due to the changing level of inflow of funds from the DDAGTF and other trust funds, flexible spending rules were adopted for specific types of activities. Thus, the scope and types of activities under the TRTA were made dependent on the amount of contributions from WTO member states.

\subsection{Evaluation of WTO Activities in the Field of Technical Assistance}

The evaluation of technical assistance carried out by the WTO depends on the type of action. The first attempts to summarize the activities of the WTO by applying the Results-Based Management were carried out in 2013 and 2014 (see Figure 20). In the short term, it was easiest to evaluate the results of the basic level training, as each of them ended with an exam. The remaining courses were assessed by the recipients themselves and received very positive opinions (WTO: Enhanced...). Assessment was based on feedback from course participants.

Long-term assessment of the WTO engagement turned out to be the most difficult task. The reasons were practical and methodological ones. This was due to the fact that the data needed to be compiled for the evaluations of the conducted trainings came from the recipient countries, and the answers were included in the questionnaires filled out by the training participants even several weeks after the end of the classes, so it was difficult to obtain reliable and representative data. Moreover, the number of countries participating in the trainings and the variety of activities undertaken by the WTO made it impossible to compare the information received. Recipient states indicated difficulties in collecting and processing data. On the other hand, the way in which they were collected and made available by developing countries was to a small extent in line with the RBM procedures. The evaluation of WTO activities was therefore limited to examining the organization's contribution to the achievement of the main goal, such as the implementation of the WTO agreement or membership in the organization (see Results 1 and 2) (WTO, 2015a, par. 42).

Attempts to improve the efficiency of monitoring and evaluation of TRTA encountered numerous limitations. First, there is resistance from the WTO Secretariat. According to the members of the Secretariat, the introduction of the RBM complicated the process of providing technical assistance and increased transaction costs due to more demanding administrative procedures. Second, difficulties in implementing 
RBM in developing countries were an obstacle to better TA outcomes. Obtaining reliable data on the activities carried out by the WTO turned out to be a difficult task in many cases due to administrative, staffing, and competence limitations in the recipient states. Thirdly, due to the reduction of the budget for technical assistance (lower payments from the DDAGTF), the organization was forced to change the training system - primarily to expand the offer of online courses at the expense of stationary training conducted at the WTO headquarters or in the member states (regional activities).

Another way to assess the activities of the WTO is through the analysis of the four main results on TA. Firstly, the implementation of the strategic goal of the WTO, i.e., the implementation of WTO agreements, is a long-term and complex task (Result 1). The condition for success is not only the involvement of the WTO and a series of trainings, but most of all the introduction of comprehensive regulatory changes at the international and national level. To this end, systemic and economic reforms in developing countries as well as measures aimed at minimizing adjustment costs in the process of adopting new regulations are necessary. The activity of the WTO (courses and training) is a significant help in building trade capacities related to both building a trade policy that is compatible with WTO regulations and conducting negotiations on the WTO multilateral forum. Moreover, a positive outcome also depends on cooperation between various multilateral organizations and bilateral donors. An example is the joint efforts to adopt the WTO Trade Facilitation Agreement (TFA). Secondly, the best results in terms of WTO technical assistance were achieved when candidate countries participated in accession negotiations in accordance with WTO procedures (Result 2). It is the most measurable criterion for assessing the effectiveness of an organization. Since the creation of the WTO, the number of states (GATT contracting parties) has increased from 128 in 1994 to 164 in 2018. Currently (as of 2018), 22 governments of states or autonomous customs areas are in open negotiations towards WTO membership (Table 10).

Third, the access of developing countries to WTO information and data is gradually improved in order to better fulfill their rights and obligations (Result 3). It is closely related to increasing the level of knowledge about the WTO and the ability to use analytical tools offered by the organization, which undoubtedly translates into the more and more active involvement of developing countries in international trade negotiations. The result is access for developing countries to information on third countries' trade policies, but also the ability to exercise their rights by participating in the WTO dispute settlement mechanism. According to the basic rule of the WTO concerning reciprocity of obligations, similar standards for the collection and disclosure 
of information by developing countries are required to improve the transparency of the WTO and member states (Hoekman, Mavroidis, 2016, p. 21).

Table 10. States and Autonomous Territories in WTO Accession Negotiations (As of February 2018)

\begin{tabular}{|c|c|}
\hline & Autonomous States or Territories \\
\hline 1 & Algeria (1987) \\
\hline 2 & Andorra (1997) \\
\hline 3 & Azerbaijan (1997) \\
\hline 4 & The Bahamas (2001) \\
\hline 5 & Belarus (1993) \\
\hline 6 & Bhutan (1999) \\
\hline 7 & Bosnia and Herzegovina (1999) \\
\hline 8 & The Comoro Islands (2007) \\
\hline 9 & Equatorial Guinea (2007) \\
\hline 10 & Ethiopia (2003) \\
\hline 11 & Iran (1996) \\
\hline 12 & Iraq (2004) \\
\hline 13 & Lebanon (1999) \\
\hline 14 & Libya (2001 \\
\hline 15 & Sao Tome and Principe (2005 \\
\hline 16 & Serbia (2004) \\
\hline 17 & Somalia (2015) \\
\hline 18. & South Sudan (2017) \\
\hline 19 & Sudan (1994) \\
\hline 20 & Syria (2001) \\
\hline 21 & East Timor (2015) \\
\hline 22 & Uzbekistan (1994) \\
\hline
\end{tabular}

In brackets: the year in which accession negotiations started. Source: own study.

A sign of developing countries' use of information on WTO regulations and negotiating skills is the number and variety of coalitions and interest groups involved in multilateral negotiations. The activity of such groups strengthened the bargaining power and the ability of developing countries to influence other negotiating participants (Narlikar, 2003, p. 10). Coalitions between developing countries made it possible to overcome negotiating weaknesses and achieve common goals. On the other hand, their number and diversity mean that some developing countries 
participate in groups that have different goals and interests, and this makes it much more difficult to adopt a common position (Grącik-Zajaczkowski, 2002).

Fourthly, activities of developing countries at the WTO forum are further strengthened by cooperation with members of parliaments, representatives of civil society, and by providing support for research, academic institutions and students dealing with international trade and WTO issues (Result 4). The result of the WTO's work in this field is the growing interest in WTO-related issues not only at the level of the administrative apparatus in recipient countries, but also among students and academics in developing countries. This is evidenced by the increasing number of course and training participants, as well as the emerging WTO information centers (reference centers), of which more than 65 were established after 2016.

Activities undertaken by the WTO in the field of technical cooperation are modified in line with the changes taking place within multilateral aid system. First of all, it concerns the rules of financing. Nearly one fifth of the funds come from the WTO general budget, and the vast majority from the DDAGTF. An additional source of funding are trust funds with the participation of several or a dozen WTO members. These are multi-bi funds that carry out specific initiatives, usually requiring a short implementation period. Therefore, with the expanding pool of multi-bi funds, multilateral aid system is even more fragmented and difficult to coordinate. Multi-bi aid has become the fastest growing funding channel and can gradually replace the main source of TA funding. Therefore, the changes that took place within the framework of WTO confirm the thesis on the bilateralization of multilateral development aid. This is evidenced by the increase in requests from WTO members to allocate contributions to the DDAGTF for specific purposes (WTO, 2015a, par. 7.2). This means a gradual shift from jointly agreed goals within multilateral institutions to individual decisions of donor states.

\subsection{Summary}

The obligation of the WTO to provide technical assistance results from its regulatory function, which enables member states to create, adopt, and implement regulations relating to international trade (Article III of the Agreement establishing the WTO). Technical cooperation is implemented on the basis of multilateral actions and consists in the transfer of knowledge and know-how related to trade and WTO rules of operation to recipient countries. WTO activity in this area is manifested in:

- organizing and conducting courses and training on WTO agreements and the functioning of the organization; 
- coordinating and administering programs and initiatives jointly developed by the WTO and other multilateral organizations.

Organizing and conducting courses and training is the basic form of providing WTO's technical assistance. The aim is to improve trade capacity of developing countries in the process of negotiating and adopting WTO trade regulations. This also applies to participation in the accession negotiations. Due to the new approach to development cooperation, as well as changing financial resources, the WTO training and course system was reorganized. First of all, the number of face-to-face courses has been limited in favor of a greater offer in the e-learning formula.

The WTO regulatory function implies the coordinating and monitoring role that the WTO, through its Secretariat, performs for several programs and trust funds. The overriding challenge is therefore, to ensure coherence by entrusting the WTO with the role of administrator and manager of several initiatives. These include:

- an instrument to provide assistance to developing countries following the adoption of the WTO Trade Facilitation Agreement Facility;

- a strengthened and integrated framework for assistance to LDCs;

- a mechanism for financing grants for the adjustment of sanitary and phytosanitary standards in developing countries to WTO rules (STDF).

The main source of funding for the WTO's technical and training assistance is the DDAGTF. Despite the fact that the inflows have been decreasing for several years, it is still the basic instrument of support for aid activities provided by the WTO. This is followed by contributions from the WTO core budget for technical and training assistance, and from other trust funds. This group includes funds for the sole purpose of implementing WTO technical assistance. However, unlike the DDAGTF, whose resources are at the disposal of the WTO, funds transferred from other WTO trust funds fall under mixed categories (multi-bi). Decisions about their destination are made by individual donors. This group includes the Scholarship program for LDCs financed by China, the French \& Irish Mission Internship Program, the Netherlands Trainee Program, and the support fund for LDCs participation in the WTO Ministerial Conferences. In addition, there is another group of trusts fund where the WTO has an administrative role, such as the STDF, the EIF.

The challenge for the governance of a multilateral organization is the use of non-core resources (multi-bi). Their growing importance in financing aid activities leads to the phenomenon of bilateralization of multilateral aid system and limitation of the operational autonomy of multilateral institutions. Within the WTO, this tendency is not progressing to the same extent as in the case of other multilateral institutions, e.g., within the UN system. The problem of replacing funding from the core budget with multi-bi ones is relatively small. On the other hand, there is 
a significant decrease in the inflow of funds from the DDAGTF, which is not being replaced by contributions from other WTO trust funds. On the other hand, funds for multilateral programs such as TFAF and STDF, related to the WTO to a different extent, are growing. This may be for at least two reasons. First, the decline in the donors' interest in the activities provided by the WTO, which may be a consequence of difficulties in concluding the Doha Round. Secondly, due to the establishment of new initiatives (TFAF and STDT) and the need to supplement them with additional financial resources.

The best results of activities related to technical assistance undertaken by the WTO were achieved in the area of the participation of candidate countries in the accession negotiations. Application of the RBM instrument to coordinate and evaluate WTO activities provided more reliable data on planned results. However, considerable difficulties with obtaining information remain on the side of developing countries. Moreover, thanks to the RBM as well as the Progressive Learning Strategy, the training and course system was adapted to the staff capacity and financial resources of the WTO. Despite decreasing resources, the offer of courses was expanded, especially in the e-learning formula.

In the priority area, which is the implementation of WTO agreements by developing countries, some satisfactory results have been achieved, although much remains to be done. Improving the adoption of WTO regulations by developing countries does not depend only on the organization itself, but on cooperation with other multilateral institutions (WB, IMF, UN, OECD) and bilateral donors. It is for this reason that initiatives and programs co-established by the consortia of multilateral institutions can improve the harmonization of development cooperation activities. In the case of trade-related initiatives, the WTO acts as the oversight and administration body for joint initiatives. The transfer of knowledge and know-how in the field of international trade rules and principles, which result from the statutory functions of the WTO, creates opportunities for developing countries to make fuller use of trade. The activities undertaken by the WTO in this area are a significant complement to the activities carried out within the framework of a wider structure, i.e., multilateral development assistance 


\section{Chapter 4}

\section{AID FOR TRADE}

The obligation for developing countries to adopt and apply WTO rules has proven to be one of the toughest challenges faced by the organization. Problems with the implementation of regulations relating to international trade resulted from high adjustment costs associated with the preparation of administrative apparatus, institutions or legislation, especially by LDCs. Extending trade liberalization to developing countries, nearly excluded from the process during the GATT period, was conditioned by the adoption of new WTO regulations and the initiation of costintensive reforms. This required additional support. Increasing the involvement of developing countries in trade did not depend solely on decisions made by the WTO. A comprehensive effort was needed from various multilateral aid and development institutions as well as bilateral donors. This gave rise to the idea of setting up an Aid for Trade (AFT) program to boost development in developing countries by mobilizing trade.

The starting point for launching the AFT was the concept of development cooperation and the focus of international development institutions on closer cooperation with beneficiary countries. The process of implementing principles of development cooperation in practice began. Its main assumption was the cooperation of various participants of aid system and providing support in accordance with needs of the recipients. This meant a shift away from aid in the strict sense to creating a comprehensive approach, supporting the implementation of reforms in various areas and with regard to the specific development needs. In the case of the AFT, these are trade-related areas, which include both sectors of the economy directly affecting trade (infrastructure, manufacturing) and those more loosely related to it (e.g., health, education). Due to the complex and extensive scope of activities needed, the AFT was created thanks to the involvement of a consortium of multilateral institutions, which included the WTO, IMF, WB, UNDP, UNCTAD, ITC and the OECD. 
Both economic and political factors were responsible for establishing the AFT. The aim was to mobilize additional funds to support developing countries. It was about accepting greater liberalization commitments, which could lead to the erosion of their trade preferences. Moreover, there was a need to launch a coherent mechanism of coordination and monitoring of activities in a situation where the international aid system became more and more fragmented. The AFT was also expected to contribute to breaking the deadlock in the Doha Round negotiations and the adoption of the final agreement by WTO members.

The activities undertaken by the WTO in the context of AFT are of various nature. On the one hand, it is the implementation of the WTO's statutory tasks, which include technical assistance, and on the other hand, the coordination and administration of the program. This chapter analyzes WTO's activities under the AFT program. An attempt was also made to indicate the changing role of the organization in the field of international trade. In this case, the evolution of the WTO consists in broadening the activity and greater involvement in the implementation of WTO rules and regulations by less developed countries.

\subsection{The Origins of the AFT}

With the creation of the WTO, it was deemed necessary to establish cooperation between the newly established organization and multilateral aid institutions. In this way, it was intended to obtain financial support for WTO members in connection with their obligation to adopt and implement multilateral trade agreements. The idea was to create a mechanism called the Integrated Framework for Trade-Related Technical Assistance (in short: Integrated Framework, IF). At the WTO Ministerial Conference in Singapore in 1996, a decision was made to set up a program for LDCs by the WTO and five other multilateral aid and development institutions (IMF, ITC, UNCTAD, UNDP and WB). Its main task was to identify trade-related technical assistance needs. Over time, the IF structure has become an integral part of the AFT program.

The establishment of the IF was an important signal from institutional donors to change the approach to development aid. This meant that more attention was paid to issues related to developing countries' trade capacity. In such an arrangement, trade would play a fundamental role in influencing growth and development while supporting other sectors of the economy. In the early 2000s, many developing country governments called for increased resources to stimulate economic growth. For instance, the UN Millennium Task Force argued that trade could make a significant 
contribution to achieving the MDGs and reduce poverty by generating higher growth rates. The Commission for Africa was of a similar opinion (UN, 2005, pp. 13, 16, 37; Commission for Africa, 2005, p. 15).

Although many previous aid programs had an impact on trade development, this was not directly due to their inherent objectives, but more of their side effects (Hallaert, 2012, p. 5). Therefore, the IF was a reference point for the creation of later initiatives, especially the AFT. According to the concept of complementary policies, the potential benefits of trade cannot be effectively used without improving production capacity, reducing transport costs, increasing productivity in agriculture, developing the services market, and creating a good investment climate (Hoekman, Kostecki, 2011, p. 593). The IF was an example of using of this type of approach in practice.

The IF became operational in October 1997. The aim was to establish new guidelines for the provision of technical assistance to LDCs. A platform for cooperation between multilateral institutions and bilateral donors was established, the participants of which were also recipient states from LDCs (Nielson, 2006, p. 328). It was supposed to be an instrument for identifying specific needs for trade capacity development of these countries. However, in the initial years of IF's operation, the results of the undertaken activities were not satisfactory. First of all, this was due to the low financial resources of the Framework. It was not until the establishment of the IF Trust Fund in 2001 that funding could be increased. The IF fund resources were allocated to cover costs related to diagnosing commercial needs of LDCs for technical support and were not sufficient to finance technical assistance programs. The implementation of these tasks fell under the responsibility of traditional development aid allocation mechanisms (Hoekman, 2011, p. 5).

The IF was the first formal attempt to integrate development aid issues into the WTO structure. According to B. Hoekman, the idea came not from development agencies, but from a group of entities involved in the development of international trade (Hoekman, Kostecki, 2011, p. 591). The same was true of the Joint Integrated Trade Assistance Program (JITAP), which served similar purposes to the IF, although targeting fewer developing countries and involving more than LDCs. ${ }^{37}$ In 2006, as a result of a change in the approach to development aid, the name of the IF initiative was changed to Enhanced Integrated Framework (EIF). To this end, an independent secretariat was established, an action program and a budget were adopted. It was recommended to establish a fund of USD 200-400 million.

The statutory tasks of the EIF are financed by a multilateral trust fund. The entity is governed by the United Nations Office for Project Services. The WTO is

37 The program was targeted at 16 African countries, 10 of which belonged to the LDCs group. 
a member of the Council and also acts as the Secretariat that serves the EIF structure. Due to the limited financial resources and the way in which the EIF is managed, it is believed that it requires reform (Prowse, 2006, p. 255). Financing of the EIF's tasks is based on long-term plans. In the first phase of the program, in the years 2009-2015, recipient countries received support in the amount of USD 140690 million, despite the initial target of obtaining USD 250 million (UN, 2016a). In the second phase, in 2016-2022, donor countries committed to donate around USD 90 million (EIF, 2017). The initial seven-year budget was estimated at USD 274-320 million, and it is known by the end of this period that it will be difficult to raise the necessary funds.

The changes introduced to the EIF in 2006 were related to the necessity to extend the scope of responsibilities, which resulted from the commitments made by the international community with regard to increasing the effectiveness of development cooperation. The emphasis was placed on the long-term development of resources for technical assistance and capacity building, as well as strengthening the management structures and supervision of recipients over their development programs (principle of ownership). In addition, assistance to integrate trade into national development strategies and ensuring policy coherence and donor coordination remained a priority task.

Within the framework of the EIF, the following actions were committed (IMF, 2005, pp. 13-14; Nielson, 2006, p. 330):

- increasing financial resources and predictability of contributions (e.g., reducing the number of loans granted in favor of increasing preferential grants);

- strengthening the internal structures in the recipient country, which would be able to implement new solutions and support aid programs (e.g., appointment of executive units related to the state sector, but also to the private sector and civil society organizations);

- support for improving management in order to use funds from aid programs more effectively;

- pay more attention to needs of developing countries during the program preparation process;

- creating multi-annual technical assistance programs and building trade capacity (e.g., to strengthen major trade institutions, implement administrative and regulatory reforms, promote private sector initiatives);

- extending the scope of activities to include other less developed countries than just LDCs.

Within the structure of the EIF, the possibilities of cooperation between multilateral financial institutions, UN agencies, and the WTO were created. Each of them was assigned a specific role. The WTO was to be responsible for coordinating and 
monitoring the implementation of trade rules and rules by developing countries. The other partners dealt with issues related to financing for development (IMF, WB) and harmonization of development policy and trade (UNDP, UNCTAD). Due to the growing number of entities involved, the challenge for the EIF was to maintain consistency between the activities under the AFT and the national development priorities of a given country (Prowse, 2006, p. 258). The goal is to maintain greater harmonization of efforts while committing donors to increasing aid.

\subsection{Aims and Assumptions of the AFT}

The need to mobilize special support for developing countries emerged immediately after the conclusion of the GATT Uruguay Round. When all members of the newly established WTO obligatory organization were obliged to accept WTO agreements, the vast majority of member states were unable to fulfill their obligations. This was due to structural and institutional constraints and the low competitiveness of their economies, but also to the lack of constant and regular support from multilateral institutions and bilateral donors.

The necessity to accept the rights and obligations contained in the WTO agreements was associated with high implementation costs. Even if it was found that the adopted WTO regulations were beneficial for developing countries, the costs associated with the implementation of the agreements could be disproportionately greater than the potential gains (Finger, Schuler, 2000). Poor countries were unable to take full advantage of market opportunities due to their lack of competitiveness of their economies and the inability to cover the adjustment costs arising in the process of adopting new rules. As a result, developing countries made demands to mobilize additional funds to overcome constraints and increase their capability to reap benefits of international trade. Further assurances by WTO member states that they would make efforts to help implement the regulations were no longer sufficient (Hallaert, 2015 , p. 3). The establishment of the AFT made it possible to bring together different types of development assistance activities - from training negotiators to mechanisms to integrate markets in a coherent trade development strategy.

The basis of the AFT was an approach based on the integration of less developed countries with the world economy through trade policy liberalization. The main purpose of aid was to support developing countries in overcoming difficulties related to trade and their integration into the international trading system. At the beginning of the 1990s, the attention of international institutions dealing with development aid was shifted towards close cooperation with recipient countries by 
creating national strategies for reducing poverty (Hoekman, Kostecki, 2011, p. 593). The emerging concept of development cooperation was additionally reinforced by the adoption of the MDGs in 2000. One of the points of the Goal 8 (MDGs) was a commitment to develop an accessible, clear regulated, predictable and nondiscriminatory commercial and financial system for all, taking into account special needs of LDCs, in particular increasing access to markets of developed countries, reducing debts, improving development assistance. The result was not only a growth in aid expenditures, but most of all efforts to increase its effectiveness in meeting development needs.

In line with the theoretical assumption adopted in Chapter I, the AFT reflects the concept of complementary policies. The formula consisting in comprehensive support for various areas of the economy with an emphasis on trade development. However, more trade does not necessarily lead to an increase in national income or a reduction in poverty, but it is the result of a whole set of economic, social, and political conditions that influence development. Trade should be supported by additional channels which, by influencing it, contribute to the achievement of the assumed goals. The most important channels of influence on the sphere of trade include investments and production capacity, but also the construction of infrastructure and the financial sector as well as areas related to production (Hallaert, 2010, pp. 32-33). Therefore, the aim of the AFT was to mobilize those channels which, by influencing trade, contribute to the achievement of development goals, i.e., stimulating economic growth and reducing poverty. The range of complementary policies can be wide, which indirectly shapes business environment and increases the impact of the AFT.

Within the concept of interrelated policies that can have the greatest impact on the development of trade, the policies relating to investment, infrastructure construction and productive capacity building are distinguished. Education and research policies, as well as those related to institution building and regulation, play a much smaller role. Although some empirical studies provide evidence of their direct relationship with trade, their scope and impact are limited in the AFT.

The AFT initiative was neither a new development fund nor a new category of aid. In 1997 the aforementioned EIF structure was established. In the regional dimension, the Joint Integrated Technical Assistance Program for Africa (JITAPA) has operated since 1998. In most cases these activities were dispersed, and the impact difficult to assess. Therefore, it was decided to establish a coherent and integrated AFT program. 


\subsection{Scope and Categories of the AFT}

The AFT is part of regular development aid belonging to ODA (WTO/OECD, 2009 , p. 52). It includes government transfers provided by state or local government institutions to aid recipient countries on the official OECD-DAC list. The emphasis is placed on the concessional nature of loans granted to developing countries in the form of grants, as well as the regular and timely reporting the amount and categories of aid provided. In this context, WTO activities meet the requirements and qualify as ODA. In practice, the implementation of tasks is carried out by three entities closely institutionally related to the WTO. These are the Advisory Center on WTO Law, the Doha Development Agenda Global Trust Fund and the International Trade Center (OECD, 2010a, p. 57).

The program was founded on postulates to improve the development aid system (the Monterrey Consensus, OECD High-Level Forums, the Paris Declaration) (Hynes, Holden, 2013, pp. 3, 8; Hallaert, 2012, p. 2). It was related both to the increase of financial obligations for ODA to the level of $0.7 \%$ of GNI, but also the reorganization of international aid system and the application of the principle of ownership and accountability of aid recipients as well as the results-based management mechanism (RBM). Decisions on the establishment of AFT were taken by heads of state and government at the G-8 forum in May 2005 and in a joint IMF-WB meeting in March and September 2005. Only the confirmation of the possibility of finding additional funds by international financial institutions (IMF and WB) directly contributed to the commencement of the program (IMF, 2005, pp. 8-9). The official inauguration took place in December 2005 at the WTO Ministerial Conference in Hong Kong. In fact, the program started operating in January 2006.

The AFT importance grew as difficulties emerged with the Doha Round agreement and the convincing of developing countries to make concessions. The intention was to send a clear signal that the involvement of developing countries in trade liberalization would be backed by additional financial resources to cover adjustment costs. The guarantee of additional aid in the form of the AFT was to encourage them to participate more in trade negotiations and accept the agreement (Kopiński, 2009, pp. 33-40). Moreover, the assurance of support for less developed countries was included in the WTO Doha Ministerial Declaration, which recognized the need to enhance “ (...) support for technical assistance and capacity building (...)” (WTO, 2001b, part 21).

Under the leadership of the WTO, the international WTO Task Force was established, which prepared recommendations on how to implement the AFT and strengthen the development dimension of the Doha Round (Hynes, Holden, 2013, 
p. 3). The Task Force included representatives of the EU, the United States, Japan, Brazil, China, and India, as well as the chairmen of negotiating groups or coalitions operating within the WTO, i.e., the ACP, Africa, and LDCs. Additionally, special advisory groups were established within the OECD, IMF, and the World Bank. Since the concept of trade-based aid programs was not new, the AFT program was expected to be more effective (Stiglitz, Charlton, 2012, p. 11). Therefore, the main goal was to mobilize additional funds, but without creating new mechanisms to handle them. A decision was made to use the available instruments or to modify them within the founding organizations of AFT. The OECD and the WTO took care of the administration and monitoring of activities. According to the objective of the WTO Task Force, activities undertaken within the framework of AFT were to be closely related to the development programs of the state or region, as well as the national development strategy of the beneficiary country. The AFT included, in line with the concept of complementary policies, the following areas:

- technical assistance on trade policy and regulation (e.g., providing assistance in preparing trade strategies, negotiating trade agreements, and implementing their outcomes);

- assistance in building trade-related infrastructure (e.g., building roads, ports, telecommunications networks that connect local markets to the global economy);

- assistance in capacity building (supporting the private sector to exploit its competitive advantage, diversifying exports, stimulating investments in those sectors that give an opportunity to diversify the export structure and achieve comparative advantages);

- assistance related to adjustment costs resulting from trade liberalization (e.g., costs resulting from a decrease in tariff revenues or the removal of certain trade preferences);

- other development and trade-related needs, if identified as trade-related development priorities in partner countries' national development strategies (WTO/OECD, 2009, p. 53).

Within the AFT structure, the formula of undertaking actions aimed at launching specific support was relatively complex. First, the reference points were the areas of support (in terms of trade policy and regulation, capacity building, etc.). Second, the preparatory stage for the selection of support areas consisted of several elements: diagnosis of the recipient country's trade, extensive evaluation of its trade and preparation of a matrix of priority needs. Third, the final selection of development needs in order to prepare the AFT offer had to be in line with the recipient's programming document, i.e., the Poverty Reduction Strategy Papers, and be preceded by extensive consultations with bilateral and multilateral donors. 
From the WTO perspective, the most important goal of the AFT Initiative was to mobilize additional assistance to developing countries to engage more in the Doha Round negotiations and to commit to further trade liberalization. In the WTO Ministerial Declaration, adopted in Hong Kong in December 2005, it was assumed that the AFT should aim to help LDCs "to build the supply-side capacity and traderelated infrastructure that they need to assist them to implement and benefit from WTO Agreements and more broadly to expand their trade" (WTO, 2005b, par. 57). The WTO recognized that the platform for cooperation between major financial institutions, i.e., the IMF, the World Bank, regional development banks and the OECD was an effective incentive to increase financial commitments for traderelated programs (WTO, 2006a). The aim was therefore to increase the effectiveness of support through the inflow of more funds and to expand the scale of available instruments and mechanisms of financial and technical support.

The definition of activities classified as AFT was created on the principles adopted in the Paris Declaration. It was agreed that programs and projects could be treated as the AFT if they were included in the trade-related development priorities under the national development strategies of the recipient country (WTO, 2006c). The AFT activities fell into the following categories:

- trade policy and regulations,

- trade and development,

- capacity building,

- trade-related infrastructure,

- trade-related adjustment activities,

- other trade-related needs (WTO/OECD, 2007, pp. 71-72).

The adoption of a wide range of AFT activities has been beneficial from the perspective of recipient countries. Developing countries have opted for a variety of programs going beyond technical assistance and covering various economic sectors. The recommendations of the Task Force emphasized that "the scope of Aid for Trade should be defined in a way that is broad enough to reflect diverse trade needs of individual countries" (WTO, 2006c, par. D).

\subsection{Coordination and Monitoring of the AFT}

The main task of the WTO under the AFT is to coordinate and monitor activities undertaken by its participants, both on the donor and recipient side. Together with the OECD, the WTO supervises and assesses the progress of the program. For this purpose, two basic tools are used: 
- The OECD Creditor Reporting System under the OECD (CRS OECD);

- The Aid for Trade Global Review of the implemented and planned projects and programs under the initiative.

The decision to launch both tools was made by WTO members at a joint OECD/ WTO meeting in May 2007. The aim of the adopted formula for monitoring the AFT was "to promote dialogue and encourage all key actors to honor commitments, meet local needs, improve effectiveness and reinforce mutual accountability [which in turn it may] create incentives, through enhanced transparency, scrutiny and dialogue" (WTO, 2009, par. 16). The approach was based on greater transparency of operation, control, and access to information on the AFT. This was connected with taking two types of actions: including trade in aid programs aimed at the development of various sectors of the economy and improving the coherence of operations and coordination of the AFT with other aid programs targeted at developing countries (WTO, 2009, par. 16).

The CRS is a database covering approximately $90 \%$ of ODA flows. It was established in 1967 to collect information on ODA and other official financial flows directed to developing countries. It has become the main tool for tracking AFT commitments and disbursements and has replaced the WTO's trade-related technical assistance and capacity building database (TCBD) which was previously used to analyze technical assistance flows.

In addition to the CRS, the DAC maintains another database on ODA, known as "DAC statistics". The main differences are that the DAC data focuses on the overall ODA cash flows, while the CRS contains more detailed data such as individual projects. In general, the information from both databases should match, but there may be some discrepancies, especially in the historical data, and also in some aggregates reported as contributions, while in the CRS report they may reflect actual expenses. Currently, the DAC Secretariat maintains a single set of rules for flow reporting that applies to both the DAC and CRS. This enables aggregation of data from both sources.

Due to the necessity to adjust the AFT categories to those applicable in the CRS, there were numerous misunderstandings. The biggest differences occurred in the case of data relating to the category of technical assistance and regulation. The CRS used five codes to qualify activities in this area, while the TCBD database had 20 (OECD. Aid for Trade: CRS). The five subcategories of technical assistance and regulation in the CRS are:

- trade policy and administrative management,

- trade facilitation,

- regional trade agreements,

- multilateral trade negotiations,

- trade education/training. 
Slightly smaller differences were found in the area of infrastructure. In the CRS, it is an economic infrastructure, while the term trade-related infrastructure was introduced into the AFT. On the other hand, the AFT category of "trade and development" was included in the CRS in the category related to the construction of production potential (see Table 11). The exception is that the CRS does not have a category called "other trade-related needs." It concerns those projects which are not directly related to trade, but are eligible for AFT, provided that some part of them had an impact on improving trade capacity. Examples include projects in the field of education and health.

Including the AFT in ODA meant that it was up to the donors to decide what part of their resources may be qualified to the AFT or be entirely ODA. The question concerns the issue of separating the AFT component from the overall ODA, i.e., whether the aid providers are able to identify the component of the infrastructure project that clearly contributes to the improvement of the commercial potential and fits within the scope of the AFT. Practice shows that the distinction between the AFT and ODA is difficult to implement (ICTSD, 2012; Srinivasan, 2009, p. 116). The data show that around $20-30 \%$ of total ODA belongs to the AFT. In the initial years of the AFT operation, this result was on average about $20 \%$, and in 2015 it approached the level of $30 \%$ of AFT in total ODA (WTO/OECD, 2017, p. 493).

\section{Table 11. Differences Between the Categories Under the AFT and the CRS}

\begin{tabular}{|l|l|}
\hline \multicolumn{1}{|c|}{ AFT } & \multicolumn{1}{c|}{ CRS } \\
\hline Trade policy and regulations & Technical assistance for trade policy and regulations \\
\hline Development and trade & - \\
\hline Trade-related infrastructure & Economic infrastructure \\
\hline $\begin{array}{l}\text { Productive capacity building (including trade } \\
\text { development) }\end{array}$ & $\begin{array}{l}\text { Productive capacity building (including trade } \\
\text { development) }\end{array}$ \\
\hline Trade-related adjustment & Trade-related adjustment \\
\hline Other trade-related needs & - \\
\hline
\end{tabular}

Source: own study.

The second tool for controlling and evaluating the AFT are periodic reviews issued in the form of the Aid for Trade Global Review. The results of the initiative implementation are presented at a meeting organized at the WTO headquarters in Geneva. In 2007, the first AFT Global Review was held with representatives from donor states, multilateral organizations, NGOs, and the private sector. The last of the AFT Reviews analyzed in the book is from 2017 (Table 12). Published biennially, the Review analyzes, evaluates and forecasts the development of the AFT. It is the result of cooperation between the WTO and OECD in the AFT monitoring exercise. 
The AFT progress assessment is based on questionnaires completed by donors and recipients. In addition to traditional donors (members of the DAC and multilateral intergovernmental organizations on the official DAC list), representatives of regional organizations and donors from third countries can participate in the Review. The participants themselves report and evaluate the activities they have undertaken. An additional source of information are case stories that were included in the Review in $2011 .^{38}$ These are reports of AFT participants (from different regions, with different status and income levels) who share their knowledge about the positive and negative effects of the AFT. The authors of the reports are predominantly recipients from developing countries themselves, but also bilateral donors and multilateral institutions. On the basis of the case study, the WTO and OECD prepare regional reports on the implementation of AFT tasks in Africa, Asia and the Pacific, Latin America and the Caribbean (WTO/OECD, 2017). All information collected in the reports is the basis for identifying new areas of activity and creating plans for the coming years.

\section{Table 12. Responses Submitted under the WTO/OECD Aid for Trade Monitoring Exercise, 2007-2017}

\begin{tabular}{|c|c|c|c|c|c|}
\hline & \multirow{3}{*}{\begin{tabular}{|c|}
$\begin{array}{c}\text { Number of } \\
\text { donor responses } \\
\text { (bilateral and } \\
\text { multilateral) }\end{array}$ \\
39 \\
39
\end{tabular}} & \multirow{3}{*}{$\begin{array}{c}\begin{array}{c}\text { Number of } \\
\text { responses on } \\
\text { the recipients' } \\
\text { side }\end{array} \\
8\end{array}$} & \multirow{3}{*}{\begin{tabular}{|c|}
$\begin{array}{c}\text { Number of donors from } \\
\text { developing countries } \\
\text { under the South-South } \\
\text { cooperation }\end{array}$ \\
-
\end{tabular}} & \multirow{3}{*}{\begin{tabular}{|c|}
$\begin{array}{c}\text { Regional } \\
\text { economic } \\
\text { communities }\end{array}$ \\
n.d.
\end{tabular}} \\
\hline & & & & & \\
\hline 2007 & $\begin{array}{l}\text { Aid for Trade 1st Global } \\
\text { Review }\end{array}$ & & & & \\
\hline 2009 & $\begin{array}{l}\text { Aid for Trade at a Glance } \\
\text { 2009: Maintaining } \\
\text { Momentum }\end{array}$ & 57 & 89 & 5 & n.d. \\
\hline 2011 & $\begin{array}{l}\text { Aid for Trade at a Glance } \\
\text { 2011: Showing Results }\end{array}$ & 43 & 84 & 10 & 9 \\
\hline 2013 & $\begin{array}{l}\text { Aid for Trade at a Glance } \\
\text { 2013: Connecting } \\
\text { to Value Chains }\end{array}$ & 43 & 80 & 9 & n.d. \\
\hline 2015 & $\begin{array}{l}\text { Aid for Trade at a Glance } \\
\text { 2015: Reducing trade } \\
\text { costs for inclusive, } \\
\text { sustainable growth }\end{array}$ & 37 & 62 & 3 & 10 \\
\hline 2017 & $\begin{array}{l}\text { Aid for Trade at a Glance } \\
2017 \text { Promoting } \\
\text { Trade, Inclusiveness } \\
\text { and Connectivity for } \\
\text { Sustainable Development }\end{array}$ & 38 & 63 & 3 & 7 \\
\hline
\end{tabular}

Source: own study based on WTO/OECD, 2007, 2009, 2011a, 2011b, 2015, 2017.

38260 case stories were presented in the Aid for Trade Global Review (WTO/OECD, 2011a). 
In the first AFT review, the main challenge for the WTO and OECD was the low participation of representatives from developing countries in the survey. In the 2007 global report, they came from eight beneficiary countries (WTO/OECD, 2007). Traditional aid donors and multilateral organizations were strongly represented, and practically absent - representatives of developing countries, regional institutions, and NGOs (see Table 12). The activation of other groups and participants of development aid took place only after the adoption of the Paris Declaration and the Accra Agenda for Action. The turning point was the High-Level Forum (HLF-4) in Busan (2011), at which the contribution and role of donors from the South, regional economic institutions and the private sector were formally recognized. Accordingly, in subsequent AFT Reviews not only an increase in the participation of recipients was noted, but also of donors from developing countries (not belonging to the DAC) and regional economic groups (WTO/OECD, 2009, 2011a).

Oversight of the implementation of the AFT has been integrated into the WTO Trade Policy Review Mechanism (TPRM). Through TPRM, the organization regularly evaluates the trade policy and related areas in its member states. The AFT section replaced the previous item, which was dedicated to the evaluation of TA activities directed only to LDCs. In the new version, all developing countries covered by the AFT are subject to supervision under TPRM (Agboghoroma, Busse, Falatik, Hoekstra, Königer, Koopman, Kühne, Roloff, 2009, p. 34). By taking such steps, the WTO was to ensure greater coherence of action between the three policy areas related to the AFT: trade, development, and financial policy (WTO, 2006b, 2006c). Consequently, the WTO emerged as an institution seeking to coordinate and oversee the various types of trade support activities.

\subsection{Financing of the AFT}

The activities taken under the AFT fall under ODA. The ODA flow data is broken down into two categories: commitments and disbursements. A commitment is a written confirmation from the government or other public institution to provide financial support in a specified amount. These resources are transferred, in accordance with agreed conditions and for a clearly defined purpose, directly to the recipient country or through a multilateral institution (agency). This allows one to track donors' intentions and monitor their spending and provides guidance on planning aid activities. The amount of commitments changes with the evolution of the donors' aid policy, which reflects their political propensity to provide aid. Commitments to multilateral institutions are reported as the sum of any disbursements in the year 
not previously reported as commitments, but also as expected disbursements in the subsequent year. They are deemed to have been incurred on the date of signing the loan or donation agreement.

Disbursement, in turn, is understood as the transfer of funds, i.e., their allocation to the disposal of the recipient country or multilateral institution, but also in the case of mobilization of expenditure related to internal activities for development aid purposes (e.g., for refugees). This payment shows actual development aid expenditures each year. They reflect real intentions of donors, and thus the implementation of their aid policy. Disbursement accurately reflects the scale of aid from the recipient's point of view (OECD, 2016, pp. 33-34).

The analysis of commitments and disbursements is the primary source of information on the provision of aid, but also a considerable challenge for researchers of the subject. Commitments are often long-term, and subsequent payments are spread over several years. In the DAC statistical data even multi-year commitments are recorded in full in the year in which they were reported. Therefore, it is reasonable to present their average levels, which limits fluctuations. This means that subsequent disbursements refer to previously reported commitments that are registered annually, i.e., in the years in which they are transferred from donors to recipients. The actual increase in aid allocation is therefore only visible as disbursements after a few years. Consequently, the level of expenditure in a given year cannot be directly compared to commitments made in the same year as disbursements usually relate to commitments recorded in previous years. For this reason, there are often different figures for the same years, published at successive interval (OECD DAC Financing for...).

\section{Figure 23. AFT Commitments and Disbursements, 2006-2016 (USD billion, 2016 Constant Prices)}

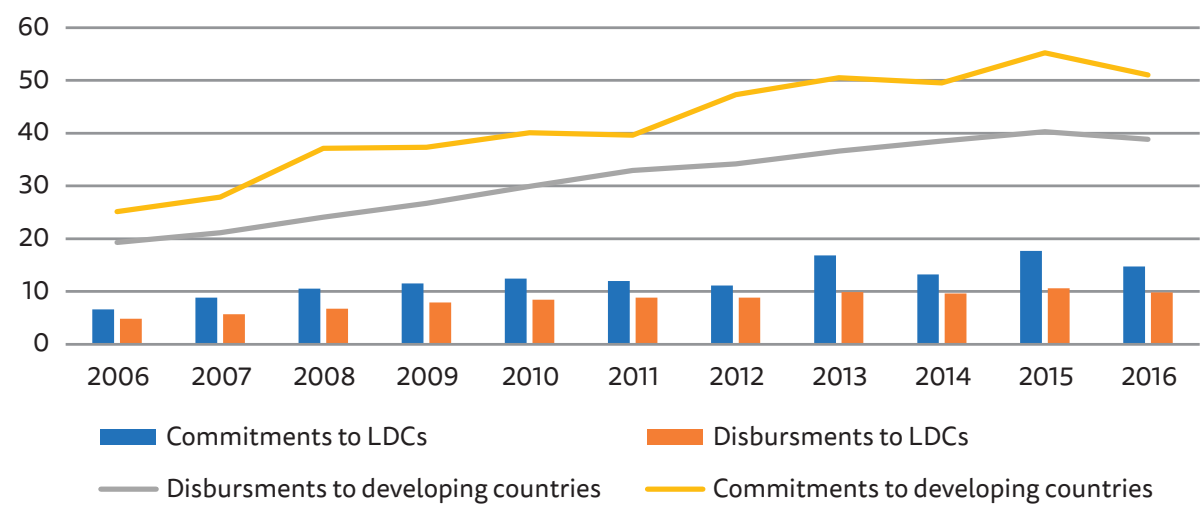


From the beginning of the AFT, an increase in expenditure has been evident. Between 2002-2005 and 2015, aggregate commitments increased from USD 25.2 billion to over USD 55 billion per year. This means a growth in real terms by $120 \%$. On the expenditure side, this was a surge from USD 19.3 billion to over USD 40 billion. In 2016, a decrease was recorded for the first time compared to the previous year. Commitments were lower by approximately $5 \%$ and amounted to over USD 51.2 billion, while disbursements were down $8 \%$ and amounted to USD 38.8 billion. Overall, AFT disbursements totaled USD 342350 billion between 2006 and 2016.

The dynamics of changes regarding the funds allocated to LDCs was directly proportional to the total level of commitments under the AFT (Figure 23). The largest AFT donors among multilateral institutions include the WB, EU, AsDB, AfDB, and the IDB. Among bilateral donors, Japan ranks first, followed by the United States, Germany, and South Korea (Figure 24). In turn, the main recipients of AFT funds are India, Vietnam, Turkey, Egypt, Pakistan, Indonesia, China, and Brazil (Figure 25).

Figure 24. The Largest Donors of AFT, Disbursements, 2006-2016 (USD million, 2016 Constant Prices)

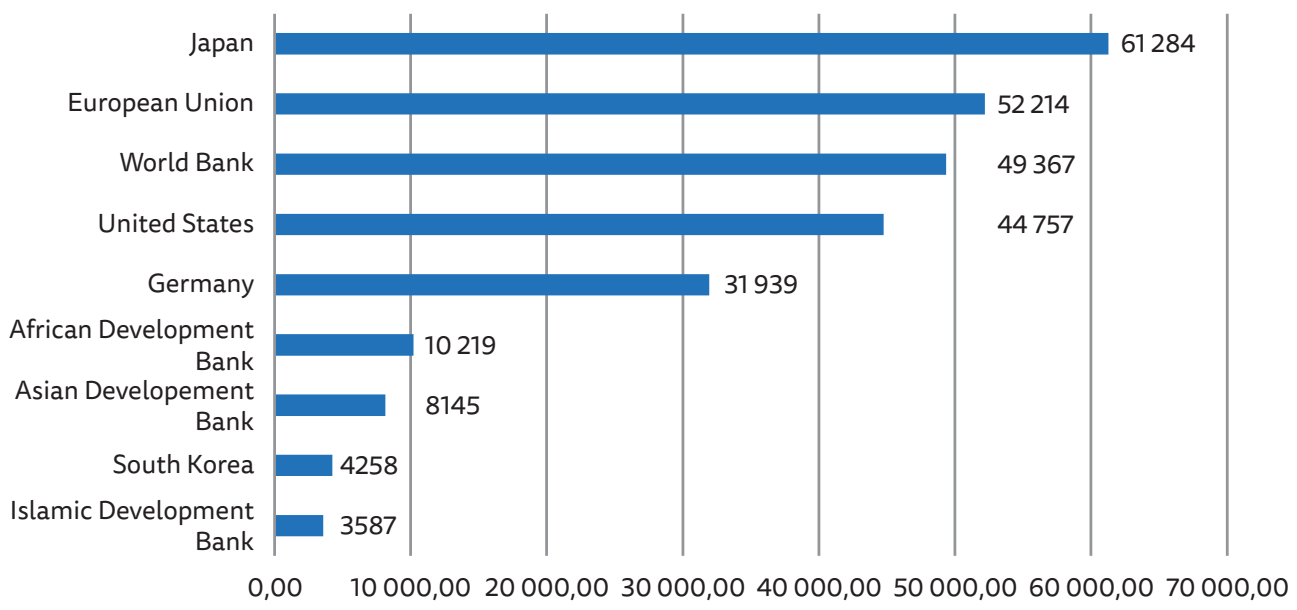

Source: OECD-DAC, 2018.

About 146 developing countries benefited from AFT support in 2006-2016. Most funds were directed to lower-middle income countries (around 36\%) and to LDCs (28\%) in Asia and Africa (WTO, 2018b, p. 151).

Among the basic categories of AFT, most funds are allocated to goals related to the development of economic infrastructure, and the least to trade policy and regulations (see Figure 26). In 2006-2015, the share of disbursements related to the development of economic infrastructure accounted for $52.4 \%$ of the AFT, which 
corresponded to USD 129 billion, in terms of building productive capacity it was 44.5\% (USD 109.6 billion), and in the sphere of trade policy and regulation $-3.1 \%$ (USD 7.6 billion) (WTO/OECD, 2015, p. 13). Compared to the base period, designated for the years 2002-2005, the share of the framework has decreased the AFT in the category of capacity building, trade policy and regulations, while commitments and disbursements in the field of economic infrastructure grew.

Figure 25. Main Beneficiaries under the AFT, Disbursements, 2006-2016 (USD million, 2016 Constant Prices)

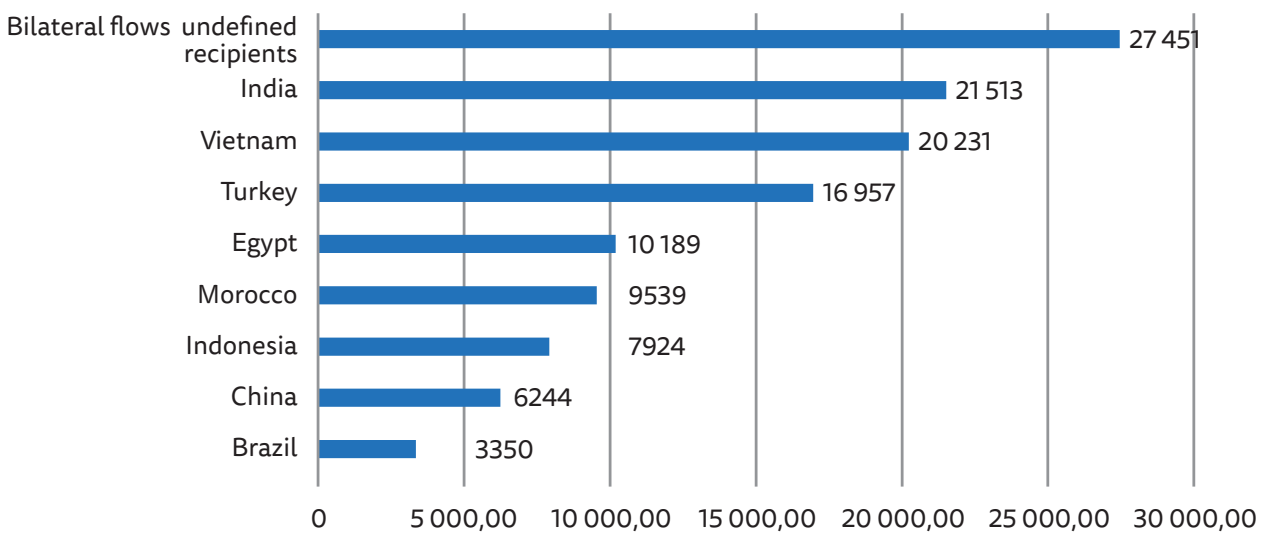

Source: OECD-DAC, 2018.

Figure 26. Commitments and Disbursements under the AFT by Category, 2002/2005-2015 (USD billion, 2015 Constant Prices)

Commitments

Disbursements

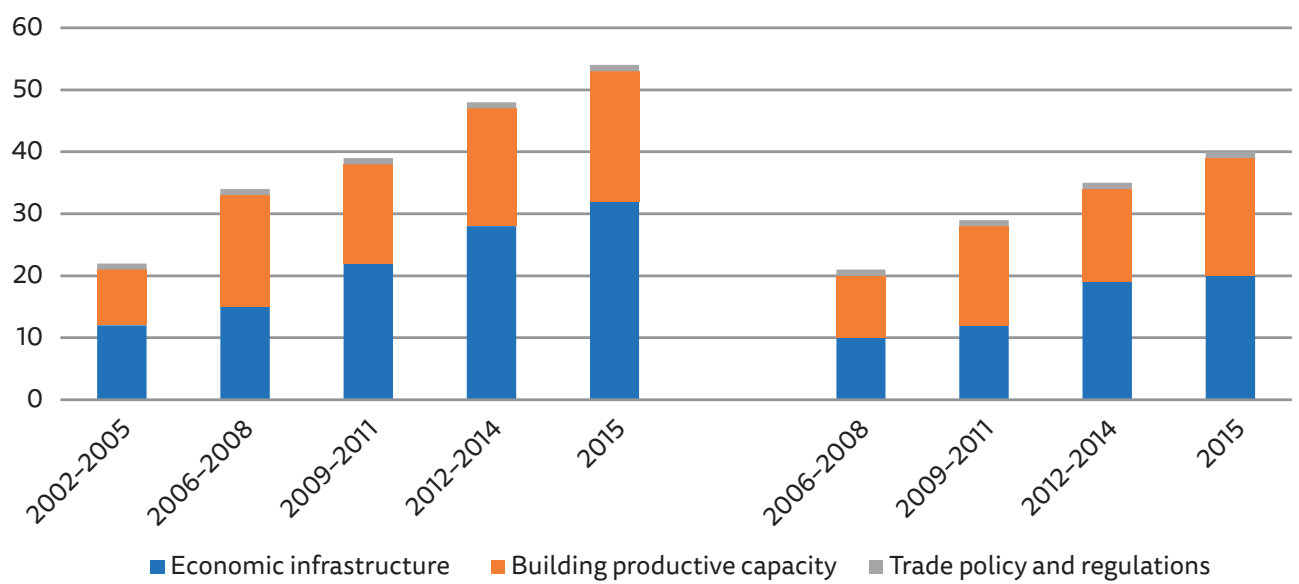

Source: WTO/OECD, 2017. 


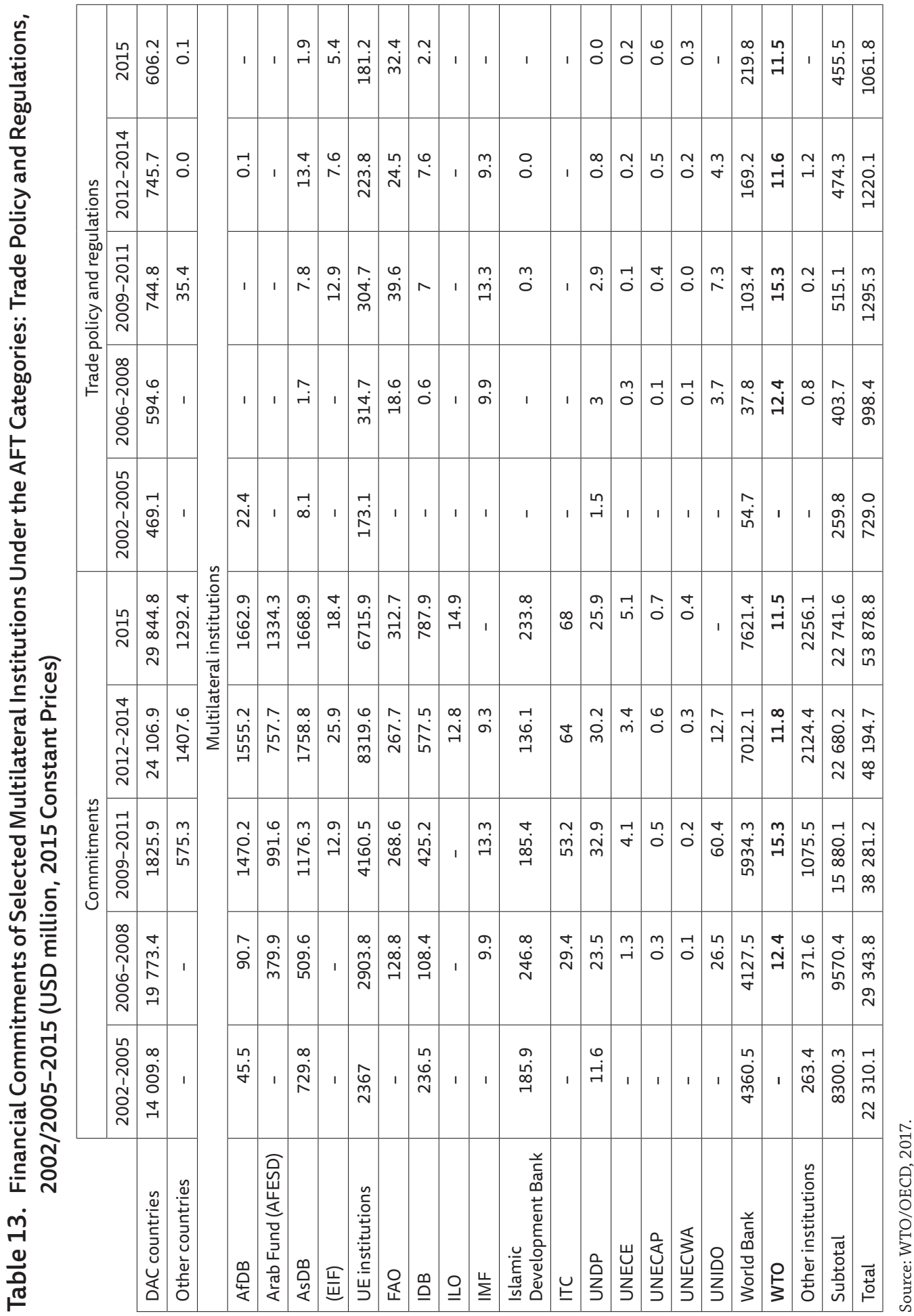


In 2006-2008, the share of the category relating to trade policy and regulations in total AFT amounted to 3.4\%, and in 2015 it lowered to 2\% (in the case of disbursement it was $3.2 \%$ and $2.5 \%$ respectively). On the other hand, the share of commitments under the category of "economic infrastructure" increased from 53.4\% in 2006-2008 to 59\% in 2015 (WTO/OECD, 2017, p. 493).

Since the inception of the AFT, the involvement of the WTO in terms of financial outlays has remained at a low level. It is about funds allocated to the purposes of technical assistance and trade capacity building of developing countries. Compared to the funds managed by the World Bank, regional development banks, UN and EU institutions, the financial contributions of the WTO are relatively modest (see Table 13). Almost all WTO resources are allocated to the "trade policy and regulations" category. The average annual level of commitments and in 2002/2005-2015 was around USD 12 million. The exceptions were the years 2010 and 2008, when the level of commitments amounted to USD 18 million and USD 20 million, respectively. The exception was 2016, when there was a sharp increase in pledges and disbursements to nearly USD 23 million (Figure 27). It was largely due to the newly adopted Trade Facilitation Agreement and the desire to inject funds into special support facility for developing countries (TFAF). In the subsequent year, both indicators returned to their standard levels of around USD 12 million.

Figure 27. WTO Commitments Under the AFT, 2006-2016 (USD million, 2016 Constant Prices)

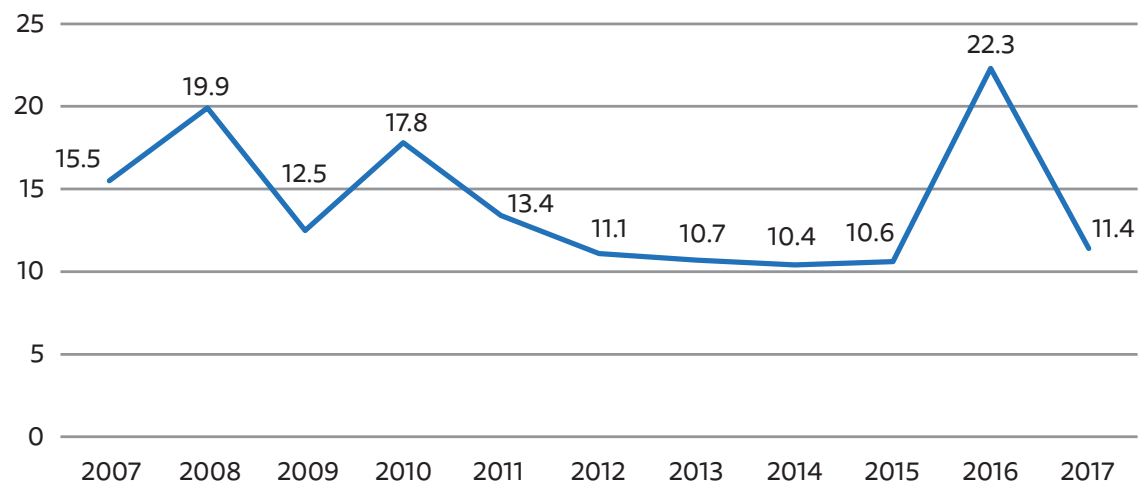

Source: OECD-DAC, 2018; WTO/OECD, 2018.

Outside of the AFT category - trade policy and regulations, WTO resources are diverted to a very limited extent. Little activity was shown in the field of building productive capacity (Figure 28) (OECD-DAC, 2018). In the CRS, the category related to trade policy and regulations consists of five subcategories, among which the one 
related to courses and training enjoys the greatest support from the WTO. This fact is not surprising given the importance of technical and training assistance as the main instrument of the WTO's support to developing countries. The remaining types of AFT are of less interest to the organization.

Figure 28. WTO Engagement in "Trade Policy and Regulations" Category, 2002/2005-2016 (USD million, 2016 Constant Prices)

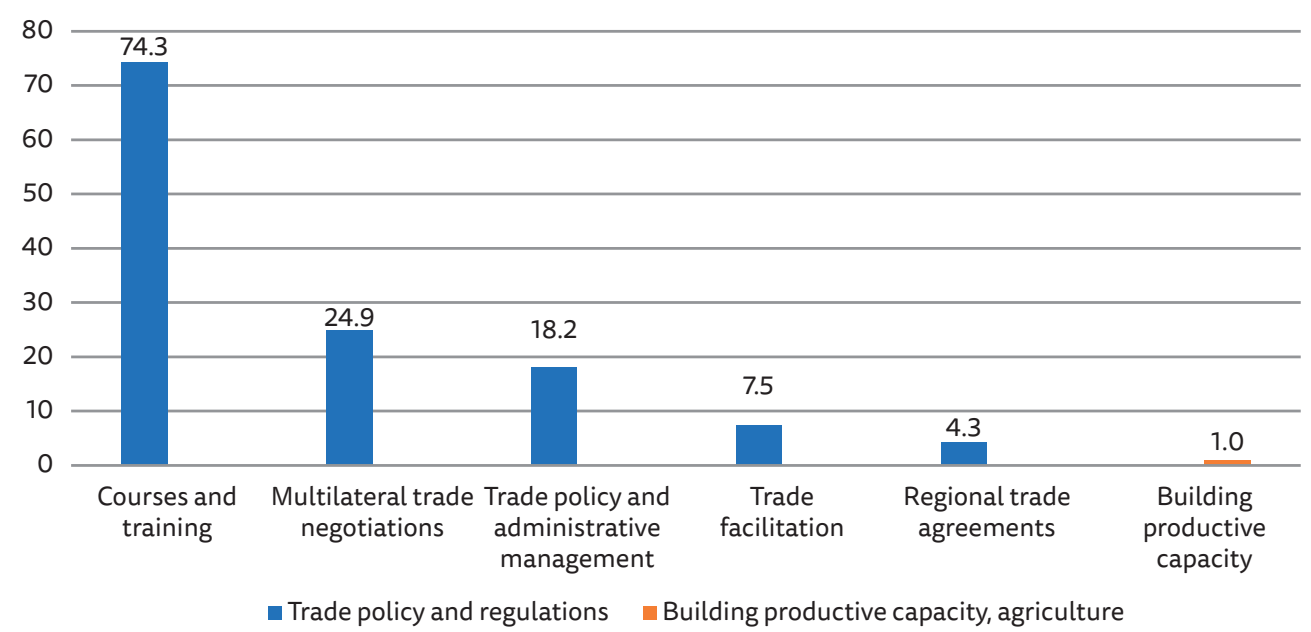

Source: OECD-DAC, 2018.

At the root of this situation is the specific role of the WTO in terms of trade. The organization has no mandate to provide ODA in the form of loans and grants, as is the case of other multilateral institutions (IMF, WB, EU). Technical assistance provided by the WTO is not a transfer of funds to developing countries. This also results in a relatively small WTO core budget for technical assistance, amounting to around CHF 4.5 million annually (around $2.5 \%$ of the total WTO budget). The tasks performed by the WTO within the framework of AFT come down to the performance of TRTA activities as well as the supervision and evaluation of the AFT implementation process. In the first case, these are courses and trainings organized by the WTO Secretariat, in the second - control, monitoring, and evaluation of activities, which are presented in the form of the AFT Global Review. Together with the OECD, the organization evaluates the actions taken and makes forecasts. 


\subsection{Achievements and Limitations of the AFT}

The assessment of the AFT initiative is ambiguous. Despite its clearly stated objective, the evidence of its direct impact in improving trade performance is relatively modest. Different views are based on the global reach of the AFT and the variety of programs related in various ways to development of trade. The attempt to evaluate the program was based on the analysis of two issues:

- broad definition of the AFT,

- mobilization of additional financial resources for development assistance purposes.

Both issues are closely related. The accumulation of additional funds was possible thanks to adopting a broad definition, and thus including various activities into the scope of the AFT, which in turn encouraged and mobilized a large group of donors and recipients to cooperate (Hallaert, 2012, p. 18; Hynes, Holden, 2013, p. 13; 2016, p. 605).

The broad definition of the AFT allowed for the inclusion of various participants and donors in one program. As a result, considerable funds were accumulated relatively quickly, which could be transferred to support reforms in various areas of the economy, with an emphasis on the sphere of trade. This approach was in line with the concept of complementary policies. However, the loose attitude to the issue of the AFT's scope had consequences for the further development of the program and its practical operation in accordance with the adopted assumptions. As for the first point, the WTO's desire to expand the scope of programs qualified as the AFT led to a situation where tasks related to the development of trade were financed to a small extent. On the other hand, the broad definition made it possible to maintain or increase the involvement of both traditional donors centered in the OECD-DAC as well as new ones from developing countries.

In practice, both donors and recipients of aid had problems with the correct qualification of tasks and resources to the relevant AFT categories. As intended, the aim was to improve trade capacity, but in reality, it was difficult to define a priori what constituted only aid to trade and distinguish it from what contributed only slightly to this objective. Theoretically, at the stage of preparation of the recommendations by the Task Force, this distinction seemed justified, but it did not work in practice. For instance, an infrastructure project could serve both to improve trade capacity as well as contribute to the achievement of other development goals. In OECD terminology (in the $\mathrm{CRS}$ ), no trade-related infrastructure projects were distinguished from those serving more general economic purposes (OECD Explanatory Note...). This was due to the different approach of donors and recipients of aid. The donor countries were 
not able to determine the potential effects of the program in a given sector, and it was in the interest of the recipients to include in the program as many different tasks as possible, the relationship of which with trade was ambiguous.

It is believed that due to the broad interpretation of the AFT's scope, the data on financial flows are overestimated (Hallaert, 2012, p. 9; Hynes, Holden 2016, p. 613). A large part of the reason for this is that Aid for Trade is part of ODA and therefore donors may have qualified the same activities for ODA and as AFT. The problem with distinguishing types of aid programs is particularly visible at the local level in recipient countries. According to the recipients' assessment, aid concerned broadly understood development goals, and to a small extent was related to the development of trade (Delpeuch, Jouanjean, Le Vernoy, Messerlin, Orliac, 2010, pp. 5-6). For officials and activists involved in aid, it often did not matter which programs the funds came from. This is evidenced by the information contained in the questionnaires carried out for the purposes of the AFT Global Review. For example, in a 2009 report, several representatives of LDCs reported a lack of funding from AFT programs, although according to the donor report they had been transferred (WTO/OECD, 2009, pp. 38-39).

Different assessments result from a different approach to achieving the AFT objectives. It is about finding evidence that there has been a real mobilization of resources under the AFT and whether the implementation of the AFT program has resulted in increased trade benefits or reduced transaction costs for developing countries. As highlighted in the WTO Action Plan, "mobilizing additional, predictable, sustainable and effective financing remains at the heart of the Aid-for-Trade initiative" (WTO, 2011a, p. 3). On the other hand, the 2011 AFT Global Review stated that the assessing progress in mobilizing resources "has increased substantially, although its distribution among developing countries remains uneven" (WTO/OECD. 2011a, p. 47). In a consequence, the evaluation seemed to be vague, conditioned by overall economic situation and the financial crisis of 2008. Nevertheless, only in the light of increasing in funding, the AFT can be considered a success. Since its launch, the level of donations has increased, reaching approximately USD 54 billion in 2015. In 2015, commitments were over $120 \%$ higher than in 2002-2005, and disbursements in real terms rose by over $10 \%$ annually. Nevertheless, the impact of the $2008+$ economic crisis on the amount of spending for development purposes was significant. After a period of growth of $28 \%$ in 2008, contributions to the AFT in the following years grew by only $2 \%$ (Hallaert, 2012, p. 8). After 2011, they increased steadily.

If it is assumed that the AFT generated more financial resources, the question remains whether they were really additional or not increased at the expense of other aid programs. According to J. Stiglitz and A. Charlton (2012, pp. 12-13), 
these were not additional outlays. A different position was presented by W. Hynes and P. Holden, who stated that additional funds had been raised and that they had not been transferred from other programs (Hynes, Holden, 2013, p. 14). This hypothesis is supported by an example concerning the share of AFT in total ODA, which in the years $2002 / 2005-2011$ was on the average level of about $30 \%$. This means that the vast majority of aid funds that were directed to economic sectors (production and economic infrastructure), did not come from the pool of funds allocated to the health or education. The latter were supplied with additional funds. It follows that the inclusion of AFT in ODA had a positive impact on the issue of resource mobilization and greater activation of traditional bilateral and multilateral donors, but also new donors from developing countries (Lammersen, Roberts, 2015, p. 21). However, the assessment of the AFT initiative may be different in the event of a decrease in ODA expenditure as in 2011 (excluding the debt relief category).

Another question is what impact the AFT has on increasing trade benefits for developing countries. Empirical research has confirmed the great potential and possibilities of the AFT's influence both at the micro and macro levels (Velde, 2003). The positive but mixed impact of ODA funds on infrastructure improvement, private sector recovery and trade policy improvement was indicated. At the same time, however, it was emphasized that the effects may be different. This may depend on the type of AFT activities and the depth of changes brought about by their intervention, as well as on the income level of the targeted sector and the geographical region of the recipient country. For instance, E. Ferro, A. Portugal-Perez, J. Wilson (2012, p. 11) found that an increase in aid by $10 \%$ in the sectors of transport, information and communication technology, energy and banking services was associated with an increase of $2 \%, 3 \%, 6.8 \%$, and $4.7 \%$ in exports of goods from recipient countries.

Overall, the most positive impact of AFT in improving trade performance was seen in the economic infrastructure sphere and within categories of trade policy and regulations. The least amount of evidence was found in sectors related to production (Cadot, Fernandes, Gourdon, Mattoo, 2011, p. 9). The sector studies showed considerable differences within the same AFT category. For example, the greatest gains related to infrastructure construction were recorded in mining and energy, and the smallest in tourism and food exports (Cali, Velde, 2010, p. 738). In this way one can explain, among others, the increase in AFT disbursements in the sphere of economic infrastructure.

A relatively large potential in terms of influencing the development of trade was noted in the category of trade policy and regulations, especially in the area of trade facilitation (Cali, Velde, 2010, p. 725). It is assumed that the implementation of unified and simplified regulations on trade facilitation by developing countries would 
allow them to reduce transaction costs in exports and imports in a relatively short time (Agboghoroma, 2009, pp. 35-36). It mainly concerns administrative services and customs procedures related to packing, loading, storage and transportation of goods. In research, empirical evidence confirmed the possibility of achieving relatively large benefits with low expenditure in the field of trade facilitation. M.C. Helble, C.L. Mann and J.S. Wilson (2012) studied the results of trade flows within various AFT categories, i.e., related to trade policy reform and regulations, capacity building, and economic infrastructure. These authors proved that a $1 \%$ increase in trade facilitation aid could boost global trade by USD 415 million. In turn, M. Cali, D.W. Velde (2010, p. 738) showed that the increase in aid amounting to USD 390000 is associated with a reduction of the cost of imported goods in one container at the level of USD 82. Research has shown that relatively small amounts of aid earmarked for trade policy and regulatory reforms have a greater impact on increasing trade flows (Helble et al., 2012) or reducing trade costs (Cali, Velde, 2010) than channeled aid as part of major projects for the development of production potential or infrastructure.

Examination of the role of the WTO within the AFT boils down mainly to the assessment of activities undertaken by the organization within the framework of the OECD-WTO monitoring exercise. The evaluation covers both the biennial AFT Global Review, prepared jointly with the OECD, and the OECD CRS used for the analysis of financial flows. On the one hand, the materials collected in the Global Review are a valuable source of information on the perception of the AFT, and on the other hand, they raise concerns about the preparation process and methodology of data collection (Cali, Velde, 2010, p. 726). The primary objection is that donors and recipients themselves evaluate and report on their involvement with the program, and the case stories attached to the Review are essentially uncritical and express an enthusiastic attitude towards the initiative. Although AFT beneficiaries pointed out some shortcomings, none of the parties involved was interested in disclosing negative information (WTO/OECD, 2011b, p. 7). In some countries, the need to improve the hitherto activities under the AFT has only been signaled (Lammersen, Roberts, 2015, p. 15).

On the other hand, the use of the CRS for AFT purposes already operating within the OECD allowed for the collection of comparable data in a relatively short time and saved resources. The joint decision of the WTO and the Task Force not to set up a trust fund to operate the AFT and the control mechanism was well received. The creation of additional institutions and further fragmentation of the international aid system were avoided. The WTO has become the pivotal center responsible for coordinating and monitoring the conduct of the AFT. 


\subsection{Summary}

The AFT is an aid framework program that emphasizes the development of trade potential to accelerate economic growth and reduce poverty in developing countries. It is part of ODA and its share is estimated at around 30\%. On the donor side, participants in the program are multilateral institutions as well as individual donors. The AFT is a structure covering a wide range of activities, which is divided into three basic categories: trade policy and regulations, productive capacity building, economic development and infrastructure, as well as two complementary ones: trade-related adjustment and other trade-related needs. Overall, the program combines both traditional trade-related technical assistance measures as well as those related to the development of economic infrastructure, building productive capacity, and the adaptation of businesses and households to changes brought about by trade liberalization.

The WTO is the leading institution supervising the performance of AFT tasks and promoting its development, however in terms of contribution to AFT spending, the organization's role is marginal. Financial support mainly falls into the category of "trade policy and regulations" through the Doha Development Agenda Global Trust Fund. This is due to the strictly defined role of the WTO in the international trading system, which boils down to creating the rules of international trade. The organization has no mandate to provide development aid in the form of loans and grants qualified as ODA, as is the case with other multilateral institutions (IMF, WB, EU).

The role that the WTO plays in the AFT comes to three types of activity:

- first, it is the role of the advocate and catalyst for action; the organization disseminates knowledge about the program, conducts a debate, as well as plans and forecasts activities; the work is coordinated by the Committee on Trade and Development;

- second, the WTO is responsible for implementing the Aid for Trade Work Program; the work is carried out through Trade-Related Technical Assistance, but also through joint programs with other multilateral organizations; these include the Standards and Trade Development Facility, the Joint Integrated Technical Assistance Program and the Enhanced and Integrated Framework;

- third, the WTO monitors and evaluates AFT activities; for this purpose, the AFT Global Review prepared by the WTO and OECD is used, which includes an analysis of financial flows, as well as an assessment and forecasts of AFT development; the basic source of data on financial flows is the CRS. Each publication of the results of the Aid for Trade at a Glance report is an opportunity to start an international 
discussion on the AFT operation with the participation of representatives of donors and recipients of aid, both on the side of state governments, NGOs, the private sector, and local activists.

The assessment of the AFT in terms of its main goals is ambiguous. From a political point of view, the launch of the program to accelerate negotiations and complete the Doha Round was unsuccessful. Developing countries were reluctant to accept liberalization commitments and give up their trade preferences. The economic aspects of the AFT implementation were assessed much better. Most of the authors stated that thanks to the initiative it was possible to mobilize additional financial resources and direct them to goals related to the development of trade capability. However, the effects were not the same even within one category. It depended on the type of the AFT project, sector, industry, or region. The best results were obtained in the category related to the construction of economic infrastructure. Relatively high potential to influence the development of trade was noticed under the category of "trade policy and regulations," especially in the area of trade facilitation. In connection with the adoption in 2017 of the WTO Trade Facilitation Agreement, greater involvement on the part of aid recipients is expected, i.e., the implementation of the TFA rules and the mobilization of additional financial resources by aid donors. 


\section{Chapter 5}

\section{PREFERENTIAL TREATMENT FOR DEVELOPING COUNTRIES}

A set of rules called special and differential treatment for developing countries (SDT) is an enduring component of the multilateral trading system. It was built and developed under the GATT and then taken over by the WTO. The SDT system is based on the assumption of preferential treatment of less developed countries in their adoption and implementation of WTO agreements. It is therefore a certain form of assistance aimed at integrating developing countries into the international trading system.

The adoption of SDT under the GATT meant that developing countries were granted the right to be treated differently in trade relations than other parties to the GATT. It was the introduction of the GSP to the GATT agenda, which in practice meant exempting developing countries from application of Art. I of the GATT, i.e., the most-favored-nation clause (MFN). Contrary to the original assumptions, this kind of aid mechanism for less developed countries did not bring them significant benefits.

Preferences in SDT contributed to the limited involvement of developing countries within the multilateral trading system, as it gave them the opportunity to take advantage of many exceptions and exemptions from adopted principles and rules. ${ }^{39}$ Accordingly, the maintenance of SDT in their current form or attempts to introduce

39 The distinction between commercial principles and rules results from the adopted theoretical formula, which was explained in the Introduction to the study. The international trading system under the auspices of the WTO is treated as an international regime where principles, norms, and rules as well as decision-making procedures are justified. For example, the WTO rules assume that global welfare will be maximized through free trade in line with the principle of non-discrimination in international economic transactions. The principle of world trade liberalization underlies the establishment of the organization. The rules, on the other hand, operate at a lower level of generality than rules and norms. They are established to mitigate conflicts that may arise between principles and norms. Rules are strictly defined and related to specific activities. In practice, it is difficult to make a clear distinction between rules and standards. Rules are more detailed, they emphasize 
changes constitute a major challenge for the WTO. The main source of disagreement is the access to the SDT system of a group of countries differing in terms of economic development, goals, and interests. While the use of SDT by LDCs does not raise any major objections, controversies arise with regard to emerging economies, i.e., China, India, and Brazil.

SDT regulations are not an effective tool to pursue commercial interests of developing countries. With the establishment of the WTO, new possibilities for integrating these countries with the international trading system appeared, which was associated not only with more active involvement in multilateral negotiations and the willingness to benefit, but also with obtaining tangible aid to overcome development difficulties. This chapter examines the effects of SDT and its impact on the participation of developing countries in the GATT/WTO and on the organization itself. The analysis is dominated by two threads: the problem of marginalization of developing countries in the multilateral trade negotiations and the attempt to modify SDT undertaken as a part of the Doha Round. The first part presents the stages of development of the provisions. The second part is devoted to the analysis of their main assumptions and purposes. The third one explains the effects of the application of these regulations in the context of implementing multilateral trade liberalization commitments. The last one presents the evaluation of the operation of SDT and the reasons for introducing changes to the WTO system of preferences.

\subsection{Evolution of SDT Provisions}

Developing countries viewed the GATT as an institution that led the process of trade liberalization discriminatory against them. (Srinivasan, Park Jr., 1999, pp. 9, 25; South Center..., 2017, p. 5). For nearly 47 years, the GATT was treated as a "club" of rich countries where the developing countries' possibilities to influence were limited, and the initiatives undertaken for their development were symbolic. The creation of the WTO was supposed to change this situation. Developing countries expected the new institution to change its policy towards greater involvement in development and poverty reduction. Activities in this area progressed slowly but gradually, which was a result of the increasing activity of developing countries in the multilateral trading system and their growing role in the global economy.

the rights and duties of regime members, and they can be more easily changed than rules or norms without changing the nature of the entire international regime (Keohane, 1984, p. 57; Baylis, Smith, 2001, p. 303). 
The SDT was not created as a uniform and finite set of rules. The process of its formation began with the establishment of the GATT and was continued over the years of the institution's operation. At the WTO, efforts were made to limit the application of SDT provisions to LDCs. This evolution reflected the degree of involvement and participation of developing countries in the GATT/WTO multilateral trading system. The application of SDT during the operation of the GATT led to the practical exclusion of developing countries from multilateral negotiations and trade liberalization. This was particularly detrimental to economic sectors, such as agriculture and textiles, which are important to the commercial interests of developing countries. Liberalization was very slow and limited. Under SDT regulations, developing countries were not obliged to grant tariff concessions or undertake binding tariff commitments. In addition, they were exempted from the obligation to apply the reciprocity principle, which meant they were not involved in reducing trade barriers, while rich countries did not expect them to take action in this direction.

The following stages of development of the provisions on the preferential treatment for developing countries in the GATT/WTO are distinguished (cf. Keck, Low, 2006, p. 148):

- Phase I: from the establishment of the GATT in 1947 to the start of the Tokyo Round in 1973;

- Phase II: concerns the negotiations and decisions made during the Tokyo Round in 1973-1979;

- Phase III: from the end of the Tokyo Round in 1979 to the adoption of the final provisions of the Uruguay Round in 1994;

- Phase IV: from the end of the Uruguay Round to the current activities of the WTO. A similar classification, consisting of four stages, was created by B. Hoekman and M.M. Kostecki (2011). It was based on an analysis of the activity of developing countries within the GATT and WTO, and the distinguishing element was the number and willingness of countries to participate in multilateral negotiations. ${ }^{40}$ Therefore, due to the subject of the analysis, a more appropriate division is the one relating

40 B. Hoekman and M.M. Kostecki (2011) assume the following phases of the participation of developing countries in the international trading system:

- Phase I covers the years 1947-1964; it is the participation of 12 developing countries in the creation of the GATT; formally, these countries were subject to the same trade obligations as the other parties to the Agreement;

- Phase II (1965-1986) is the extension of the GATT to new developing countries; thanks to the introduction of SDT, these countries were more willing to participate in the GATT, taking advantage of the numerous exemptions and special rules;

- Phase III (1987-1997) is deepening the developing countries' integration into the international trading system; as a result of adopting the provisions of the Uruguay Round, the involvement of the countries of the South increased and the relations were based on greater reciprocity; 
to the evolution of the provisions leading to the establishment of SDT. Moreover, this approach clearly shows the shaping of the position of developing countries towards the liberalization of trade within the GATT/WTO.

The first stage (Phase I) was dominated by problems related to the access of export goods from developing countries to the markets of highly developed countries. It was about addressing issues such as low export revenues in developing countries and thus the inability to meet development needs, protectionism in the agricultural sector in developed countries, and fluctuations in commodity prices in world markets. The main unit within the GATT, set up to deal with issues important to trade in developing countries, was Committee III, which was tasked with creating an action program for the expansion of international trade. The Committee's work focused on trade barriers that hinder access of goods from developing countries to industrialized markets. The final result of its activity was the adoption in 1963 of the Action Plan consisting of eight points. The proposals, however, were quite radical and had no chance of being accepted by the contracting parties to the GATT. Nevertheless, they became part of multilateral negotiations under the Kennedy Round (1964-1967), as well as an element of subsequent trade negotiations under the GATT. The most important proposals included in the Plan were to freeze all trade barriers to products important to commercial interests of developing countries, and to remove tariffs on tropical and primary products (Keck, Low, 2006, p. 149).

The following events had a direct impact on development of regulations concerning the preferential treatment for developing countries. In March 1955, the parties of GATT adopted a resolution on international investment and economic development, and the following year - a resolution on problems related to trade in primary commodities. In 1957, at the 12th session of the GATT, a decision was adopted to appoint a panel of experts to prepare a report on trends in international trade, with particular emphasis on threats to trade in developing countries. Consequently, in 1958 a report was prepared under the direction of Gottfried Haberler, which focused on trade barriers created by developed countries. It concluded that high barriers and unfavorable price fluctuations significantly deteriorate terms of trade in developing countries (Wilkinson, 2006, p. 13).

The basic regulations of the SDT are included in Part IV of the GATT under the title of Trade and Development. The decision preceding its establishment was the resolution of 1963 calling for a program of action to improve trade situation of developing countries (Srinivasan, 2001, p. 1051). The provisions of Part IV concerned

- Phase IV (1998 - present) is a period of increasing differences between the countries of the South and the North; this was due to the unfulfilled commitments of the Uruguay Round and the pressure to start new multilateral negotiations. 
the commitment of highly developed countries to eliminate or gradually reduce trade barriers to goods that were of interest to developing countries and to refrain from or not to increase customs tariffs and other non-tariff barriers on these goods.

One of the essential features distinguishing Part IV of the GATT was the adoption of the principle of non-reciprocity (Art. XXXVI: 8). The issue of reciprocity of commitments raised controversies already at the initial stage of the GATT development, when the principle of parity of commitments was introduced, i.e., no distinction between developing and highly industrialized countries. However, through practice, it has been adopted to depart from the principle of reciprocity in the case of less developed countries, which has been common since the mid-1960s. This meant that developing countries were not expected to make commitments that they might consider incompatible with their development, financial, or trade needs. The effect was to exclude developing countries from participating in the multilateral trading system and deprive them of any influence on the course of the negotiations.

Phase II of the development of provisions on preferential treatment for developing countries falls on the GATT Tokyo Round (1973-1979). In 1979, a framework agreement was adopted containing an Enabling Clause, which became the legal basis for the operation of the SDT. The official name is the Decision of Differential and More Favorable Treatment, Reciprocity and Fuller Participation of Developing Countries (GATT, 1979). On the basis of the clause, a permanent legal basis was adopted for the application of the GSP, which was established under the UNCTAD. Under the GSP, developed countries have been obliged to give preferential treatment to developing countries by applying zero or low tariffs to products from developing countries. Countries granting preferences could unilaterally determine which developing countries and which products could be covered by their programs (WTO Development...).

On the basis of the Enabling Clause, a set of rules was incorporated into the GATT system which sanctioned the principle of non-involvement and non-reciprocity in market access for developing countries. In this way, they could deviate from the application of MFN and other GATT rules. A permanent legal basis has been introduced for the use of GSP under the GATT agreements, as well as for certain aspects of regional and global agreements between developing countries and for special treatment for LDCs. ${ }^{41}$ The clause also applied to the Global System of Trade Preferences (GSTP), under which developing countries grant trade concessions to each other.

41 Developing countries creating a free trade area or other regional agreement with each other were obliged to meet requirements much less restrictive than in the case of the necessity to notify such an agreement under Art. XXIV of the GATT. The Enabling Clause allowed them to do so. 
The achievement of the Tokyo Round was the adoption of regulatory codes. They influenced not only the continued functioning of the GATT, but also the participation of developing countries in the trade system. This marked the beginning of gradual reduction of non-tariff barriers in the GATT. On the one hand, they were codified, and on the other, the possibilities of using some barriers were reduced. Those that were allowed could not inhibit or distort trade. The new regulations covered six areas: technical barriers to trade (TBT), customs valuation (CV), import licensing (AIL), subsidies and countervailing measures (SCM), as well as anti-dumping (the Agreement on the interpretation of Article VI of the GATT) and government procurement (GPA).

Developing countries' participation in the Tokyo Round was limited, although there were significant improvements compared to previous negotiations. Mostly developing nations were not interested in adopting regulatory codes. Their activities focused primarily on ensuring that the new solutions had a minimal impact on their trade policy. The idea was to avoid additional administrative and financial burdens resulting from the implementation of new regulations. Therefore, a general rule was adopted concerning the obligation to apply provisions in codes only to the signatory states of the agreements.

In Phase III, the developing countries' approach to SDT gradually changed. Simultaneously with the increased activity in trade relations, it turned out that the rules of the SDT limited the possibilities for developing countries to operate in international trade. Therefore, they were used selectively and temporarily. With the start of the Uruguay Round, an increasing number of developing countries were more interested in joining the negotiations than in blocking them (Whalley, 1999, part. B).

Several factors were at the root of the new approach. Firstly, it was the economic success of some Asian and Latin American countries, which caused them to be more involved in international trade and openly express their trade interests, manifesting greater openness to external competition and trade liberalization, often even unilateral. Secondly, within the GATT, demands were made more and more often regarding the necessity to introduce changes within the international trading system. The idea was to extend trade rules to areas such as agriculture, textiles, or to introduce completely new regulations related to investments, trade in services and trade aspects of intellectual property rights. Thirdly, greater activity of developing countries in world trade required the necessity to increase their commitments, and thus to modify SDT provisions based on concessions and exemptions.

The change of the SDT system turned out to be controversial and difficult to implement. The declaration opening the Uruguay Round contained a clear and unequivocal confirmation that SDT was a permanent set of rules under the international trading system (WTO, 1986, part. B). This meant keeping Part IV of 
the GATT and the Enabling Clause within the newly created organization. Developing countries agreed only to such a change, which meant strengthening preferences by granting them legal force. Under the GATT, the obligation to apply SDT provisions to developing countries was not legally binding. The Graduation Clause (Art. XVIII: B GATT), which was introduced as a counterweight to the Enabling Clause, was not respected. It assumed that with the improvement of economic indicators and a decrease in poverty, developing countries to which SDT regulations were applied should voluntarily give up such preferences. Moreover, during the Uruguay Round, the division among developing countries deepened. This was caused by different and often competing interests (e.g., group of countries exporting manufactured goods, group of countries exporting and importing agricultural products and LDCs). It was mainly developed countries that wanted to change the SDT regulations.

Phase IV of the development of GATT/WTO preferential treatment provisions for developing countries covers the period from the end of the Uruguay Round to the Doha Round negotiations. The major change is the acceptance by all WTO members of the provisions negotiated during the Uruguay Round on the basis of single undertaking. Developing countries departed from the practice adopted during the Tokyo Round, where acceptance of the codes then proposed was voluntary and selective. As a consequence, developing countries, becoming WTO members, were obliged to accept agreements negotiated during the Uruguay Round. Although special regulations of SDT were maintained, allowing for the extension of the deadline for adoption of the agreements, they did not exempt developing countries from the obligation of their final implementation after the end of the transition period. Attempts to give legal force to the provisions of SDT were unsuccessful (Marceau, 2015, p. 175).

The main challenge faced by the WTO was the implementation by developing countries of agreements adopted during the Uruguay Round. The obstacle was the high adjustment costs that developing countries had to bear in order to comply with WTO regulations and to initiate appropriate reforms. Therefore, the aim was to amend WTO rules that were not in line with commercial interests of developing countries. Therefore, on the one hand, efforts were made to modify the WTO rules and, on the other, to work out a solution consisting in less restrictive compliance by developing countries with WTO obligations.

During the Doha Round negotiations, an attempt was made to change the SDT system. According to the provisions of the WTO Ministerial Declaration in Doha, SDT regulations were to be "strengthened [...] more precise, effective and operational" (WTO 2001b, par. 44). Increasing the efficiency of the SDT meant starting negotiations in two areas. First, the idea was that SDT's obligations, which had no binding force, 
could be converted into mandatory regulations that had legal effects. Second, the aim was to limit the application of the SDT provisions to LDCs and WTO member states that are currently at an economic disadvantage. The most controversial was the issue of covering selected groups of countries with SDT.

\subsection{Fundamentals of the SDT System}

The source of establishing the SDT system were the views on the development of states, presented in the 1950s by R. Prebisch (1950) and H. Singer (1950). The researchers formulated, independently of each other, a hypothesis about the causes of the growing development disproportions between developing and highly industrialized countries, which became the basis of the dependency theory. The authors advocated increasing productive capacity by developing countries in order to reduce their dependence on imports and move away from exports, based mainly on traditional primary commodities and raw materials. They saw the deteriorating terms of trade in the commodity production of developing countries in low diversification and cyclical price fluctuations (Srinivasan, Park Jr., 2000, p. 3).

Recognizing that resource-dependent developing countries are always faced with unfavorable terms of trade, and thus a decline in the prices of their exports relative to the prices of imported goods, Prebisch and Singer suggested introducing regulatory tools that would reduce harmful effects of such actions. The proposal was based on the assumption of preferential access to the markets of developed countries in order to counterbalance the unfavorable conditions for their exchange. Most developing countries were considered unable to accept trade liberalization commitments due to the imminent increase in trade deficits (Whalley, 1999, p. 5). The introduction of protection of newly established industries was considered a beneficial solution, which in fact led to increasing barriers to trade. At the same time, developing countries demanded preferential access to the markets of highly developed countries. In practice, this resulted in a better treatment of goods exported from developing countries than on the basis of MFN, while maintaining the protection of their markets.

During the GATT Uruguay Round, it was agreed that SDT regulations should be maintained within the newly created organization. In return for confirming the right of developing countries to benefit from special preferences, their consent was obtained to accept agreements negotiated during the Uruguay Round, including GATS, TRIPS, and TRIMs. The provisions of the GATT 1947 were incorporated into the WTO, becoming part of the GATT 1994 under Annex 1A to the Agreement Establishing the World Trade Organization. This means that, apart from minor 
amendments, SDT regulations in force in the GATT were maintained within the WTO (see Table 14). Based on the principle of single undertaking it was agreed that the inclusion of SDT into the WTO would be accompanied, firstly, by the extension of commitments to developing countries in the areas negotiated in the GATT, i.e., anti-dumping, subsidies and countervailing measures, technical barriers to trade, and secondly, the implementation by developing countries of regulations in new areas, such as GATS, TRIPS, TRIMs, and thirdly, by improving the operation of the dispute settlement mechanism.

\section{Table 14. Key Elements of Special and Differential Treatment in GATT and WTO}

\begin{tabular}{|c|c|}
\hline $\begin{array}{l}\text { Art. XVIII of GATT } \\
\text { (1994) }\end{array}$ & $\begin{array}{l}\text { Art. XVIII: A - allowed developing countries to renegotiate bound tariff rates to create } \\
\text { new industries; } \\
\text { Art. XVIII: B - allowed for the application of quantitative restrictions due to balance of } \\
\text { payments problems; } \\
\text { Art. XVIII:C - allowed developing countries to apply quantitative restrictions in newly } \\
\text { established industries, and as with Articles XVIII: A it provided for compensation and } \\
\text { retaliation in the absence of a negotiated agreement. }\end{array}$ \\
\hline $\begin{array}{l}\text { Art XXVIII bis (iii) } \\
\text { of GATT } 1994\end{array}$ & $\begin{array}{l}\text { It required developed countries to take into account in trade negotiations the use tariffs } \\
\text { by developing countries as a means for fiscal and economic development purposes. }\end{array}$ \\
\hline $\begin{array}{l}\text { Part IV of GATT } \\
\text { "Trade and } \\
\text { Development" }\end{array}$ & $\begin{array}{l}\text { Article XXXVI - obliges developed countries to recognize the special development } \\
\text { needs of developing countries, i.e. market access, stabilizing prices); Recognizes } \\
\text { non-reciprocity on the part of developing countries in trade negotiations, meaning } \\
\text { that developing countries need not reciprocate trade concessions given to them by } \\
\text { developed countries in multilateral negotiations; } \\
\text { Article XXXVII - requires developed countries to give priority to products of interest } \\
\text { to developing countries in any trade liberalization. } \\
\text { Article XXXVIII - provides for joint action by developed and developing countries } \\
\text { in commodity matters, cooperation between institutions, or studies on the export } \\
\text { potential of developing countries. }\end{array}$ \\
\hline Enabling Clause & $\begin{array}{l}\text { - Provides a permanent legal basis for the application of GSP under the GATT; } \\
\text { - Provides special treatment for developing countries with respect to the Tokyo Round } \\
\text { Codes; } \\
\text { - Addresses certain situations in connection with the establishment of global and } \\
\text { regional trade agreements among developing countries. }\end{array}$ \\
\hline $\begin{array}{l}\text { Graduation } \\
\text { Principle }\end{array}$ & $\begin{array}{l}\text { A general recommendation based on which it was assumed that with economic } \\
\text { development and reduction in poverty rates, developing countries should give up } \\
\text { their right to apply SDT regulations and successively assume the rights and obligations } \\
\text { of membership in the organization (commitment to negotiations and reciprocity of } \\
\text { obligations). }\end{array}$ \\
\hline
\end{tabular}

* The original balance of payments provision was in Article XII of the GATT 1947. After the 1954-1955 revision of the Agreement, this provision was supplemented by adding an explicit reference to developing countries and creating Article XVIII. This article also allowed for quantitative restrictions on newly established industries in developing countries (Josling, 2006, p. 63).

Source: own study based on Whalley, 1999.

The SDT system, within the newly created organization, included 145 provisions scattered in multilateral WTO agreements. Of these, 107 were adopted as a result of decisions taken during the Uruguay Round, of which 22 were directed exclusively to the LDCs group (WTO, 2000, p. 3). The provisions of SDT can be divided into two 
categories: the first concerns obligations of a general nature that were performed in good faith, and the second is related to specific regulations. As part of this division, general declarations in favor of preferential treatment for developing countries are included in the preamble of the Agreement Establishing the WTO and other multilateral agreements, such as the Agreement on Agriculture (AA). The preamble states that "there is need for positive efforts designed to ensure that developing countries, and especially the least developed among them, secure a share in the growth in international trade commensurate with the needs of their economic development." On the other hand, detailed provisions on SDT are contained in individual WTO agreements and decisions, which are divided into six objectives (see Table 15):

1) increasing trade opportunities of developing countries - occurs in 12 cases under four agreements and one decision: the GATT 1994 (Articles XXXVI-XXXVIII); AA, Agreement on Textiles and Clothing (ATC), GATS, and the Enabling Clause;

2) protection of the interests of developing countries - the total number of rules relating to the protection of interests of developing countries is 49 and this is the most common category of SDT; relevant regulations are found in 13 WTO agreements and two decisions, they are: Part IV of GATT 1994, SPS, ATC, TBT, SCM, Agreement on the implementation of the anti-dumping article (GATT 1994 - Art. VI), CV (Implementation of Article VII of the GATT), AIL, GATS, TRIPS, DSU, Decision on Measures on Possible Negative Effects Reform Program for LDCs and Developing Countries and Net Food-Importing Developing Countries (NFIDC), and Decision on Texts Relating to Minimum Values and Imports by Sole Agents, Sole Distributors and Sole Concessionaires; these provisions concern actions to be taken by WTO members or those members should avoid in order to protect the interests of developing countries (WTO, 2000, p. 5);

3) flexibility of commitments and relevant trade policy instruments with respect to developing countries - include 30 provisions appearing in nine different WTO agreements, these are: the GATT 1994 (Art. XVIII and Art. XXXVI), AA, TBT, TRIMs, SCM, GATS, DSU; GATT 1994 - Art. XVIII, Safeguards Agreement (SG) and the Enabling Clause; these provisions concern activities related to the exemption of developing countries with liabilities or with a lower level of contributions;

4) transition periods for the adoption of agreements by developing countries - 18 provisions are contained in eight WTO agreements: AA, SPS; TBT, TRIMs, AIL, GATT 1994 - Art. VII, SCM, SG; these provisions concern temporary exemptions from the obligations of all WTO members; most developing countries took advantage of transitional periods under the GATT 1994 - Art. VII, TRIMs and TRIPS (Hoekman, Michalopoulos, Winter, 2004, p. 483); it should be noted that 
some transition periods in various contracts have expired. In many cases, the relevant provision, in addition to specifying a period, includes ways in which an extension can be requested; for instance, this is the case with the TRIPS Agreement;

5) technical assistance - its provisions are contained in six WTO agreements and one ministerial decision; they are: SPS, TBT, GATT 1994 - Art. VII, GATS, TRIPS, DSU, and the NFIDC Decision;

6) provisions on $\mathrm{LDCs}^{42}$ - there are 22 of them and they are included in seven WTO agreements and three decisions; these are: AA, ATC, TBT, TRIMs, GATS, TRIPS, DSU, the facilitation clause, the decision on measures for LDCs and the decision to exempt LDCs from strictly defined provisions contained in the WTO agreement (waiver) ${ }^{43}$ these exemptions are time-limited, and their extensions must be justified.

Table 15. SDT Provisions Included in the WTO Agreements

\begin{tabular}{|c|c|c|c|c|c|c|c|}
\hline Agreement & 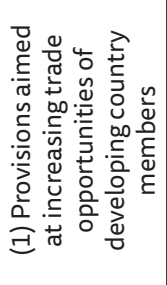 & 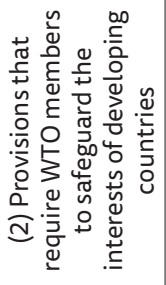 & 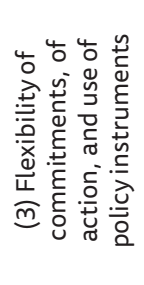 & 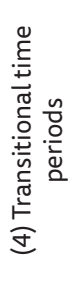 & 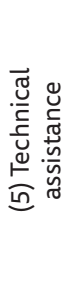 & 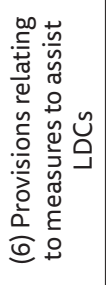 & 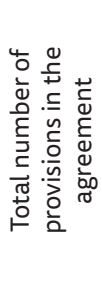 \\
\hline $\begin{array}{l}\text { AA and the decision of the } \\
\text { NFIDCs }\end{array}$ & 1 & 4 & 9 & 1 & 1 & 3 & 19 \\
\hline SPS & & 2 & & 2 & 1 & & 5 \\
\hline ATC & 1 & 3 & & & & 2 & 6 \\
\hline TBT & & 6 & 1 & 1 & 7 & 1 & 16 \\
\hline TRIMs & & & 1 & 2 & & 1 & 4 \\
\hline $\begin{array}{l}\text { Implementation of } \\
\text { Article VI of GATT } 1994\end{array}$ & & 1 & & & & & 1 \\
\hline
\end{tabular}

42 The WTO Secretariat has established a separate category for LDCs, although in each of the other five, LDCs may also benefit from preferential treatment.

43 With regard to LDCs, there is a solution that allows developing countries to be exempted from strictly defined regulations under multilateral or bilateral agreements (waiver). Such exemptions are granted by the WTO General Council in accordance with Art. IX: 3 of the Agreement establishing the WTO. Examples include trade agreements between the European Community and Morocco, Caribbean Basin Economic Recovery Act (CBERA), the system of tariff preferences granted by Canada to the countries of the Caribbean Community, the Act on the granting of trade preferences by the United States to the Andean group, or the Partnership Agreement between the European Community and the countries of Africa, the Caribbean and the Pacific (ACP-EC Partnership Agreement). 
cont. Table 15

\begin{tabular}{|c|c|c|c|c|c|c|c|}
\hline Agreement & 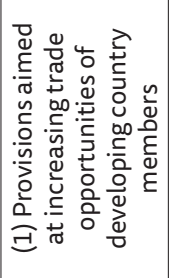 & 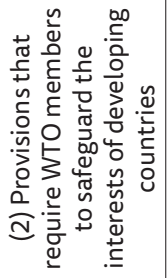 & 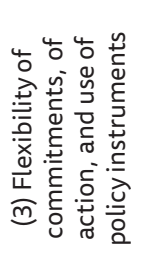 & 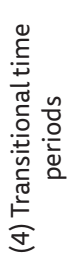 & 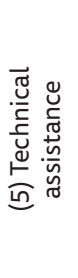 & 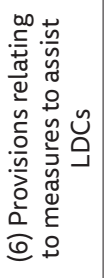 & 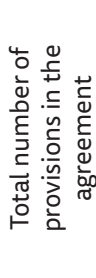 \\
\hline $\begin{array}{l}\text { Implementation of } \\
\text { Article VII of the GATT } \\
1994 \text { and Decision on } \\
\text { Texts Relating to Minimum } \\
\text { Values and Imports by Sole } \\
\text { Agents, Sole Distributors } \\
\text { and Sole Concessionaires }\end{array}$ & & 1 & 2 & 4 & 1 & & 8 \\
\hline $\begin{array}{l}\text { Agreement on pre- } \\
\text { shipment inspection }\end{array}$ & & & & & & & 0 \\
\hline $\begin{array}{l}\text { Agreement on rules of } \\
\text { origin }\end{array}$ & & & & & & & 0 \\
\hline AIL & & 3 & & 1 & & & 4 \\
\hline SCM & & 2 & 8 & 6 & & & 16 \\
\hline SG & & 1 & & 1 & & & 2 \\
\hline GATS & 1 & 1 & 2 & & 2 & 1 & 7 \\
\hline TRIPS & & 2 & & & 1 & 3 & 6 \\
\hline DSU & & 7 & 1 & & 1 & 2 & 11 \\
\hline GATT 1994 Art. XVIII & & & 3 & & & & 3 \\
\hline GATT 1994 Art. XXXVI & 4 & 3 & 1 & & & & 8 \\
\hline GATT 1994 Art. XXXVII & 2 & 6 & & & & & 8 \\
\hline $\begin{array}{l}\text { GATT } 1994 \\
\text { Art. XXXVIII }\end{array}$ & 2 & 5 & & & & & 7 \\
\hline Enabling Clause & 1 & & 2 & & & 1 & 4 \\
\hline $\begin{array}{l}\text { Decision on Measures } \\
\text { in Favor of the LDCs }\end{array}$ & & & & & & 7 & 7 \\
\hline $\begin{array}{l}\text { Waiver; preferential tariff } \\
\text { treatment for LDCs. }\end{array}$ & & & & & & 1 & 1 \\
\hline Total & 12 & 47 & 30 & 18 & 14 & 22 & 143 \\
\hline
\end{tabular}

Source: own study based on WTO, 2000.

Taking into account the above classification, developing countries can benefit from the SDT regulations in two ways. First, they have the option of applying commercial policy measures that restrict access to their markets or provide support to domestic producers or exporters in a manner not permitted by other WTO members. In practice, this means obtaining special exemptions from the application of WTO regulations. Second, developing countries have more time to fulfill their obligations under the WTO agreements. In the case of transitional periods, their application has been ensured 
in virtually all WTO agreements, except for the Anti-Dumping Agreement (GATT 1994 - Art. VI) and the Agreement on Pre-Shipment Inspection. The introduction of longer transition periods, especially for LDCs, is underway mainly under TBT, SPS, TRIPS, SCM, and AA. However, numerous examples of developing countries show that despite the lapse of transition periods (8 years for SCM, 5 years for TRIPS, 10 years for $\mathrm{AA}$ ), it was not possible to implement the relevant agreements (WTO Annual Report, 2014).

\subsection{Effects of Using SDT}

As a result of the Uruguay Round, the scope of SDT was extended to new areas (GATS, TRIPS, TRIMs). This gave rise to the conviction that developing countries could act more flexibly and adapt to new conditions (Petersmann, 2005, pp. 347, 351). On the other hand, it became clear that the SDT system was not a sufficient tool to integrate developing countries into the international trading system (Kleen, Page, 2005, p. 23). Examples of successful integration of some developing countries from Asia or South America showed that greater benefits could be achieved by joining trade liberalization (full or partial) and increasing its competitiveness (Anderson, 2004, pp. 24, 52-53). Therefore, the most effective form of assistance to developing countries is to remove barriers to market access (Inama, 2002). How gains from liberalization can be achieved in practice, especially in the case of less developed countries, depends on complementary policies undertaken to improve the investment climate, trade capacity, or reduce adjustment costs (Prowse, 2006, pp. 237-238). Although the greatest benefits are likely to be obtained by larger and more developed economies, also for LDCs, profits supplemented by aid measures and additional trade preferences are expected.

The increasing marginalization of developing countries in trade negotiations under the GATT led to a gap between the level of tariff concessions granted to each other by developed countries and those relating to developing countries. As a result, the level of tariffs and other trade barriers for exports of highly developed countries was declining (see Table 16). In the case of developing countries, the benefits of liberalization were much smaller, which discouraged them from taking more active steps. Areas such as clothing and textiles, where developing countries had a comparative advantage, were completely excluded from GATT's remit. Similarly to agricultural products, which, subject to numerous exemptions and exceptions, practically remained outside the regulatory system of the GATT, and later the WTO. 


\section{Table 16. Average Tariffs for Industrial Products Before the Uruguay Round and After, by Group of Countries}

\begin{tabular}{|c|c|c|c|c|c|c|c|c|c|}
\hline & \multicolumn{3}{|c|}{ Developed economies } & \multicolumn{3}{|c|}{ Developing economies } & \multicolumn{3}{|c|}{ Total } \\
\hline & 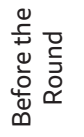 & 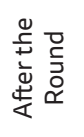 & 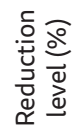 & 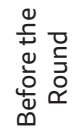 & 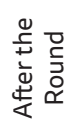 & 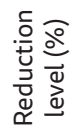 & 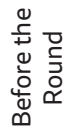 & 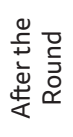 & 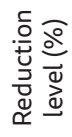 \\
\hline United states & 2.1 & 1.1 & 50 & 16.1 & 12.5 & 23 & 4.8 & 3.2 & 32 \\
\hline European Union & 5.1 & 3.1 & 39 & 20.8 & 16.2 & 22 & 8.0 & 5.5 & 31 \\
\hline Japan & 4.9 & 3.3 & 33 & 24.1 & 16.9 & 30 & 8.1 & 5.6 & 32 \\
\hline \multicolumn{10}{|l|}{$\begin{array}{l}\text { Other industrialized } \\
\text { economies }\end{array}$} \\
\hline Asia & 7.3 & 5.3 & 28 & 22.1 & 16.3 & 26 & 9.9 & 7.2 & 27 \\
\hline $\begin{array}{l}\text { Other industrialized } \\
\text { economies }\end{array}$ & 2.7 & 1.4 & 50 & 14.3 & 10.9 & 24 & 3.6 & 2.1 & 43 \\
\hline $\begin{array}{l}\text { Industrial economies } \\
\text { together }\end{array}$ & 3.9 & 2.3 & 40 & 19.6 & 14.7 & 25 & 6.3 & 4.2 & 33 \\
\hline $\begin{array}{l}\text { South American } \\
\text { developing countries }\end{array}$ & 4.2 & 2.8 & 34 & 6.5 & 5.2 & 20 & 4.5 & 3.1 & 31 \\
\hline $\begin{array}{l}\text { Developing countries } \\
\text { from Asia }\end{array}$ & 5.9 & 4.3 & 26 & 20.1 & 15.5 & 23 & 6.9 & 5.2 & 20 \\
\hline $\begin{array}{l}\text { Developing countries } \\
\text { from Africa }\end{array}$ & 7.9 & 6.4 & 20 & 10.4 & 7.7 & 25 & 8.2 & 6.5 & 26 \\
\hline $\begin{array}{l}\text { Developing countries } \\
\text { from Europe }\end{array}$ & 7.2 & 4.9 & 31 & 12.6 & 10.9 & 14 & 8.3 & 6.1 & 26 \\
\hline $\begin{array}{l}\text { Developing countries } \\
\text { from Europe }\end{array}$ & 5.5 & 3.9 & 28 & 13.0 & 10.3 & 21 & 6.3 & 4.6 & 27 \\
\hline All economies together & 4.1 & 2.6 & 38 & 18.8 & 14.2 & 25 & 6.3 & 4.3 & 32 \\
\hline
\end{tabular}

Source: Francois, McDonald, Nordstrom, 1996.

The harmful effects of SDT, which resulted, inter alia, from non-participation in the process of reducing trade barriers and non-reciprocity of concessions by developing countries, have led to the following effects:

- products that have given developing countries a comparative advantage have had limited preferences;

- the use of preferences was conditioned by many regulations of an administrative nature, e.g., restrictive rules of origin. As a result, a small part of exports from developing countries was covered by special regulations; ${ }^{44}$

44 In the case of EU and US preferential programs, the SDT regulations covered a small part of exports from developing countries. In the case of the EU and the Everything but Arms (EBA) and GSP + programs, their total value accounted for little, more than $1 \%$ of EU imports. In the case of American programs, eligible imports, i.e., those covered by the United States' preference under the GSP, as well as African Growth and Opportunity 
- developed countries could apply barriers to product imports that were inconsistent with the GATT rules (e.g., the Multifilament Agreement of 1974 and the quota system for textile goods and clothing from developing countries);

- developed countries maintained tariff peaks on products of particular interest to developing countries. ${ }^{45}$

According to researchers, SDT provisions were ineffective and did not bring the expected benefits to a wider group of recipients from developing countries. Some even claimed that they had negative consequences for their development (McCulloch, Winters, \& Gaviera, 2001, p. 168; Finger, Winters, 1998, p. 383; Michalopoulos, 2000, pp. 25-26; Srinivasan, 1998, pp. 27-28; Finger, 2008, pp. 887-904). Therefore, it is considered more beneficial to liberalize trade in goods and services on the basis of MFN than to extend SDT or GSP (Prowse, 2006, p. 237; Hoekman, Michalopoulos, Winter, 2004, p. 485; Dugiel, 2008, p. 13). This is confirmed by the conclusions of empirical studies on the impact of GATT and WTO membership on economic growth and trade in developing countries. For example, A. Subramanian and S-J. Wei (2007, p. 152), who focused on the development asymmetry between developing and developed countries, concluded that the influence of GATT and WTO membership was significant. Due to the asymmetry of development, the effects of membership were unequal. More positive effects were recorded in the case of highly developed countries. This meant that countries actively participating in multilateral negotiations, which were ready to make mutual concessions in certain sectors, benefited. In turn, developing countries, despite their formal membership, did not participate in the GATT/WTO negotiations, hence their impact on trade was smaller.

A critical opinion on the SDT was presented in their study by M.K. Tang and S.J. Wei (2008, pp. 26-27). They found that developing countries that acceded to the WTO after the end of the Uruguay Round achieved much better economic development results than the GATT contracting parties. These countries had to meet more stringent requirements, which was possible thanks to the accompanying countries. The benefits of faster growth and investment inflows have translated into improved trade performance and a better investment climate (Maggie, Rodriguez-Clare, 1998, 2007). Furthermore X. Liu and E. Ornelas (2014, pp. 33, 62) reached similar conclusions. Researchers found that stricter requirements for WTO membership or free trade agreements lead to better growth rates in developing countries. These

Act and the Caribbean Basin Initiative, accounted for less than 3\% of American imports (Ornelass, 2016b, s. 12-15).

45 Due to various types of regulations, including administrative regulations, the SDT system covers a small part of the exports of developing countries. This volume constituted a small part of the imports of the EU and the United States approx. 0.9-0.4\% (Dugiel, 2008, pp. 12-13; Srinivasan, 2002, p. 29; Hertel, Martin, 1999, pp. 8, 39). 
countries also showed a greater propensity to liberalize trade. The smaller scale of preferences in the case of WTO accession countries as compared to those belonging to the GATT made it necessary for them to undertake domestic reforms leading to economic growth and improvement in trade. When comparing FTAs created by developing and developed countries, the researchers found that the lack of greater commitments in the case of agreements established exclusively by developing countries, did not lead to their benefits. It should be noted that there is an obligation to notify the newly established agreement to the WTO pursuant to Art. XXIV of the GATT 1994. Where a developing country is a member of the FTA, notification shall be made under the Enabling Clause. Due to the fact that the provisions of the Clause do not impose on FTA participants the conditions under which they should conduct the exchange, their implementation is relatively low compared to the agreements notified in the standard formula, i.e., under Art. XXIV of the GATT 1994.

For those countries that joined the organization after the end of the Uruguay Round, the positive effect was greater than for the old members. This leads to two main conclusions regarding SDT. First, the Uruguay Round was aimed at reducing the gap in the level of commitments and mutual concessions between developing and developed member states. Indeed, new WTO member states had to take on higher commitments than were required of the original members. This has contributed to the narrowing of the commitment gap. Second, the provisions of the SDT are the key to increasing the effectiveness of the WTO in the area of trade liberalization (Subramanian, Wei, 2007, p. 172; Tang, Wei, 2009).

\subsection{Evaluation of the Operation of SDT}

It is difficult to clearly assess the effects of applying the SDT regulations. The prevailing view among researchers is that SDT preferences did not contribute to promoting economic development in developing countries but made it difficult to participate in the multilateral trading system (Chang, 2008, p. 124; Hoekman, Mihalopoulos, Winter, 2004, p. 503; Michalopoulos, 2000, p. 9; Hoekman, Kostecki, 2011, p. 566-567; Ornelas, 2016a; Dugiel, 2009, pp. 11-12). On the other hand, the SDT made it possible for less developed countries to join international trade on preferential terms. Although the principle of reciprocity of obligations, which characterized the GATT, was ineffective in the case of developing countries, thanks to special treatment they could at least partially participate in this system. Perhaps the absence of SDT would force developing countries to participate more fully in trade liberalization? 
The sources of the limited participation of developing countries in trading system can be found in the deepening development disparities between the GATT parties. Therefore, support for the growth of domestic protectionism in developing countries meant rejecting trade liberalization and striving to increase trade preferences of SDT (Hoekman, Kostecki, 2011, p. 566). The low effectiveness of SDT could be due to the following factors:

- first, the SDT provisions were not legally binding;

- second, the content of their provisions was vague, leading to different interpretations;

- third, the groups of developing countries and LDCs covered by the preferences were diverse and divided.

Ad. 1. Most of the provisions of SDT are non-binding, therefore there is no legal obligation to apply them to developing countries. Although the Enabling Clause strengthened the legal basis of SDT and formalized the concept, it did not oblige developed countries to apply SDT in trade relations with less developed countries. Taking into account practical considerations, the adoption of a coherent system of SDT regulations and its introduction to the GATT was a kind of declaration of preferential treatment for developing countries without the legally binding obligation to apply these rules. Therefore, in the literature on the subject, the terms "commitment to effort" or "best endeavors" are used in relation to this type of situation (Michalopoulos, 2000, pp. 6-8; Josling, 2005, p. 64; Hoekman, Kostecki, 2011, p. 565). A developing country could not bring a GATT dispute settlement complaint against a party that failed to deliver on its Part IV of the GATT promises. A similar situation currently exists within the WTO. Since the end of the Uruguay Round, efforts were made to strengthen SDT regulations and give them legal force, but the majority of WTO members did not support such a change.

Ad. 2. The use of SDT was selective and often conditioned by political considerations. Moreover, the regulations were imprecise, which led to a diversified interpretation (UN ESCAP, 2005, p. 75). For instance, with the Agreement on Textiles and Clothing some regulations relating to preferential treatment for LDCs were not applied at all (ATC: Art. 6.6, Art. 12). On the other hand, on the basis of the Agreement on the application of Art. VI of the GATT (Art. 15) developed countries took advantage of the possibility of initiating anti-dumping proceedings against developing countries. This was due to the lack of guidelines for the implementation of this article, but on the other hand, it contradicted the principle of special treatment for less developed countries. ${ }^{46}$ Another example are the provisions contained in the GATS, which were

46 Anti-dumping procedures were predominantly directed against developing countries with higher rates of development, which in turn recorded a sharp increase in anti-dumping activities against both their own group and 
practically not respected by WTO members. It is about regulations concerning such actions that would enable greater access to markets of well-developed service providers from developing countries and LDCs. In Art. VI: 2 GATS recommended creating the so-called "contact points" to provide information and support to interested parties. In fact, this has actually been used by 34 member states both highly developed and developing (GATS, Art. IV: 2) (WTO, 2016b).

Ad. 3. The need to introduce changes to SDT resulted from the growing diversity among WTO member states included in the group of developing countries. There was no uniform definition of a developing country (Deszczyński, 2011). In the GATT, the practice was that each country determined its own status, usually at the time of accession to the agreement. A similar approach was used in the WTO. Therefore, there has been a lot of controversy about the status of countries such as Singapore, South Korea, and Israel, which defined themselves as developing countries (Michalopoulos, 2000, p. 566). A much better solution was adopted for LDCs. Their affiliation was based on the UN classification. By the end of 2017, out of the 47 LDCs on the UN list, 36 had become WTO members, and another 8 were negotiating to join the organization.

The application of similar preferences to a diverse group of developing countries raised many questions. The differences kept growing, and the criteria for access to SDT remained unchanged. Therefore, already during the Uruguay Round, the concept of formal differentiation of this group appeared, so that the aid mechanism, based on the system of exemptions and concessions, would be directed primarily to the LDCs. Under the provisions of SDT, developing countries were not expected to grant tariff concessions or bind their tariffs at a certain level. However, the exemptions did not apply to all developing countries, and the differences resulted from the way a given country acceded to the GATT (Hoekman, Kostecki, 2011, p. 564). In the case of the former colonies, commitments negotiated by the former metropolis were accepted and the new candidate did not have to submit any letters of concession. This was true for most of the developing countries. In contrast, the second category of states, non-colonies, had to negotiate terms and conditions before joining the GATT, thus presenting its list of tariff concessions. This type of accession usually entailed increased tariff and non-tariff requirements that the candidate country had to meet, which in turn forced them to undertake economic reforms, and these, thanks to the prospect of GATT membership, could proceed at a faster pace.

OECD countries since the late 1980s. The share of developed countries in anti-dumping investigations fell by more than half between 1994 and 1997. During the same period, developing countries initiated most of these activities. The average annual number of anti-dumping investigations initiated by developed countries decreased from 160 in 1989-1993 to 95 in 1994-1997. After this period, the number increased slightly again, especially in the United States (Michalopoulos, 1999, pp. 55-56). 
Preferences in SDT formula are inherently discriminatory because they bring benefits to a specific group of entities (Gowa, Hicks, 2012, p. 252). Moreover, the use of SDT has negative consequences in the form of various exemptions and exceptions, which take the form of protection of one's own market. The measures most often used by developed countries to protect their markets are export subsidies, import quotas on textiles, as well as customs escalation on products with a higher degree of processing and tariff peaks (Michalopoulos, 2000, p. 9). Maintaining the SDT led to an extensive system of tariff and non-tariff instruments, which effectively protected developed countries. As a result, access to exports from less developed countries was limited. This means that SDT provisions were counterproductive as they led to protectionism in developing countries as well as in highly developed countries.

By using the SDT system, developing countries in this seemingly privileged way deprived themselves of the possibility to act and influence the development of the international trading system. The literature on the subject indicates at least a few factors that adversely affected the development of these countries in the long run. Firstly, the application of SDT allowed for the continuation of the policy of import substitution by developing countries, which was additionally supported by high protection of developing countries' markets. Although the protection of infant industries was justified, however, developing countries used this type of preferences extensively (Dugiel, 2009, pp. 10-11). Secondly, developed countries did not abandon the use of barriers inconsistent with GATT regulations, which violated trade interests of developing countries, e.g., in the import of textile products from developing countries. Such a practice of quantitative restrictions continued long after the decision to progressively integrate trade in textile goods into the GATT 1994 and to abolish the Multifiber Agreement, which was in breach of GATT rules. Third, the SDT provisions allowed developed countries to maintain tariffs higher than the average MFN rate on goods of particular importance to developing countries' exports in textile and clothing and agriculture sectors (Srinivasan, 2001, p. 1052).

The SDT system has become a barrier to the integration of developing countries into the international trading system. The solutions adopted in Part IV of the GATT and under the Enabling Clause discouraged developing countries from engaging in multilateral negotiations on the elimination of trade barriers. Therefore, with the new approach of developing countries to economic integration, the importance of SDT within the WTO has diminished. There were at least two reasons for this. Firstly, as agreed in the Uruguay Round, the margin of preference decreased due to the MFN tariff reduction. Preferences were eroded, and thus the state lost its competitive advantage in trade due to the use of preferential market access. The source of the erosion of preferences may be not only the reduction of tariffs, but 
also the granting of preferences to a larger group of countries or their complete elimination (Kopiński, 2009, p. 36). Second, the limited impact of SDT regulations resulted from the growing importance of non-tariff barriers, especially in areas of interest to developing countries. Examples are textile products that have had limited special preferences or have been excluded from the SDT system.

Various studies show that the preferential system was mostly used by a limited number of developing countries (including Brazil, South Korea, Hong Kong, and Taiwan), while LDCs were not the main beneficiaries of preferential treatment under the GATT (Karsenty, Laird, 1987, after: Whalley, 1989, p. 39). Given the declining importance of trade preferences, liberalization efforts seem necessary for both developing countries and LDCs. Deepening and expanding the system of preferences - a goal pursued by evolving countries - may in the future lead to its erosion, which would have negative consequences, especially for LDCs. The reason for this is the gradual reduction of barriers to trade in goods and services on the basis of MFN. This means that preferential access to the market under SDT will not be of great importance, especially in a situation where the level of MFN tariffs is either low or equal to zero. Therefore, other types of support are needed, such as simplification and harmonization of rules of origin.

The rules of origin play an important role in determining the tariffs on imported goods. Choosing the right rate depends on the origin of goods. The differentiation of the duty rates of a state or economic group results from various international agreements with other countries or groups. Due to the fact that more than one country may be involved in the production and distribution of a good, the rules of origin are helpful in determining which country is considered to be the place of origin of the product and which ultimately enjoys the preferential, i.e., lower or zero duty rate. At the Sixth WTO Ministerial Conference, held in December 2005 in Hong Kong, it was agreed to undertake a commitment by developed and developing countries to grant duty-free and quota-free access to their markets for all products derived from LDCs. Currently, highly developed countries provide access to their markets under national GSP. The range of products covered by the preferences ranges from 90 to nearly $100 \%$. The joint commitment under the WTO has not yet been formally accepted, although work in this direction is underway, mainly with regard to the common formula of rules of origin (UNCTAD, 2017).

Assuming that LDCs did not benefit much from the SDT preferences, it should be presumed that their propensity to undertake a liberalization effort will be quite low in their case. Therefore, it is important that in the process of modifying SDT provisions, efforts should focus on strengthening development assistance to LDCs and other small and vulnerable economies. 


\subsection{Attempts to Change SDT Provisions}

Under the Doha Round all WTO members agreed on the necessity to deal with the SDT issue but perceived the nature and direction of changes differently. Developed countries saw the need to differentiate the status of developing countries, while the parties concerned opposed such a change and called for the extension of the scale and scope of preferences. There was an opinion among developing countries that since the rules and rules applicable within the WTO were not co-created by them, they required changes and adaptation to new conditions.

Most developing countries agreed that SDT regulations should be modified, but there was no agreement on the form and scope, as well as how to implement the changes (ICTSD/IISD, 2003). From 2002, the discussion has taken place mainly in a specially appointed group operating within the WTO Committee on Trade and Development Special Session (CTD-SS). The negotiations were divided into two parts. The first includes cross-cutting regulations (the SDT principles and objectives, issues related to the right to use regulations, issues related to technical assistance, trade capacity, transitional periods, monitoring mechanism), and the second - regulations relating to specific WTO agreements, 88 of which were distinguished in total (WTO, 2002). In May 2003, the section devoted to the WTO agreements was divided into three categories. The first included 38 proposals that were relatively easy to agree on, the second - more complex issues, and the third - those that were the source of the greatest controversy. Developing countries only managed to present a jointly agreed draft reform of SDT in 2015. It consisted of 25 different proposals. Until then, they were negotiating between 88 different variants of changes (South Center..., 2017, p. 8). The management of the debate was taken over by the African Group, which together with the G-90 Group (African Group, LDCs, and ACP) submitted the final draft for deliberation. At the WTO Ministerial Conference in Nairobi in 2015, a decision was announced on this matter, but it was not finally taken (WTO, 2015b).

The main obstacle in introducing changes to the SDT system was the differences in positions between developing and developed countries. Developing countries were in favor of major amendments to the WTO agreements, which could lead to changes in the rights and obligations of members of the organization. They believed that the agreements adopted under the GATT/WTO were created only in the interests of developed countries. ${ }^{47}$ Therefore, they treated the SDT as a kind of compensation

47 The argument concerning the exclusion of a developing country from multilateral negotiations for reasons beyond its control, such as joining negotiations too late, was raised many times (WTO, 1999, pp. 15-16). 
for the lost profits that resulted from the lack of involvement in multilateral trade negotiations. Their goal was not only to maintain the SDT provisions, but even to expand their scope of application. Therefore, they demanded confirmation that SDT is a permanent and legally binding element of the WTO system, as contained in Part IV of the GATT.

Developed countries did not agree to such far-reaching changes, especially as in their opinion the negotiating mandate under the Doha Round did not permit it (WTO, 2003a). They wanted to renegotiate the SDT preference system in such a way that access to it would depend on the status and economic development of a member state. Moreover, they refused to accept legally binding commitments to provide technical assistance insisted on by developing countries (South Center..., 2017, p. 14). On the other hand, they were in favor of limiting the regulation of SDT to LDCs only. They treated the SDT system as a temporary tool to integrate the less developed countries with the international trading system (Chang, 2008, p. 123). A helpful, albeit ineffective, mechanism for departing from SDT was the Graduation Clause. As a counterweight to the provisions contained in the Enabling Clause, it provided a formal basis for the gradual phasing out of the use of SDT by developing countries that have made some progress in development (Michalopoulos, 2001, pp. 29, 207-208). This principle was not respected by states, which complicated the application of preferences mainly towards richer developing countries.

The issue of formal differentiation of developing countries in access to SDT rules is the key to solving the problem. Any debate on SDT makes no sense without making such changes and adopting criteria to distinguish between less developed countries (Hoekman, Michalopoulos, Winter, 2004, pp. 483, 492). The difficulties are evidenced by the fact that even the expansion of the LDCs group to include new members raised concerns. These countries benefit from a special system of preferences, largely based on duty-free and quota-free market access (DFQF). As part of the SDT debate, it is proposed to extend this type of preferences to all products, as well as to disseminate and systematize the rules of origin. The lack of uniform and simplified rules in this area is a source of increasing transaction costs and smaller benefits to LCDs from preferential market access (Inama, 2002; Brenton, 2003). A desirable solution is to adopt an approach which, on the one hand, would strengthen the importance of the WTO in the sphere of development, and, on the other, minimize deviations from the application of fundamental principles and rules of the WTO. In the first case, it is about increasing support for development of trade capacities of less developed countries, and in the second, about abandoning the application of such provisions that have led to distortions in the international trading system. This means that aid should be directed to LDCs, and other developing countries should join multilateral 
liberalization based on MFN. In turn, progress in liberalization depends on the degree of economic advancement and reforms undertaken by a given country.

Despite a robust debate, it was not possible to accept any binding arrangements for the revision of SDT. The divisions were too large and attempts to introduce differentiating criteria for developing countries met with resistance from the countries concerned. At the same time, however, multilateral negotiations were underway for an academic debate on the future of SDT. The aim of the discussion was to increase the effectiveness of the WTO's operation and raise the importance of the organization in the sphere of development (Hoekman, 2005, pp. 405, 412-413). Two approaches emerged. The first concerned the adoption of new criteria for access to SDT depending on the type of WTO agreement (agreement-specific approach) or the development needs of a given member state (country-specific approach). The second was related to the renegotiation of SDT measures and the adoption of new solutions, consisting in the possibility of withdrawing from the application of extended preferences.

The supporters of the first option (Ch. Stevens and S. Prowse) postulated the introduction of criteria that would indicate which countries are entitled to take advantage of special concessions and transitional periods in the implementation of WTO agreements. Ch. Stevens was an advocate of the agreement-specific approach, for example in the agricultural sector (Stevens, 2002, pp. 25-29). S. Prowse, on the other hand, represented the approach of modifying SDT provisions in accordance with the needs of a given country (country-specific approach). In this case, the main criterion was whether the member state, that was obliged to implement the WTO agreement, pursued development goals accordingly (Prowse, 2002).

K. Wang and L.A. Winters came up with a proposal to make SDT regulations more flexible (2000). The researchers concluded that as implementation costs increase, the possibilities of flexible adoption of WTO agreements by developing countries should also increase (Wang, Winters, 2000, as cited in Chang, 2008, p. 126). They proposed the adoption of certain criteria under a given WTO agreement (agreementspecific approach). On this basis, each WTO member could be assessed in terms of the possibility of using the SDT. The point was therefore to create the status of a country on the basis of an assessment of the possibilities and potential costs resulting from the adoption of the WTO agreement. In practice, the idea was that a given state could use, to a different extent and scope, certain preferences (transition periods, more flexible trade rules, the amount of technical assistance and assistance in building trade capacity) in accordance with the criteria established for a given WTO agreement (Chang, 2008, p. 127). 
A different concept, based on the creation of a special subgroup of developing countries eligible for SDT, was presented by B. Hoekman, C. Michalopoulos, L.A. Winters (2004 pp. 493-494). The purpose of such a change was to depart from the practice of determining the status of a WTO member state by the party concerned and access to SDT on the basis of transparent criteria. The authors supported the introduction of formal differentiation among developing countries and criticized the approach based on criteria adapted to a given agreement or individual needs of a developing country. In their opinion, LDCs and other small and sensitive economies would qualify for the new subgroup, which would significantly reduce the number of countries benefiting from SDT preferences and exemptions (Hoekman, Michalopoulos, Winters, 2004, pp. 493-494). They therefore allowed the possibility of adopting different thresholds and criteria for certain SDT provisions, but all were to be clearly articulated and broadly applicable. The possibility of adopting criteria on the basis of a case-by-case analysis was ruled out, considering it too costly and unfair. For example, a group of the poorest countries could benefit from more extensive preferences, e.g., those relating to transition periods and waivers of certain commitments. For all developing countries, on the other hand, the proposal was based on a softer application of instruments such as anti-dumping or safeguard proceedings, as well as the provision of technical assistance.

Although the concepts presented above were not implemented, some of them influenced further work carried out within the WTO Committee on Trade and Development (WTO, 2002). They mainly concerned demands to increase technical and financial assistance under the Aid for Trade to improve trade capacities and the investment climate in low-income countries. The need to increase such an assistance became even more apparent in the context of lower MFN-based trade barriers and the resulting lower preferential access gains for developing countries. The problem of the erosion of trade preferences has arisen, in particular for LDCs. Therefore, it was postulated to separate development policy from trade policy. It is a move away from the current strategy of allowing a limited number of countries to benefit from preferences that disrupt the international trading system. According to B. Hoekman, C. Michalopoulos, L.A. Winter, this kind of aid system, based on SDT preferences and created by developed countries, should be gradually abolished and replaced by a system based on direct aid, serving the development of trade capacity and economic efficiency (Hoekman, Michalopoulos, Winter, 2003, p. 23-24). An exception are LDCs, for which it is necessary to maintain the system of preferences combined with an increase in development aid. 


\subsection{Summary}

The SDT regulations were established to enable developing countries to participate in international trade on preferential terms. This meant, on the one hand, granting developing countries the right to protect their own market, and, on the other hand, more favorable access to the markets of developed countries than was required by the MFN. In line with the rules and practice of SDT, during the GATT period, developing countries were not obliged to grant tariff concessions or accept binding tariff commitments. Moreover, they were exempted from the obligation to apply the principle of reciprocity, and thus from not engaging in the reduction of trade barriers. It was a kind of assistance mechanism which, contrary to the intentions, did not bring the intended benefits to the recipients.

There has been a slight change with regard to SDT within the WTO. While the provisions were maintained, the approach to adopting and applying WTO rules under the single undertaking principle changed. The main difference from the GATT was that WTO member states were obliged to accept all multilateral agreements, but at the same time presented schedules of concessions and commitments. In addition, various transition periods for certain WTO agreements were adopted, and developing countries were required to reduce tariff rates much less.

Since the GATT Uruguay Round, attempts have been made to change SDT regulations in order to adapt them to new circumstances. The need to modify the SDT system resulted from several reasons. First, developing countries wanted to be more involved in multilateral negotiations and to benefit from trade. Second, their approach to trade liberalization has changed, which meant the gradual acceptance of commitments and the principle of reciprocity in trade negotiations. Third, there was a need to differentiate in the status of developing countries. The protection of developing countries' markets and special preferences in access to highly developed countries could not be practiced on such a scale and towards such a diverse group of developing countries. As a result, the effectiveness of SDT provisions decreased. Consequently, the preferential regime did not play the same role as it did during the GATT period and largely hindered integration into the multilateral trading system. The exception were LDCs. In their case, the SDT system and development assistance were the conditions for participating in the international trading system.

Attempts to negotiate changes in SDT focused on three issues. First, the legitimacy of SDT provisions, which were considered a central element of the WTO, was confirmed. Second, although the set of SDT regulations was extended to new areas (agriculture, services, TRIPS), the relevant provisions were not given legal force, 
which meant that they were still non-binding rules in developed countries. Third, the position of developing countries has changed, moving away from a strategy of blocking negotiations towards greater engagement and integration into the multilateral trading system. Instead of applying the principle of non-reciprocity on the part of developing countries (which was maintained for LDCs), an approach based on the obligation of acceptance by all members of multilateral WTO agreements was adopted.

The diversity of developing countries within the framework of the WTO was one of the reasons for the lack of agreement on the change of SDT in the framework of the Doha Round negotiations. This topic concerns the potential change in the rights and obligations of members of the organization, and therefore touches upon a fundamental issue relating to the functioning of the WTO. The aim of the SDT reform is to create a system of preferences more effective than the present one, based on specific and legally binding rules, and to increase the role of the WTO in the sphere of development, which would mean a deeper commitment of the organizations to help the adoption of binding trade rules by developing countries. The disagreement with the formal differentiation of developing countries makes SDT commitments vague, based on political rather than economic criteria. Exceptions are LDCs for which the system of preferences is better designed, but it also requires clearer rules, for example as regards rules of origin.

Preferences are not given once and for all and constitute a temporary measure, allowing states to adjust to adopted rules and implement multilateral agreements. It therefore seems necessary to separate development aid from trade policy. It is a move away from the current strategy of allowing one group of countries to reap benefits of preference, to one that emphasizes direct support to increase trade opportunities and improve economic growth. Increased development aid, in the case of the WTO - technical assistance, should be provided for specific purposes, taking into account the specific needs of the recipients. Maintaining SDT is justified only in the case of LDCs. 


\section{Chapter 6}

\section{THE WTO \\ AS A DEVELOPMENT INSTITUTION}

Launched in 2001, the Doha Development Round was the longest-running series of trade negotiation in the history of the GATT and the WTO. On the one hand, it reflected the growing role of developing countries within the organization, and on the other, due to the suspension of official negotiations, it showed a crisis and a decline of importance of the WTO. According to the agenda, developing countries were to play a key role in the round because of their vital economic interests and the will to actively engage in negotiations. This was a new situation, because during the previous rounds of GATT negotiations, the vast majority of developing countries were passive observers of the decisions taken. They were satisfied with the status of countries under the SDT regulations, where the principle of reciprocity of obligations was burdened with numerous exceptions and exemptions. In practice, their participation in the GATT system was selective, and the benefits were limited. The turning point was the Uruguay Round (1986-1994) and the establishment of the WTO.

The Doha Round, regardless of the final result, symbolizes the mainstreaming of development issues into the international trading system. While development problems and support to developing countries were present in the GATT multilateral trade negotiations, the range of issues under negotiation was selective and limited. Broader integration of development issues into the WTO was associated with the adoption of a new approach. It was about reconciling two seemingly contradictory commitments - the liberalization of trade and the preferential treatment for less developed countries. Given the experience of the Doha Round negotiations, this course of action could mean limited and selective liberalization. The question is whether liberalization and SDT can be aligned with each other. To agree to this kind of approach means, first of all, adoption regulations adjusted to the level of 
development and potential of developing countries, secondly, flexible application of SDT regulations to all developing countries and, thirdly, a selective approach to sectors subject to liberalization, thus identifying the least controversial areas of trade. The failure of the Doha Round negotiations resulted from the lack of agreement on the methods of reaching solutions. This has direct implications for the subject and scope of the WTO's activities, as well as the role that the organization has to play in the multilateral trading system.

The chapter is divided into three parts. The first concerns the arrangements made during the Uruguay Round and reasons for the negative attitude of developing countries to adopting commitments to trade liberalization. An example is the failure to launch the WTO round in Seattle in 1999 and the difficulties that developing countries faced in order to implement the WTO agreements. The second part focuses on those areas of the Doha Round negotiations that were most likely to contribute to enhancing the benefits of trade for less developed countries. This largely applies to market access for agricultural and textile products, as well as those areas that determine the growth of state capacity, i.e., intellectual property (TRIPS) and services (GATS and TiSA). The final section is devoted to the multilateral Trade Facilitation Agreement, which aims to reduce costs by streamlining and simplifying customs and administrative procedures for trade in goods. The solutions applied in the TFA, including those concerning assistance to developing countries, set a new course of action in trade negotiations.

\subsection{The Uruguay Round}

One of the most important achievements of the Uruguay Round is greater predictability of member countries' trade policies. This is the result of binding tariffs in trade in goods and the acceptance of commitments on tariffication, that is, the conversion of non-tariff barriers into tariff equivalents. This, in turn, contributed to reduce arbitrary market protection measures, and also gave some credibility to reforms undertaken by developing countries. Negotiations in the area of agriculture and textiles and clothing, which were of particular interest to developing countries, did not mean that these sectors were immediately subject to liberalization. Indeed, a number of trade instruments and measures were introduced that delayed the process of removing barriers, however, solid foundations for a fuller and deeper liberalization were prepared.

As a result of the decision made during the Uruguay Round, there was a sharp increase in the binding of tariffs on agricultural and industrial products. Before the 
Uruguay Round, only one-third of tariff lines for agricultural products were bound. For developing countries, it meant an increase from 17 to 100\%, and for highly developed countries and economies in transition - from 58 and 57 to $100 \%$, respectively (Table 17). As a result, the level of predictability in agricultural trade improved. Tariff line bindings for industrial products were slightly lower at $83 \%$ for all countries combined. Before the Uruguay Round, this level was $43 \%$. Furthermore, non-tariff barriers have become increasingly important in agriculture trade. A particularly large increase was recorded in the case of sensitive goods. For instance, the introduction of import quotas effectively limited the access of this goods to foreign markets.

\section{Table 17. Bound Tariffs on Industrial and Agricultural Products by Group of Countries and Regions After the Uruguay Round (in \%)}

\begin{tabular}{|c|c|c|c|c|c|c|c|c|}
\hline \multirow{3}{*}{ Groups } & \multicolumn{4}{|c|}{ Industrial products } & \multicolumn{4}{|c|}{ Agricultural products } \\
\hline & \multicolumn{2}{|c|}{$\begin{array}{c}\% \text { of tariff lines } \\
\text { bound }\end{array}$} & \multicolumn{2}{|c|}{$\begin{array}{c}\% \text { of imports under } \\
\text { bound rates }\end{array}$} & \multicolumn{2}{|c|}{$\begin{array}{c}\% \text { of tariff lines } \\
\text { bound }\end{array}$} & \multicolumn{2}{|c|}{$\begin{array}{l}\% \text { of imports under } \\
\text { bound rates }\end{array}$} \\
\hline & Pre & Post & Pre & Post & Pre & Post & Pre & Post \\
\hline Total & 43 & 83 & 68 & 87 & 35 & 100 & 63 & 100 \\
\hline \multicolumn{9}{|c|}{ By group of countries } \\
\hline Developed countries & 78 & 99 & 94 & 99 & 58 & 100 & 81 & 100 \\
\hline Developing countries & 21 & 73 & 13 & 61 & 17 & 100 & 22 & 100 \\
\hline Economies in transition & 73 & 98 & 74 & 96 & 57 & 100 & 59 & 100 \\
\hline \multicolumn{9}{|c|}{ By regions } \\
\hline North America & 99 & 100 & 99 & 100 & 92 & 100 & 94 & 100 \\
\hline Latin America & 38 & 100 & 57 & 100 & 36 & 100 & 74 & 100 \\
\hline Western Europe & 79 & 82 & 98 & 98 & 45 & 100 & 87 & 100 \\
\hline Central Europe & 63 & 98 & 68 & 97 & 49 & 100 & 54 & 100 \\
\hline Africa & 13 & 69 & 26 & 90 & 12 & 100 & 8 & 100 \\
\hline Asia & 16 & 68 & 32 & 70 & 15 & 100 & 36 & 100 \\
\hline
\end{tabular}

Source: GATT, 1994.

The principle of non-reciprocity, which was commonly used during the GATT period, was not officially excluded from the WTO rules. On this basis, some developing countries did not bind their tariffs on industrial goods, or if they did, then at a much higher level than in the case of developed countries (Martin, Winters, 1995, p. 30). For instance, most Latin American countries decided to bind all their tariff lines. For over two-thirds of the tariff lines that were bound by developing countries, the liberalization commitments were still quite weak because the bound tariff rate was set at a much higher level than the applied rate - around 10-15\% (GATT, 1994, p. 26). Developing countries also enjoyed greater freedom not only in applying tariff 
barriers, but also non-tariff barriers (e.g., frequent recourse to Article XVIII: B of the GATT, problems with the balance of payments) (Michalopoulos, 2000, p. 14).

During the Uruguay Round negotiations, two areas were the most important for the interests of developing countries: market access for agricultural products and increased exports of textiles and clothing. In the rest of the areas of intellectual property rights, trade related investment and services, the impact was low and commitments for developing countries were postponed or suspended due to the application of SDT. The most tangible decisions made during the Round concerned:

- the abolition of quantitative restrictions on trade in textiles and clothing;

- binding customs tariffs on agricultural products and applying tariffs in the agricultural sector;

- lowering the tariff escalation for agricultural products of various degrees of processing;

- announcements of the elimination of subsidies in agriculture.

The level of tariffs on industrial products imported from developing countries was lowered, however, it remained at a relatively high level compared to rates in highly developed countries. The average level of tariffs on goods imported from developing countries was $3.4 \%$ in developed countries, but in the case of other developing countries it was four times higher and amounted to about $12.8 \%$ (Table 18). This means that developing countries protected each other's markets, which specialized in the production of labor-intensive goods (clothing, textiles, footwear).

In the textile and clothing sector, the decision to lift trade restrictions was linked to the expiry of the Multifibre Agreement, which had been in force since 1974. The agreement sanctioned the introduction of quantitative restrictions on the export of textiles and clothing from developing countries. The MFA imposed restrictions on exporters from developing countries in the form of voluntary export restrains (VER) (Hudec, Finger, 2010, p. 54). Formally, they were treated as voluntary measures, imposed and enforced by developing countries. The voluntary nature of export restrains was however a fiction because importing countries wanted to limit the exports of cheap and competitive goods from developing countries. Along with increasing their comparative advantage and increasing international competitiveness in the textile and clothing sector, developing countries sought to change these rules. An additional, disadvantageous element of the MFA was a special protection mechanism. It could be activated by the importer against textiles and clothing products not subject to quantitative restrictions in a situation where their import caused market disturbances (Synowiec, 2002). 
Table 18. Tarff Protection of Industrial Products, 1995 (in \%)

\begin{tabular}{|l|c|c|}
\hline \multirow{2}{*}{\multicolumn{2}{|c|}{ Exporting region }} & \multicolumn{2}{c|}{ Importing region } \\
\cline { 2 - 3 } & \multicolumn{3}{|c|}{ High-income countries } & Developing countries \\
\hline High-income countries & 0.8 & 10.9 \\
\hline Developing countries & 3.4 & 12.8 \\
\hline World & 1.5 & 11.5 \\
\hline
\end{tabular}

Source: own study based on Hertel, Martin, 2000.

The MFA regulations were inconsistent with basic GATT principles and selectively restricted the access of textile goods to foreign markets. Formally, they were contrary to Art. 1 of the GATT on the principle of non-discrimination, Art. XI of the GATT banning import or export quotas and Art. XVI of the GATT prohibiting export subsidies (Finger, 1995, p. 289). The first step to eliminate the MFA was to replace it with the interim Agreement on Textile and Clothing (ATC), which set a timetable for the phasing out of quantitative restrictions, including VER. The ATC was to be in force for 10 years, until the rules of trade in textile goods were fully incorporated into the GATT 1994. There were four integration stages for which the amount of successive tranches of exemption from restrictions was determined, measured as a share of total imports in $1990 .^{48}$

Although developing countries sought to remove barriers to trade in textiles and clothing, the liberalization process that had already begun did not fully meet their interests. They criticized the excessively slow process of lifting quantitative restrictions by importers and called for improved market access to developed countries. The obstacles were the persisting quantitative restrictions and the slow process of liberalizing market access, which could be explained by the desire to restructure less competitive textile and clothing sectors in importing countries, i.e., in highly developed countries.

In the field of agricultural trade, the arrangements adopted during the Uruguay Round were an important step towards deeper reform of the sector. The most frequently used barriers in agriculture included: tariffs, import quotas, voluntary export restrictions, minimum price of imported products, other variable fees, as well as export subsidies and domestic support for agriculture (McCulloch, Winters, Gaviera, 2001, p. 178). An essential step in the process of making changes was

48 The first phase, which began in 1995 , covered $16 \%$ of each member's total import volume measured for the 1990 base period, the second, which was scheduled to start in 1998, was to cover another $17 \%$, and the third could begin started in 2002 and concerned 18\% of imports. For the fourth and last phase, the largest exemption from restrictions was provided for, which amounted to $49 \%$ (Synowiec, 2002, p. 220). 
the Agreement on Agriculture, which contained four basic elements. First of all, tariffication, i.e., the replacement of non-tariff barriers with the equivalent of tariff rates. Secondly, a reduction of the then existing tariffs, which were not bound, as well as those introduced after the tariffication. Third, binding all customs tariffs over a specified period of time. Fourth, the adoption of a minimum market access commitment, thus keeping imports as low as possible. ${ }^{49}$

On the basis of AA, the groundwork was laid for the proper changes. However, despite the commitments made, the level of protection in agricultural trade in all member states remained at a relatively high level, which means that, in fact, proper liberalization did not take place (Hathaway, Ingco, 1995, p. 7; Francois, McDonald, Nordstrom, 1996, p. 128). In terms of market access, tariff reduction by an average of $36 \%$ and $24 \%$ for developed and developing countries, respectively, and a minimum reduction of $15 \%$ (10\%) for each tariff line were adopted. LDCs were virtually excluded from making commitments. Due to the changes, the level of tariffs for developing countries exporting agricultural products amounted to $15.6 \%$ in highly developed countries and 20.1\% in developing countries (Table 19) (Hertel, Martin, 1999, p. 464; Hertel, Hoekman, Martin, 2002).

Table 19. Tariff Protection of Agricultural Products, 1995 (in \%)

\begin{tabular}{|c|c|c|}
\hline \multirow{2}{*}{ Exporting region } & \multicolumn{2}{|c|}{ Importing region } \\
\hline & High-income countries & Developing countries \\
\hline \multicolumn{3}{|c|}{ Import-weighted average tariffs } \\
\hline High-income countries & 15.9 & 21.5 \\
\hline Developing countries & 15.1 & 18.3 \\
\hline World & 15.6 & 20.1 \\
\hline
\end{tabular}

Source: own study based on Hertel, Martin, 2000.

The limited impact of decisions taken during the Uruguay Round on the liberalization of agricultural sector resulted from several factors. Firstly, in highly developed countries the level of bound tariffs was set at a much higher level than previously used nontariff barriers (Anderson, 2000, pp. 40-41). Secondly, the adoption of a ceiling on bound tariffs, for which reductions were to be carried out, was set at a higher level than the level of applied tariffs, which provided opportunities for developing countries to raise and lower tariff levels freely (Hathaway, Ingco, 1995, pp. 42-43; Hertel, Hoekman, 2002, p. 115; Srinivasan, 2002, p. 8). This means that achieving

49 The minimum market access undertaking was to be implemented through tariff quotas, which meant setting lower import duties up to the minimum level of obligations. The minimum commitment was to correspond to the MFN rate level (AA: Annex 3, section C, par. 14). 
any degree of liberalization in applied tariff rates required a significant reduction in the level of bound rates (Francois, 1999, after: Hertel, Hoekman, 2002, p. 92). The changes introduced during the Uruguay Round even contributed in some cases to an increase in the level of protection of agricultural sector. This was because the largest reductions (36\%) were made for products with low tariffs, and the minimum reductions, at the level of $15 \%$, were for products that were subject to non-tariff barriers and to which high tariffs were applied (sensitive products). Moreover, the base period for the tariffication of agricultural trade was set to 1986-1988, when world agricultural commodity prices were at very low levels compared to previous decades. Consequently, when comparing the base period prices with the domestic prices of barrier-protected goods, the difference between them was exceptionally high. The difference became the basis for determining the amount of the tariff equivalent.

Due to the exceptional case of the base period for many agricultural products, the tariff equivalent reported in member states' schedules was significantly higher than the same base period tariff equivalent (Hathaway \& Ingco, 1995, p. 11). This mechanism was described as dirty tariffication and occurred both in developing countries as well in the EU and the United States. As a result of the conducted tariffication and uneven distribution of tariff cuts, the net effect of tariff reduction led to increased disturbances in customs protection on the market of agricultural products. This means that for heavily protected items (i.e., wheat, corn, dairy products, meat), the level of protection was either maintained or increased, and for relatively low tariff products such as soybeans, it was reduced.

Another decision made during the Uruguay Round concerned high tariff rates and tariff escalation. The problem of high tariffs, i.e., those exceeding $15 \%$, concerned the following sectors: agri-food, fruit, vegetables and fish, food and processing industry, textiles and clothing, footwear and leather, automotive and high-tech industries. In many cases where there were tariff peaks, preferences towards developing countries were limited. For example, sensitive products have been excluded from preference regimes or subject to quantitative restrictions, both in terms of the amount under the preferential tariff rate (tariff quota) and in terms of eligible countries (Michalopoulos, 1999). Thus, even after the implementation of the Uruguay Round decisions and the inclusion of GSP preferential rates, the average level of ad valorem tariffs above $15 \%$ in the EU, the US, Japan and Canada (i.e. Quad members) exceeded $10 \%$ of total tariffs (UNCTAD, 2000). The highest tariff rates in Quad countries were between 350 and $900 \%$ for goods exported from developing countries, which mainly included food and footwear (Table 20) (Aksoy, 2005, p. 48).

The tariff structure of highly developed countries shows a significant escalation, which means that market access for more processed products (with higher value- 
added) is more restricted. Tariffs increase with the degree of processing. This was detrimental to developing countries, which faced major difficulties in terms of exporting more processed goods. As a result of the Uruguay Round decisions, there has been some improvement in this area. Among the Quad, the average level of tariff escalation was highest in Japan and lowest in Canada. Taking into account the Uruguay Round decisions, this level averaged $15-16 \%$ on the EU market (down from 23\%), $27 \%$ on the Japanese market (down from 35\%) and 9\% on the US market (down from $12 \%$ ). Nevertheless, the level of tariffs for selected products remained relatively high. For instance, in the EU and Japan, fully processed food products have double the customs duties of products in the first stage of processing. They amount to $24 \%$ and $65 \%$, respectively (Table 21 ). This means that for heavily protected items (i.e., wheat, corn, dairy products, meat), the level of protection was either maintained or increased, and for relatively low tariff products such as soybeans, it was reduced.

Table 20. Tariff Peaks in Selected Countries (in \%)

\begin{tabular}{|l|c|c|c|c|}
\hline \multicolumn{1}{|c|}{ Country or group } & $\begin{array}{c}\text { Average applied } \\
\text { tariffs }\end{array}$ & Maximum tariff & Standard deviation & $\begin{array}{c}\text { Share of lines } \\
\text { covered }\end{array}$ \\
\hline Canada & 4.1 & 238 & 13.5 & 74.2 \\
\hline Japan & 10.9 & 50 & 10.1 & 84.8 \\
\hline United States & 9.9 & 350 & 26.5 & 99.5 \\
\hline European Union & 19 & 506.3 & 27.3 & 85.9 \\
\hline South Korea & 39.9 & 917 & 107.9 & 97.9 \\
\hline Brazil & 13.2 & 55 & 5.6 & 100 \\
\hline Costa Rica & 14.2 & 154 & 18 & 100 \\
\hline Morocco & 67.4 & 376.5 & 70.6 & 100 \\
\hline Indonesia & 8.9 & 170 & 25.6 & 100 \\
\hline Malawi & 16.5 & 25 & 8.5 & 100 \\
\hline Togo & 15.6 & 20 & 6.1 & 99.9 \\
\hline Uganda & 13.6 & 15 & 3.2 & 100 \\
\hline
\end{tabular}

Source: Aksoy, 2005.

Table 21. Tariff Escalation for Food Manufacturing in Selected Countries (in \%)

\begin{tabular}{|l|c|c|c|}
\cline { 2 - 4 } \multicolumn{1}{c|}{} & Canada & EU & Japan \\
\hline First stage of processing & 3 & 15 & 35 \\
\hline Semi-processed & 8 & 18 & 36 \\
\hline Fully processed & 42 & 24 & 65 \\
\hline
\end{tabular}

Source: McCulloch, Winters, Cirera, 2001. 
The highest rates are applied to fully processed products, which discourages developing countries from independently processing agricultural raw materials and exporting them to highly developed countries (Diakantoni, Escaith, 2009, p. 10). The reason is protection of processing industry and fear of competition from developing countries. This in turn leads to protectionist measures and undermines the effects of trade liberalization.

\section{Consequences of the Uruguay Round}

Developing countries were disappointed with the results of the Uruguay Round. The asymmetry related to their negotiating power with developed countries was particularly evident in areas where they had special interests, i.e., the agricultural and textile sectors. Developing countries agreed to adopt new agreements in return for lifting the MFA, VER, and some barriers to agriculture. They accepted regulations which were burdened with high implementation costs. It was a kind of compensation for the elimination of practices incompatible with the GATT agreement, but serving commercial interests of developed countries (Hertel, Hoekman, 2002, pp. 128-129). Decisions on the agricultural sector were of particular importance. The effects of the applied tariffication, as well as the liberalization of agricultural sector, turned out to be of little benefit to developing countries. Although tariffication has contributed to increasing transparency in agricultural trade and the elimination of some hidden forms of protection, there has been an increase in the level of protection for some products (defined as sensitive). Maintaining high barriers to some agricultural commodities was the result of applying the tariff peaks, exceeding the level of $15 \%$ and reaching even $300 \%$, as well as tariff escalation (UNCTAD, 1999, p. 49).

Estimates of the benefits to be achieved by developing countries under the Uruguay Round focused mainly on two areas: trade in textiles and agricultural products. Although developing countries' exports were assumed to increase in these areas, greater benefits were expected to come from increased consumption as a result of falling prices in textile and clothing sectors. This meant that greater benefits associated with increased income and trade dynamics were to accrue to developed countries than to developing countries (Francois, McDonald, and Nordstrom, 1995, p. 123). Moreover, in the agricultural trade it was possible to carry out more liberalization than resulted from the final decisions of the Round. However, countries belonging to the CAIRNS ${ }^{50}$ group,

50 CAIRNS - the group was established during the Uruguay Round. It consists of representatives of agricultural exporting countries. The aim of the group was to liberalize the agricultural sector, therefore it applied for the elimination of export subsidies, improved market access, and a significant reduction in internal support for agricultural production. 
exporting agricultural products, benefited from the increase in prices for agricultural products. In the textile sector, on the other hand, the market share of some exporters may have changed after the elimination of the MFA quota system in favor of new, less competitive manufacturers and exporters from developing countries and LDCs. The elimination of quantitative export restrictions has substantially boosted the exports of developing countries (Evolution of Trade..., Hayasi, 2007, pp. 4-5).

In a situation where many of the provisions of the Uruguay Round were not implemented, developing countries were against starting a new series of negotiations. Therefore, the attempt to establish the first WTO round in Seattle in 1999 failed. There were several reasons. First, the failure to prepare a mutually agreed agenda for negotiations. Developing countries were opposed to accepting new commitments and the related high implementation costs. Second, suspicions were raised by the way in which the Seattle conference negotiations were conducted, which consisted in agreeing decisions in the subgroups of countries (the Green Room's procedure), and then presenting the results in the plenary forum (Srinivasan, 2002, pp. 2-4, 14). In such an arrangement, most of the developing countries, except for large economies, had no influence on negotiations. Third, the manner of conducting negotiations and the selection of topics by the hosts of the meeting - the US delegation - who pledged to include environmental and labor standards in the WTO regulatory system, were also not appreciated. ${ }^{51}$

The benefits of trade liberalization are always accompanied by adjustment costs, usually automatic and direct. They are borne by WTO member states due to the need to make regulatory changes as a result of adopting new multilateral agreements. According to a study by J.M. Finger and P. Schiler (2000), in 2000, regulatory changes resulted in costs that in developing countries could be much higher than the benefits of access to new markets. In the case of LDCs, these costs often exceeded the budget expenditures for development purposes (Finger, 2000, p. 425; Hertel, Hoekman, Martin, 2002, p. 129). Three agreements adopted during the Uruguay Round that led to high adjustment costs in developing countries were analyzed: CV (GATT 1994 - Art. VII), SPS and TRIPS.

In all cases, it was not possible for a developing country to implement regulations without external assistance. The high adjustment costs accompanying the reforms exceeded the capacities of a developing country faced with a shortage of administrative infrastructure, institutional and legislative facilities. Therefore, provisions on special

51 The issue of incorporating regulations related to environmental protection and labor law standards into the WTO divided the states participating in the WTO Ministerial Conference in Seattle. On this issue, the President of the United States, Bill Clinton, declared the introduction of sanctions for non-compliance with basic employee rights (Hertel, Hoekman, Martin, 2000, p. 2; Odell, 2002, pp. 24,27). 
treatment for developing countries and the provision of technical assistance have been incorporated into each contract. The problem, however, was that the obligation to provide assistance was not legally binding for donor countries. The adopted formula for technical cooperation was not very precise, so the scale and scope of support depended on the decisions of aid donors (Kostecki, 2001, pp. 11-12; Henson, Loader, 2001).

In line with the approach adopted during the Uruguay Round (one-size-fits-all), developing countries were obliged to adopt all the regulations that were optional prior to the Round. This included TBT, SPS, customs valuation, anti-dumping, and the subsidy agreement. The regulations that were in force in most developed countries had to be implemented by the less developed countries, and the process was not based on the principle of mutual exchange of concessions. While they were given a longer time to implement commitments (on average 5 years and longer extendable periods for LDCs), most developing countries failed to do so within the foreseen period. By 2000, approximately 80-90 developing countries out of $109 \mathrm{did}$ not comply with the requirements of TRIPS, SPS, and the CV (Finger, 2000, p. 435). There is consensus that the approach taken during the Uruguay Round to ensure and support the implementation of WTO agreements by developing countries proved to be ineffective (Srinivasan, 1998; Finger, Schuler, 2000; Ostry, 2000). Above all, there was no flexibility in making decisions about specific countries. While most researchers admit that a uniform approach to the reduction of tariff and non-tariff barriers is justified all regions have generally gained as a result of tariff barrier reduction (Martin, Winters, 1996) - the same approach, applied to other WTO agreements, was not beneficial for most developing countries. The main point is that at least minimal institutional capacity is needed to adopt some WTO agreements, as in the case of TRIPS, CV or SPS. It was therefore necessary to mobilize additional development assistance from highly developed WTO members.

\subsection{The Doha Round}

The main goal of the Doha Round was to work out principles and rules of international trade which, to a greater extent than the existing WTO agreements, would support interests of developing countries and allow them to integrate more into the multilateral trading system. Divergent interests and objectives among WTO member states led to suspension of negotiations which dragged on, with varying degrees of frequency, until the 2015 Ministerial Conference in Nairobi. Despite the stalemate, that first emerged in 2003 at the Ministerial Conference in Cancún, consultations in selected areas were conducted even after 2016. 
The main objective of the round was the reduction or elimination of tariffs, including the highest tariffs, and the escalation of tariffs, as well as non-tariff barriers, especially regarding the export of products in which developing countries were interested (WTO, 2001b). The agenda covered the following areas: agriculture, industrial products or manufactured goods (NAMA), ${ }^{52}$ services, intellectual property rights (geographical indications, health protection rules), Singapore issues (investments, competition policy, the principle of transparency in government procurement, trade facilitation), WTO rules relating to anti-dumping, subsidies, regional trade agreements, and the problems of relationship between trade and environmental protection (WTO, 2005a). In the context of the adoption of the Trade Facilitation Agreement, it should be noted that three of the four Singapore issues were withdrawn from the negotiations in 2004. Only trade facilitation issues were the subject of negotiations, which were incorporated in the TFA in a slightly reduced version. As part of the Doha Round, a commitment was made to provide support to poorer countries by strengthening their export capacities, diversifying production capabilities and accessing goods to new markets, while introducing further solutions to liberalize international trade. Traderelated technical assistance and the continued application of SDT became an integral part of efforts to integrate LDCs into the global economy. It is assumed that the adoption of a new assistance package accompanying the liberalization arrangements should be complementary to ongoing efforts to remove trade barriers.

Several negotiating areas of the Doha Round that are important for developing countries' trade interests are the subject of further analysis. First, there are market access issues for agricultural and industrial goods, second, liberalization of services and, third, protection of intellectual property rights. A separate issue is the Trade Facilitation Agreement and the accompanying Trade Facilitation Agreement Facility. Their selection was based on the following assumptions:

- negotiations in agricultural sector and NAMA were the key to breaking the deadlock and adopting a comprehensive agreement in the Doha Round;

- TRIPS and services issues, although not in the mainstream of the negotiations, have a major impact on the development of the economic capacity of developing countries;

- the TFA is so far the only multilateral agreement adopted under the Doha Round;

- solutions applied in the TFA, including those related to assistance to developing countries, set a new direction of action in trade negotiations.

52 NAMA refers to the following categories: manufactured goods, industrial goods, textiles, fuel and mining products, footwear, jewelry, forestry products, fish and fishing, and chemicals. 


\section{Agricultural and Manufactured Goods}

The proposals to increase market access in agricultural sector and NAMA are the subject of this section. The basis for the final agreement among WTO members was the July 2008 package. Based on postulates-offers presented by the parties, it was possible to prepare a document containing preliminary findings and differences in the positions of the participants. A set of various proposals was distributed for consultation on December 6, 2008 (WTO, 2008). It was the fourth revised version of the draft agreement in agricultural sector (the previous ones were from 2006 and July and September 2008), which included formulas for tariff reductions, domestic support and export subsidies (Table 22).

\section{Table 22. Preliminary Arrangements for Agricultural Sector under the July 2008 Package}

\begin{tabular}{|c|c|}
\hline $\begin{array}{l}\text { rt } \\
\text { ort }\end{array}$ & $\begin{array}{l}\text { - Complete elimination of export subsidies by } 2013 \text {, longer transition period for developing } \\
\text { countries } \\
\text { - Revision of the rules on export credits, guarantees and insurance, and international food aid }\end{array}$ \\
\hline & $\begin{array}{l}\text { - Commitment to reduce (as part of the Amber Box + Blue Box and the De Minimis Rule): EU - by } \\
80 \% \text {, the United States and Japan - by } 70 \% \text {, developing countries by } 55 \% \text {. Immediate cuts will } \\
\text { affect the EU, US, and Japan (by } 33 \% \text { ), the rest by } 25 \% \text {. Implementation period: for developed } \\
\text { countries - } 5 \text { years, for developing countries - } 8 \text { years, arrangements for reducing support } \\
\text { under the Amber Box (AMS): EU by } 70 \% \text {, the United States and Japan by } 60 \% \text {, developing } \\
\text { countries by } 45 \% \\
\text { - De Minimis Rule: production cut for developed countries by } 25 \% \text {, for developing countries by } \\
\text { two thirds for } 3 \text { years to } 6.7 \% \text { of production } \\
\text { - The Blue Box: } 2.5 \% \text { production reduction for developed countries and } 5 \% \text { for developing } \\
\text { countries } \\
\text { - The Green Box: maintaining the formula for decoupling income from production, and in the } \\
\text { case of developing countries - from food stocks }\end{array}$ \\
\hline & $\begin{array}{l}\text { - Using the tiered formula for tariff cuts: the biggest cuts for the highest tariffs: for developed } \\
\text { countries - a } 50 \% \text { reduction for tariffs below } 20 \% \text { and by } 70 \% \text { for tariffs above } 75 \% \text {; two-thirds } \\
\text { cut for developing countries in each tariff band compared to the developed country band } \\
\text { - Sensitive products (available to all members) subject to a smaller reduction, as are special } \\
\text { products (for developing countries) } \\
\text { - Changes to the application of special agricultural safeguard clauses for developing countries } \\
\text { - LDCs were excluded from the obligation to tariff cuts }\end{array}$ \\
\hline
\end{tabular}

Source: own study based on WTO, 2008c.

According to the July 2008 package, parties managed to initially agree on modalities to achieve tariff reduction. It covered agricultural and non-agricultural tariff rates for goods from four groups of countries - low and middle income, high income, and LDCs. The proposals concerned applied and bound tariff rates (all offers are included in Table 23). The modalities of reduction were specified in the tiered formula for agricultural sector and the Swiss formula for NAMA. The aim was to lower the average bound rate on agricultural commodities from 40 to nearly 
$30 \%$, and on industrial goods - from 9.9 to 5.3\%. In both cases, the proposed rate reductions meant higher cuts for higher tariffs..$^{53}$ Assuming that the tiered formula was adopted and applied in agricultural sector, the average bound rate could be reduced even by half, from the baseline of $40.3 \%$ to $20.7 \%$ (Table 23).

\section{Table 23. Weighted-Average Applied and Bound Tariff Rates (in \%): The Doha Round Proposals}

\begin{tabular}{|c|c|c|c|c|c|c|}
\hline & \multicolumn{3}{|c|}{ Applied rates } & \multicolumn{3}{|c|}{ Bound rates } \\
\hline & Base* & Formula** & $\begin{array}{c}\text { Formula } \\
\text { plus flex*** }\end{array}$ & Base* & Formula** & $\begin{array}{l}\text { Formula } \\
\text { plus flex }\end{array}$ \\
\hline \multicolumn{7}{|c|}{ Agriculture } \\
\hline All countries & 14.6 & 9.0 & 11.9 & 40.3 & 20.7 & 29.9 \\
\hline $\begin{array}{l}\text { Low- and middle-income } \\
\text { countries }\end{array}$ & 13.3 & 11.3 & 13.2 & 53.0 & 33.0 & 45.4 \\
\hline High-income countries & 15.5 & 7.5 & 11.1 & 30.9 & 12.1 & 18.4 \\
\hline LDCs & 12.5 & 12.2 & 12.5 & 94.1 & 59.3 & 93.7 \\
\hline \multicolumn{7}{|c|}{ NAMA } \\
\hline All countries & 2.9 & 2.0 & 2.3 & 9.9 & 4.7 & 5.3 \\
\hline $\begin{array}{l}\text { Low- and middle-income } \\
\text { countries }\end{array}$ & 6.1 & 4.6 & 5.3 & 22.3 & 10.9 & 12.3 \\
\hline High-income countries & 1.6 & 1.0 & 1.0 & 4.6 & 2.1 & 2.1 \\
\hline LDCs & 10.9 & 8.0 & 10.9 & 40.9 & 14.3 & 40.9 \\
\hline
\end{tabular}

* Base refers to the base rate in the absence of an agreement during the round.

** Formula - a rate negotiated and implemented without exceptions.

*** Formula plus flex - a rate that includes special preferences for LDCs and special and sensitive products within the agricultural sector.

Source: Laborde and Martin 2011a, 2011b.

However, this option does not take into account exceptions for special and sensitive products, the share of which in developing countries' exports is of particular importance. The share of sensitive products in total tariff lines is strictly defined: for developed countries it reaches $4 \%$ of tariff lines, and for developing countries $-5.33 \%$. The identification of products as sensitive is often associated with the existence of tariff quotas. In contrast, the category of special products is reserved only for developing countries and is based on criteria related to food security, human health, and rural development. Their share may be up to $12 \%$ of the country's tariff

53 The Swiss formula for NAMA is a non-linear formula for cutting tariffs. It is applied for base rates equal to the binding rates or the average applicable MFN rates for the period 1999-2001 and 25\% for the current unbound tariff lines. The Swiss formula, like the tiered formula, requires ad valorem tariffs. The tired formula for agricultural produce also implies larger cuts for higher tariffs. The condition is that the tariffs are available as a percentage of the value of the imported goods. 
lines (Brink, 2014, pp. 10-11). Both highly developed and developing countries have the right to mark some of their products as sensitive, and only developing countries as special products.

Under the Swiss formula, separate reduction coefficients were established for developed and developing countries. For the first group of countries, it was decided to maintain one coefficient, while for the poorer countries, several options were adopted, depending on the possibility of adjustment. A higher ratio for poorer countries means a lower reduction of tariffs. A higher coefficient for poorer countries means a lower tariff reduction. The arrangements adopted in December 2008 included the following formulas: a coefficient of $8 \%$ for highly developed countries and 20\%, 22\%, and 25\% for developing countries and LDCs (WTO: Non-agriculture...; Decreux, Fontagné, 2011, p. 25). Applying the proposal in practice would mean that maximum tariffs in rich countries would not exceed $8 \%$ in total, and bound tariffs would remain on an average level below $3 \%$. In addition, the highest tariffs on sensitive products would be below $8 \%$. In the case of developing countries, each of them would have a choice, depending on their status from three possible coefficients. Most tariff lines correspond to a formula where tariff rates are below $12-14 \%$. This would mean that bound rates for developing countries would remain, after agreeing the coefficient, at an average level of $11-12 \%$, and for the group of least developed countries - above $15 \%$. As a consequence, the gap between bound and applied rates would be significantly reduced. The draft also contained provisions prohibiting the concentration, i.e., preventing states from excluding entire sectors from tariff cuts, e.g., cars or clothing.

Exceptions and preferential treatment rules for goods from developing countries limit the impact of the Swiss formula on tariff reduction in manufactured sector and the tired formula in agriculture. In line with the tiered formula for agricultural commodities, deeper reductions are projected for the level of bound tariffs. This type of approach, with larger cuts in higher tariffs (usually generating greatest costs), is economically desirable, but may result in considerable political resistance and pressure to apply exceptions (Laborde, Martin, 2011a, 2011b). Similar effects may occur in non-agricultural sector. The scale of reductions may therefore be smaller due to the application of the flexibility rule within SDT. In addition, the effect of tariff reduction can be reduced by the existence of large differences between the bound and the applied rates. The effect may be to reduce the impact of the cuts on the level of applied rates, and thus to increase market access. Flexibility provisions for specific groups of countries or products where members may apply cuts smaller than those resulting from the formula adopted, may lead to a smaller reduction in applied rates. This means that the depth and scope of actual liberalization depends 
on an agreement on the manner and amount of reductions for developing countries benefiting from a range of flexible solutions.

LDCs are in a special situation. While they are not subject to the obligation to reduce their tariffs, their margin of preference may decrease due to liberalization of the agricultural sector. Firstly, because numerous preferences are already applied to them, which will erode as a result of progressive reduction of tariffs (erosion of preferences). Their only commitment is to increase the level of tariff bindings. Secondly, these countries are mostly net food importers, which means that because of liberalization in agricultural sector, prices of their goods may increase slightly. Thirdly, they are not committed to reform their own trade policy, therefore, as a result of the changes, they cannot count on increasing efficiency in production and reducing costs, for example by choosing cheaper sources of product supply (Bouët, Laborde, 2011, p. 171).

Due to trade liberalization, LDCs are exposed to lower preferences and a decrease in benefits resulting from the use of lower tariffs in agricultural sector. This is because many agricultural products from LDCs are not competitive on world markets. In turn, in textile and apparel trade, competition between developing country producers may be intensified and the share of products from LDCs may be reduced in favor of other countries (Bhagwati, Sutherland, 2011, p. 11). Without protecting the exports of LDCs, i.e., the establishment of full duty-free and quota-free market access (DFQF), the negative process for these countries may worsen. The MFN tariff reduction will lead to lowering barriers for other developing countries, and thus reducing the margin of preference for LDCs. The benefits for LDCs for participating in DFQF programs are twofold. This includes participation in initiatives such as the EU Everything but Arms (EBA) program, the EU Economic Partnership Agreement (EPA) with ACP countries, and the U.S. African Growth and Opportunity Act (AGOA). Firstly, it is preferential market access with relatively high prices for agricultural products. Secondly, it applies high protective tariffs to other developing countries, not covered by special preferences. Liberalization of agricultural sector, which would lead to a reduction in trade preferences and lower prices for goods exported from developing countries, is therefore not in the interest of LDCs. Moreover, there are significant differences between higher and lower income developing countries. For the latter, liberalization of trade in agricultural goods would expose them to competition from larger and richer developing countries such as Brazil, China, and India. For this purpose, the change in rules of origin is needed.

Rules of origin are an integral part of preferential market access for developing countries. The aim pursued by the interested states is to reduce restrictions and costs associated with their application. While not directly negotiated in the Doha 
Round, they were recommended for liberalization and simplification. The scope and application of the rules are left to the importing countries, which - depending on international trade agreements - may apply various preferential tariffs, including zero rate. Empirical evidence shows that liberal rules of origin allow for cumulation and substantial use of imported goods from third countries, which is a significant indicator of export growth in LDCs (Martin, Mattoo, 2011, p. 12).

It is estimated that gains from the implementation of the Doha Round provisions will be lowest for LDCs. In turn, more developed and developing countries, such as China, India, Vietnam, Brazil, Indonesia, can benefit the most, especially as a result of liberalization in NAMA (Polaski, 2006, pp. 24-25). Forecasts of benefits to countries and regions from the completion of the Doha Round are presented in Table 24. The long-term effect of the projected liberalization of trade in goods is $0.09 \%$ of global GDP annually, equivalent to USD 70 billion by 2025. In the case of services, it is an increase in global GDP by $0.11 \%$, and in terms of trade facilitation by $0.20 \%$ (Decreux, Fontagné, 2011, p. 27). The greatest benefits are expected in the area of trade facilitation through improved customs procedures and administrative requirements. In the regional breakdown, the largest gains from liberalization of agricultural goods and services may accrue to the EU and China. The share of both entities in the benefits of global GDP growth may amount to $22 \%$ for everyone. In the case of the United States, it is 7\%, and in the case of ASEAN countries - 9\%. Japan should expect very good results, especially thanks to liberalization in goods (15\%). On the other hand, the losses - from the countries of the Caribbean, Mexico, and Sub-Saharan Africa. However, taking into account trade facilitation issues, these regions, apart from Mexico, may record gains (see Table 24).

Table 24. Long-Term GDP Growth Projections for Doha Round Participants at Regional or Country Level (USD million, 2004 Constant Prices)

\begin{tabular}{|l|r|r|c|}
\cline { 2 - 4 } \multicolumn{1}{c|}{} & Goods & Services & Trade facilitation \\
\hline Argentina & 694 & 730 & 890 \\
\hline ASEAN & 6.492 & 7.319 & 12.973 \\
\hline Australia and New Zealand & 1.401 & 1.545 & 1.714 \\
\hline Brazil & 366 & 456 & 2.044 \\
\hline Canada & 859 & 1.197 & 1.302 \\
\hline Caribbean & -718 & -696 & 131 \\
\hline China & 15.981 & 18.443 & 36.465 \\
\hline EFTA & 7.289 & 7.669 & 7.669 \\
\hline EU & 11.847 & 18.571 & 30.731 \\
\hline India & 3.821 & 4.328 & 6.932 \\
\hline
\end{tabular}


cont. Table 24

\begin{tabular}{|c|c|c|c|}
\hline & Goods & Services & Trade facilitation \\
\hline Japan & 10.194 & 10.703 & 13.772 \\
\hline Korea & 635 & 887 & 4.512 \\
\hline Mexico & -473 & -353 & -296 \\
\hline North Africa & 1.062 & 1.150 & 1.279 \\
\hline Africa (exc. South Africa) & -549 & -394 & 6.024 \\
\hline Other Mercosur countries & 438 & 480 & 889 \\
\hline $\begin{array}{l}\text { Other South American } \\
\text { countries }\end{array}$ & 977 & 1.057 & 2.533 \\
\hline Other South Asian countries & 454 & 582 & 1412 \\
\hline Other countries & 1.001 & 1.809 & 7.390 \\
\hline Taiwan & 2.498 & 2.622 & 4.524 \\
\hline United States & 5.344 & 6.45 & 9.480 \\
\hline
\end{tabular}

Source: Decreux, Fontagné, 2011.

At the WTO Ministerial Conference in Hong Kong in December 2005, a proposal was made to extend the possibility of applying the duty-free and quota-free market access to LDCs by all WTO member states, including developing countries (WTO, 2005). Decisions on modalities to implement DFQF were initially made in 2008. The proposal for free access for LDCs exports to developed and developing markets concerned the allocation of a minimum of $97 \%$ of LDCs' tariff lines. In this arrangement, this meant excluding the remaining 3\% from the preferences (WTO, 2008b). Depending on a country and structure of its exports, $3 \%$ of tariff lines removed from the DFQF system may constitute a significant part of exports of all LDCs to a given market. However, the matter was not easy to agree between WTO members. In 2008, developing countries withdrew from the DFQF proposal for LDCs (Bouët, Laborde, 2011 , pp. 165-166). The extension of the DFQF to $100 \%$ is mainly advocated by highly developed countries. An example is cotton export from LDCs. Negotiations concern the complete elimination of tariffs and quantitative restrictions. However, the increase in LDCs exports does not depend only on the reduction of tariffs but is conditioned by the reduction of internal support programs in developed countries, which lead to distortions in cotton trade market (Hoekman, Martin, Mattoo, 2010).

\section{Services}

The importance of liberalization in trade in services for the development of the WTO member states is incomparably greater than in the case of liberalization of trade in goods. Nevertheless, this area was not a priority in the Doha Round negotiations. In recent years, the share of developing countries in the global export 
of commercial services has been systematically growing. In 2016 , over $30 \%$ of global exports of services came from developing countries. In the case of highly developed countries, this share amounted to over $67 \%$ (Table 25). The value of commercial services exports in developing countries reached USD 1.466 billion in 2016 but was lower by $1 \%$ compared to the previous year. Imports of services reached USD 1.796 billion and its share in the global import of services decreased to $38.3 \%$. The main reason was the decline in activity in traditional services, primarily transport, and construction (WTO, 2017e, pp. 62-63).

Table 25. Developing Economies' Trade in Services by Region, 2015-2016 (USD billion, Annual change, in \%)

\begin{tabular}{|c|c|c|c|c|c|c|c|c|c|c|}
\hline & \multicolumn{5}{|c|}{ Export } & \multicolumn{5}{|c|}{ Import } \\
\hline & \multirow{2}{*}{$\begin{array}{l}\text { Value } \\
2016\end{array}$} & \multicolumn{2}{|c|}{$\begin{array}{c}\text { Share } \\
\text { in world } \\
\text { trade }\end{array}$} & \multicolumn{2}{|c|}{$\begin{array}{l}\text { Annual \% } \\
\text { change }\end{array}$} & \multirow{2}{*}{$\begin{array}{l}\text { Value } \\
2016\end{array}$} & \multicolumn{2}{|c|}{$\begin{array}{l}\text { Share } \\
\text { in world } \\
\text { trade }\end{array}$} & \multicolumn{2}{|c|}{$\begin{array}{l}\text { Annual \% } \\
\text { change }\end{array}$} \\
\hline & & 2015 & 2016 & 2015 & 2016 & & 2015 & 2016 & 2015 & 2016 \\
\hline Developing countries & 1466 & 30.8 & 30.5 & -3 & -1 & 1796 & 38.6 & 38.3 & -5 & 0 \\
\hline $\begin{array}{l}\text { Latin America and the } \\
\text { Caribbean }\end{array}$ & 168 & 3.5 & 3.5 & -2 & 1 & 196 & 4.4 & 4.2 & -10 & -4 \\
\hline $\begin{array}{l}\text { Developing countries } \\
\text { from Europe }\end{array}$ & 50 & 1.2 & 1.1 & -9 & -14 & 29 & 0.6 & 0.6 & -10 & 0 \\
\hline Africa & 90 & 2 & 1.9 & -3 & -6 & 135 & 3.2 & 2.9 & -13 & -10 \\
\hline Middle East & 179 & 3.6 & 3.7 & 4 & 4 & 267 & 5.8 & 5.7 & -6 & -1 \\
\hline $\begin{array}{l}\text { Developing countries } \\
\text { from Asia }\end{array}$ & 979 & 20.5 & 20.4 & -3 & 0 & 1170 & 24.5 & 24.9 & -2 & 3 \\
\hline World & 4808 & 100 & 100 & -6 & 0 & 4694 & 100 & 100 & -6 & 1 \\
\hline $\begin{array}{l}\text { Highly developed } \\
\text { countries }\end{array}$ & 3250 & 67.2 & 67.6 & -7 & 1 & 2783 & 58.6 & 59.3 & -6 & 2 \\
\hline $\begin{array}{l}\text { A community of } \\
\text { independent states }\end{array}$ & 92 & 2 & 1.9 & -16 & -2 & 115 & 2.8 & 2.4 & -24 & -12 \\
\hline
\end{tabular}

Source: WTO, 2017e.

An upward trend was recorded in export and import of other commercial services (as opposed to traditional transport, tourism, and construction industries), i.e., in the flow of financial, telecommunications, and IT services and in broadly defined business services. In 2016, nearly a quarter of global exports (24.1\%) of this type of services came from developing economies (Figure 29). For comparison, in 2005 it was $17 \%$. The largest increase was in services related to intellectual property (IP) revenues from the use of licenses and fees increased in 2016 by 5\% (WTO, 2017e, p. 63). Developing countries in Asia such as China, India, and Singapore play a leading role in the export of high-tech services. They are responsible for two- 
thirds of exports of this type of service. Together, they export twice as many services (business, financial) as other developing countries from Latin America, the Middle East, Africa, and developing economies from Europe. On the other hand, the share of LDCs in global exports of commercial services amounted to $0.7 \%$ in 2016, and in imports $-1.4 \%$ (WTO, 2017e, p. 68).

\section{Figure 29. Developing Economies' Participation in Global Exports of Commercial Services by region, 2016 (in \%)}

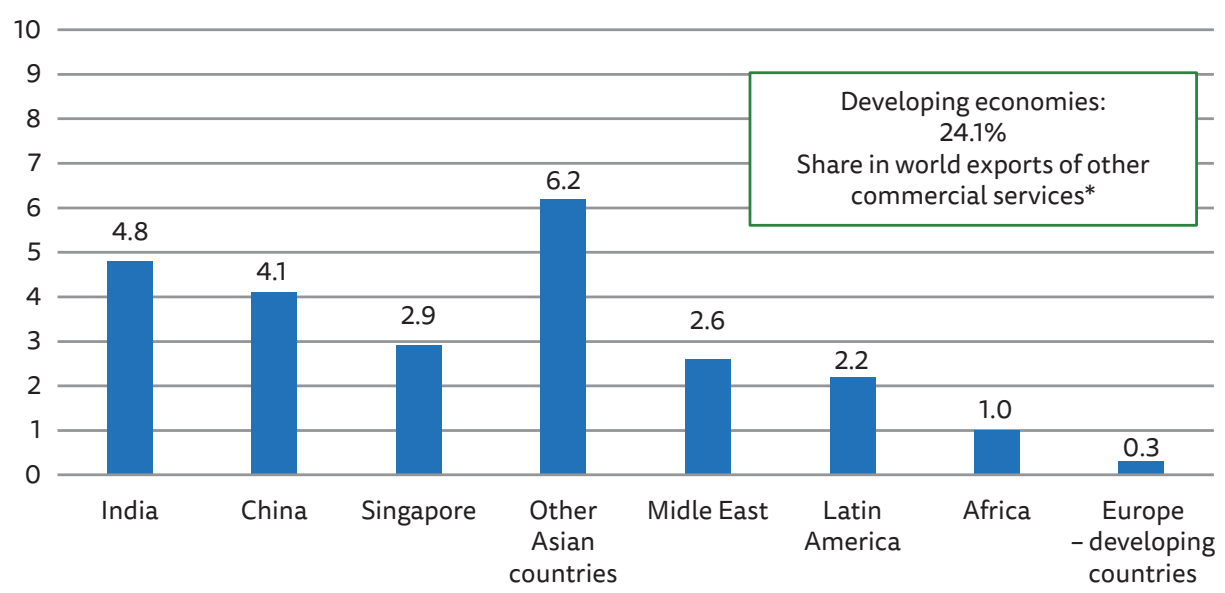

* Other commercial services include financial, telecommunications, IT, and broadly defined business services Source: WTO, 2017e.

The Doha Round negotiations did not envisage progress in multilateral liberalization, but only increasing security of access to markets based on GATS regulations (Borchert, Gootiiz, Mattoo, 2011, pp. 121-122). It is assumed that the greatest benefits of liberalization of services for developing countries would come from greater openness to FDI inflows (Mode 3), especially in the case of infrastructure services, as well as the introduction of regulations on the movement of people providing services under Mode 4 of the GATS. Due to the comparative advantage in the supply of labor and human capital, developing countries are interested in liberalization of labor market in highly developed countries, with strong opposition from the latter (Srinivasan, 2002, p. 16; Srinivasan 1999, p. 11; Hoekman, 2000, p. 130). T. Walmsley and L.A. Winters (2002, pp. 28-29) indicated great benefits from the implementation of postulates of less developed countries. They concluded that opening of labor markets in developed countries to external workers at the level of $3 \%$ of the labor force in these countries would generate a real income greater than could be achieved with full liberalization of trade in goods. However, in practice, 
all WTO members maintain formal restrictions on access to their services market (Hertel, Hoekman, Martin, 2002, p. 124).

According to the GATS rules, the provision of services between member states takes place in four manners. Mode 1 occurs when services are provided at a distance (by post, telephone or the Internet). It is a way of supplying services that is very similar to trade in tangible goods and has the character of cross-border trade. In case of Mode 2, the consumer goes abroad and uses the services there (e.g. tourism). This means that a consumer from one country buys and consumes a service in the territory of another country. The service does not cross the border, only the consumer does so (consumption abroad). Mode 3 refers to a situation where a commercial presence is established in the territory of another member state and thus an investment is made. This presence is understood as the provision of a service by a service company (commercial presence). Mode 4 is one of the most controversial ones, because it involves a need to move individuals to a country where the services are provided. In this case, the presence of natural persons and direct contact with the client are necessary, as the service must be provided on-site (presence of natural persons providing services). The stay of such people on the territory of another country is subject to formalities, most often in the form of, for instance, visas or work permits (Grącik-Zajaczkowski, 2011).

For most developing countries, liberalization of services on the basis of reciprocity is not beneficial due to limited possibilities of negotiating concessions (Singh, 2006, pp. 42, 51). In order to change the current state, national reforms are necessary to increase the efficiency of domestic service providers and the ability to compete on foreign markets (Hoekman, 2006, p. 16). So far, liberalization of services has been undertaken unilaterally or within regional groupings. While the adoption of the GATS was a significant step towards establishing universal rules in international trade, countries did not agree to significant progress in this area. The negotiations led to a slight opening of the markets. From the point of view of richer developing countries (China, India, Brazil), it was the preservation of possibility of establishing their own regulations, e.g., in financial services and data trading. On the other hand, less developed countries were not prepared to adopt regulations or compete on international services market. A common obstacle regarding liberalization under the GATS was the lack of mechanism to allow for regulatory cooperation among financial regulators, competition authorities and immigration offices (Martin, Mattoo, \& Winkler, 2011, p. 23). Consequently, the impact of the GATS on the degree of liberalization in developing countries was small.

As decided during the Uruguay Round, developing countries were allowed to accede and implement GATS provisions under less restrictive conditions than other WTO 
members. This was due to preferential treatment of developing countries (SDT rules). In addition, the GATS adopted solutions that hampered multilateral liberalization. First of all, these were market access criteria, which were determined by the type of sector, as well as provisions allowing for exclusion from the application of national treatment. This was due to two reasons: first, the limited number of regulated service sectors and second, the possibility of circumventing the principle of nondiscrimination, i.e., national treatment.

Developed countries have regulated about $45 \%$ of their service sectors by the GATS, while developing countries have regulated $12-15 \%$. As part of this, only $25 \%$ of all service activities declared by developed countries were not subject to any barriers to market access, as well as to application of the national treatment. In the case of developing countries, this figure was about 7\% (Hoekman, 1995, 327-328; 2000, p. 21). Under the GATS (Art. XIX: 2) it was accepted for developing countries that "there shall be appropriate flexibility for individual developing country Members for opening fewer sectors, liberalizing fewer types of transactions, progressively extending market access in line with their development situation and, when making access to their markets available to foreign service suppliers."

The rules of access to services market were based on a criterion depending on the type of individual sector. This means that the principle of non-discrimination could be applied to all types of services, except for those expressly indicated by member states. As a consequence, national treatment provision was justified in the case of only those sectors that were listed in the schedules (the so-called positive list) and that were not covered by exceptions. For developing countries, it was more important to present a negative list, i.e., one consisting of those service sectors that have not been subject to GATS regulations. This meant that commitments to market access and liberalization referred to the positive list, containing only sectors that were admitted to the market.

Since 2013, talks on further liberalization of trade in services have been held under the Trade in Services Agreement (TiSA). Formally, they are conducted outside the WTO, but the GATS Council for Trade in Services is regularly informed of any progress. It is possible that the final agreement may be incorporated into the WTO and replace the existing agreement (Adlung, 2015). This is made possible by the provisions of the GATS. WTO member states may, in accordance with Art. V of the GATS, create or join liberalization agreements, the progress of which is much greater than in the case of a multilateral agreement. However, participation in integration groupings must not lead to an increase in overall level of barriers to trade in services, compared to situation before the conclusion of a trade liberalization agreement. With regard to movement of persons, this provision has been extended to the integration of labor 
markets (Art. V bis GATS). It was assumed that the agreement "shall not prevent any of its Members from being a party to an agreement establishing full integration of the labor markets between or among the parties to such an agreement."

Most developing countries are not interested in liberalizing services under the TiSA formula. Negotiations were initiated by the United States and the EU, and most of the participants were OECD members and a few developing countries. So far, the following participants have taken part in the negotiations: Australia, Canada, Chile, Taiwan, Colombia, Costa Rica, the EU, Hong Kong-China, Iceland, Israel, Japan, Korea, Liechtenstein, Mauritius, Mexico, New Zealand, Norway, Pakistan, Panama, Peru, Switzerland, Turkey, and the United States. Participants tentatively agreed that TiSA should go beyond the margin of preference already established in existing regional and bilateral trade agreements, which would block the current levels of unilateral liberalization. This would make it possible to expect an increase in the level of liberalization. Achieving this goal depends on several factors:

- the possibility of expanding existing GATS schedules to include new service sectors;

- the inclusion in negotiations of a broad range of WTO members;

- the setting of a deadline for conclusion of negotiations, which is important in view of discussions under way on this issue in the framework of other regional agreements.

The most important of these factors is the absence of the BRICS group (Brazil, Russia, India, China, and South Africa). Therefore, one of the discharges against TiSA is negative impact on countries that do not participate in negotiations (Stephenson, Ragoussis, Sotelo, 2016). However, due to the impasse, the chances of adopting TiSA are so far slim.

\section{Trade-Related Intellectual Property Rights}

The Agreement on Trade-Related Intellectual Property Rights (TRIPS), to which developing countries acceded in 1995, was a far-reaching compromise. In return for concessions in agricultural, textiles and clothing sectors, developing countries agreed to accept a new package of commitments. The main proponents of setting global standards for protection of intellectual property rights (IPRs) were the United States, the EU, Japan, and Switzerland.

For developing countries, minimum standards were adopted regarding the availability, scope and use of IPRs, which included copyright and related rights, trademarks, geographical indications, industrial designs, patents, topographies of integrated circuits, protection of classified information, control of anti-competitive practices in contractual licenses. While developing countries were left with the choice 
of how to implement TRIPS, its adoption was obligatory. A complete and permanent exemption from the implementation of the agreement was not possible, but only an extension of transition period, which could be shortened when, as a result of improving macroeconomic indicators, a country ceased to belong to the group of LDCs (Bossche, Zdouc, 2017, p. 1052).

The controversy around TRIPS stemmed from high implementation and transaction costs associated with the obligation to adopt and apply rules on IPRs. In most cases, a developing country did not have national regulations in a given field or the level of protection of IPRs was insufficient in comparison to rules contained in TRIPS (Hoekman, Kostecki, 2011, pp. 404-405). Thus, it was a matter of creating a system of national regulations and then adjust them to international rules. For instance, in the field of patents for 90 developing countries listed in Annex 1 to the TRIPS Agreement, 25 had no patent protection for pharmaceutical products, and 13 - for chemical products (Braga, 1995, p. 396). The need for thorough changes also concerned the right to copy or the adoption of compulsory licensing with regard to production of pharmaceutical drugs.

The potential gains for developing countries from the introduction of TRIPS remain the subject of lively debate. Those who supported the introduction of changes argued that benefits of so-called dynamic factors could be significant not only as a compensation for costs incurred. These factors included FDI inflow, technology transfer, licensing and deployment of innovative solutions, stimulated by higher research and development spending at national and international levels. In contrast, opponents of changes argued that profits were uncertain, and negative elements included additional costs due to the introduction of regulations. Among the most important were costs resulting from increased domestic prices, reduced domestic production, and increased imports, which could lead to lower incomes and the transfer of financial resources from developing to highly developed countries (Braga, 1995, pp. 399-402).

One of the most controversial issues in TRIPS was public health provisions. Developing countries saw TRIPS as an obstacle in fighting infectious disease epidemics. They recognized that these regulations limited their access to patented pharmaceuticals and allowed the transfer of resources to patent holders and manufacturers in highly developed countries (Hoekman, Kostecki, 2011, p. 417). As agreed by the Uruguay Round, TRIPS regulations referred to the situation related to the shortage of pharmaceuticals and the need to meet the demand for patentprotected drugs in a country threatened by an epidemic (Art. 31: TRIPS). Under the compulsory licensing rule, a government facing a public health emergency could require a drug manufacturer to grant an additional license to meet its needs. At the 
same time, however, the regulations required that additional drug production under the compulsory license procedure be primarily directed to the domestic market. However, this posed a major problem for those developing countries, especially LDCs, which did not have sufficient productive capacity and were forced to import pharmaceuticals. The TRIPS provisions thus perpetuated the imbalance between the countries with production capacity and those without it.

The issue of amending TRIPS provisions on compulsory licensing was a kind of test for the WTO's commitment to development. The organization tackled the problem in 2001. At the inaugural meeting of the Doha Round, Declaration on TRIPS and Public Health was adopted, committing to expanding access to medicines for countries without pharmaceutical manufacturing capacity (WTO, 2001a, par. 6). So far, the only amendment to TRIPS that has been introduced was the procedure of compulsory licensing. Negotiations on this matter concerned the scope and possibility of invoking the enabling clause under SDT regulations. Ultimately, the WTO General Council authorized WTO members to grant compulsory licenses allowing pharmaceutical exports to countries without capacity to produce them (WTO, 2003b). The only condition for applying the waiver was insufficient or no manufacturing capacity.

The provision was finally accepted at the WTO Ministerial Conference in Hong Kong in December 2005 and entered the regulatory order as Art. 31 bis of the TRIPS. Against pressure from developed countries (primarily the United States), the WTO did not agree to limit the number of countries eligible for compulsory licensing and the list of diseases for which the importing country could invoke the public health clause. As in the Declaration on TRIPS and Public Health, the list of diseases was not closed and concerned all epidemiological diseases (WTO, 2003b, par. 5c). As a consequence, developing countries were able to export pharmaceutical products under compulsory licensing to other countries which, in the face of an epidemic or other emergency, invoked the public health clause. It was an important arrangement that was mutually agreed in favor of developing countries and LDCs.

In practice, the compulsory licensing under the more flexible amendment to the TRIPS had rather little effect on the availability of medicines in the poorest countries (Art. 31 bis of the TRIPS). Benefits of the amendment was modest due to the unprofitable distribution of generic pharmaceutical in LDCs. A large number of pharmaceutical products were off-patent and existed in market as generics. In addition, importing countries have been obliged to introduce appropriate mechanisms to prevent re-export of pharmaceuticals or their improper distribution through specially labeled packaging (Hoekman, Kostecki, 2011, 418-419).

It is estimated that the highest costs associated with the implementation of TRIPS provisions in developing countries are associated with training of official apparatus and 
a creation of an administrative system. Simply copying the IPRs mechanism in force in OECD countries is not enough. The types of rights that are protected under TRIPS vary from country to country, as do institutional capabilities, especially in LDCs. Although steps have been taken in this direction through the offer of a training and internship system under the WTO Trade-Related Technical Assistance, the scale of the problem is much larger. Certainly, the WTO alone cannot meet the needs of developing countries in this area without broad and comprehensive action by both various multilateral institutions and bilateral donors. Support programs such as AFT or EIF are a helpful tool here.

\subsection{Trade Facilitation Agreement}

The WTO Multilateral Trade Facilitation Agreement is the first and so far, the only agreement adopted under the Doha Round. It was approved at the Ninth WTO Ministerial Conference held in Bali (Indonesia) in December 2013 and entered into force on February 22, 2017, after it was ratified by two thirds of the WTO members. TFA is included in Annex IA of the Agreement on the Establishment of the WTO.

The trade facilitation regulations were part of negotiating package at the start of the Doha Round and were known as "Singapore issues." In addition to trade facilitation provisions, it also covered issues related to investment, competition policy, and government procurement. The decision to keep trade facilitation (in a limited version) and remove the remaining Singapore issues from the Doha Round negotiation agenda was made in 2004. Developing countries were afraid of additional costs associated with adopting new agreements, and furthermore argued the need to meet commitments made back during the Uruguay Round (Zajaczkowski, 2014).

The TFA was based on two assumptions: the possibility of flexible application of SDT regulations and the guarantee of receiving technical assistance and other support. In order to streamline the process of adopting the agreement, an approach was taken based on flexible implementation of regulations, which consists in the possibility of individually setting transition periods and stages of implementation of rules by developing countries. As a result, a country was able to set its own conditions of support together with aid donor (individual or institutional). The purpose of such arrangements was to protect developing countries and LDCs from high and unexpected implementation costs associated with the agreement.

The TFA is founded upon three articles of the GATT 1994 which relate to freedom of transit (Article V), import and export fees and formalities (Article VIII), and publication and management of trade regulations (Article X) (WTO, 2004). This 
means that the TFA is nothing more than a new approach to the already existing regulations within the GATT/WTO, based on a revised implementation formula. Moreover, in addition to the WTO, the issues of trade facilitation were actively addressed by institutions such as UNCTAD, the World Bank, the IMF, the OECD, as well as the World Customs Organization (WCO), the International Maritime Organization (IMO) and the International Civil Aviation Organization (ICAO). The work on adopting unified regulations also involved regional integration groups, especially APEC, as well as the private sector, whose interests were represented by the International Chamber of Commerce (ICC) (Wilson, Mann, Woo, Assanie, \& Choi, 2002, p. 85). Despite the involvement of many institutions, the effects of their actions were limited. The biggest obstacle to implementing the rules was dispersion, fragmentation and a lack of coordination in action. Therefore, the WTO was chosen as the most effective forum to adopt coherent and unified TFA rules.

The choice of the WTO as a coordinator and administrator of the TFA was based on several premises. First, the rules and regulations contained in WTO multilateral agreements are legally binding, which means that obligations can be effectively enforced through dispute settlement mechanism. Second, trade facilitation regulations are an integral part of the GATT 1994. Third, the adoption of the TFA by developing countries was made conditional on their obtaining development assistance. WTO members who were unable to accept the agreement within regular timeframe had two options: the possibility of using SDT or obtaining technical, financial, and other support provided for by the TFAF.

Under the TFA, an aid delivery mechanism was developed. For this purpose, the roles and responsibilities of the parties were defined, i.e., aid recipients on the one hand and bilateral donors, and international organizations on the other (TFA, 2014, art. 21). Institutions and procedures supporting the delivery of assistance were established, in particular the TFA Committee and the TFA Instrument. Developing countries and LDCs were obliged to prepare individual timetables for implementing TFA commitments, which were incorporated into national development strategies. A special program (WTO Program for National Self-Assessments of Trade Facilitation Needs and Priorities) was established for this purpose, according to which states were to identify their own trade facilitation needs and classify TFA implementation commitments into one of three categories - A, B, or C. Category A is a set of provisions to be implemented by developing countries by February 22, 2017, and LDCs by February 22, 2018. Category B are provisions that developing countries and LDCs committed to implement after the end of transition period and the entry into force of the agreement. This means that they could apply the SDT regulations concerning, inter alia, an additional transitional period. Category $C$ consists of 
provisions that developing countries and LDCs can implement after the transition period and the entry into force of the agreement, and which require the acquisition of implementation capacity by providing them with technical assistance or other support in building trade capacity (TFA, 2014).

In order to receive technical assistance or other support, a developing country or LDC was required to place a specific TFA provision under category $C$. The remaining categories, A and B, include those types of TFA regulations that countries committed to implement without technical and financial assistance, but with the possibility of using SDT. Detailed obligations, and thus provisions covering the TFA, are grouped according to the following types of activities (TFA, 2014, Section I: Art. 1-12): 1. Publication and availability of information, 2. Comments and consultations, 3. Regulations, 4. Appeal procedures or review, 5. Measures to increase impartiality, non-discrimination and transparency, 6. Fees and commissions, 7. Release and clearance of goods, 8. Cooperation with border agencies, 9. Customs control, 10. Formalities related to import, export and transit, 11. Freedom of transit, 12. Customs cooperation. In their TFA implementation schedules, WTO members were asked to indicate what support they needed and how they would use it. In turn, additional formalities were imposed on aid donors. They concerned mainly the principles of transparency and openness of procedures related to aid financing. These include requirements to provide information on their assistance programs, as well as information on application process and annual submission of technical assistance projects.

The actions of all parties to the TFA were based on the concept of flexibility. This means that potential donors were not obliged to provide assistance, but the formula of acting in good faith and making every effort to meet this obligation was adopted. Under the TFA, there are regulations that are both legally binding and based on a "good faith" commitment. The emphasis is on building international cooperation and good practices. This means a shift from the application of WTO enforcement mechanism in favor of domestic legal systems (Hoekman, 2016, pp. 177-178). In turn, the recipients of aid were obliged to implement provisions of the agreement, but at the same time it was made dependent on their ability to receive support. This kind of flexibility formula allows each country to implement provisions in the way it deems appropriate, according to its regulatory, technical and institutional capacities. Due to their special status, LDCs obtained additional preferences, including in the form of longer transitional periods than other developing countries, as well as exemption from the WTO dispute settlement procedure (the grace period) (TFA, 2014, Art. 20: 4, 20: 5). 


\section{Effects of the Implementation of the TFA}

The main objective of the TFA is to increase benefits of international trade for developing countries by lowering transaction costs and improving their trade capacity. The agreement requires signatories to carry out reforms in the field of legal regulations, administrative apparatus, and institutions, which are expected to lead to greater efficiency in terms of trade and lowering costs of its servicing. It is estimated that the high transaction costs are largely the result of differing customs procedures and administrative requirements as well as complex provisions on fees and charges. Burdensome inspections and a lack of information on fixed fees charged at borders, as well as the large number and variety of customs agencies and other checkpoints, were identified by respondents to Aid for Trade Global Review 2015 as being among the most important obstacles to trade in developing countries (WTO/OECD, 2015).

The economic benefits that countries could achieve by eliminating such barriers are the subject of a variety of studies (Dee, Geisler, \& Watts, 1997; Hertel, Walmsley \& Itakura, 2001; Wilson, Mann, Woo, Assanie, Choi, 2002; Wilson, Mann, Otsuki, 2003; Wilson, Mann, Otsuki, 2004; Francois, van Meijl, van Tongeren, 2003; OECD, 2003b; Haralambides, London-Kent, 2002). According to the OECD estimates from 2013 and 2014, the scale of costs reduction depends on a country's level of development, as well as whether the provisions of the TFA are implemented in full or in part. Assuming the most realistic scenario, i.e., based on a partial implementation, the reduction of trade-related costs for the lowest income countries would reach $12.6 \%$ ( $3.9 \%$ less than with the implementation of all the provisions), for lower middle-income countries $-13.7 \%$ (less by $3.7 \%$ than with full implementation) and for upper middle-income countries - $12.8 \%$ (1.8\% less) (OECD, 2018a). For OECD countries, gains from full implementation of regulations and cost reductions would increase by $11.8 \%$, and a partial increase by $10.4 \%$ (Figure 30 ).

Potential benefits to developing countries from implementing the TFA may be greater than in other areas negotiated at the WTO. This is shown by the aforementioned research by Decreux and Fontagné (2011, pp. 27-29), who stated that the only gains that LDCs can obtain come from the implementation of TFA rules. This is also confirmed by the research of G.C. Hufbauer, J.J. Schott, M. Adler, C. Brunel, and W.F. Wonga (2010), who announced that the benefits of implementing TFA rules would be higher for developing countries than for developed countries, both in terms of exports and imports. If the regulations are implemented, it will be of particular importance for inland developing countries, as their trade expenditures depend primarily on transit costs and efficiency of customs clearance (Hufbauer et al., 2010, p. 15). According to the researchers, developing countries may gain USD 47.3 billion 
in exports and USD 84 billion in imports (for developed countries, trade benefits are estimated at USD 39.5 billion and USD 54.5 billion, respectively). In terms of GDP growth, it may amount to $0.6 \%$ (USD 60,4 billion) and $0.1 \%$ (USD 43,2 billion) for developing and developed countries, respectively (Hufbauer et al., 2010, p. 15).

\section{Figure 30. Forecasts for Trade Costs Reductions Due to the Implementation of the TFA by Income Group (in \%)}

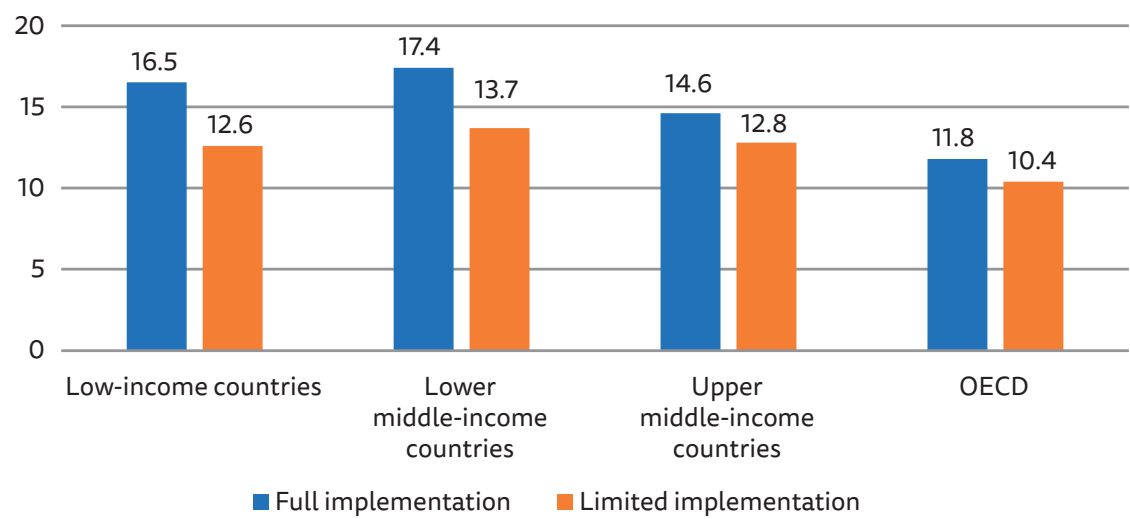

Source: OECD, 2014a.

Gains from FTA implementation will not be the same for all developing countries. Such conclusions were reached in their research by S. Wilson, C.L. Mann, T. Otsuki (2005), who presented forecasts of an increase in trade flows. These indicators were 40.3\% for South Asia, 30\% for the countries of Central and Eastern Europe, 24\% for East Asia, 20\% for the Caribbean and Latin America, and only 4\% for OECD. Developing countries, in which trading procedures are particularly burdensome and outdated, should benefit much more from TFA implementation than highly developed economies as J. Francois, H. van Meijl, and F. van Tongeren also wrote in their studies (2005).

Aid directed at trade development objectives is more effective and brings greater benefits in the form of export growth than in other areas, such as investment in infrastructure or manufacturing. Such conclusions were reached in their empirical studies by M. Helble, C.L. Mann, J.S. Wilson. They showed the relationship between various categories of assistance under the Aid for Trade program and trade performance. They found that the most beneficial effect on increasing trade was those financial expenditures that were provided in the form of assistance for narrowly defined trade facilitation issues, i.e. border management, administration of customs procedures, and creation of regulations and institutions needed for this purpose (Helble, Mann, 
Wilson, 2012) ${ }^{54}$ According to their estimates, a $1 \%$ increase in AFT funds for trade facilitation purposes, worth USD 117 million, translates into an increase in exports of recipient countries by USD 347 million. On the other hand, a 1\% increase in the volume of aid for productive capacity and infrastructure building (worth USD 219 million) may increase exports of recipient countries by approximately USD 291 million. This regularity was presented as follows: USD 1 in broadly understood aid (development policy, infrastructure) leads to an increase in exports of USD 1.33, and in the case of investments related to regulatory reforms and trade policy, leads to an additional USD 71 in recipient country exports (Helble, Mann, Wilson, 2012; Taylor, Wilson, 2011, p. 219).

Assuming that resources directed to regulatory development and trade policy contribute to stimulating trade flows in the most effective way, it is arguable that the ongoing trend should be reversed. The current trend is characterized by the fact that the least amount of resources of all Aid for Trade categories are allocated to trade facilitation purposes. TFA issues fall under trade policy and regulation, which is one of the four core categories of the AFT program. While it is much more difficult and costly to implement infrastructure and productive capacity-building projects (Taylor, Wilson, 2011, pp. 214, 219-220), much better performance in terms of results is taking place in the area related to TFA. This is confirmed by the study commissioned by the World Bank, in which regulatory reform projects showed higher efficiency (rated 85\%) compared to large investments in new infrastructure and technology. Also projects that required recipients to develop institutional capacity achieved much weaker results, amounting to about 56\% (World Bank, 2006).

\section{Support for Trade Facilitation Agreement Facility}

Assistance related to the implementation of TFA is provided through a specially established for this purpose TFAF instrument. Assistance is provided in three forms:

- advice to identify development needs, and then to appropriately classify regulations into one of three categories (A, B, or C);

- support in trade capacity building, which in practice means access to training materials, participation in courses and internships;

- financial aid in the form of two types of grants - project preparation grants of up to USD 30000 and project implementation grants of up to USD 200000 (TFAF grants...).

54 The study was conducted over a period of 16 years for 40 donor countries and 170 recipient countries. 
Assistance for the implementation of TFA rules is provided only to developing countries that have declared their commitments under category C. In 2014-2017, member states' contributions to the TFA trust fund totaled around CHF 7.5 million (Table 26). Access to this type of support is limited as only those countries that have not received support from other sources of funding are eligible for TFAF grants.

Table 26. Donations to the TFAF, 2014-2017 (CHF million)

\begin{tabular}{|l|c|c|c|c|c|}
\hline \multicolumn{1}{|c|}{ Donor country } & 2014 & 2015 & 2016 & 2017 & \multicolumn{1}{c|}{ Total } \\
\hline Norway & - & 2780663 & 2000000 & - & 4780663 \\
\hline Australia & - & 831398 & - & - & 831398 \\
\hline Austria & - & 104900 & - & - & 104900 \\
\hline United Kingdom & - & 369004 & - & - & 369004 \\
\hline EU & - & 174400 & 660000 & - & 834400 \\
\hline Ireland & - & 35599 & - & - & 35599 \\
\hline Switzerland & - & 13098 & - & - & 13098 \\
\hline New Zealand & - & 48763 & - & - & 48763 \\
\hline United States & - & 44530 & - & - & 44530 \\
\hline Finland & - & - & 176840 & 230000 & 405840 \\
\hline Taiwan & - & - & 35000 & - & 35000 \\
\hline Total & - & 4402355 & 2865840 & 230000 & 7498195 \\
\hline
\end{tabular}

Source: own study based on WTO TFA.

Tasks related to the implementation of trade facilitation regulations are carried out under the Aid for Trade, in the category of "AFT Facilitation". Since the inception of AFT, the main donors of TFA assistance have been the United States, the European Union, and the World Bank, which together account for $78 \%$ of all TFA funding. In 2016, donors' contributions totaled over USD 363 million, which is a fivefold increase in relation to the base average AFT for 2002-2005 (Figure 31).

The decrease in the amount of funds transferred since 2013 may have resulted from an unclear situation related to the procedure of adopting and implementing the agreement. In total, from 2005 to 2016, over USD 3.9 billion was transferred under the AFT for purposes related to trade facilitation (OECD-DAC, 2018) (see Table 32). Moreover, since 2014, a special TFAF trust fund has been operating for the implementation of provisions of the TFA, which is an additional source of financing activities. Assistance is most often directed at building cooperation networks between customs agencies and border units, implementation of information and communication technologies (equipment purchases), training of the administrative apparatus and simplification of procedures (OECD, 2018b, p. 117). The regional 
distribution of funds transferred to recipient countries is uneven. Beneficiaries from Africa and Asia received the most funds. In 2013, Asian countries obtained more trade facilitation finance than Africa for the first time. In 2013, the regions received USD 277 million for Asia and USD 263 million for Africa, respectively (Figure 32) (WTO/OECD, 2015, p. 24).

Figure 31. Trade Facilitation Commitments under the Aid For Trade, 2002-2016 (USD million, 2015 Constant Prices)

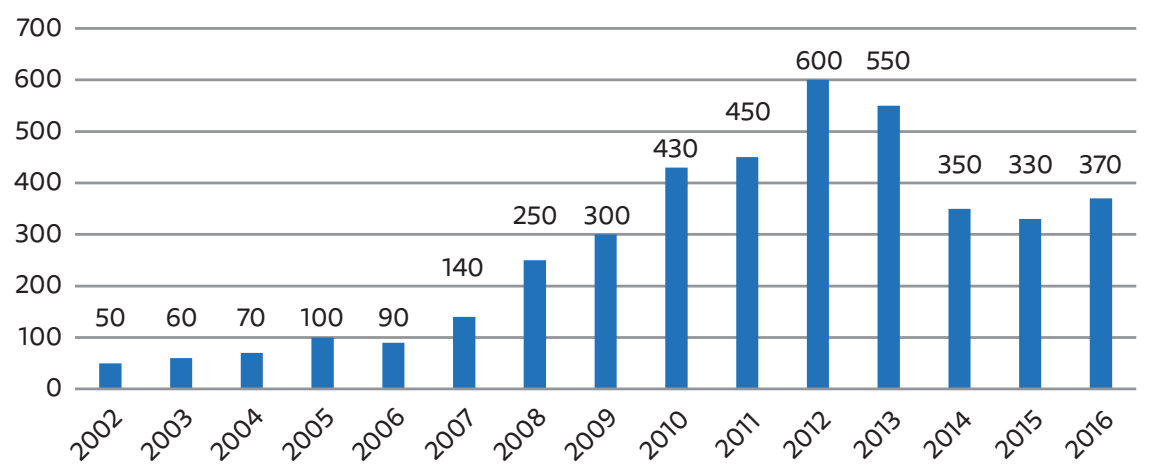

Source: OECD, 2018d.

Figure 32. Trade Facilitation Commitments by Region (USD million, 2012 Constant Prices)

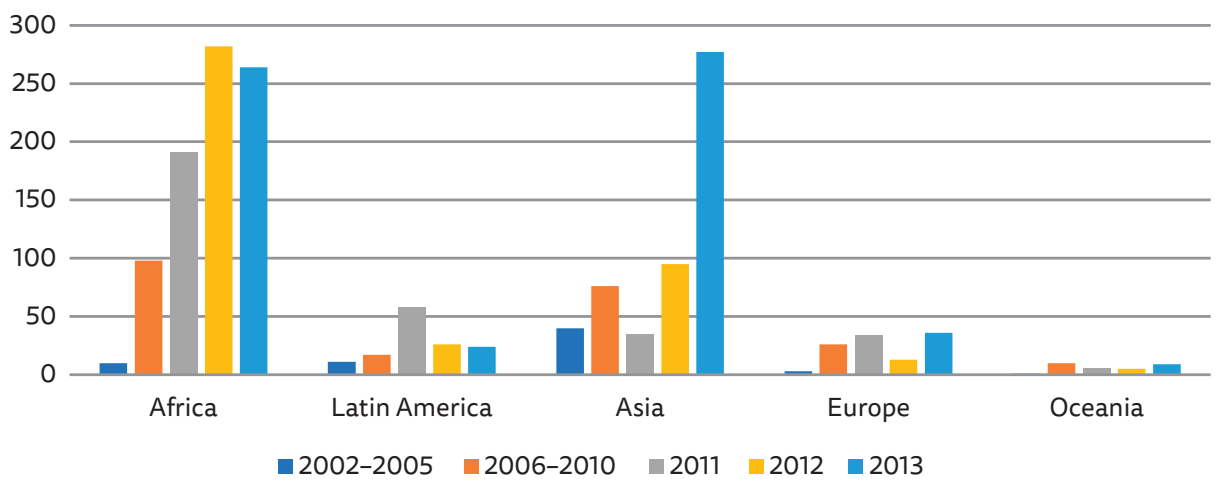

Source: WTO/OECD, 2015.

Most of the provisions in the TFA concern the implementation of simple measures aimed at increasing the transparency of regulations and reducing costs related to customs and administrative procedures. A major part of the TFA commitments does not require signatories to incur high implementation costs (Taylor, Wilson, 
2011, p. 222). This means that the implementation of trade reforms that were considered beyond the capabilities of some developing countries can actually be carried out without SDT and financial assistance. Most developing countries had begun implementing technical measures under the TFA before the agreement was adopted at the WTO, often with donor support within the AFT program. These efforts were part of the countries' modernization program. However, taking into account the fact that developing countries themselves assess the needs and the amount and types of assistance, in many cases they have applied for assistance, even if it was not necessary. The reason for this is, for example, the desire to extend or improve existing programs (Trade Facilitation Agreement Database...). In such a situation, assistance is also anticipated and may be provided from different sources.

It is estimated that the adoption of the TFA will help developing countries attract FDI, enhance their ability to compete in foreign markets and gain greater access to markets in developed countries. The introduction of standardized and simplified TFA procedures is necessary for those developing countries that want to participate in global supply chain as well as in international intra-industry trade. Dynamics of changes, associated with structural transformations in the sphere of production and consumption, and technological progress, give developing countries more and more opportunities to compete effectively with entities from developed countries. The basis is not only lower costs of trade operations, but also appropriate regulations and supervisory institutions.

\subsection{Summary}

The evolution of the WTO towards an institution more concerned with development issues is due to several factors. Firstly, the source of the changing role and importance of the WTO is the pursuit of meeting development needs of member states, which is a consequence of growing position of developing countries in the world economy and the need for their greater integration into the multilateral trading system. The second factor is the desire to reconcile the achievement of development goals (i.e., economic growth and poverty reduction) with the obligation to liberalize trade. In practice, this means limited and selective liberalization, but on conditions favorable to the realization of interests of developing countries. This type of approach, currently presented by the WTO, was shaped during the last multilateral negotiations, which in practice blocks the work of the organization. A long-term disagreement among bargaining participants has various consequences. First of all, it raises concerns about the effectiveness of the organization and the fulfillment of its basic functions. 
Moreover, it leads to the emergence of proposals for reform of the organization and its search for new areas of activity.

At the current stage of development of the international trading system, activities of the WTO come down to the role of coordinator and administrator of multilateral agreements. It is significant that without the involvement of other multilateral organizations, the adoption of the TFA would have been even more difficult. This means that in the face of failure of the Doha Round, the organization has largely become the executor of jointly agreed decisions with other economic organizations, such as the WB, IMF, OECD, EU, UN, and the UNDP. It can therefore be concluded that the role of the WTO as the main forum for making decisions on international trade has diminished. In other words, the position of the WTO as a center of global governance, which was the GATT institution in the previous period, has declined. On the other hand, the choice of the WTO as a coordinator of activities related to support for trade (e.g., under the Aid for Trade) proves the potential and possibilities of effective operation as part of development cooperation.

The importance and role of the WTO within the international trading system is due to several factors. First of all, from the mechanism of enforcing obligations, and thus the legally binding nature of adopted regulations, as well as the large representation of developing countries and institutional cooperation with other international organizations. First, providing WTO trade obligations with legal force means that, in the event of their violation or exceeding, it is possible to activate a dispute resolution mechanism and impose retaliation measures. Second, among the distinguishing features of the WTO is its large membership (by 2018, the WTO had 164 members), as well as its extensive network of cooperation with multilateral organizations. Third, this makes it easy to undertake joint initiatives in the sphere of development and assistance with organizations such as UNCTAD, WB, OECD, IMF, OECD. This results in the ability to raise more funds for technical cooperation and capacity building, although the organization itself has a relatively small budget for these purposes.

The difference in positions among developing countries has as much impact on further negotiations as traditionally divergent trade interests between developing and highly developed countries. For instance, reaching an agreement in agricultural sector depends on the reconciliation of interests between developing countries, i.e., net food exporters (CAIRNS group), and importers of agricultural products, to which LDCs belong. Moreover, in sectors that have already been liberalized, progress in removing trade barriers for developing countries has been rather limited. An example is trade in agricultural commodities and NAMA as well as services. The adoption of specific arrangements in agricultural sector is conditional on reaching 
a compromise on liberalization in NAMA. Moreover, unfinished business of the Uruguay Round, such as liberalization of services and the implementation of TRIPS provisions, is holding back developing countries from making further commitments. Because of developing countries' lack of interest in deeper liberalization in services sector, the chance for a multilateral agreement under the TiSA formula is slim. This may lead countries to engage in bilateral agreements and regional groupings.

In the context of development cooperation, it may result in the adoption of differentiated criteria enabling the adjustment of assistance to individual country needs. An example of choosing such a course of action is the Trade Facilitation Agreement. A key element of the TFA is the concept of conditionality of commitments and the related capacity building assistance. The receiving of aid by a developing country in exchange for acceptance of an agreement creates a new kind of approach to negotiations, and a new area of activity for the WTO. In the first case, it is the need to build into new agreements mechanisms for support to developing countries, and in the second - to expand the role of the WTO in the sphere of development. WTO involvement is expected to increase in these areas. It is therefore likely that such a solution will become a model for other WTO multilateral agreements. 


\section{SUMMARY AND CONCLUSIONS}

The purpose of this study was to define the role of the WTO in development cooperation and to examine the importance of the organization in international aid system. The analysis of the WTO's involvement in development and assistance for less developed countries allowed for the formulation of responses and final conclusions which prove that the role of the organization in the area of development cooperation is increasing. This is related to the growing activity of the organization in this field, as well as to its changing position in international trading system due to the impasse in Doha Round negotiations.

Increasing the role of the WTO in development cooperation results from an evolving approach to the issue of providing aid and striving to increase its effectiveness in terms of achieving development goals. Therefore, activities that the WTO undertakes to build trade capacity and integrate developing countries into the international trading system fall within the framework of development cooperation, covering the following areas (Figure 34):

- technical assistance, which is part of ODA. The WTO is on the OECD-DAC's list of multilateral donors and is therefore entitled to provide assistance in the form of ODA;

- global Aid for Trade program, in which the WTO acts as a concept promoter, administrator, and coordinator of activities;

- rules of preferential treatment for developing countries, i.e., special trade benefits for less developed WTO members;

- multilateral negotiations under the Doha Round, in which attempts were made to adopt new regulations that would take more account of development needs of less developed WTO members. An example is the Trade Facilitation Agreement and the accompanying Trade Facilitation Agreement Facility.

These claims support the main thesis adopted in the study that activities carried out by the WTO as part of its statutory functions (regulatory, operational, and control) - understood narrowly (i.e. technical assistance) or broadly (i.e. SDT regulations, coordination and supervision of joint initiatives and cooperation with other international institutions) can be treated as an activity within development 
cooperation. The WTO's involvement reflects an aim to improve the efficiency of development assistance provision and to increase the achievement of development goals, particularly in the area of trade. The main thesis was proved by additional research hypotheses, which were positively or partially positively verified. On their basis, the following conclusions were made.

\section{Figure 33. Areas of WTO's Involvement in Development Cooperation}

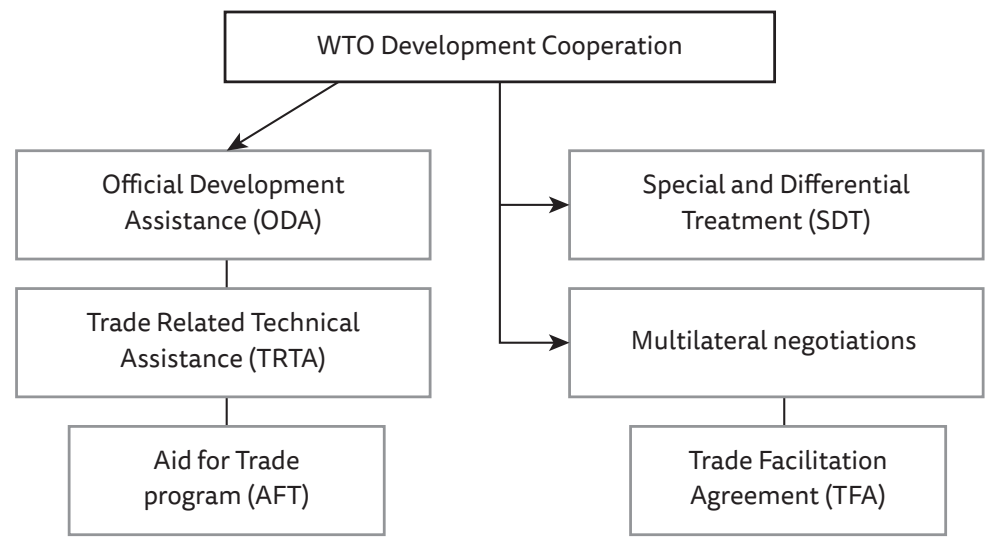

Source: own study.

Hypothesis 1 (positively verified): Changes that are taking place within international aid system indicate the need for a new approach to development assistance and greater involvement of the WTO.

The evolution of the WTO into an institution more concerned with development issues and support for developing countries is a result of changes within multilateral aid system. This is evidenced by the following factors. Firstly, the distinction between certain types and forms of aid has blurred. An example is the aid defined as multi-bi, that is bilateral aid directed through multilateral institutions and the accompanying financial resources, known as earmarked or mixed (multi-bi). Secondly, the circle of donors willing to allocate their resources to development aid has widened. These include countries outside the OECD-DAC, included in the group of developing countries, as well as private sector - NGOs. Third, trust funds have become one of the primary instruments for financing development goals. In connection with the above premises, there have been fundamental changes within multilateral aid system and the emergence of a phenomenon known as bilateralization of multilateral development aid. Its basic source is the growing share of multi-bi funds in financing development programs. In practice, this means increasing the control of individual donors over resources sent to organizations. Implications of this are twofold: it may 
limit the autonomy of an institution and the performance of its statutory tasks, but on the other hand, it may extend the scope of organization's activities into new areas that could not be financed from core budget and make the procedures for mobilizing resources faster and more flexible. The analysis of WTO activities indicates that the organization is more subject to changes contained in the second scenario.

Within the WTO, the tendency to bilateralization of technical assistance has not progressed as much as in other multilateral institutions, such as the UN or the World Bank. Therefore, the problem of substitution of core budget resources by multi-bi contributions is so far relatively small. On the other hand, there has been a significant decrease in the inflows from the DDAGTF - the main source of financing for WTO technical assistance. Contributions to trust funds operating multilateral programs such as TFAF and STDF and EIF, which the WTO benefits from jointly with other multilateral organizations, are increasing instead. Such a situation may result, first, from difficulties in concluding the Doha Round and, second, from the emergence of new multilateral initiatives (TFAF and STDT) and a need to provide them with additional funds.

There is a need for greater involvement of the WTO in aid initiatives, carried out jointly with other multilateral organizations, such as the World Bank, United Nations, and the OECD. Assuming that the international aid system is a kind of a regime complex, the cooperation carried out within it results from the existence of common interests, in this case - increasing the effectiveness of providing aid and achieving development goals. Improving the adoption and implementation of WTO regulations by developing countries depends not only on the organization itself, but on support provided jointly with other multilateral institutions and bilateral donors. It is for this reason that initiatives and programs co-created by consortia of multilateral institutions can improve the harmonization of development cooperation activities and increase its effectiveness. For trade-related initiatives (AFT, EIF, STDF), the WTO plays the role of coordinating, supervising, and administering joint initiatives.

Hypothesis 2 (positively verified): The WTO's technical cooperation activities are complementary to those carried out under the overall ODA. While the WTO provides little support in context of funding, it is essential in terms of institutional and technical support.

The transfer of knowledge and know-how in the field of international trade rules creates an opportunity for greater integration of developing countries in the international trading system. WTO technical assistance is the primary, but not the only, instrument for providing support to developing countries. It reflects the performance of the WTO's regulatory and operational functions. The regulatory function is to enable member states to create and implement regulations relating 
to international trade, and the operational one to provide support based on their own decisions and using human resources and materials at the disposal of the organization.

The basic forms of technical assistance provided by the WTO are courses and training on WTO rules, trade policy and functioning of the organization. Their purpose is to improve trade capacity of developing countries in the process of negotiating and adopting WTO regulations. This also applies to participation in accession negotiations. Due to the growing interest of representatives from developing countries in participation in WTO courses and training, a need arose to expand their scale and scope. On the other hand, with the reduction of WTO financial resources for technical assistance, the system of training and courses was reorganized - their topics and types were adjusted to the financial and staffing capabilities of the WTO. The number of face-to-face courses was reduced, and the e-learning offer was expanded.

The best results in terms of technical assistance were achieved in the area of the participation of candidate countries in accession negotiations. Moreover, compared to the GATT period, the involvement of representatives of developing countries in WTO multilateral negotiations on trade liberalization has improved significantly. This is evidenced by increased number of coalitions and interest groups. Their activity has strengthened bargaining power and the ability of developing countries to influence other participants in trade negotiations. On the other hand, however, the excessive number and diversity of such coalitions can make it difficult to build a coherent position in the talks, as the Doha Round showed.

Hypothesis 3 (partially positively verified): Modification of special and different treatment offers an opportunity to increase the effectiveness of the WTO, which is currently in crisis.

One of the sources of the crisis is the SDT. The lack of solution regarding the use of these regulations by developing countries leads to conflicts between highly developed countries and developing members of the organization. Under the SDT provisions, developing countries may be temporarily exempted from applying certain WTO rules, and may be granted a longer period to implement the WTO agreement. While the use of SDT by LDCs does not raise major concerns, the controversy is related to their application by emerging economies such as China, India, and Brazil. This is due to the status of a developing country within the organization. In the WTO, as in the GATT, it was assumed that each state determined its own status, most often at the time of accession to the organization. As regards LDCs, a solution based on the UN classification has been implemented.

The maintenance of SDT regulations within the WTO, as well as proposals to extend their scope to new trade-related areas, pose a serious challenge to the organization. 
Their application in GATT has led to a practical exclusion of developing countries from multilateral negotiations and trade liberalization. This has been detrimental in the case of economic sectors important to their trade interests, i.e. agriculture and textiles. Under the SDT provisions, developing countries were exempted from reciprocity during the GATT period, which meant not engaging in trade barrier reductions and not taking on tariff obligations.

The situation related to the application of SDT changed with the establishment of the WTO. It has turned out that the SDT provisions serve to a small extent to fulfill the rights and obligations of WTO members by developing countries. Moreover, they may also lead to limiting their activity in the organization. There has been a change in the approach of developing countries to participating in multilateral negotiations. Limited liberalization, with the possibility of using SDT regulations seemed to be the most beneficial. This approach has been criticized by highly developed countries. While the protection of less competitive sectors of the economy or industries was fully justified, the problem was the abuse or misapplication of SDT. Therefore, the aim of the negotiations under the Doha Round was to change the regulations. The most radical proposal was put forward by academics. It assumed abolition of SDT for a wide range of developing countries. Instead, they were to be integrated into the international trading system according to the rule of the MFN. SDT regulations were to be applied only to LDCs, and their effect was strengthened by additional development assistance. Due to the deadlock in the Doha Round negotiations, the chance to modify SDT regulations is so far very small. This leads to tensions between WTO members, exacerbating the organization's crisis.

Hypothesis 4 (positively verified): The WTO requires reforms, and thus adaptation to new international circumstances and related challenges, which means that the organization is more inclined to increase its role in the area of development cooperation.

In the face of the failure of the Doha Round, the role of the WTO as the main forum for making decisions on international trade diminished. This means that the position of the WTO as a center for managing the international trading system, which GATT performed, has decreased. Taking into account the perspective of development cooperation, the WTO has become, to a large extent, the executor of jointly agreed decisions with other multilateral organizations, i.e., the WB, IMF, OECD, UN, UNDP. On the other hand, the organization made an attempt to break the deadlock and look for a new place in the international trading system. In this regard, the following activities were initiated:

- commitment to improve coherence and harmonization of activities within multilateral aid system; the election of the WTO as the administrator of the Aid for Trade and the Enhanced Integrated Framework, as well as its role as the 
institution that oversees and enforces the implementation of the TFA, is a move in this direction;

- improving the implementation of WTO agreements by developing countries, which in practice means adopting rules that would promote the pursuit of trade interests by developing countries; examples include administration of the STDF or oversight of the implementation of trade facilitation regulations (TFA);

- strengthening the role of the WTO as an intermediary institution for the provision of aid from various funding sources; the WTO's task is to facilitate contacts with relevant international actors providing such assistance (Lamy, 2006); an example is institutional cooperation with other economic organizations involved in development and aid.

The WTO's role as coordinator and administrator of international development aid initiatives and trust funds stems from several factors:

- broad representation of countries; by 2018, the WTO had 164 members, and a further 22 states and autonomous territories continued accession negotiations;

- legally binding nature of adopted rules; in the WTO, regulations can be made legally binding and enforced through the Dispute Settlement Understanding; the organization has relatively the most effective enforcement mechanism among existing multilateral international institutions; although it does not apply in the context of preferential treatment of developing countries (Chapter IV of the GATT 1994) and provision of technical assistance, the areas belong to the practice of the organization and are implemented by member states; the main donors are WTO member states belonging to the OECD-DAC;

- cooperation with other organizations; the WTO has extensive networking with multilateral organizations involved in aid and development, including, in particular, the World Bank, United Nations, and the OECD; since the organization has a relatively small budget for technical assistance, support for trade-related development objectives is drawn from other available sources at the disposal of multilateral organizations (i.e., AFT, EIF, STDF).

Hypothesis 5 (partially positively verified): Greater WTO support for developing member states should entail their active involvement in trade liberalization on conditions adjusted to individual economic needs of recipients.

The WTO Doha Round was an attempt to mainstream development issues into world trade. The basis of this process is reconciling the needs of developing countries with the obligation to liberalize trade. In practice, this means limited and selective liberalization on conditions favorable to interests of developing countries. The course of the Doha Round shows that only such agreements that will not lead to high implementation costs and that may bring benefits to less developed member 
states are acceptable. Empirical studies indicate that the potential benefits for developing countries from implementing the TFA may be greater than for other areas of multilateral negotiation. The way to reach a compromise, then, is to narrow the negotiation agenda down to the easiest and least controversial issues. This is evidenced by the TFA, in which the provisions on trade facilitation were limited to three articles contained in Art. V, VIII, and X of the GATT 1994.

The approach related to selective trade liberalization indicates a departure from the applied one-size-fits-all model. A major change, compared to previous multilateral negotiations, is the individual and developing country-specific approach to adopting new WTO commitments. The pace and manner of adoption of regulations depended on the individual decisions of developing countries, their economic, political, and institutional capacity to introduce changes, especially LDCs'. In context of the TFA, provisions on special and differential treatment were made more flexible, but the obligation to adopt multilateral agreements under the single undertaking formula has been maintained. This means that developing countries have not so far been exempted from the obligation to implement multilateral WTO agreements.

Hypothesis 6 (partially positively verified): Adopting a new formula for implementing WTO rules - as used in the Trade Facilitation Agreement and based on a flexible approach - will increase the application of WTO rules by developing countries.

The cornerstone of the WTO is a commitment to trade liberalization, which is based on a system of mutual concessions in market access. In such a situation, it is difficult to find a place for assistance. On the other hand, reciprocity of concessions or commitments is not the only formula underpinning trade liberalization. It can also be a system of non-reciprocity of concessions, based on SDT regulations. Such a direction of change was initiated in the Doha Round and the adoption of the multilateral TFA in 2017. A key element of the TFA is the conditionality of commitments and the related trade capacity building assistance. Perhaps such a solution will become a model for other agreements negotiated within the WTO? But what can highly developed countries count on in such a situation?

The answer to this question may be the proposal based on a flexible negotiation formula, put forward by the EU in 2018. In view of the increasing number of voices on the reform of the WTO, which appeared both on the side of highly developed and developing countries, a concept was created to distinguish WTO negotiations on the basis of a criterion of greater willingness of WTO members to liberalize trade (EC, 2018). On this basis, members could take part in trade liberalization on terms suited to their own potential. In practice, this would mean a choice between two types of negotiation. First, these would be multilateral negotiations, ending with a final agreement and binding only to the parties to the agreement. The second type would 
be plurilateral negotiations, conducted in those areas where the chance of accepting a multilateral agreement would be low. The latter would be open to all WTO members, and the agreed rules would be applied on the basis of the MFN clause. The procedure for their acceptance would be simplified compared to multilateral negotiations.

A solution of this kind would formally distinguish WTO member states into at least two groups. The first one would include countries willing to tighten trade relations and further reduce barriers, while the second one - countries not prepared to exchange concessions. As a consequence, it would risk a limited participation of the second group of states in the international trading system and exclusion from advanced negotiations. The dividing line would run essentially between highly developed and developing countries, with some exceptions on both sides. This direction of changes would have two kinds of effects. First, it would mean a rejection of the single undertaking principle and further erosion of the multilateral trading system under the auspices of the WTO. Secondly, in the face of a paralysis of the organization, this proposal may, however, lead to overcoming the deadlock and tightening regulatory cooperation between WTO members willing to deepen trade relations.

This study confirms the main claim, taken at the outset, about the expanding role of the WTO in the sphere of development cooperation. The scope of these activities is relatively broad and dispersed, which is due to the WTO's relatively short period of operation in this area. Nevertheless, this activity, directly or indirectly, serves to support developing countries within the multilateral trading system. There are three basic forms of such an engagement:

- assistance in building institutions, administrative apparatus, legal solutions and training of public officials in the field of international trade regulations; technical assistance, transfer of knowledge and know-how on WTO regulations and rules of the organization's operation play a major role here;

- creation of rules and regulations conducive to interests of developing countries and support for the implementation of provisions contained in WTO agreements; the main manifestation of this type of activity are the provisions of SDT and the proposal to extend their scope to new areas; should new trade-related regulations be incorporated into the WTO, for example those relating to environmental protection or labor law standards, it is expected that the SDT provisions will also apply there;

- cooperation with other multilateral organizations in order to increase the effectiveness in achieving development goals; the aim is to reduce fragmentation of development aid system and to achieve greater harmonization of programs; the role of the WTO is to coordinate and administer joint initiatives and mobilize additional financial resources for development assistance. 
The assessment of the WTO's activities in development cooperation is ambiguous. This is due to several factors. First, the evolving formula of development cooperation, treated in the book as an international regime or a set of interrelated regimes in the sphere of international development assistance. Second, the declining importance of the WTO within the international trading system, the main reason for which lies in the failure of the Doha Round negotiations. Third, the organization's search for a new area to operation related to development and support for developing countries. Given the above circumstances, it can be concluded that the WTO is in a period of transition. In this context, greater involvement in development cooperation seems a legitimate option of choice. This is in line with expectations of WTO members. Developing countries count on greater support for the implementation of their development goals related to trade, while it is in the interest of highly developed countries to increase the efficiency of the organization. This means changing the rules and regulations of trade in order to adapt to new international conditions, including those related to assistance for developing countries. 


\section{Bibliography}

Accra Agenda for Action (2008). The Third High Level Forum on Aid Effectiveness. 2-4 September, Accra, Ghana.

Acharya, A.K., Fuzzo de Lima, A.T., Moore, M. (2006). Proliferation and fragmentation: Transaction costs and the value of aid, Journal of Development Studies, 42(1): 1-21.

Addis Ababa Action Agenda on Financing for Development (2015). Third International Conference on Financing for Development, 13-16 July. Addis Ababa, Ethiopia.

Addison, T., Mavrotas, G., McGillivray, M. Burnisede (2005). Aid, Debt Relief and New Sources of Finance for Meeting the Millennium Development Goals, Journal of International Affairs, 58(2): 113-127.

Addison, T., Morrissey, O., Tarp, F. (2017). The Macroeconomics of Aid: Overview, The Journal of Development Studies, 53(7): 987-997.

Adelman, C.C., Norris, J., Weicher, J. (2005). America's Total Economic Engagement with the Developing World: Rethinking the Uses and Nature of Foreign Aid. Washington: Hudson Institute.

Adlung, R. (2015). The Trade in Services Agreement (TISA) and Its Compatibility with GATS: An Assessment Based on Current Evidence, World Trade Review, 14(4): 617-641.

Agboghoroma, A., Busse, M., Falatik, S., Hoekstra, R., Königer, J., Koopman, G., Kühne K., Roloff N. (Ed.) (2009). Aid for Trade: making trade effective for development. Case studies from Kenya, Tanzania and Uganda. Maintal: PricewaterhouseCoopers, Hamburg Institute of International Economics.

Agenda for Development (1994). Report of the Secretary-General. 6 May. United Nations. A/48/935.

Agreement Establishing the WTO (1994).

Agreement on Agriculture (1995).

Agreement on Trade Facilitation (2014). Annex to the Protocol Amending the Marrakesh Agreement Establishing the World Trade Organization. 27 November. WT/L/940. Geneva: WTO.

Aid Effectiveness, Help in the Right Places (2002). The Economist, http://www.economist.com/ node/1034563 (access: 09.08.2017).

Aksoy, M.A. (2005). Global Agriculture Trade Policies. In: Global Agricultural Trade and Developing Countries (pp. 37-53), M.A. Aksoy, J.C. Beghin (Eds.). Washington: The World Bank.

Alesina, A., Dollar, D. (1998). Who Gives Foreign Aid to Whom and Why?, NBER Working Papers, 6612: 1-47.

Alesina, A., Dollar, D. (2000). Who gives foreign aid to whom and why?, Journal of Economic Growth, 5(1): 33-63.

Alonso, J.A., Glennie, J. (2015). What is development cooperation?, Development Cooperation Forum Policy Briefs, 1: 1-5. 
Anderson, K. (2002). Developing country interests in WTO - induced agriculture trade reform. In: Developing Countries in the World Trading System: The Uruguay Round and Beyond (pp. 40-67), R. Adhikari, P. Athukorala (Eds.). Cheltenham: Edward Elgar.

Anderson, K. (2004). The Challenge of Reducing Subsidies and Trade Barriers, World Bank Policy Research Working Paper, 3415: 1-59.

Andreopoulos, G., Andreopoulos, G., Panayides, A. (2011). Multilateral vs Bilateral Aid: Addressing Some Puzzles, European Journal of Management, 11(4): 73-78.

Andrzejczak K. (2010). Pomoc rozwojowa Francji dla krajów rozwijających się w latach 1981-2007, http://www.wbc.poznan.pl/Content/137109/Andrzejczak_Katarzyna-rozprawa_doktorska. pdf (access: 15.05.2017).

Annen, K., Knack, S. (2015). On the Delegation of Aid Implementation to Multilateral Agencies, World Bank Policy Research Working Paper, 7455: 1-35.

Antipin J.E., Mavrotas, G. (2006). On the empirics of aid and growth: A fresh look, UNU-WIDER Research Paper, 2006(05): 1-25.

Arndt, Ch. (2000). Technical Cooperation. In: Foreign aid and Development. Lessons Learnt and Directions for The Future (pp. 154-177), F. Tarp (Ed.). London: Routledge.

Atwood, J.B. (2012). Creating a Global Partnership for Effective Development Cooperation. Washington: Center for Global Development.

Bagiński P., Kowalska M. (2010). Finansowanie rozwoju krajów słabiej rozwiniętych jako element polityki zagranicznej państw rozwiniętych. In: Pomoc rozwojowa dla krajów rozwijających się na przełomie XX i XXI wieku (pp. 88-92), E. Latoszek (Ed.). Warszawa: Oficyna Wydawnicza SGH.

Bagiński, P., Czaplicka, K., Szczyciński J. (2009). Międzynarodowa wspótpraca na rzecz rozwoju. Warszawa: Polskie Wydawnictwo Ekonomiczne.

Baliamoune-Lutz, M., Mavrotas, G. (2009). Aid effectiveness: looking at the aid social capital growth nexus, Review of Development Economics, 13(1): 510-525.

Barakat, S. (2009). The failed promise of multi-donor trust funds: aid financing as an impediment to effective state-building in post-conflict contexts, Policy Studies, 30(2): 107-126.

Barakat, S., Rzeszut, K., and Martin, N. (2011). What is the track record of multi donor trust funds in improving aid effectiveness? An assessment of the available evidence. London: EPPI-Centre, Social Science Research Unit, Institute of Education - University of London.

Baylis, J. Smith, S. (Eds.) (2001). The Globalization of World Politics. An Introduction to International Relations. New York: Oxford University Press.

M. Bauhr, N. Charron, N. Nasiritousi (2013). Does Corruption Cause Aid Fatigue? Public Opinion and the Aid-Corruption Paradox?, International Studies Quarterly, 57(3): 568-579.

Berg, A., Krueger, A. (2003). Trade, Growth, and Poverty: A Selective Survey, IMF Working Paper, WP/03/30: 1-51.

Beynon, L. (2003). Poverty Efficient Aid Allocations: Collier/Dollar Revisited, Economic and Statistics Analysis Unit Working Paper, 2: 1-64.

Bhagwati, J., Sutherland, P. (Eds.) (2011). The Doha Round: setting a deadline, defining a final deal. Interim Report, https:/voxeu.org/sites/default/files/file/doha-round-setting-deadlinedefining-final-deal-interim-report-jan-2011.pdf (access: 06.09.2017).

Birdsall, N., Kharas, H. (2010). Quality of official development assistance assessment. Washington: Center for Global Development. 
Blackhurst, R. Enders, A. Francois, J.F. (1996). The Uruguay Round and Market Access: opportunities and Challenges for Developing Countries. In: The Uruguay Round and the Developing Countries (pp. 97-115), W. Martin, L.A. Winters (Eds.). Cambridge: Cambridge University Press.

Bolaky, B., Freund, C. (2006). Trade, Regulations, and Growth. Washington: paper presented at the Trade and Growth Conference, https://www.imf.org/external/np/res/seminars/2006/trade/ pdf/freund.pdf (access: 06.09.2017).

Boone P. (1996). Politics and the effectiveness of foreign aid, European Economic Review, 40(2): 289-329.

Borchert, I., Gootiiz, B., Mattoo, A. (2011). Services in Doha: What's on the Table? In: Unfinished Business? The WTO's Doha Agenda (pp. 115-143), W. Martin, A. Mattoo (Eds.). Washington: The World Bank.

Bosch, E. (2011). Making the most of the international aid system, OECD Journal: General Papers, 2010/ (1): 27-36.

Bossche, P. van den, Zdouc, W. (2017). The Law and Policy of the World Trade Organization. Cambridge: Cambridge University Press.

Bouët, A., Laborde D. (2011). Duty Free, a Round for Free and the Least-Developed Countries. In: Unfinished Business? The WTO's Doha Agenda (pp. 145-177), W. Martin, A. Mattoo (Eds.) Washington: World Bank.

Braga, C.A.P. (1995). Trade-related intellectual property issues: The Uruguay Round Agreement and Its Economic Implications. In: The Uruguay round and the developing economies (pp. 381411), W. Martin, L.A. Winters (Eds.). Washington: The World Bank.

Brenton, P. (2003). Integrating the Least Developed Countries into the World Trading System: The Current Impact of EU Preferences under Everything But Arms, Journal of World Trade, 37(3): 623646.

Brink, L. (2014). Comments under the WTO Agreement on Agriculture and the Doha Draft Modalities: How Do They Compare to Current Policy? Paris: OECD Publishing.

Burnell P. (Ed.). (1997). Foreign Aid in a Changing World. Buckingham-Philadelphia: Open University Press.

Burnside, C., Dollar, D. (1997). Aid, Policies and Growth, World Bank Policy Research Working Paper, 1777: 1-64.

Burnside, C., Dollar, D. (2000). Aid, Policies, and Growth, The American Economic Review, 90(4): 847-868.

Busan Partnership for Effective Development Co-operation Agreement (2011). The Fourth HighLevel Forum on Aid Effectiveness, 29 November - 1 December. Busan (Korea).

Cadot, O., Fernandes, A.M., Gourdon, J., Mattoo, A. (2011). Impact Evaluation of Trade Assistance: Paving the Way. In: Where to Spend the Next Million? Applying Impact Evaluation to Trade Assistance (pp. 1-38), O. Cadot, A.M. Fernandes, J. Gourdon, A. Mattoo (Eds.). Washington: The World Bank.

Cali, M., te Velde, D.W. (2010). Does Aid for Trade Really Improve Trade Performance?, World Development, 39(5): 725-740.

Calster, G.V., Prévost, D. (2013). Research Handbook on Environment, Health and the WTO. Cheltenham-Northampton: Edward Elgar.

Caporal, J. (2018). WTO Reform: The Beginning of the End or the End of the Beginning? Washington: Center for Strategic and International Studies. 
Cassen, R. and Associates (1994). Does Aid Work? Report to an Intergovernmental Task Force. Oxford: Clarendon Press.

Chang R., Kaltani L., Loayza, N.V. (2009). Openness can be good for growth: the role of policy complementarities, Journal of Development Economics, 90(1): 33-49.

Chang, S.W. (2008). WTO for Trade and Development Post-Doha. In: The Future of International Economic Law (pp. 115-131), W.J. Davey, J.H. Jackson (Eds.). Oxford: Oxford University Press.

Clemens, M.A., Moss, T.J. (2005). The Ghost of 0,7 per cent: Origins and Relevance of the International Aid Target, Center for Global Development Working Paper, 68: 1-20.

Collier, P., Dollar, D. (2001). Can the world cut poverty in half? How policy reform and effective aid can meet international development goal, World Development, 29(11): 1787-1802.

Collier, P., Dollar, D. (2002). Aid allocation and poverty reduction, European Economic Review, 45(8): 1470-1500.

Commission for Africa. (2005). Our Common Interest. Report of the Commission for Africa, http:// www.commissionforafrica.info/2005-report (access: 23.11.2017).

Crawford, G. (2001). Foreign Aid and Political Reform: A Comparative Analysis of Democracy, Assistance and Political Conditionality. Basingstoke UK: Palgrave Macmillan.

Custer, S., Rice, Z., Masaki, T., Latourell, R., Parks, B. (2015). Listening to Leaders: Which Development Partners do they Prefer and Why? Williamsburg: AidData.

Dalgaard, C.J., Hansen, H., Tarp, F. (2004). On the Empirics of Foreign Aid and Growth, Economic Journal, 114(496): 191-216.

Dalgaard, C.J., Hansen, H. (2001). On Aid, Growth and Good Policies, Journal of Development Studies, 37(6): 17-41.

Davies, R., Pickering, J. (2015). Making Development Cooperation Fit for the Future A Survey of Partner Countries, OECD Development Cooperation Working Papers, 20: 1-58.

Dee, P., Geisler, C., Watts., G. (1997). The Impact of Trade Liberalization in APEC. Asia Pacific Economic Cooperation. November. Singapore: APEC Secretariat.

Decreux, Y. Fontagné, L. (2011). Economic impact of potential outcome of the DDA II. Economic Analysis in Support of Bilateral and Multilateral Trade Negotiations. Paris: CEPII-CIREM.

Delpeuch, C., Jouanjean, M.A., Le Vernoy, A., Messerlin, P., Orliac, T. (2010). Aid for Trade: A Metaevaluation, www.oecd.org/dataoecd/14/61/47423967.pdf (access: 09.09.2017).

Deszczyński, P. (2011). Konceptualne podstawy pomocy rozwojowej. Wydawnictwo Uniwersytetu Ekonomicznego w Poznaniu, Poznań.

Diakantoni, A., Escaith, H. (2009). Mapping the Tariff Waters. Staff Working Paper ERSD, 2009-13. Geneva: WTO.

Dugiel, W. (2008). Światowa Organizacja Handlu a kraje rozwijające się, International Journal of Management and Economics, 24: 9-37.

Dugiel W. (2009). Światowa Organizacja Handlu a kraje rozwijające się, Zeszyty Naukowe Kolegium Gospodarki Światowej, 24: 9-37.

Easterly, W. (2001). The Elusive Quest for Growth: Economists' Adventures and Misadventures in the Tropics. Cambridge: MIT Press.

Easterly, W. (2003). Can Foreign Aid Buy Growth? Journal of Economic Perspectives, 17(3): 23-48.

Easterly, W., Levine, R., Roodman, D. (2004). New Data, New Doubts: A Comment on Burnside and Dollar's Aid, Polices and Growth (2000), American Economic Review, 94(2): 774-780. 
Easterly, W., Pfutze, T. (2008). Where does the money go? Best and worst practices in foreign aid, Journal of Economic Perspectives, 22(2): 29-52.

EC (2010). Europeans, development aid and the Millennium Development Goals. Special Eurobarometer 352. Brussels: European Commission.

EC (2008). Reforming Technical Cooperation and Project Implementation Units for External Aid provided by the European Commission: A Backbone Strategy. Brussels: European Commission.

EC (2016), Annual Report on the implementation of the European Union's instruments for financing external actions in 2015. Brussels: European Commission.

EC (2018). European Commission presents comprehensive approach for the modernisation of the World Trade Organisation, http://trade.ec.europa.eu/doclib/press/index.cfm?id=1908 (access: 11.12.2018).

Eichenauer, V.Z., Reinsberg, B. (2016). What Determines Earmarked Funding to International Development Organizations? Evidence from the New Multi-Bi Aid Data, AidData Working Paper, 25: 1-64.

Eichenauer, V.Z., Reinsberg, B. (2017). What determines earmarked funding to international development organizations? Evidence from the new multi-bi aid dataset, Review of International Organizations. DOI: 10.1007/s11558-017-9267-2.

EIF (2017). The Enhanced Integrated Framework Funding, https://www.enhancedif.org/en/funding (access: 12.11.2017).

European Center for Development Policy Management (2014). Measuring Policy Coherence for Development. Final Report ECDPM No. 2, https://www.oecd.org/pcd/ECDPM\%20Paper_ Measuring\%20PCD.pdf (access: 06.11.2017).

Ferro, E., Portugal-Perez A., Wilson J.S. (2011). Aid to the services sector. Does it affect manufacturing exports? Policy Research Working Paper, 5728: 1-28.

Finger, J.M. (1995). Legalized Backsliding: Safeguard Provisions in GATT. In: The Uruguay round and the developing economies (pp. 285-304), M.W. Winters, L. Alan (Eds.). Washington: The World Bank.

Finger, J.M. (2008). Developing countries in the WTO system: applying Robert Hudec's analysis to the Doha Round, The World Economy, 31(7): 887-904.

Finger, J.M., Schuler, P. (2000). Implementation of Uruguay Round Commitments: The Development Challenge, The World Economy, 23(4): 511-525.

Finger, J.M., Winters, L.A. (1998). What can the WTO do for developing countries?. In: The WTO as an international organization (pp. 365-397), A.O. Krueger. (Ed.) Chicago: University of Chicago Press.

Finger, J.M. (2000). The WTO's Special Burden on Less Developed Countries, Cato Journal, 19(3): $425-437$.

First High-Level Meeting of The Global Partnership for Effective Development Cooperation (2014). http://effectivecooperation.org/wp-content/uploads/2015/01/MEMORIA-FINAL. pdf> (access: 21.11.2017).

Francois, J., van Meijl, H., van Tongeren, F. (2005). Trade Liberalization in the Doha Development Round, Economic Policy, 20(42): 349-391.

Francois, J. (1999). The ghost of Rounds past: the Uruguay Round and the Shape of the next multilateral trade round, https://www.gtap.agecon.purdue.edu/resources/res_display.asp?RecordID=238 (access: 12.11.2017). 
Francois, J.F., McDonald, B., Nordstrom, H. (1996). Assessing the Uruguay Round, in: The Uruguay Round and the Developing Countries (pp. 253-289), W. Martin, L.A. Winters (Eds.). Cambridge: Cambridge University Press.

Francois, J. F, Van Meijl, H., Van Tongeren, F. (2003). Economic Implications of Trade Liberalization Under the Doha Round, CEPII Working Paper, 20: 1-41.

G20(2006). Ministerial Statement. Geneva, 29 June 2006, http://www.g-20.mre.gov.br/conteudo/ ministerials_Genebra03.htm (access: 29.12.2017).

GATS (1995). General Agreement on Trade in Services.

GATT (1979). General Agreement on Tariffs and Trade: Differential and more Favorable Treatment, Reciprocity and Fuller Participation of Developing Countries, Decision of 28 November 1979 (L/4903).

GATT (1994). The results of the Uruguay Round of multilateral trade negotiations: market access for goods and services: overview of the results. Geneva: GATT Secretariat.

Gowa, J., Hicks, R. (2012). The most-favored nation rule in principle and practice: Discrimination in the GATT, The Review of International Organizations, 7(3): 247-266.

Graham, E.R. (2015). Money and multilateralism: how funding rules constitute IO governance, International Theory, 7(1): 162194.

Grant, J.P. (1979). Perspectives on Development Aid: World War II to Today and beyond, The Annals of the American Academy of Political and Social Science, 442(1): 1-12.

Grącik-Zajaczkowski, M. (2011). Przepływ osób fizycznych w ramach WTO. In: Współczesne problemy demograficzne: rzeczywistość i mity. Ujęcie krajowe, regionalne i globalne (pp. 401-414), J. Osiński (Ed). Warszawa: Oficyna Wydawnicza SGH.

Grącik-Zajaczkowski, M. (2012). Państwa afrykańskie w WTO. In: Afryka o godność życia (pp. 241259), A. Kłosiński (Ed.). Lublin: KUL.

Gulrajani, N. (2016). Bilateral versus multilateral aid channels: Strategic choices for donors. Report. London: Overseas Development Institute.

Gulcz, M. (1988). Kraje rozwijające się a zewnętrzne środki finansowania rozwoju. Warszawa: PWN.

Haggard, S., Simmons, B.A. (1987). Theories of international regimes. International Organization, 41(3): 491-517.

Haliżak, E. (2009). Ujęcie roli państwa w ekonomii politycznej stosunków międzynarodowych. In: Państwo w teorii i praktyce stosunków międzynarodowych, M. Sułek, J. Symonides (Eds.). Warszawa: Wydawnictwo Uniwersytetu Warszawskiego.

Haliżak, E. (2017). Międzynarodowa ekonomia polityczna - subdyscyplina nauki o stosunkach międzynarodowych, Stosunki Międzynarodowe, 1(53): 9-34.

Hallaert, J.J. (2010). Increasing the Impact of Trade Expansion on Growth: Lessons from Trade Reforms for the Design of Aid for Trade, OECD Trade Policy Working Papers, 100: 1-42.

Hallaert, J.J. (2012). Aid for Trade is reaching its limits, so what's next?, http://www.gem.sciences-po. $\mathrm{fr} /$ content/publications/pdf/Hallaert_Aid\%20for\%20Trade\%20-\%20reaching\%20its\%20 limits\%20so\%20whats\%20next.pdf (access: 11.10.2017).

Hallaert, J.J. (2015). The Aid for Trade Initiative: A WTO Attempt at Coherence, RSCAS Policy Paper, 06: 1-14.

Hallaert, J.J., Munro, L. (2009). Binding Constraints to Trade Expansion: Aid for Trade Objectives and Diagnostics Tools, OECD Trade Policy Working Papers, 94: 1-34. 
Hansen, H., Tarp F. (2001). Aid and Growth Regressions, Journal of Development Economics, 64(2): 547-570.

Hansen, H., Tarp, F. (2000). Policy Arena Aid Effectiveness Disputed, Journal of International Development, 12(3): 375-398.

Hansen, H., Tarps, F. (2000). Aid Effectiveness Disputed, Journal of International Development, 12(3): 375-398.

Hathaway, D.E., Ingco, M.D. (1995). Agriculture Liberalization and the Uruguay Round. In: The Uruguay round and the developing economies (pp. 1-24), M.W. Winters, L. Alan (Eds.). Washington: The World Bank.

Hayashi, M. (2007). Trade in Textiles and Clothing, Assuring Development Gains in a Rapidly Changing Environment. Geneva: United Nations Conference on Trade and Development.

Headey, D. (2008). Geopolitics and the effect of foreign aid on economic growth: 1970-2001, Journal of International Development, 20(2): 161-180.

Helble, M.C., Mann, C.L., Wilson, J.S. (2012). Aid for trade facilitation, Review of World Economics, 148(2): 357-376.

Henson, S., Loader, R. (2001). Barriers to Agricultural Exports from Developing Countries: The Role of Sanitary and Phytosanitary Requirements, World Development, 29(1): 85-102.

Hertel, T., Hoekman, B., Martin, W. (2002). Agriculture Negotiations in the Context of a Broader Round: A Developing Country Perspective. In: Agricultural Trade Policies in the New Millennium, (pp. 89-112), P.L. Kennedy, W.W. Koo (Eds). New York: Food Products Press.

Hertel, T., Hoekman, B., Martin, W. (2002). Developing Countries and a New Round of WTO Negotiation, The World Bank Research Observer, 17(1): 113-140.

Hertel, T., Martin, W. (1999). Developing Countries Interests in Liberalizing Manufactures Trade. London: CEPR Workshop, 19-20 February.

Hertel, T., Martin, W. (2000), Liberalizing Agriculture and Manufactures in a Millennium Round: Implications for Developing Countries, The World Economy, 23(04): 455-469.

History of the 0,7\% ODA Target (2000). DAC Journal, 3(4): 3-11, https://www.oecd.org/dac/ stats/ODA-history-of-the-0-7-target.pdf (access: 19.12.2017).

Hoekman, B. (1995). Assessing the General Agreement on Trade in Services. In: The Uruguay round and the developing economies (pp. 327-364), M.W. Winters, L. Alan (Ed.). Washington: The World Bank.

Hoekman, B. (2000). Towards a More Balanced and Comprehensive Services Agreement. In: The WTO after Seattle (pp. 119-135), J.J. Schott (Ed.). Washington: Institute for International Economics.

Hoekman, B. (2005). Operationalizing the Concept of Policy Space in the WTO: Beyond Special and Differential Treatment, Journal of International Economic Law, 8(2): 405-424.

Hoekman, B.M. (2006). The General Agreement on Trade in Services: Doomed to Fail? Does it Matter?, http://citeseerx.ist.psu.edu/viewdoc/download?doi=10.1.1.491.2565\&rep=rep1\&type=pdf (access: 19.12.2017).

Hoekman, B. (2007). Development, and Trade Agreements: Beyond Market Access. In: Global Trade and Poor Nations - The Poverty Impacts and Policy Implications of Liberalization, (pp. 225-245), B. Hoekman, M. Olarreaga (Eds.). Washington: Brookings Institution Press.

Hoekman, B. (2011). Aid for Trade: Why, what and where are we? In: Trade beyond Doha: Prospects for Asia-Pacific Least Developed Countries (pp. 95-114). United Nations Economic and Social Commission for Asia and the Pacific (ESCAP). 
Hoekman, B. (2016). The Bali Trade Facilitation Agreement and Rulemaking in the WTO: Milestone, Mistake or Mirage? In: The World Trade System: Trends and Challenges (pp. 149191), Bhagwati, J.N., Krishna, P., Panagariya A. (Eds.). Cambridge: The MIT Press.

Hoekman, B., Mavroidis, P.C. (2016). World Trade Organization (WTO): Law, Economics, and Politics. London: Routledge.

Hoekman, B., Ng, F., Olarreaga, M. (2002). Eliminating Excessive Tariffs on Exports of Least Developed Countries. Washington, The World Bank Economic Review, 16(1): 1-21.

Hoekman, B., Prowse, S. (2005) Economic Policy Responses to Preference Erosion: From Trade as Aid to Aid for Trade, World Bank Policy Research Paper, 3721: 1-26. DOI: 10.1596/18139450-3721.

Hoekman, B., Kostecki, M.M. (2011). Ekonomia światowego systemu handlu. WTO: zasady i mechanizmy negocjacji. Wrocław: Wydawnictwo Uniwersytetu Ekonomicznego we Wrocławiu.

Hoekman, B., Martin, W., Mattoo, A. (2009). Conclude Doha: It Matters! Policy Research Working Paper World Bank, 5135: 1-35.

Hoekman, B., Martin, W., Mattoo, A. (2010). Conclude Doha. It matters! World Trade Review, 9(3): 505-530. DOI: 10.1017/S1474745610000297.

Hoekman, B., Michalopoulos, C., Winter, L.A. (2003). Special and Differential Treatment for Developing Countries. Towards a New Approach in the WTO. Draft version. https://pdfs. semanticscholar.org/1505/855742313096582ba53c7ed8249332788eae.pdf (access: 18.12.2017).

Hoekman, B., Michalopoulos, C., Winter, L.A. (2004). Special and Differential Treatment of Developing Countries in the WTO: Moving Forward After Cancún, The World Economy, 27(4): 481-506.

Hopkins, R.F. (2000). Political Economy of Foreign Aid. In: Foreign Aid and Development: Lessons Learnt and Directions for the Future (pp. 423-448), F. Tarp, P. Hjertholm (Eds.). New York: Routledge.

How to make aid work? (1999), The Economist, 24 June, https://www.economist.com/ special/1999/06/24/how-to-make-aid-work (access: 09.12.2017).

Hudec, R., Finger, J. (2010). Developing Countries in the GATT Legal System. Cambridge: Cambridge University Press. DOI: 10.1017/CBO 9780511976810

Hudson, J. (2004). Introduction: Aid and Development, Economic Journal, 114(496): 185-190.

Hufbauer, G.C., Schott, J.J., Adler, M., Brunel, C., Wong, W.F. (2010). Figuring out of the Doha Round. Washington: Peterson Institute for International Economics.

Hynes W., Holden P. (2013). What future for the Global Aid for Trade Initiative? Towards a fairer assessment of its achievements and limitations. Paris: OECD Publishing. http://www.oecd.org/ dac/aft/WhatfutureAFT.pdf (access: 22.09.2017.).

Hynes, W., Holden, P. (2016). What future for the Global Aid for Trade Initiative? Towards a fairer assessment of its achievements and limitations, Development Policy Review, 34(4): 593-619. DOI: $10.1111 /$ dpr.12165.

Hynes, W., Scott, S. (2013). The Evolution of Official Development Assistance: Achievements, Criticisms and a Way Forward, OECD Development Co-operation Working Papers, 12: 1-28. DOI: $10.1787 / 5 \mathrm{k} 3 v 1 \mathrm{dv} 3 f 024-\mathrm{en}$.

ICTSD/IISD. (2003). Developments Since the Fourth WTO Ministerial Conference, Doha Round Briefing Series, 1(6):1-4. 
IMF (2002). Financing for Development Implementing the Monterrey Consensus, https://www.imf. org/external/np/pdr/FfD/2002/imp.htm (access: 02.11.2017).

IMF (2005). Doha Development Agenda and Aid for Trade. Washington: IMF, World Bank.

Inama, S. (2002). Market Access for LDCs - Issues to be Addressed, Journal of World Trade, 36(1): 85-116.

Josling, T. (2006). Special and Differential Treatment for Developing Countries, in: Agricultural Trade Reform and the Doha Development Agenda (pp. 63-78), K. Anderson, W. Martin (Eds.). New York: Palgrave Macmillan.

Julca, A., Montes, M., Vos, R. (2014), Towards a new aid architecture. In: Retooling Global Development and Governance (pp. 49-72). New York: UN DESA. DOI: 10.18356/201dfed9-en.

Kaberuka, D. (2007). New International Aid Architecture: New Players, New Challenges, Old Problems?, https://ideas4development.org/en/the-new-international-aid-architecture-newplayers-new-challenges-old-problems/ (access: 12.05.2017).

Kamińska-Blichowska T. (2007). Polityka gospodarcza krajów rozwijających się w skali międzynarodowej. In: Kraje rozwijające się w światowym systemie gospodarczym, S. Miklaszewski (Ed.). Warszawa: Difin.

Karsenty, G., Laird, S. (1987). The Generalized System of Preferences: A Quantitative Assessment of the Direct Trade Effects and of Policy Options, UNCTAD Discussion Paper No. 18. Geneva: UNCTAD.

Keck, A. Low, P. (2006). Special and Different Treatment in the WTO: Why, When and How? In: Economic Development and Multilateral Trade Cooperation (pp. 147-188), S.J. Evenett, B.M. Hoekman (Eds.). New York: Palgrave Macmillan.

Keohane, R.O. (1984). After Hegemony. Cooperation and Discord in the World Political Economy. New Jersey: Princeton University Press.

Keohane, R.O. (1989). International Institutions and State Power. Essays in International Relations Theory. Boulder San Francisco \& London: Westview Press.

Keohane, R.O., Victor, D.G. (2010). The Regime Complex for Climate Change. Cambridge: Harvard Project on International Climate Agreements.

Keohane, R., Macedo, S. Moravcsik, A. (2009). Democracy-Enhancing Multilateralism, International Organization, 63(1): 1-31. DOI: 10+10170S0020818309090018.

Keohane, R. O, Nye, J.S. (2001). Power and Interdependence. New York: Longman.

Kharas, H. (2007a). The New Reality of Aid. Report, https://www.brookings.edu/wp-content/ uploads/2016/06/08aid_kharas.pdf (access: 19.11.2017).

Kharas, H. (2007b). Trends and Issues in Development Aid, Wolfensohn Center for Development Working Paper, 1: 1-32.

Kharas, H. (2010). Rethinking the Roles of Multilaterals in the Global Aid Architecture. In: The 2010 Brookings Blum Roundtable Policy Briefs (pp. 55-61). Washington: The Brookings Institutions.

Kharas, H. Linn, J. (2008). Better aid: responding to gaps in effectiveness. Global Views Policy Brief 2008/06. Washington: Brookings Institution.

Kleen, P., Page, S. (2005). Special and Differential Treatment of Developing Countries in the World Trade Organization, Global Development Studies, 2: 1-154.

Kołodziejczyk K. (2010). Globalizacja a nierówności rozwojowe we współczesnej gospodarce światowej. In: Świat wobec współczesnych wyzwań i zagrożeń (pp. 104-126), J. Symonides (Ed.). Warszawa: Wydawnictwo Naukowe Scholar. 
Kopiński, D. (2009). Inicjatywa „Aid for Trade” a liberalizacja handlu światowego. In: Procesy globalizacji internacjonalizacji i integracji $w$ warunkach wspótczesnej gospodarki światowej (pp. 33-40), T. Sporek (Ed.). Katowice: Akademia Ekonomiczna w Katowicach.

Kopiński, D. (2011). Pomoc rozwojowa. Warszawa: Difin.

Kostecki, M. (2001). Technical Assistance Services in Trade-Policy. A Contribution to the Discussion on Capacity-Building in the WTO, ICTSD Resource Paper, 2: 1-50.

Knorr K. (1975). The Power of Nations. The Political Economy of International Relations. New York: Basic Books.

Krasner, D. (1983) (Ed.). International Regimes. Cambridge: Cornell University Press.

Laborde, D., Martin, W. (2011a). Agriculture Market Access. In: Unfinished Business? The WTO's Doha Agenda (pp. 35-54), W. Martin, A. Mattoo (Eds.). Washington: World Bank.

Laborde, D., Martin, W. (2011b). Non-agricultural Market Access, in: Unfinished Business? The WTO's Doha Agenda (pp. 55-68), W. Martin, A. Mattoo (Eds.). Washington: World Bank.

Lammersen, F., Roberts, M. (2015). Aid for trade 10 years on: Keeping it effective, OECD Development Policy Papers, 1: 1-26. DOI: 10.1787/5jrqc6q4xxr5-en.

Lamy, P. (2006). Making Trade Work for Development: Time for a Geneva Consensus, https://www. wto.org/english/news_e/sppl_e/sppl45_e.htm (access: 02.02.2018).

Lancaster, C. (1999). Aid Effectiveness. The Problem of Africa, Development Outreach, 1(2): 22-24.

Lancaster, C. (2007). Foreign Aid: Diplomacy, Development, Domestic Politics. Chicago: University of Chicago Press.

Latoszek E. (red). (2010). Pomoc rozwojowa dla krajów rozwijających się na przełomie XX i XXI wieku. Warszawa: Oficyna Wydawnicza SGH.

Latoszek E. Proczek M. (2006). Organizacje międzynarodowe we wspótczesnym świecie. Warszawa: Dom Wydawniczy Elipsa.

Latoszek, E., Proczek, M. (Eds.). (2013). Polityka rozwojowa. Rola organizacji międzynarodowych w zwalczaniu ubóstwa na świecie. Warszawa: Oficyna Wydawnicza SGH.

Levy, M.A., Keohane, R.O., Haas P.M. (Eds,). (1993), Institutions for the Earth - Sources of Effective International Environmental Protection. Cambridge: MIT Press.

Liu, X., Ornelas, E. (2014). Free Trade Agreements and the Consolidation of Democracy, American Economic Journal: Macroeconomics, 6(2): 29-70.

Lombaerde, P.D., Mavrotas, G. (2009). Aid for trade, Aid Effectiveness and Regional Absorption Capacity. In: Aid for Trade: Global and Regional Perspectives (pp. 39-61), P. De Lombaerde, L. Puri (Eds.). New York - Dordrecht: Springer. DOI: 10.1007/978-1-4020-9455-2_3.

Lundsgaarde, E. (2013). The Domestic Politics of Foreign Aid. London: Routledge.

Łoś-Nowak, T. (Ed.) (1997). Współczesne stosunki międzynarodowe. Wrocław: Wydawnictwo Uniwersytetu Wrocławskiego.

Łoś-Nowak, T. (2000). Stosunki międzynarodowe. Teorie - systemy - uczestnicy. Wrocław: Wydawnictwo Uniwersytetu Wrocławskiego.

Łoś-Nowak, T. (2004) (Ed). Organizacje w stosunkach międzynarodowych. Istota - mechanizmy działania - zasięg. Wrocław: Wydawnictwo Uniwersytetu Wrocławskiego.

Maggie, G. Rodriguez-Clare, A. (1998). The value of trade agreements in the presence of political pressures, Journal of Political Economy, 106(3): 574-601.

Maggie, G., Rodriguez-Clare, A. (2007). Political economy theory of trade agreements, American Economic Review, 97(4): 1374-1406. 
Maizels, A., Nissanke, M.K. (1984). Motivations for aid to developing countries, World Development, 12(9): 879-900.

Malek, M.H. (1991). Contemporary Issues in European Development Aid, Avebury: Alderhot UK.

Maran, M. (2000). Financial Times, 2 February.

Marceau, G. (Ed.) (2015). A History of Law and Lawyers in the GATT/WTO: The Development of the Rule of Law in the Multilateral Trading System. Cambridge: Cambridge University Press.

Martin, W. Mattoo, A. Winkler D. (2011). Introduction. In: Unfinished Business? The WTO's Doha Agenda (pp. 1-33), W. Martin, A. Mattoo (Eds.). Washington: The World Bank.

Martin, W., Winters, L.A. (Eds.). (1995). The Uruguay round and the developing economies, World Bank Discussion Papers No. 307. Washington: The World Bank.

Matera, P. (2012). Związki polityki i ekonomii w badaniu stosunków międzynarodowych, Przegląd Strategiczny, 1: 219-239.

McCulloch, N., Winters, L, Gaviera, X. (2001). Trade Liberalization and Poverty: A Handbook. London: Centre for Economic Policy Research.

McGillivray, M. (2003). Aid effectiveness and selectivity: Integrating Multiple Objectives in Aid Allocations, DAC Journal, 4(3): 23-36.

McGillivray, M., Ouattara, B. (2005). Aid, Debt Burden and Government Fiscal Behavior in Cote d'Ivoire, Journal of African Economies, 14(2):247-269. DOI: 10.1093/jae/eji003.

McMahon, G. (1997). Applying Economic Analysis to Technical Assistance Projects, Policy Research Working Paper No. 1749, World Bank. DOI: 10.1596/1813-9450-1749.

Michalopoulos, C. (1999). Trade Policy and Market Access Issues for Developing Countries, Policy Research Working Paper No. 2214, World Bank. DOI: 10.1596/1813-9450-2214.

Michalopoulos, C. (2000). The Role of Special and Differential Treatment for Developing Countries in GATT and World Trade Organization, Policy Research Working Paper No. 2388. DOI: 10.1596/1813-9450-2388.

Michalopoulos, C. (2001). Developing Countries in the WTO. London: Palgrave Macmillan.

Michalopoulos, C. (2014). Emerging Powers in the WTO: Developing Countries and Trade in the 21st Century. New York: Palgrave Macmillan.

Milner, H.V., Tingley, D. (2013). The Choice for Multilateralism: Foreign Aid and American Foreign Policy, The Review of International Organizations, 8(3): 313-341. DOI: 10.1007/s11558-0129153-x.

Milner, H.V. (2006). Why Multilateralism? Foreign aid and domestic principal-agent problems, in: Delegation and Agency in International Organizations (pp. 107-139), D.G. Hawkins, D.A. Lake, D.L. Nielson, M.J. Tierney (Eds.). New York: Cambridge University Press.

Monterrey Consensus on Financing for Development (2002). International Conference on Financing for Development Monterrey. United Nations, Mexico, 18-22 March.

Mosley, P. (1986). Aid effectiveness: the micro - macro paradox, Institute of Development Studies Bulletin, 17: 22-27.

Mosley, P. (1987). Foreign Aid: Its Defense and Reform. Lexington: University Press of Kentucky.

Mosley, P. (1997). Overseas Aid: Its Defense and Reform. Brighton: Wheatsheaf Books.

Moyo, D. (2009). Dead Aid: Why Aid Is Not Working and How There Is a Better Way for Africa, New York: Farrar, Straus, and Giroux.

Mueller D.C. (1997). Perspectives on Public Choice: A Handbook. New York: Cambridge University Press. 
Munro, L. (2005). Focus-Pocus? Thinking critically about whether aid organizations should do fewer things in fewer countries, Development and Change, 36(3): 425-447.

Nielson, J. (2006). Aid for Trade. In: Trade, Doha and Development: A Window into the Issues (pp. 323-332), R. Newfarmer (Ed.). Washington: The World Bank.

Nowak, A. (1997). Polityka RFN na rzecz rozwoju krajów Trzeciego Świata: (Entwicklungspolitik). Wrocław: Wydawnictwo Uniwersytetu Wrocławskiego.

Nunnenkamp, P., Öhler, H., Thiele, R. (2011). Donor Coordination and Specialization: Did the Paris Declaration Make a Difference?, Kiel Working Paper, 1748: 1-21.

Odell, J. (2002). The Seattle Impasse and Its Implications for The World Trade Organization. In: Developing Countries in the World Trading System: The Uruguay Round and Beyond, R. Adhikari, P. Athukoralge (Eds.). Cheltenham: Edward Elgar.

OECD (1993). Financial Resources for Developing Countries: 1992 and Recent Trends, http:// www.oecd.org/officialdocuments/publicdisplaydocumentpdf/?cote=SG/PRESS (93) 41\&docLanguage=En (access: 23.04.2017).

OECD (1996). Shaping the 21st Century: The Contribution of Development Cooperation. Paris: OECD Publishing.

OECD (2001). Glossary of Key Terms and Concepts. OECD: Development Co-operation Report: Efforts and Policies of Members of the Development Assistance Committee. Paris: OECD Publishing, https://stats.oecd.org/glossary/detail.asp?ID=2686 (access: 22.04.2018).

OECD (2002). History of the 0.7\% ODA Target, DAC Journal, 3(4), https://www.oecd.org/dac/ stats/ODA-history-of-the-0-7-target.pdf (access: 09.11.2017).

OECD (2003a). Philanthropic Foundations and Development Co-operation, DAC Journal, 4(3): $1-81$.

OECD (2003b). Trade Facilitation Principles in GATT Articles V, VIII and X: Reflections on Possible Implementation Approaches, Working Party of the Trade Committee. TD/TC/WP (2003) 12 FINAL. Paris: OECD Publishing.

OECD (2005). Survey on Harmonisation and Alignment of Donor Practices. Measuring Aid Harmonisation and Alignment in 14 partner counties. Paris: OECD Publishing.

OECD (2008). 2008 Survey on Monitoring the Paris Declaration: Making Aid More Effective by 2010. Paris: OECD Publishing. DOI: 10.1787/9789264050839-en.

OECD (2010). 2008 DAC Report on Multilateral Aid. Paris: OECD Publishing.

OECD (2010a). DAC Statistical Reporting Directives. Paris: OECD Publishing.

OECD (2011a). Aid Effectiveness 2005-10: Progress in Implementing the Paris Declaration. Paris: OECD Publishing.

OECD (2011b). The Third DAC Report on Multilateral Aid. Paris: OECD Publishing.

OECD (2012a). Aid Effectiveness 2011: Progress in Implementing the Paris Declaration: Better Aid. Paris: OECD Publishing. DOI: 10.1787/9789264125780-en.

OECD (2012b). DAC Report on Multilateral Aid Report. Paris: OECD Publishing.

OECD (2012c). The Busan Partnership for Effective Development Cooperation, https://www.oecd. org/dac/effectiveness/Busan\%20partnership.pdf (access: 12.11.2017).

OECD (2013). Multilateral Aid Report. Paris: OECD Publishing.

OECD (2014). DAC High Level Meeting. Final Communique. Paris: OECD Publishing.

OECD (2014a). The WTO Trade Facilitation Agreement - Potential Impact on Trade Costs. Paris: OECD Publishing. 
OECD (2015). Multilateral Aid 2015: Better Partnerships for a Post-2015 World. Paris: OECD Publishing.

OECD (2016). Converged Statistical Reporting Directives for the Creditor Reporting System (CRS) and the Annual DAC Questionnaire. Paris: OECD Publishing

OECD (2016a). Development aid in 2015 continues to grow despite costs for in-donor refugees, https:// www.oecd.org/dac/stats/ODA-2015-detailed-summary.pdf (access: 23.02.2017).

OECD (2016b). OECD Development Co-operation Report 2016: The Sustainable Development Goals as Business Opportunities. Paris: OECD Publishing. DOI: 10.1787/20747721.

OECD (2016c). Converged Statistical Reporting Directives for the Creditor Reporting System (CRS) and the Annual DAC Questionnaire. Paris: OECD Publishing.

OECD (2016d). Taking stock of aid to least developed countries (LDCs). Paris: OECD Publishing.

OECD (2017a). DAC List of ODA-eligible international organisations (annex 2 for 2017 flows). Paris: OECD Publishing.

OECD (2017b). Development finance of countries beyond the DAC. Paris: OECD Publishing, http:// www.oecd.org/development/stats/non-dac-reporting.htm (access: 04.05.2018).

OECD (2017c). Global Private Philanthropy for Development. Paris: OECD Publishing, http:// www.oecd.org/dac/financing-sustainable-development/development-finance-standards/ Philanthropy-Development-Survey.pdf (access: 07.05.2018).

OECD (2017d). Aid-for-trade statistical queries, http://www.oecd.org/dac/aft/aid-fortradestatisticalqueries.htm (access: 22.11.2017).

OECD (2018a). Implementation of the WTO Trade Facilitation Agreement: The Potential Impact on Trade Costs, https://www.oecd.org/tad/policynotes/oecd-tfi-implementation-impact-tradecosts.pdf (access: 22.03.2018).

OECD (2018b). Trade Facilitation Indicators: An overview of available tools, http://www.oecd.org/ trade/facilitation/indicators.htm (access: 21.05.2018).

OECD (2018c). Development aid stable in 2017 with more sent to poorest countries, http://www.oecd. org/dac/financing-sustainable-development/development-finance-data/ODA-2017-detailedsummary.pdf (access: 04.05.2018).

OECD (2018d). Trade Policy Note. May, https://www.oecd.org/tad/policynotes/oecd-tfiimplementation-impact-trade-costs.pdf (access: 21.05.2018).

OECD (2018e). Development finance data, online database, http://www.oecd.org/dac/financingsustainable-development/development-finance-data/ (access: 21.05.2018).

OECD (2018f). Resource flows beyond ODA in DAC statistics, http://www.oecd.org/dac/stats/ beyond-oda.htm, http://www.oecd.org/development/beyond-oda.htm (access: 20.05.2018).

OECD-DAC (2018). Aid activities database (CRS), http://www.oecd.org/dac/aft/ (access 22.05.2018).

OECD (2018). Data, https://data.oecd.org/drf/grants-by-private-agencies-and-ngos.htm (access: 20.05.2018).

Ornelass, E. (2016a). Special and Differential Treatment for Developing Countries (March 23), CESifo Working Paper Series, 5823: 1-86.

Ornelass, E. (2016b). Special and Differential Treatment for Developing Countries, CEP Discussion Paper No. 1415. Centre for Economic Performance, London School of Economics.

Ostrom, E. (1999). Institutional Rational Choice. In: Theories of the Policy Process (pp. 35-71), P. Sabatier (Ed.). Boulder: Westview Press. 
Ostry, S. (2000). The Uruguay Round North-South Grand Bargain: Implications for Future Negotiations, http://sites.utoronto.ca/cis/ostry/docs_pdf/Minnesota.pdf (access: 10.06.2017).

Paris Declaration on Aid Effectiveness (2005). Paris: High Level Forum on Aid Effectiveness, February 28 - March 5.

Petersmann, E.U. (2005). Introduction Mini-Symposium on Developing Countries in the Doha Round, Journal of International Economic Law, 8(2): 347-362.

Piasecki R. (2008). Ekonomia rozwoju wobec problemów nędzy i nierówności społecznych na świecie, Annales - Etyka w życiu gospodarczym, 11(1): 225-232.

Polaski, S. (2006). Winners and Losers: Impact of the Doha Round on Developing Countries. Washington: Carnegie Endowment for International Peace.

Popiuk-Rysińska I. (2001). Uczestnicy stosunków międzynarodowych, ich interesy i oddziaływania, in: Stosunki międzynarodowe. Geneza, struktura, dynamika (pp. 86-106), E. Haliżak, R. Kuźniar (red.). Warszawa: Wydawnictwa Uniwersytetu Warszawskiego.

Porter, R.B., Sauve, P., Subramanian A., Zampetti, A.B. (Eds.). (2001). Efficiency, Equity and Legitimacy. The Multilateral Trading System at the Millennium. Washington: Brookings Institution Press.

Powell, A., Bobba, M. (2006). Multilateral intermediation of foreign aid: What is the trade-off for donor countries? Working Paper Inter-American Development Bank, 594: 1-29.

Pozen D.E. (2007). Tax Expenditures as Foreign Aid, Yale Law Journal, 116(4): 869-880.

Prebisch, R. (1950). The economic development of Latin America and its principal problems. Economic, Bulletin for Latin America, 7(1): 1-12.

Prowse, S. (2002). The Role of International and National Agencies in Trade-related Capacity building, The World Economy, 25(9): 1235-1261.

Prowse, S. (2006). "Aid for Trade”. A Proposal for Increasing Support for Trade Adjustment and Integration. In: Economic Development and Multilateral Trade Cooperation (pp. 229-267), S. Evenett, B. Hoekman (Eds.). New York: The World Bank and Palgrave Macmillan.

Puchala, D.J., Hopkins, R.F. (1982). International Regimes: Lessons from the Inductive Analysis, International Organization, 36(2): 61-92.

Qureshi, A.H. (2009). International Trade for Development: The WTO as a Development Institution?, Journal of World Trade, 43(1): 173-188.

Qureshi, A.H. (2003). Interpreting WTO agreements for the Development Objective, Journal of World Trade, 37(5): 847-882. DOI: 10.1017/CBO9780511674488.007.

Rajan, R.G., Subramanian, A. (2008). Aid and Growth: What Does the Cross-Country Evidence Really Show? Review of Economics and Statistics, 90(4): 643-665.

Rajan, R., Subramanian, A. (2005). What undermines Aid's Impact on Growth?, NBER Working Paper, 11657: 157.

Raustiala, K., Victor, D.G. (2004). The Regime Complex for Plant Genetic Resources. International Organization, 58(2): 277-310.

Reinsberg, B. (2015). Foreign Aid Responses to Political Liberalization, World Development, 75 (C): 46-61. DOI: 10.1016/j.worlddev.2014.11.006.

Reinsberg, B.W. Michaelowa, K. Knack, S. (2015). Which donors, which funds? The choice of multilateral funds by bilateral donors at the World Bank, Policy Research Working Paper, 7441: 1-36. 
Reinsberg, B., Michaelowa K., Eichenauer, V.Z. (2015). The rise of multi-bi aid and the proliferation of trust funds. W: Handbook on the Economic of Foreign Aid (pp. 527-554), B. M. Arvin, B. Lew (Eds.). Cheltenham: Edward Elgar Publishing Limited.

Report of the Commission on International Development "Partners in Development" (1969). Lester B. Pearson (Chairman). New York - Washington.

Riddell, R.C. (2007). Does Foreign Aid Really Work?. Oxford: Oxford University Press.

Rittberger, V. (1993) (Ed). Regime Theory and International Relations. Oxford: Oxford University Press, Oxford.

Rodrik, D. (1995). Why Is There Multilateral Lending? National Bureau of Economic Research Working Paper, 5160: 1-52. DOI: 10.3386/w5160.

Rome Declaration on Harmonization (2003). Rome, February 25, http://www.who.int/hdp/ publications/1b_rome_declaration.pdf (access: 03.11.2017).

Roodman, D. (2007). The Anarchy of Numbers: Aid, Development and Cross-Country Empirics, The World Bank Economic Review, 21(2): 255-277.

Roodman, D. (2014). Straightening the Measuring Stick: A 14-Point Plan for Reforming the Definition of Official Development Assistance (ODA), Center for Global Development Policy Paper, 044: 1-47.

Ruggie, J.G. (Ed). (1993). Multilateralism Matters: The Theory and Praxis of an Institutional Form. New York: Columbia University Press.

Samecki, P. (1997). Zagraniczna pomoc ekonomiczna. Warszawa: Fundacja Edukacji i Badań nad Pomocą Zagraniczną PECAT.

Severino, J.M., Ray, O. (2009). The End of ODA: Death and Rebirth of a Global Public Policy, Center for Global Development Working Paper, 167: 1-32.

Singer, H.W. (1950). The Distribution of Gains between Investing and Borrowing Countries, The American Economic Review, 40(2): 473-486.

Singh, J.P. (2006). The evolution of national interests: new issues and Noth - South negotiations during the Uruguay Round. In: Negotiating Trade: Developing Countries in the WTO and NAFTA (pp. 41-83), J.S. Odell (Ed.). Cambridge: Cambridge University Press.

Sobotka, B. (2008). Efektywność pomocy rozwojowej, Annales Universitatis Mariae CurieSklodowska Lublin-Polonia, XVI (2): 163-177.

South Centre/ African Trade Policy Centre (2017). The WTO's Special and Differential Treatment Negotiations (Paragraph 44). Analytical Note SC/AN/TDP/2017/3. Geneva: South Center.

Sridhar, D., Woods, N. (2013). Trojan Multilateralism: Global Cooperation in Health, Global Policy, 4(4): 325-335. DOI: 10.1111/1758-5899.12066.

Srinivasan, T.N. (1999). Developing Countries in the World Trading System: From GATT 1947 to the Third Ministerial Meeting of WTO, https://pdfs.semanticscholar. org/0c83/1e1707498892c8bddc581634add21b6e2123.pdf. (access: 24.09.2017).

Srinivasan, T.N. (1998). Developing Countries and the Multilateral Trading System. Boulder - Oxford: Westview Press.

Srinivasan, T.N. (2002). Developing Countries and the Multilateral Trading System after Doha, Center Discussion Paper, 842: 1-39.

Stephenson, S., Ragoussis, A., Sotelo, J. (2016). Implications of the Trade in Services Agreement (TiSA) for Developing Countries, Discussion Paper German Development Institute, 10/2016: 156.

Stewart. F. (1980). The Brandt Report, Development Policy Review, A13(1): 65-88. 
Stevens, Ch. (2002). The future of Special and Differential Treatment (SDT) for developing countries in the WTO, ISD Working Paper, 163: 1-38.

Stiglitz, E., Charlton, A. (2012). The Right to Trade. A Report for the Commonwealth Secretariat on Aid for Trade. London: Commonwealth Secretariat.

Strange, S. (1988). States and Markets. An Introduction to the International Political Economy. New York: Blackwell Publishers.

Subramanian, A., Wei, S.J. (2007). The WTO promotes trade strongly but unevenly, Journal of International Economics, 72(1): 151-175.

Suwa-Eisenmann, A., Verdier, T. (2007). Aid and Trade, Oxford Review of Economic Policy, 23(3): 481-507. DOI: 10.1093/oxrep/grm028.

Synowiec, E. (2002). Zasady handlu wynikające z porozumienia w sprawie tekstyliów i odzieży. In: Polska w WTO (pp. 218-242), J. Kaczurba, E. Kawecka-Wyrzykowska (Eds.). Warszawa: Instytut Koniunktur i Cen Handlu Zagranicznego.

Szymoniczek J. (2016). Pomagać? Pomagamy! Polska w światowym systemie współpracy rozwojowej, Myśl Ekonomiczna i Polityczna, 2(53): 125-141.

Tang, M.K., Wei, S.J. (2008). The value of making commitments externally: Evidence from WTO Accessions, NBER Working Paper, 14582: 1-48.

Tang, M.K., Wei, S.J. (2009). The value of making commitments externally: Evidence from WTO accessions, Journal of International Economics, 78(2): 216-229.

Tarp, F., Hjertholm, P. (Eds.). (2000). Foreign Aid and Development: Lessons Learnt and Directions for the Future. New York: Routledge Studies in Development Economics.

Taylor, B.J., Wilson, J.S. (2011). Doha and Trade Facilitation: Lending Specificity to the Multilateral Trade and Development Agenda. In: Unfinished Business? The WTO's Doha Agenda (pp. 213231), W. Martin, A. Mattoo (Eds). Washington: The World Bank.

Tendler, J. (1975). Inside Foreign Aid. Baltimore: The Johns Hopkins University Press.

The Dutch Disease (1977). The Economist, November 26.

The Report of the Independent Commission on International Development Issues under the Chairmanship of Willy Brandt (1980), http://pubdocs.worldbank.org/ en/783141389301413696/wbg-archives-1771354.pdf (access: 12.09.2017).

Tomasevski, K. (1993). Development Aid and Human Rights Revisited. London: Pinter Publishers.

Tortora P. Steensen, S. (2014). Making Earmarked Funding More Effective: Current Practices and a Way Forward. Report. Paris: OECD Publishing.

Trade Facilitation Agreement (TFA). (2014). Protocol Amending the Marrakesh Agreement Establishing the World Trade Organization, 28 November. WT/L/940. General Council. WTO.

Trade in Services Agreement (2016). Bridges, https://www.ictsd.org/bridges-news/bridges/news/ tisa-ministerial-cancelled-officials-to-prepare-for-2017 (access: 12.03.2018).

Tussie, D., Quiliconi, C. (2014). The World Trade Organization and Development, in: International Development. Ideas, Experience, and Prospects (pp. 815-830), B. Currie-Alder, R. Kanbur, D.M. Malone, R. Medhora (Eds). Oxford: Oxford University Press.

UN (2005). Millennium Project, Task Force on Trade, Trade for Development. New York: United Nations.

UN (2010). World Economic and Social Survey 2010: Retooling Global Development. New York: United Nations. 
UN (2016a). Multilateral ODA to LDCs (2000-2013), https://www.un.org/ldcportal/multilateraloda-to-ldcs-2000-2013/ (access: 19.06.2017).

UN (2016b). Update on donor contributions to the EIF, https://www.un.org/ldcportal/update-ondonor-contributions-to-the-eif/ (access: 22.06.2017).

UNDP (2005). Millennium Project. Investing in Development: A Practical Plan to Achieve the Millennium Development Goals. New York: United Nations Development Programme.

UNCTAD (1999). Trade and Development Report 1999. Geneva: UNCTAD.

UN ESCAP (2005). Delivering on the WTO Round: A High-level Government-Business Dialogue. New York: United Nations ESCAP.

UNCTAD (2000). The post-Uruguay Round Tariff Environment for Developing Country Exports: Tariff Peaks and Tariff Escalation. TD/B/COM.1/14/Rev.1. 28 January. Commission on Trade in Goods and Services and Commodities, UNCTAD.

UNCTAD (2017). Handbook on Duty-Free and Quota-Free Market Access and Rules of Origin for Least Developed Countries. Part I. Geneva: UNCTAD, http://unctad.org/en/pages/ PublicationWebflyer.aspx?publicationid=1969 (access: 12.11.2017).

UNDP (1994). Human Development Report. Oxford: Oxford University Press.

UNDP (2011). Implementing the Paris Declaration on Aid Effectiveness: UNDP's response to the 2011 Survey on Monitoring the Paris Declaration. New York: UNDP.

United Nations General Assembly (1993). An Agenda for Development, http://www.un-documents. net/a48 r166.htm (access: 02.11.2017).

Velde te, D.W. (2013). Future Directions in Aid for Trade. In: Assessing Aid for Trade. Effectiveness, Current Issues and Future Directions (pp. 398406), M.A. Razzaque, D.W. te Velde (Ed.). London: Commonwealth Secretariat.

Waage, J. (2010). The Millennium Development Goals: a cross-sectoral analysis and principles for goal setting after 2015, The Lancet Commission, London International Development Centre Commission, 376(9745): 991-1023. DOI: 10.1016/S0140-6736(10) 61196-8.

Walmsley, T., Winters, L.A. (2002). Relaxing Restrictions on Temporary Movement of Natural Persons: A Simulation Analysis, https://www.gtap.agecon.purdue.edu/resources/download/2035.pdf (access: 29.12.2017).

Wang, C., Liu, X., Wei, Y. (2004) Impact of Openness on Growth in Different Country Groups, The World Economy, 27(4): 567-585. DOI: 10.1111/j.0378-5920.2004.00614.x.

Wang, Z.K., Winters, L.A. (2000). Putting 'Humpty’ Together Again: Including Developing Countries in a Consensus for the WTO. London: CERP.

Whalley J. (Ed.) (1989). The Uruguay Round and Beyond: The Final Report from the Ford Foundation Project on Developing Countries at the Global Trading System. London: Macmillan.

Whalley, J. (1999). Special and Differential Treatment in the Millennium Round, CSGR Working Paper, 30(99): 1-45. DOI: 10.2139/ssrn.165809.

White, H. (1992a). What do we know about aid's macroeconomic impact? An Overview of the Aid Effectiveness Debate, Journal of International Development, 4(2): 121-137.

White, H. (1992b). The macroeconomic impact of development aid: A critical survey, Journal of Development Studies, 28: 163-240.

Wilkinson R. (2006). The World Trade Organizations and the governance of global trade, EPC Working Paper, 26: 7-29. 
Wilson, J.S. Mann, C., Otsuki, T. (2003). Trade facilitation and economic development: New approach to quantifying the impact, The World Bank Economic Review, 17(3): 367-389.

Wilson, J.S., Mann, C., Otsuki, T. (2005). Assessing the potential benefit of trade facilitation: a global perspective, The World Economy, 28(6), 2005: 841-871.

Wilson, J.S., Mann, C., Otsuki, T. (2004). Assessing the Potential Benefit of Trade Facilitation: A Global Perspective, Policy Research Working Paper World Bank, 3224: 1-40.

Wilson, J.S., Mann, C., Woo, Y.P., Assanie, N., Choi, I. (2002). Trade Facilitation: A Development Perspective in the Asia-Pacific Region. Singapore: APEC Secretariat.

Winters, L.A., McCulloch, N., McKay, A. (2004). Trade Liberalization and Poverty: The Evidence so Far, Journal of Economic Literature, 42(1): 72-115.

Winiecki, J. (1975). Ekonomiczne instrumenty polityki zagranicznej we współczesnych stosunkach międzynarodowych. Warszawa: PISM.

World Bank (2006). Assessing World Bank support for trade 1987-2004: An IEG Evaluation. Washington: World Bank Independent Evaluation Group.

World Bank (2011). Trust fund support for development: An evaluation of the World Bank's trust fund portfolio. Washington: Independent Evaluation Group of the World Bank.

WTO (1986). WTO/GATT Ministerial Declaration on the Uruguay Round (Declaration of 20 September 1986). Geneva: WTO.

WTO (1999). Developing Countries and the Multilateral Trading System: Past and Present. Background Document prepared for the High-Level Symposium on Trade and Development, 17-18 March. Geneva: WTO.

WTO (2000). Implementation of Special and Differential Treatment Provisions in WTO. Agreements and Decisions, 25 October. WT/COMTD/W/77. Geneva: WTO.

WTO (2001a). Declaration on the TRIPs Agreement and Public Health adopted on 14 November. WTO Doha Ministerial 2001, 20 November. WT/MIN (01)/DEC/2. Geneva: WTO

WTO (2001b). Doha Ministerial Declaration. Ministerial Conference, Fourth Session, Doha, 9-14 November 2001. WT/MIN (01)/DEC/W/1. Geneva: WTO.

WTO (2002). Joint Communication from the African Group in the WTO, Special and Differential Treatment Provisions. WTO Committee on Trade and Development Special Session, 17 July. TN/CTD/W/3/Rev.2.

WTO (2003a). Chairman's Note on the Meetings of 7 and 18 October 2002. WTO Committee on Trade and Development Seventh Special Session, 30 April.TN/CTD/M/7.

WTO (2003b). Implementation of paragraph 6 of the Doha Declaration on the TRIPS Agreement and public health. WTO General Council, 11 September. WT/L/540 and Corr.1. Geneva: WTO.

WTO (2004). WTO Doha Work Programme: “July package”. 1 August. WT/L/579. Geneva: WTO.

WTO (2005a). Doha work programme: draft ministerial declaration: revision, 18 December. WT/MIN (05)/W/3/Rev.2. Geneva: WTO.

WTO (2005b). Ministerial Declaration adopted on 18 December 2005 at the Hong Kong Ministerial Conference, 22 December. WT/MIN (05)/DEC.

WTO (2006a). Aid for Trade: Concept Paper and Timeline for 2006, 17 January. Geneva: WTO Secretariat.

WTO (2006b). Aid for Trade: Follow-up to the Aid-for-Trade Task Force Recommendations, 12 December. JOB (06)/262. Geneva: WTO. 
WTO (2006c). Recommendations of the Task Force on Aid for Trade, 27 July. WT/AFT/1. Geneva: WTO Secretariat.

WTO (2008). Chairperson's texts 2008: Agriculture negotiations, https://www.wto.org/english/ tratop_e/agric_e/chair_texts08_e.htm (access: 22.07.2018).

WTO (2008a). Draft modalities for non-agricultural market access: third revision, 10 July. TN/ MA/W/103/Rev.2. Geneva: WTO.

WTO (2008b). Revised Draft Modalities of the Agriculture and Non-Agricultural Market Access (NAMA), 6 December. TN/MA/W/103/Rev.3. Geneva: WTO.

WTO (2008c). Doha Development Agenda: The July 2008 Package. Negotiating texts and reports. Geneva: WTO.

WTO (2009). Aid for trade Work Program 2010-11, 27 November. WT/COMTD/AFT/W/16. Geneva: WTO Secretariat.

WTO (2009a). Biennial Technical Assistance and Training Plan 2010-11, 21 October. WT/ COMTD/W/170/Rev.1. Geneva: WTO.

WTO (2011a). Aid-for-trade Work Programme 2012-2013 Deepening Coherence, WT/COMTD/ AFT/W/30. Geneva: WTO.

WTO (2011b). Biennial Technical Assistance and Training Plan 2012-13, 24 October. WT/ COMTD/W/180. Geneva: WTO.

WTO (2011c) Progressive Learning Strategy for trade-related capacity building. Institute for Training and Technical Cooperation. Geneva: WTO.

WTO (2012a). Annual report on technical assistance and training, 1 January-31 December 2011. WT/COMTD/W/18. Geneva: WTO.

WTO (2012b). Biennial Technical Assistance and Training Plan 2012-2013, 3 February. WT/ COMTD/W/180/Rev.1, Geneva: WTO.

WTO (2013). Ministerial Declaration and Decisions. Ninth Ministerial Conference 3-6 December, Bali. Geneva: WTO.

WTO (2013a) Biennial Technical Assistance and Training Plan 2014-2015, 17 October. WT/ COMTD/W/200. Geneva: WTO.

WTO (2015a). Biennial Technical Assistance and Training Plan 2016-2017, 30 October. WT/ COMTD/W/211. Geneva: WTO.

WTO (2015b). Draft Ministerial Decision on Special and Differential Treatment Proposals -Preamble and future work, Submission of the G90, 19 December. WT/MIN (15)/W/44. Geneva: WTO.

WTO (2016a). Annual Report 2016. Geneva: WTO Secretariat.

WTO (2016b). Contact and enquiry points notified to the Council for Trade in Services. S/ENQ/78/ Rev.16, 22 April. Geneva: WTO.

WTO (2016c). National Committees on Trade Facilitation: Current practices and challenges, https:// www.tfafacility.org/sites/default/files/news/tfa_national_committees_trade_facilitation_ web_e.pdf (access: 20.05.2018).

WTO (2017a). Annual Performance Report on Technical Assistance and Training 2016, 11 July. WT/ COMTD/W/225. Geneva: WTO

WTO (2017b). Annual Report 2017. Geneva: WTO Secretariat.

WTO (2017c). Biennial Technical Assistance and Training Plan 2018-19, 23 October. WT/ COMTD/W/227/Rev.1. 
WTO (2017d). Doha Development Agenda Global Trust Fund (DDAGTF) and other trust fund, Financial Report, 24 October. WT/BFA/W/433.

WTO (2017e). World Trade Statistical Review 2017: Participation of developing economies in world trade. Geneva: WTO Secretariat.

WTO (2018a). Annual Performance Report on Technical Assistance and Training 2017, 19 June. WT/ COMTD/W/235. Geneva: WTO Secretariat.

WTO (2018b). Annual Report 2018. Geneva: WTO Secretariat.

WTO (2018c). Trade-related Technical Assistance (TRTA), https://www.wto.org/english/tratop_e/ devel_e/teccop_e/ittc_newsletter_e.pdf (access: 02.08.2018).

WTO/OECD (2007). Aid for Trade at a Glance 2007: 1st Global Review. Paris - Geneva: WTO/OECD.

WTO/OECD (2009). Aid for Trade at a Glance 2009: Maintaining Momentum. Paris - Geneva: OECD/WTO.

WTO/OECD (2011a). Aid for Trade at a Glance 2011: Showing Results. Paris/Geneva: WTO/OECD.

WTO/OECD (2011b). Aid for Trade 2011: Results emerging from the case stories. Paris- Geneva: OECD/WTO.

WTO/OECD (2015). Aid for Trade at a Glance 2015: Reducing Trade Costs for Inclusive, Sustainable Growth. Paris- Geneva: WTO/OECD.

WTO/OECD (2017). Aid for Trade at a Glance 2017: Promoting Trade, Inclusiveness and Connectivity for Sustainable Development. Paris - Geneva: WTO/OECD.

Yarbough B.V., Yarbough R.M. (1987). Cooperation in the liberalization of international trade: after hegemony, what?, International Organization, 41(1): 1-26.

Young, O. (1982). Resource Regimes: Natural Resources and Social Institutions. Berkeley: University of California Press.

Young O. (1986). International Regime. Toward a New Theory, World Politics, 39(01): 104-122.

Young, O.R. (1997) Global Governance: Drawing Insights from the Environmental Experience. Cambridge: MIT Press.

Zajaczkowski, M. (2014a). Polska polityka pomocy rozwojowej jako przykład polityki publicznej. In: Polityka publiczna we wspótczesnym państwie (pp. 409-425), J. Osiński (Ed.). Warszawa: Oficyna Wydawnicza SGH.

Zajaczkowski, M. (2014b). Sekwencyjność rozwoju stosunków GATT/WTO z krajami rozwijającymi się, Kwartalnik Kolegium Ekonomiczno-Społecznego. Studia i Prace, 4(20): 33-57.

Zajaczkowski, M. (2018). Polska współpraca rozwojowa: aktualne problemy i wyzwania, in: Polska po 2015 roku - gospodarka, społeczeństwo (pp. 279-298), M. Krawczyk (Ed.). Warszawa: Oficyna Wydawnicza SGH.

Zhang, B. (2018). The Evolution of the Non-market Economy Treatment in the Multilateral Trading System. Singapore: Springer.

Zinkin, M. (1978). Aid and morals: addressing the aspiration of poor countries, The Commonwealth Journal of International Affairs, 68(271): 222-228. DOI: 10.1080/00358537808453332. 


\section{Internet sources}

Adelman C. C (2011), http://www.hudson.org/files/documents/2011\%20Index\%20of\%20 Global\%20Philanthropy\%20and\%20Remittances\%20downloadable\%20version.pdf (access: 03.10.2017).

Aid for trade data: CSR, http://www.oecd.org/trade/aft/43234667.pdf (access: 08.11.2017).

European Commission, https://ec.europa.eu/europeaid/sites/devco/files/study-eurobarometereuropeans-development-aid-and-mdgs-201009_en_5.pdf (access:25.05.2017).

Edukacja Globalna: Globalne Południe, http://globalnepoludnie.pl/IMG/pdf/Edukacja_ globalna_-_szkolenie_Zaleznosci_Globalne_PZS_2012.pdf (access:13.04.2017).

EIF. Enhanced Integrated Framework: The EIF Funding, https://www.enhancedif.org/en/funding (access: 06.09.2017).

Evolution of Trade in Textile and Clothing Trade World-Wide - Trade Figures and Structural Data, http://trade.ec.europa.eu/doclib/html/123243.htm (access: 29.05.2018).

OECD. Aid for Trade: Creditor Reporting System, http://www.oecd.org/trade/aft/43234667.pdf (access: 08.11.2017).

OECD. Explanatory Note: Aid for Trade data, http://www.oecd.org/trade/aft/43234667.pdf (access: 09.09.2017).

OECD-DAC. Financing for sustainable development, http://www.oecd.org/dac/financingsustainable-development/ (access: 12.09.2018).

OECD-ODA. Official Development Assistance: definition and coverage, http://www.oecd.org/dac/ stats/officialdevelopmentassistancedefinitionandcoverage.htm (access: 04.05.2017).

OECD. What we know about the multilateral aid?, http://www.oecd.org/development/financingsustainable-development/13_03_18\%20Policy\%20Briefing\%20on\%20Multilateral\%20Aid. pdf (access: 17.05.2017).

TFAF. Trade Facilitation Agreement Facility grants, http://www.tfafacility.org/tfaf-grants (access: 21.05.2018)

Trade Facilitation Agreement Database, https://tfadatabase.org/ (access: 21.05.2018).

Trade Facilitation Agreement Facility, http://www.tfafacility.org/annual-report-2017\#Funds (access: 29.10.2017).

UNCTAD, http://unctad.org/en/Docs/td97vol1_en.pdf (access: 12.04.2017).

WTO. Aid for Trade: Factsheet, https://www.wto.org/english/tratop_e/devel_e/a4t_e/a4t_ factsheet_e.htm (access: 08.11.2017).

WTO. Development: Legal provisions, https://www.wto.org/english/tratop_e/devel_e/d2legl_e. htm (access: 22.11.2017).

WTO. Doha Development Agenda: Negotiations, implementation and development, https://www.wto. org/english/tratop_e/dda_e/status_e/brief00_e.htm (access: 26.05.2018).

WTO. Domestic support in agriculture, https://www.wto.org/english/tratop_e/agric_e/agboxes_e. htm (access: 26.05.2018)

WTO. Enhanced Integrated Framework, https://www.wto.org/english/tratop_e/devel_e/teccop_e/ if_e.htm (access: 29.10.2017).

WTO. Non-agriculture market access, http://www.wto.org/english/tratop_e/markacc_e/guide_ dec08_e.htm (access: 29.05.2018). 
WTO. Secretariat and budget, https://www.wto.org/english/thewto_e/secre_e/budget10_e.htm (access: 14.12.2017).

WTO. Technical Assistance and Training, https://www.wto.org/english/tratop_e/devel_e/train_e/ general_courses_e.htm (access: 02.09.2017).

WTO-TFA (2014-2017). Technical Assisatance, https://www.wto.org/english/tratop_e/tradfa_e/ tradfa_e.htm (access: 21.05.2018).

WTO. TFAF grants, http://www.tfafacility.org/tfaf-grants (access: 21.05.2018). 


\section{List of Figures}

Figure 1. DAC Members' ODA as per cent of GNI, 1960-2017 ............................ 43

Figure 2. ODA Volumes of the DAC Members, 1960-2017 (USD billion, 2016 Constant Prices) ...... 44

Figure 3. ODA Grant Equivalent as Percent of GNI, DAC Member Countries, 2017 ............... 45

Figure 4. Net ODA and ODA/GNI of DAC Members and Non-DAC Donors, 2015 (USD billion) ....... 47

Figure 5. Development Aid Grants by Private Sector and NGOs in DAC Countries, 2000-2017 (million USD) ......................................................... 48

Figure 6. The Largest Philanthropic Foundations per Region, 2013-2015 (USD million) ........... 49

Figure 7. Components of DAC Countries' Net ODA, 2000-2017 (USD million, 2016 Constant

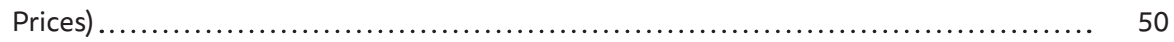

Figure 8. ODA and Other Financial Resources Directed to Developing Countries, 2000-2016 (USD million, 2016 Constant Prices)

Figure 9. Composition of Gross ODA Disbursements (Excluding Debt Relief) (USD billion, 2013 Constant Prices).

Figure 10. Core and Non-Core Contributions from DAC Countries, 2013 (USD million, 2013 Current Prices).

Figure 11. Distribution of Core and Non-Core Resources Among DAC Members (USD million, 2013 Current Prices).

Figure 12. Multilateral Funding of Non-DAC Countries, 2009-2013 (USD million, 2013 Current Prices).

Figure 13. Volume and Share of Multi-Bi Funding in Total Multilateral Aid, 2007-2013 (USD billion, 2012 Constant Prices)

Figure 14. The Use of Different Aid Financing Channels by Donor Countries, 2006-2012 (in \%)

Figure 15. WTO Technical Assistance Resources, 2007-2017 (CHF million)....

Figure 16. Volume of Funding Received Through WTO-related Trust Funds, 2012-2017 (CHF million).

Figure 17. Subjects of WTO Technical Assistance Courses and Training (in \%)

Figure 18. Number of Participants in WTO Technical Assistance Activities, 2010-2017 .......... 96

Figure 19. Types of Courses and Training under the WTO Progressive Learning Strategy (PLS) ...... 97

Figure 20. WTO Roadmap for Technical Assistance Activities ............................... 101

Figure 21. WTO Technical Assistance Activities by Impact Range, 2012-2017 (in \%) ............ 102

Figure 22. Financial Resources from the DDAGTF, 2011-2017 (CHF million) ................... 105

Figure 23. AFT Commitments and Disbursements, 2006-2016 (USD billion, 2016 Constant Prices)

Figure 24. The Largest Donors of AFT, Disbursements, 2006-2016 (USD million, 2016 Constant Prices)

Figure 25. Main Beneficiaries under the AFT, Disbursements, 2006-2016 (USD million, 2016 Constant Prices) 


\section{List of Figures}

Figure 26. Commitments and Disbursements under the AFT by Category, 2002/2005-2015

(USD billion, 2015 Constant Prices)

Figure 27. WTO Commitments Under the AFT, 2006-2016 (USD million, 2016 Constant

Prices).

Figure 28. WTO Engagement in "Trade Policy and Regulations" Category, 2002/2005-2016

(USD million, 2016 Constant Prices)....

Figure 29. Developing Economies' Participation in Global Exports of Commercial Services by region, 2016 (in \%).

Figure 30. Forecasts for Trade Costs Reductions Due to the Implementation of the TFA by Income Group (in \%)

Figure 31. Trade Facilitation Commitments under the Aid For Trade, 2002-2016 (USD million, 2015 Constant Prices)

Figure 32. Trade Facilitation Commitments by Region (USD million, 2012 Constant Prices) 199

Figure 33. Areas of WTO's Involvement in Development Cooperation 204 


\section{List of Tables}

Table 1. Classification of Forms of Development Aid.

Table 2. Estimated Financial Flows of OECD-DAC Members and Selected Non-DAC Countries, 2012-2016 (Net Disbursements, Current Prices, USD billion) ......................... 46

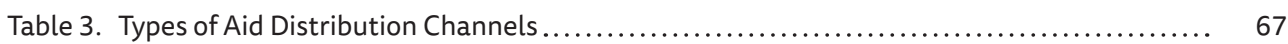

Table 4. Multilateral Aid - Arguments For and Against ................................... 70

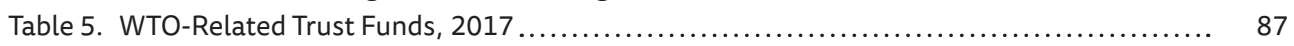

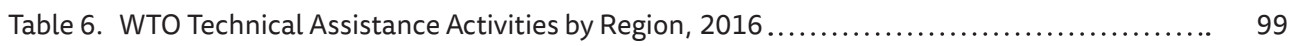

Table 7. Planned WTO Budget for Technical Assistance, 2011-2017 (CHF million) ............... 103

Table 8. The DDAGTF in 2011-2017 (CHF million) ....................................... 106

Table 9. WTO Technical Assistance Trust Fund Contributions (CHF million) .................... 107

Table 10. States and Autonomous Territories in WTO Accession Negotiations

(As of February 2018) ................................................... 111

Table 11. Differences Between the Categories Under the AFT and the CRS ................... 125

Table 12. Responses Submitted under the WTO/OECD Aid for Trade Monitoring Exercise, 2007-2017

Table 13. Financial Commitments of Selected Multilateral Institutions Under the AFT

Categories: Trade Policy and Regulations, 2002/2005-2015 (USD million, 2015 Constant Prices).

Table 14. Key Elements of Special and Differential Treatment in GATT and WTO ................ 149

Table 15. SDT Provisions Included in the WTO Agreements ................................ 151

Table 16. Average Tariffs for Industrial Products Before the Uruguay Round and After, by Group of Countries.

Table 17. Bound Tariffs on Industrial and Agricultural Products by Group of Countries and Regions After the Uruguay Round (in \%) ..................................... 169

Table 18. Tarff Protection of Industrial Products, 1995 (in \%) ................................ 171

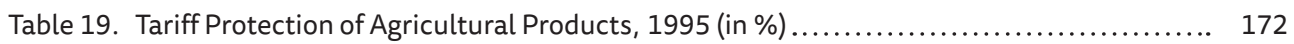

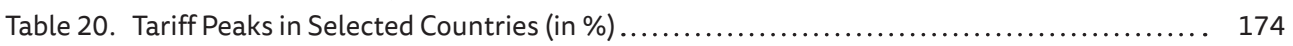

Table 21. Tariff Escalation for Food Manufacturing in Selected Countries (in \%) ................ 174

Table 22. Preliminary Arrangements for Agricultural Sector under the July 2008 Package ......... 179

Table 23. Weighted-Average Applied and Bound Tariff Rates (in \%): The Doha Round

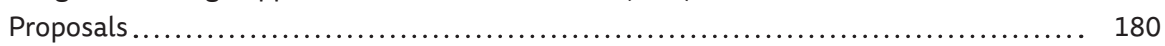

Table 24. Long-Term GDP Growth Projections for Doha Round Participants at Regional or Country Level (USD million, 2004 Constant Prices)

Table 25. Developing Economies' Trade in Services by Region, 2015-2016 (USD billion, Annual change, in \%).

Table 26. Donations to the TFAF, 2014-2017 (CHF million). 

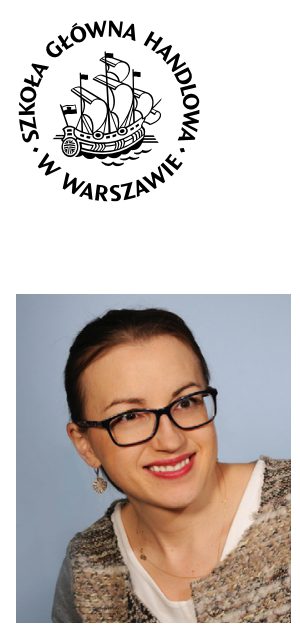

Małgorzata Zajaczkowski - Professor at the Institute of International Studies, Warsaw School of Economics. In her research work, she deals with subjects related to the international trade system, in particular the functioning of the WTO, dilemmas of development aid or an alternative model of trade - fair trade. She is the author of over 50 peer-reviewed publications in Polish and English, a participant of numerous Polish scientific programs and the EU's research grants.

"An impressive book covering multi-faceted and interdisciplinary analysis, focusing on the determinants of low effectiveness of the international development aid system and the need to redefine the position of the World Trade Organization as a leading authority among other international institutions. The study provides the reader, in a clear and reliable manner, with specialist knowledge on the implications of the phenomenon of development cooperation. It signals the need for a new look at these issues and the importance of an active role for the WTO in the area of development cooperation, which is a current challenge for all WTO member countries. The reality of the global economy shows that filling the development gap must be a priority in the coming years and the WTO will play a significant role in the context of the evolution from development aid to development cooperation. This book is an important source of knowledge for academics, students, policy makers and all those readers who are concerned with contemporary world problems."

Krystyna Żołądkiewicz, Professor at the University of Gdańsk

"The book touches upon an important area of development cooperation, which is increasingly often an element of trade or economic agreements signed around the world. The author decided to examine how the World Trade Organization supports development cooperation. This issue has not yet been the subject of a specific and comprehensive analysis in the Polish literature, so the monograph will certainly contribute to the enrichment of the literature on the subject. (...) A great advantage of the work is the rich statistical material and the review of partial studies evaluating the types of aid discussed, including initiatives, and their results. The analysis certainly deserves recognition."

Ida Musiałkowska, Professor at the Poznań University of Economics

SGH PUBLISHING HOUSE

SGH WARSAW SCHOOL OF ECONOMICS

www.wydawnictwo.sgh.waw.pl

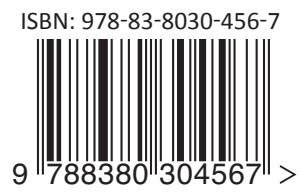

